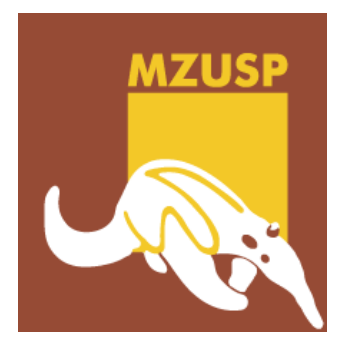

MUSEU DE ZOOLOGIA DA UNIVERSIDADE DE SÃO PAULO

\title{
Taxonomia e distribuição geográfica do complexo Penelope superciliaris Temminck, 1815 (Aves: Galliformes: Cracidae)
}

OSCAR DIEGO EVANGELISTA VARGAS

São Paulo 


\title{
MUSEU DE ZOOLOGIA DA UNIVERSIDADE DE SÃO PAULO
}

\author{
OSCAR DIEGO EVANGELISTA VARGAS
}

Taxonomia e distribuição geográfica do complexo

Penelope superciliaris Temminck, 1815

(Aves: Galliformes: Cracidae)

Dissertação apresentada ao programa de Pós-Graduação do Museu de Zoologia da Universidade de São Paulo para a obtenção do título de Mestre em Sistemática, Taxonomia Animal e Biodiversidade

Orientador:

Prof. Dr. Luís Fábio Silveira

São Paulo 


\section{Autorização}

Autorizo a reprodução e divulgação total ou parcial deste trabalho, por qualquer meio convencional ou eletrônico, para fins de estudo e pesquisa, desde que citada a fonte.

I authorize the reproduction and dissemination of this work in part or entirely by any means electronic or conventional, for study and research, provide the source is cited. 


\section{Ficha catalográfica}

Evangelista-Vargas, Oscar Diego

Taxonomia e distribuição geográfica do complexo Penelope superciliaris

Temminck, 1815 (Aves: Galliformes: Cracidae); orientador Luís Fábio Silveira São Paulo, SP: 2017.

167 p.; 41 figs; 13 tabs.

Dissertação (Mestrado) - Programa de Pós-graduação em Sistemática, Taxonomia Animal e Biodiversidade, Museu de Zoologia, Universidade de São Paulo, 2017.

1. Penelope superciliaris, 2. Taxonomia, 3. Cracidae I. Silveira, Luís Fábio. II. Título.

\section{Banca Examinadora}

Prof. Dr.

Instituição:

Julgamento
Prof. Dr.

Instituição:

Julgamento:

Prof. Dr. Luís Fábio Silveira (Orientador)

Museu de Zoologia da Universidade de São Paulo 
Para mis padres Leonor y Tomás, por el amor, apoyo y comprensión que me brindan cada día, y Shirley Sujey, mi hermana, a quien tanto admiro. Seguiremos cumpliendo juntos nuestros objetivos. 


\section{Agradecimentos}

A presente dissertação é o resultado do meu trabalho de dois anos, tempo no qual tive a ajuda de muitas pessoas e instituições, as quais agradeço em breves palavras.

Quero começar por meu orientador, o Prof. Dr. Luís Fábio Silveira, por ter me aberto as portas da Seção de Aves do MZUSP há três anos, ter me ensinado como desenvolver minha pesquisa em ornitologia, e por ter me apresentado uma família de aves tão maravilhosa como são os cracídeos. No lado pessoal, agradeço muito ele por ter acreditado em mim, e por todas as oportunidades que continua me oferecendo.

A cada um dos meus companheiros da Seção de Aves do MZUSP, que me apoiaram e motivaram ao longo do desenvolvimento da minha dissertação: Anna Ferraroni, Ana Crestani, Ana Leite, Ariane Campos, Bianca Matinata, Fernanda Bocalini, Diego Cueva, Renata Beco, Sergio Bolívar, Marcelo Felix, Marina Lima, Patrícia Mancini, Cristiane Santos, Aline Corrêa, Natalia Luchetti e Fernando Mamani.

As pessoas que passaram pela seção de Aves e que durante sua estancia acrescentaram muito na minha pesquisa com seus comentários: Gustavo Bravo, Glaucia del Rio, Marco Rêgo, Vitor Piacentini e Omar Custodio.

A os amigos que tanto admiro e que me motivaram a escrever artigos, agradeço eles porque apesar que estou começando com a produção científica, acreditaram em mim e me motivaram a trabalhar juntos: Fabio Schunck, Vagner Cavarzere e Thiago V. Costa. Agradeço também o Fabio pelas fotos dos espécimes de campo, e Thiago pelas fotos do Field Museum de Chicago. 
Pessoas que também me apoiaram muito: Rafaela Lumi Vendramel, pela paciência, pelos bons momentos, e pela incrível amizade que cresce cada dia mais; José Serrano, pelas grandes conversas sobre sistemática e taxonomia; Felipe Arantes, obrigado pelo aprendizado no trabalho de campo e a grande amizade; Bret Whitney, pelos comentários acerca do meu grupo de trabalho; e Mariellen C. Costa, agradeço muito o seu apoio nos últimos meses, seus comentários e motivação foram muito importantes para mim.

A todos os curadores, técnicos e especialistas que me receberam nas diferentes coleções científicas que visitei: Gustavo Cabanne, Darío Lijtmaer, Pablo Tubaro e Yolanda Davies do Museo Argentino de Ciencias Naturales "Bernardino Rivadavia"; Glayson Bencke do Museu de Ciências Naturais da Fundação Zoobotânica do Rio Grande do Sul; Alexandre Aleixo e Fátima Lima do Museu Paraense Emílio Goeldi; Antenor Silva do Museu de História Natural Capão da Imbuia; Marcos Raposo e Daniel Figueira do Museu Nacional. Agradeço a Jorge Nacinovic do Museu Nacional, por ter me dado o seu livro das Penelope como presente e a longa conversa sobre esse grupo de aves, foi de grande ajuda no desenvolvimento do meu mestrado. Thanks to Sylke Frahnert from the Naturkundemuseum Berlin for providing me photographs of an important specimen, and the other European museums visited by Luís Fábio Silveira who provided me photographs from there.

Às pessoas que me abriram as portas das suas casas em algumas das cidades que visitei: Guilmour Rossi e Karolyna Gutierres em Curitiba, e Lisveth Valenzuela em Belém.

Grato com os meus amigos com quem morei ao longo de dois anos e que lembro com muito carinho: Tulio Franco, Michel Gianetti e Igor Mourão. Assim como a família Silva: Tatiane, Nicolly e Igor; que sempre foram muitos amáveis comigo. 
A José Nogueira e Fernando Pinto, que foram de grande ajuda na expedição em Alagoas, viagem que marcou um ponto importante na minha pesquisa. E Fernando Straube que me ajudou com informação histórica de expedições no estado de Paraná.

Ao pessoal do Serviço de Apoio Acadêmico do programa de pós-graduação do Museu de Zoologia da USP: Marta Maria Cardeira Grobel, Omair Tizzot Filho e Sonia Favaro de Araujo, assim como a todos os professores e pessoal administrativo da mencionada instituição, por toda a ajuda ao longo do desenvolvimento do meu projeto. Sempre estiveram dispostos a me ajudar frente a qualquer situação.

Aos integrantes da minha banca examinadora: Prof. Dr. Mercival Francisco e o Dr, Thiago V. V. Costa, por ter aceitado o convite de participar na banca e por todas as sugestões e melhoras na minha dissertação.

À Coordenação de Aperfeiçoamento de Pessoal de Nível Superior (CAPES) pela bolsa de estudos outorgada para estudar meu mestrado; al Consejo Nacional de Ciencia y Tecnología (CONCYTEC) con el financiamiento del Fondo Nacional de Desarrollo Científico, Tecnológico e Innovación Tecnológica (FONDECYT), que me apoyó em mi primera visita al MZUSP em el año 2014. Also, I want to thank the non-profit organization IDEA WILD for the support with electronic equipments to continue with my taxonomy and conservation projects, and Mr. Ausverto Placencia for receiving and transporting them.

A mi familia entera, que nunca deja de motivarme para seguir cumpliendo mis sueños, comenzando por mis padres con su eterno amor y cariño, y continuando con mis tías María, Nélida, Aurora, mis tíos Julio y Pedro, Shirley Sujey, Alexei Vincent, María Isabel Leonor, Sofia Fernanda, Daniel Alejandro, Walter Martin, Natali Placencia, Brayan Martin y Silvia 
Soledad, gracias a todos por siempre estar conmigo a pesar de la distancia, cada uno de ustedes tiene un lugar importante en mi corazón.

A Brian, Alfredo y Santiago por la gran amistad de tantos años. Así como a mis compañeros biólogos de muchos años: Jeimi Porras, Ángel Romani, Augusto Franco, Luis Pillaca, Miguel Garcia y Carlos Marcelo. También a mis amigas Claudia Chiong y Cristina Montoya por su apoyo incondicional.

A Arturo Carlos por la confianza en los trabajos de campo, y Gabriel Vásquez por las enseñanzas y paciencia en mi constante aprendizaje de la ornitología peruana, así como Orson Mestanza y Gloria Levano que me motivaron a venir a Brasil por primera vez. 


\section{SUMARIO}

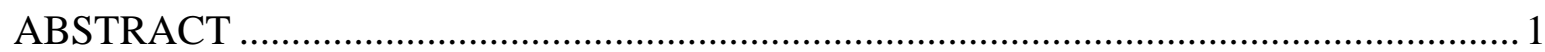

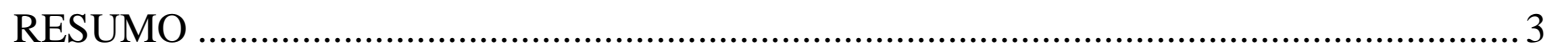

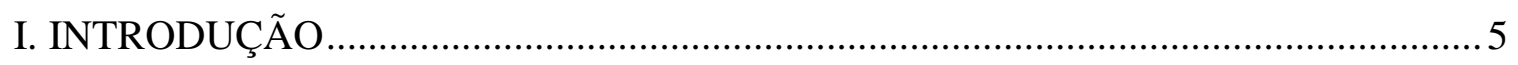

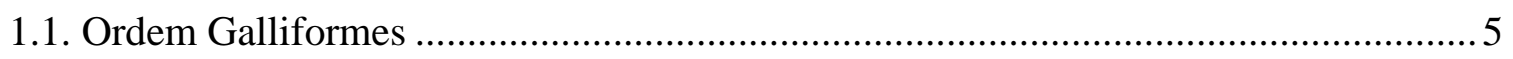

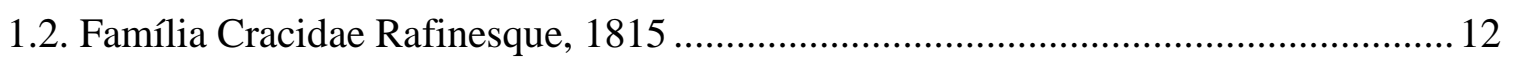

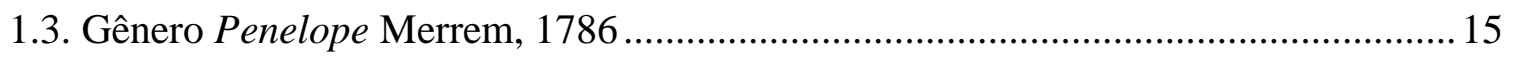

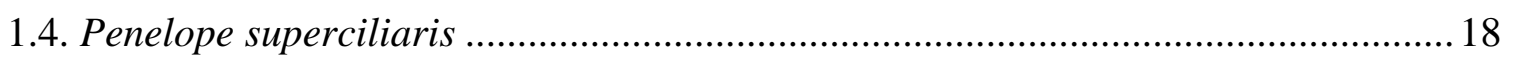

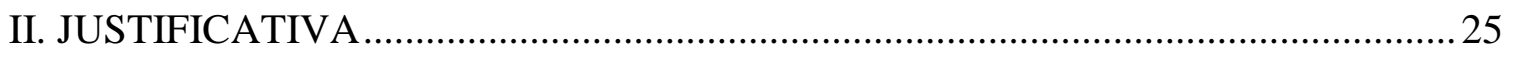

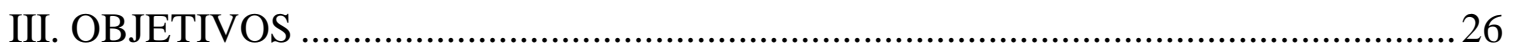

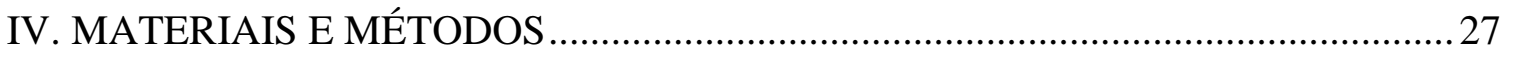

4.1. Espécimes estudados e coleções científicas................................................................27

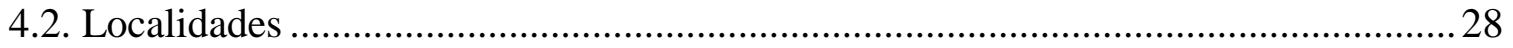

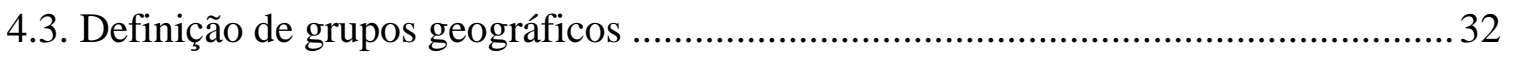

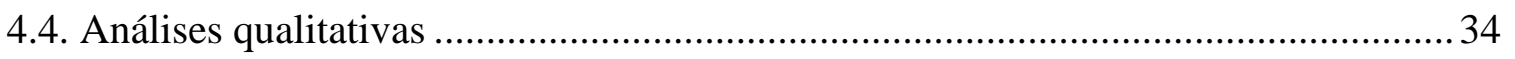

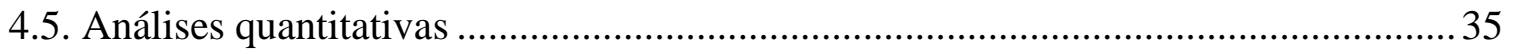

4.6. Critérios para delimitação de espécies ......................................................................42

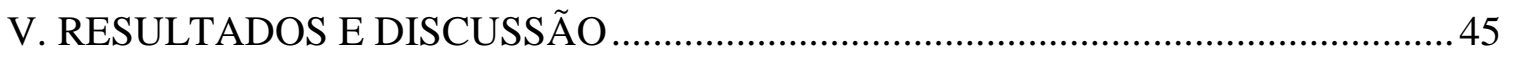

5.1. Histórico do complexo Penelope superciliaris.......................................................... 45

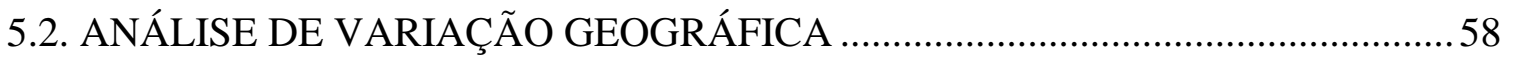

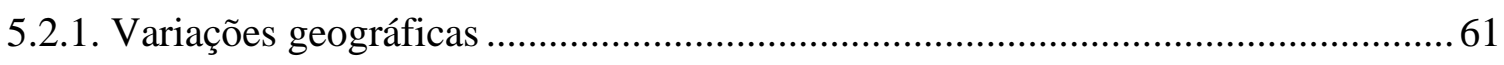

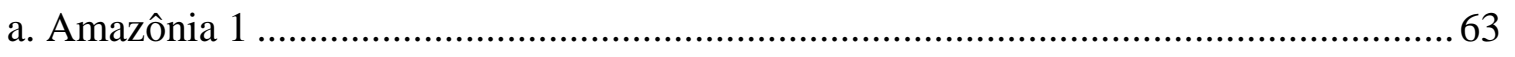

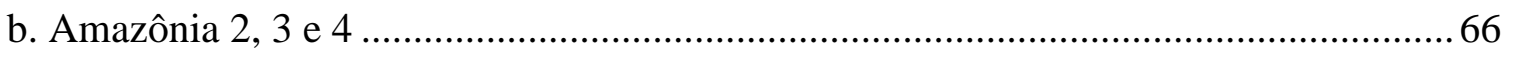

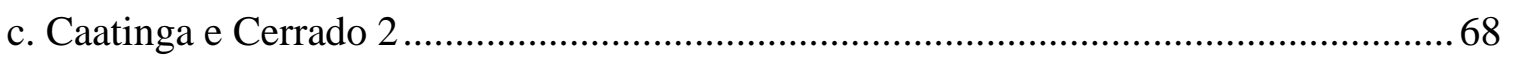

d. Amazônia 5, Pantanal e Cerrado 5 .............................................................................. 72

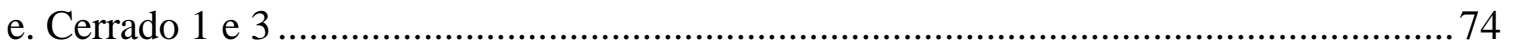

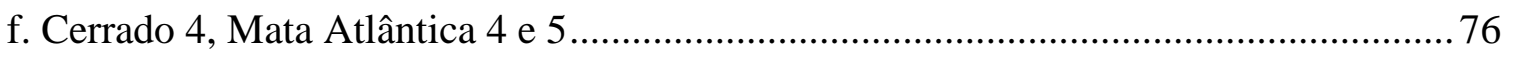

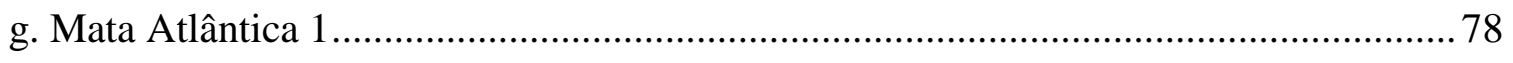

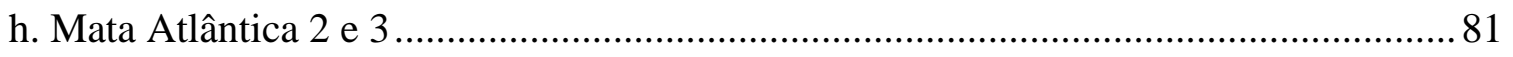




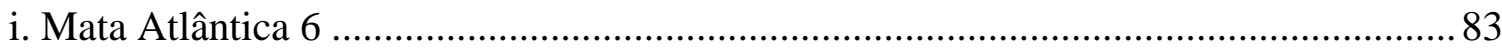

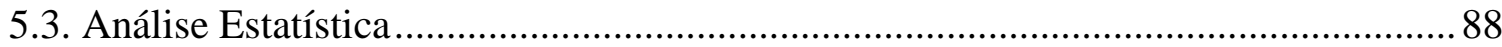

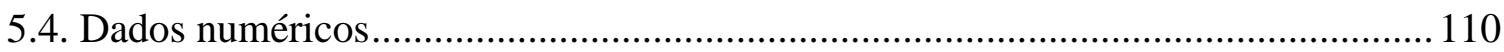

VI. TAXONOMIA DO COMPLEXO Penelope superciliaris .................................... 115

6.1. Penelope superciliaris Temminck, 1815 ......................................................... 115

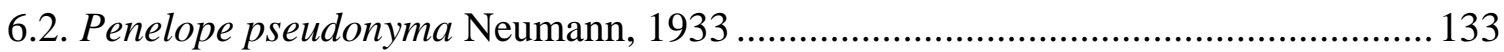

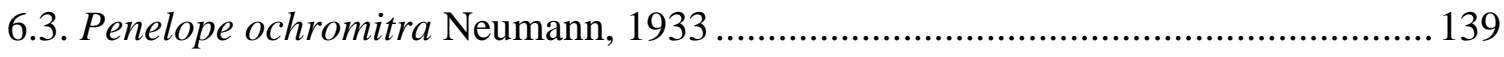

6.4. Penelope alagoensis Nardelli, 1933 ................................................................. 145

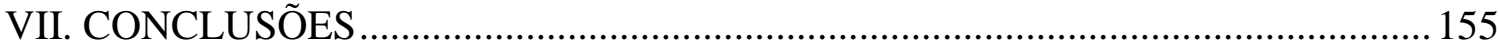

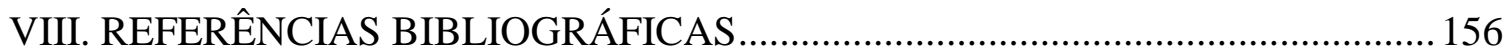




\section{LISTA DE FIGURAS E TABELAS}

Figura 1. Distribuição das aves galiformes em 1868, de acordo com Huxley...............6 Figura 2. Classificação da ordem Galliformes de acordo com o Handbook of the Birds of the World (del Hoyo et al., 1994). 9

Tabela 1a. Histórico da classificação da Ordem Galliformes, categorizado por autores $(1758-1990)$ 10

Tabela 1b. Histórico da classificação da Ordem Galliformes (1758 - 1990). 11

Figura 3. Distribuição global de Penelope superciliaris, de acordo a BirdLife International \& NatureServe (2015).

Figura 4. Localidades geográficas dos exemplares revisados de coleções científicas pertencentes ao complexo Penelope superciliaris, em um mapa separado por biomas.

Figura 5. Localidades de fotografias revisadas de indivíduos vivos silvestres pertencentes ao complexo Penelope superciliaris, em um mapa separado por biomas.

Figura 6. Medidas: comprimento do culmen exposto (A), da ponta do bico até a narina

(B) e tarso (C). 37

Figura 7. Medidas: comprimento do dedo do meio (A), asa fechada (B) e cauda (C). 38 Figura 8. Prancha de Penelope superciliaris jacupemba que acompanha a descrição de Spix (1825). 38

Figura 9. Desenho de Penelope superciliaris alagoensis que acompanha a descrição da subespécie. Extraído de Nardelli (1993). 55

Figura 10. Desenho de Penelope superciliaris cyanosparius que acompanha a descrição da subespécie. Extraído de Nardelli (1993). 57

Tabela 2. Grupos geográficos formados e seus respectivos números de peles para as análises estatísticas .58

Figura 11. Grupos geográficos do complexo Penelope superciliaris divididos por biomas: Amazônia (1-5), Caatinga (6), Pantanal (7), Cerrado (8-12) e Mata Atlântica (13-18). 60

Figura 12. Vista dorsal (A) e ventral (B) dos sete exemplares coletados no interflúvio Madeira-Tapajós. De esquerda a direita: LSUMZ B-86475, MZUSP 97239, MUZSP 
95762, LSUMZ B-80658, MZUSP 95764, MZUSP 86399 e MZUSP 86400. Foto: Fabio Schunck. 64

Figura 13. Pele azul do rosto em indivíduos machos imediatamente depois de coletados: LSUMZ B-86475 segundos (A) e MZUSP 86400 minutos (B) depois de coletados, mostrando a rápida perdida do tom azulado. Foto: Fabio Schunck. 65

Figura 14: Espécimes revisados dos grupos geográficos da Amazônia: AM2 (MZUSP 20818, MZUSP 21939), AM3 (MPEG 36074), e AM4 (MZUSP 89852). 67

Figura 15. Linhas superciliares ocre características dos grupos geográficos CE2 e CA: MPEG 45080 (A; fêmea da Colônia do Formoso - BA), MNRJ 36284 (B; fêmea da Flona Araripe, Crato - CE), MZUSP 79473 (C; macho de ESEC Serra Geral de Tocantins - TO), e MNRJ 36285 (D; macho da Flona Araripe, Crato - CE)..............69

Figura 16. Vista dorsal (A), ventral (B) e lateral (C) do exemplar MZUSP 86331 (Brejo do Piauí - PI), típico da Caatinga pela linha superciliar ocre e as bordas extensas das penas das asas de cor laranja amarelada. 70

Figura 17. Exemplares típicos da área do Cerrado que limita com a Caatinga (CE2): MPEG 43386 de Maranhão (A,B) e MZUSP 40773 de Bahía (C,D). 71

Figura 18. Espécimes revisados dos grupos geográficos do oeste do Brasil: PA (MNRJ 18863, MNRJ 18899) e CE5 (MZUSP 12243, MZUSP 36609).. 73

Figura 19. Espécimes revisados dos grupos geográficos do centro do Brasil: CE1 (MNRJ 18896, MPEG 42246) e CE3 (MNRJ 36662, MNRJ 32542). 75

Figura 20. Espécimes revisados dos grupos geográficos do sudeste do Brasil: MA5, CE4 e MA4. .77

Figura 21. Linhas superciliares branco brilhantes do grupo geográfico MA1: MZUSP 39439 (A; não determinado de Mamanguape, Camaratuba - PB) e MZUSP SN (B; fêmea da Fazenda Santa Justina, Passo de Camaragibe - AL). .79

Figura 22. Vista dorsal, ventral e lateral do exemplar MNRJ 34855 (Fazenda Santa Justina, Passo de Camaragibe - AL), típico do Centro de Endemismo Pernambuco (Mata Atlântica) pela linha superciliar branca brilhante e a coloração geral escura.....80 Figura 23. Espécimes revisados dos grupos geográficos do este do Brasil: MA2 (MZUSP 14022, MZUSP 37826) e MA3 (MNRJ 31037, MNRJ 26747). .82 
Figura 24. Espécimes revisados do grupo geográfico MA6 do limite entre Brasil, Paraguai e Argentina: MACN 31769 (ARG), MHNCI 4545 (BRA), MACN 32895 (ARG) e MACN 4608a (PAR).

Tabela 4. Média \pm desvio padrão (primeira linha), e valores mínimo e máximo (segunda linha) das medidas corporais dos grupos geográficos do complexo Penelope superciliaris representados em milímetros.

Tabela 5. Resultados das provas empregadas para testar a Distribuição Normal de cada variável em cada grupo geográfico.

Tabela 6. Prova $t$ de Student comparando machos e fêmeas de cada grupo geográfico. Áreas sombreadas indicam diferencias significativas entre ambos sexos $(\mathrm{p}<0.05)$. T e $\mathrm{P}$ valores da prova $t$ de student, M e F médias de Machos e Fêmeas. .97

Tabela 7. Frequência de indivíduos atribuídos a cada grupo geográfico a partir da Análise Discriminante Linear (LDA), representado em porcentagens. 101

Tabela 8. Número de indivíduos atribuídos a cada grupo geográfico a partir da Análise Discriminante Linear (LDA). 102

Figura 25. Análise de Variáveis Canônicas (CVA) com vectores que diferenciam os indivíduos dos grupos geográficos por suas diferenças morfométricas ..... 103

Tabela 9. Frequência de indivíduos atribuídos a cada bioma brasileiro a partir da Análise Discriminante Linear (LDA), representado em porcentagens. 105

Tabela 10. Número de indivíduos atribuídos a cada bioma brasileiro a partir da Análise Discriminante Linear (LDA). 105

Figura 26. Análise de Variáveis Canônicas (CVA) com vectores que diferenciam os indivíduos dos biomas brasileiros por suas diferenças morfométricas 106

Tabela 11. Frequência de indivíduos atribuídos a cada táxon identificado a partir da Análise Discriminante Linear (LDA), representado em porcentagens. 108

Tabela 12. Número de indivíduos atribuídos a cada táxon identificado a partir da Análise Discriminante Linear (LDA). 108

Figura 27. Análise de Variáveis Canônicas (CVA) com vectores que diferenciam os indivíduos dos táxons identificados por suas diferenças morfométricas 109 
Tabela 13. Medidas corporais preenchidas na etiqueta de espécimes de museu revisados. separados por machos $(\mathrm{M}$, azul), fêmeas ( $\mathrm{F}$, rosa) e não determinados (ND, cinza).

Figura 28. Exemplar de Penelope superciliaris mais antigo ( ZMB 11882 - Museu de Berlim), coletado por Gomes para o Conde de Hoffmannsegg entre 1801-1803. Fotos: Sylke Frahnert.

Figura 29. Especimes de museus de Penelope superciliaris Temminck, 1815, identificados com base no presente estudo.

Figura 30. Individuos de Penelope superciliaris Temminck, 1815, identificados com base no presente estudo.

Figura 31. Ambos lados da etiqueta do exemplar FMNH 407458, traduzidos ao inglês (A e B), e etiqueta original de H. Lako (C). Foto Thiago V. V. Costa.

Figura 32. Exemplar FMNH 407458 designado como lectótipo de Penelope pseudonyma. Foto: Thiago V. V. Costa . 138

Figura 33. Localidades-tipo das subespécies propostas por Neumann (1933) e Nardelli (1993), espécimes revisados de cara azul, e distribuição geográfica conhecida do complexo Penelope superciliaris de acordo com BirdLife International \& NatureServe (2015). 138

Figura 34. Espécimes de museus de Penelope ochromitra Neumann, 1933, identificados com base no presente estudo.

Figura 35. Indivíduos de Penelope ochromitra Neumann, 1933, identificados com base no presente estudo. 144

Figura 36. Indivíduo de Penelope alagoensis. 151

Figura 37. Superciliar branco largo e brilhante, característico de P. alagoensis....... 151 Figura 38. Penelope alagoensis no Criadouro Científico e Cultural Poços de Caldas. Foto: Luís Fábio Silveira (Extraido de Silveira et al., 2008)..... 152

Figura 39. Mapa com registros de ocorrência de Penelope alagoensis em usinas, reservas biológicas, reservas particulares e estações ecológicas nos estados de AL, PE, PB e RN. (Extraído de Silveira et al., 2008). 
Figura 40. Vista dorsal e ventral das quatro espécies diagnosticadas (de esquerda à direita): espécimes de Penelope pseudonyma (1), Penelope superciliaris (2-4), Penelope ochromitra (5) e Penelope alagoensis (6).

Figura 41. Espécimes de museus das quatro espécies do complexo Penelope superciliaris, separadas com base no presente estudo. Penelope superciliaris (circulos), Penelope ochromitra (quadrados), Penelope pseudonyma (triangulos) e Penelope

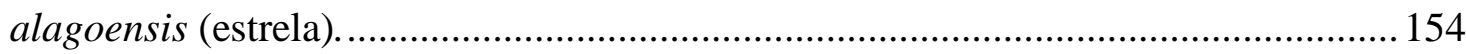




\begin{abstract}
Penelope superciliaris Temminck, 1815, known as Rusty-margined Guan, is a forest guan with the widest distribution, occurring in Brazil, Paraguay, Argentina and Bolivia, being also one of the seven species of the genus Penelope distributed in Brazil. Its subspecies have been described based on the width and shade of edges of feathers, the development of the superciliary stripe, naked parts pigmentation, general plumage coloration and size. The taxonomy of this taxon is complex and even today many authors never reached a consensus on the validity of the subordinate taxa; most of them recognize only three subspecies: $P$. s. superciliaris, $P$. s. jacupemba and $P$. s. major; other populations proposed as new races are currently synonymized with the previous three. For this complex, no review was conducted in the last 70 years that is why, with recent collection of new material, I performed a taxonomic revision based on external morphological characters. The aim on this work is to verify how many taxa exist at the species level in the Penelope superciliaris complex, and delimit their respective geographic distributions. To achieve these goals, we performed qualitative analyzes of external morphological characters as plumage coloration, naked parts pigmentation, and were tested inter- and intra-populational variations according to these characters. For statistical analyzes we performed univariate and multivariate tests to evaluate the sexual dimorphism and geographical variation. From eighteen geographic groups formed, the qualitative analyzes reveals that there is no sexual dimorphism, and most of them have a high degree of individual variation. Statistical analyzes did not discriminate the sexes and populations based on the eight body measurements used, but the taxa were discriminated by plumage coloration and naked parts pigmentation. According to the Phylogenetic Species Concept (PSC), we consider that the Penelope superciliaris complex must be divided in four species: Penelope pseudonyma Neumann, 1933, a
\end{abstract}


blue-faced guans population restricted to the Madeira-Tapajós interfluvium in the Amazon forest; Penelope ochromitra Neumann, 1933, from the Caatinga and Cerrado that borders with this biome; Penelope alagoensis Nardelli, 1993, from the Pernambuco Center of Endemism; and Penelope superciliaris Temminck, 1815, which occurs in the rest of the distribution of the complex.

Keywords: Penelope superciliaris complex, taxonomy, geographical distribution, game birds, morphology. 


\section{RESUMO}

Penelope superciliaris Temminck, 1815, comumente conhecido como jacupemba, é o jacu com a mais ampla área de distribuição, ocorrendo no Brasil, Paraguai, Argentina e Bolívia, sendo também uma das sete espécies do gênero Penelope distribuída no Brasil. Suas subespécies foram descritas com base na largura e a tonalidade das bordas das penas, no desenvolvimento da linha superciliar, pigmentação das partes nuas, coloração geral da plumagem e tamanho. A taxonomia deste táxon é complexa e até hoje muitos autores nunca chegaram a um consenso sobre a validade dos táxons subordinados, a maioria deles reconhece apenas três subespécies: P. s. superciliaris, P. s. jacupemba e P. s. major, outras populações propostas como novas subespécies geográficas são atualmente sinonimizadas com as três anteriores. Para este complexo nenhuma revisão foi realizada nos últimos 70 anos, é por isso que, com coletas recentes de material novo, estamos realizando uma revisão taxonômica com base em caráteres morfológicos externos. O objetivo deste trabalho é verificar quantos táxons estão no nível de espécie no complexo Penelope superciliaris e delimitar suas respectivas distribuições geográficas, de acordo com o bioma em que eles ocorrem. Para atingir esses objetivos, realizamos análises qualitativas de carácteres morfológicos externos como coloração da plumagem, pigmentação das partes nuas, e também foram testadas variações inter- e intra-populacionais de acordo com esses caráteres. Para a análise estatística foram realizados testes univariados e multivariados para avaliar o dimorfismo sexual e a variação geográfica. De dezoito grupos geográficos formados, as análises qualitativas revelam que não há dimorfismo sexual, e a maioria delas tem um alto grau de variação individual. As análises estatísticas não discriminaram os sexos e populações com base nas oito medidas corporais utilizadas, porém os táxons foram discriminados pela coloração da plumagem e a pigmentação das regiões nuas. De acordo com o Conceito 
Filogenético de Espécies (PSC), consideramos que o complexo Penelope superciliaris deve ser dividido em quatro espécies: Penelope pseudonyma Neumann, 1933, uma população de jacus de cara azul restrita ao interflúvio Madeira-Tapajós na floresta amazônica; Penelope ochromitra Neumann, 1933, da Caatinga e Cerrado que limita com este bioma; Penelope alagoensis Nardelli, 1993, do Centro de Endemismo Pernambuco; e Penelope superciliaris Temminck, 1815, que ocorre no resto da distribuição do complexo.

Palavras-chave: Complexo Penelope superciliaris, taxonomia, distribuição geográfica, aves cinegéticas, morfologia. 


\section{INTRODUÇÃO}

\subsection{Ordem Galliformes}

A Ordem Galliformes, como o seu nome diz, é o grupo que inclui as aves galináceas ou que são parecidas às galinhas (do inglês fowl-like birds). É facilmente caracterizada pela morfologia dos seus representantes, que possuem corpos relativamente pesados, robustos e arredondados. Além disso, eles têm cabeça pequena, bico curto, pernas fortes especializadas em subir árvores, e asas geralmente curtas que limitam o voo e permitem só movimentos curtos de baixa elevação. Por outro lado, eles têm a sua alimentação baseada em sementes, assim como pés adaptados para correr e arranhar o chão, e são de hábitos terrestres ou arborícolas (Delacour \& Amadon, 2004).

Os galiformes ocorrem em todos os continentes e várias ilhas, que vão desde o Ártico até os extremos dos continentes do Sul, estando ausentes só na Polinésia, Nova Zelândia e Antártida. No entanto, algumas famílias limitam-se a ocorrer somente em um continente ou área (Crowe et al., 2006). Por exemplo, a família Cracidae está confinada aos Neotrópicos; os Megapodiidae à Australasia, sudeste da Ásia, Filipinas, e as ilhas do sudoeste do Pacífico; os Odontophoridae ocorrem nas Américas; os Numididae na África e Madagascar; e os Phasianidae principalmente no sudeste da Ásia (Sibley \& Ahlquist, 1990).

Revisando brevemente o histórico da Ordem, o Sistema Naturae (1758) de Carl Linnaeus é o primeiro trabalho que cria uma classificação hierárquica de aves galiformes, que inclui na ordem Gallinae os gêneros Pavo, Meleagris, Crax, Phasianus e Tetrao, dentro dos quais se encontram algumas espécies que são válidas dentro da ordem até hoje. Aproximadamente 100 anos depois, autores como Blanchard (1857) e Parker (1866) trabalharam na classificação e as relações internas das aves galináceas, os 
dois baseando-se em caráteres osteológicos, só que o primeiro autor incluiu também aves fósseis nas suas análises. Pouco tempo depois, Huxley (1868), com a sua publicação em um livro da Proceedings of the Zoological Society of London, explica a classificação e distribuição dos Alectomorphae, forma como ele chamou as aves galináceas, concordando com Parker (1866) e relacionando as subdivisões do grupo com a zoogeografia, limitando os grupos internos e os grupos adjacentes, e delimitando as suas respectivas distribuições geográficas (Fig. 1). O mesmo autor também restringiu o grupo com base em caráteres osteológicos, excluindo as famílias Pteroclidae e Turnicidae, os quais eram incluídos dentro dos Alectomorphae em um outro trabalho publicado dois anos antes por ele mesmo.

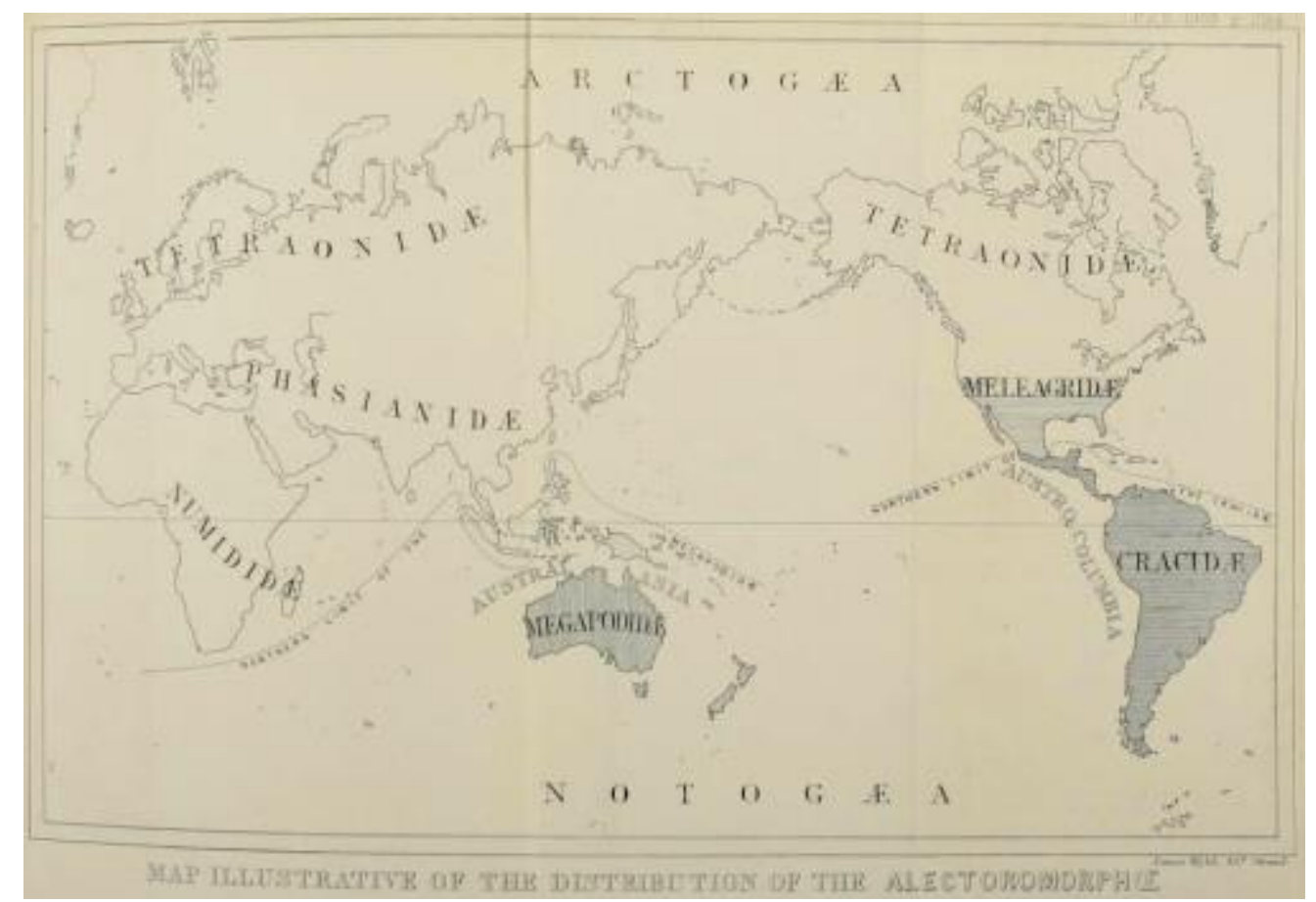

Figura 1. Distribuição das aves galiformes em 1868, de acordo com Huxley.

Ogilvie-Grant (1893), no volume 22 do Catalogue of Birds in the British Museum, segue a classificação de Sclater e considera que dentro da ordem Gallinae existem quarto famílias: Tetraonidae, Phasianidae, Megapodiidae e Cracidae, se 
aproximando um pouco ao que é conhecido atualmente. Anos depois, no Hand-List of the Genera and Species of Birds, Sharpe (1899), que parte do arranjo usado por OgilvieGrant (1893), chama a ordem de Galliformes e não de Gallinae, com um total de sete famílias: Numinidae, Meleagridae e Odontophoridae, em adição das anteriormente mencionadas. Nesse trabalho o autor considerou a família Cracidae dentro da subordem Craces.

Já no século XX, na classificação tradicional do Check-List das Aves do Mundo de Peters (1934), dentro da ordem Galliformes são consideradas as subordens Opisthocomi e Galli, esse último incluindo as superfamílias Cracoidea e Phasianoidea. Do total de 8 famílias, só uma é monogenérica (Opisthocomidae), outras três contam com menos de 10 gêneros (Megapodiidae, Numididae e Meleagrididae), e as restantes têm 10 ou mais (Cracidae, Tetraonidae e Odontophorinae), sendo a família Phasianidae a que tem o maior número de gêneros, com 47 como total divididos em duas subfamílias: Odontophorinae e Phasianinae. Pouco tempo depois, no Catalogue of Birds of the Americas, Hellmayr \& Conover (1942) consideram que a ordem Galliformes continua incluindo as subordens Galli e Opisthocomi, formando parte do primeiro as famílias Cracidae, Tetraonidae, Phasianidae, Numididae e Meleagrididae; e no segundo só a família Opisthocomidae.

Mais recentemente, em uma classificação proposta por Sibley et al. (1988), com base em estudos de hibridação DNA-DNA, é levada em conta a superordem Gallomorphae, que se divide nas ordens Craciformes e Galliformes: o primeiro inclui as famílias Cracidae e Megapodiidae, e o segundo às famílias Phasianidae, Numididae e Odontophoridae, apesar de geralmente os cracídeos e os galiformes típicos serem colocados na mesma ordem, Galliformes (Sibley \& Ahlquist, 1990). Já no livro Handbook of the Birds of the World de del Hoyo et al. (1994), são consideradas sete 
famílias dentro da ordem Galliformes unicamente, que se divide nas subordens Craci e Phasiani, com as famílias Megapodiidae e Cracidae na primeira, e Meleagrididae, Tetraonidae, Odontophoridae, Phasianidae e Numididae na segunda.

Mais recentemente, Crowe et al. (2006) estudaram as relações evolutivas dentro da ordem Galliformes, incluindo como evidências às sequências de DNA mitocondrial, proteínas, história de vida, comportamento, e morfologia de ossos e penas, mostrando que a monofilia de vários agrupamentos tradicionalmente reconhecidos não é suportada. Por exemplo, os megapodes (Megapodiidae) e os cracídeos (Cracidae), que para alguns autores compõem a ordem Craciformes ou a superfamília Cracoidea para outros, são parafiléticos uns em relação aos outros. Também contrariamente ao sugerido pelos dados de hibridização DNA-DNA de Sibley et al. (1988), os Odontophoridae não divergiram antes que os Numididae, mas sim imediatamente depois. O histórico da classificação da ordem Galliformes se resume na Tabela 1, mostrando que as relações evolutivas entre os seus integrantes ainda não estão bem resolvidas.

Na presente dissertação, consideramos a classificação proposta no Handbook of the Birds of the World (del Hoyo et al., 1994), que tem a ordem Galliformes como o único grupo que inclui as aves galináceas, com um total de sete famílias dentro das subordens Craci e Phasiani (Fig. 2). Dentro da Ordem temos as aves conhecidas comumente como megapodes (Megapodiidae), aracuãs, jacus, jacutingas, mutuns e afins (Cracidae), perus (Meleagrididae), galos (Tetraonidae), urus (Odontophoridae), faisões, perdizes (Phasianidae) e galinhas-de-angola (Numididae). No Brasil, só ocorrem representantes das famílias Cracidae e Odontophoridae, que em conjunto incluem um total de seis gêneros, 28 espécies e 47 subespécies, de acordo com a última Lista de Aves publicada pelo Comitê Brasileiro de Registros Ornitológicos - CBRO (Piacentini et al., 2015). 


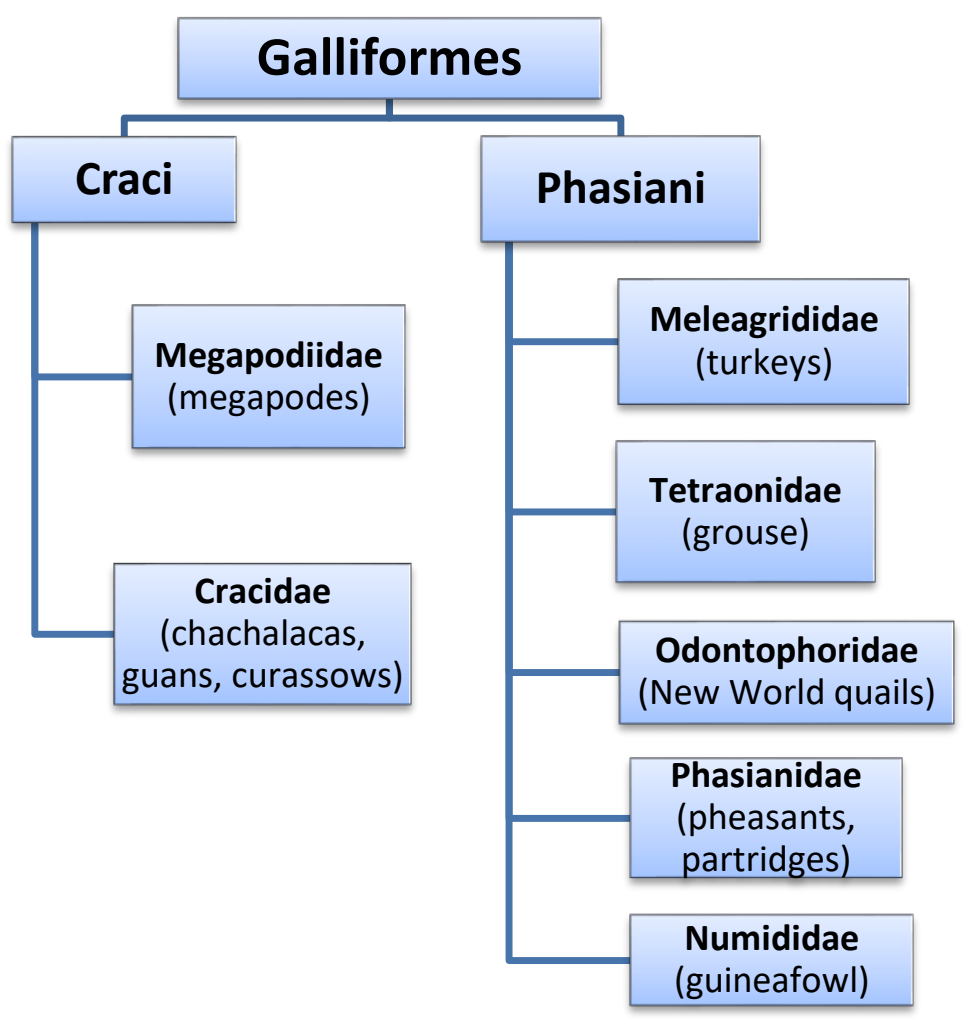

Figura 2. Classificação da ordem Galliformes de acordo com o Handbook of the Birds of the World (del Hoyo et al., 1994). 
Tabela 1a. Histórico da classificação da Ordem Galliformes (1758 - 1990). (Continua)

\begin{tabular}{|c|c|c|}
\hline Linnaeus & Ogilvie-Grant \\
$\mathbf{1 7 5 8}$ & $\mathbf{1 8 9 3}$ & Sharpe \\
& & $\mathbf{1 8 9 9}$ \\
\hline & & Ordem Galliformes \\
Classe Aves & & Subordem Megapodii \\
Ordem Gallinae & Ordem Gallinae & Família Megapodiidae \\
Gênero Pavo & Subordem Alectoropodes & Subordem Craces \\
Gênero Meleagris & Família Tetraonidae & Família Cracidae \\
Gênero Crax & Família Phasianidae & Subordem Phasiani \\
Gênero Phasianus & Subordem Peristeropodes & Família Tetraonidae \\
Gênero Tetrao & Família Megapodiidae & Família Phasianidae \\
& Família Cracidae & Família Numididae \\
& & Família Meleagridae \\
& & Família Odontophoridae \\
& & \\
\hline
\end{tabular}


Tabela 1b. Histórico da classificação da Ordem Galliformes (1758 - 1990).

\begin{tabular}{|c|c|c|}
\hline $\begin{array}{c}\text { Peters } \\
1934\end{array}$ & $\begin{array}{c}\text { Sibley et al. } \\
1988\end{array}$ & $\begin{array}{c}\text { Sibley \& Ahlquist } \\
1990\end{array}$ \\
\hline $\begin{array}{l}\text { Ordem Galliformes } \\
\text { Subordem Galli } \\
\text { Superfamília Cracoidea } \\
\text { Família Megapodiidae } \\
\text { Família Gallinuloididae (fóssil) } \\
\text { Família Cracidae } \\
\text { Superfamília Phasianoidea } \\
\text { Família Tetraonidae } \\
\text { Família Phasianidae } \\
\text { Subfamília Odontophorinae } \\
\text { Subfamília Phasianinae } \\
\text { Família Numididae } \\
\text { Família Meleagrididae } \\
\text { Subordem Opisthocomi } \\
\text { Família Opisthocomidae }\end{array}$ & $\begin{array}{l}\text { Classe Aves } \\
\text { Subclasse Neornithes } \\
\text { Infraclasse Eoaves } \\
\text { Parvclasse Galloanserae } \\
\text { Superodem Gallomorphae } \\
\text { Ordem Craciformes } \\
\text { Subordem Craci } \\
\text { Família Cracidae } \\
\text { Subordem Megapodii } \\
\text { Família Megapodiidae } \\
\text { Ordem Galliformes } \\
\text { Parvordem Phasianida } \\
\text { Superfamília Phasianoidea } \\
\text { Família Phasianidae } \\
\text { Superfamília Numidoidea } \\
\text { Família Numididae } \\
\text { Parvordem Odontophorida } \\
\text { Família Odontophoridae }\end{array}$ & $\begin{array}{l}\text { Infraclasse Neoaves } \\
\text { Parvclasse Galloanserae } \\
\text { Superodem Gallomorphae } \\
\text { Ordem Craciformes } \\
\text { Subordem Craci } \\
\text { Família Cracidae } \\
\text { Subordem Megapodii } \\
\text { Família Megapodiidae } \\
\text { Ordem Galliformes } \\
\text { Parvordem Phasianida } \\
\text { Superfamília Phasianoidea } \\
\text { Família Phasianidae } \\
\text { Superfamília Numidoidea } \\
\text { Família Numididae } \\
\text { Parvordem Odontophorida } \\
\text { Família Odontophoridae }\end{array}$ \\
\hline
\end{tabular}




\subsection{Família Cracidae Rafinesque, 1815}

A família Cracidae é um dos grupos de aves mais ameaçados e distintos da região Neotropical, e faz parte da Ordem Galliformes junto com outras seis famílias. Esse é um grupo natural e homogêneo que está bem separado das outras famílias de aves galináceas (Delacour \& Amadon, 2004). Os cracídeos ocorrem principalmente na Região Neotropical, por isso são chamados de "quase endêmicos" dessa região, embora também ocorram no extremo sul da Região Neártica, tendo uma ampla distribuição que vai desde o sul de Texas, nos Estados Unidos, com Ortalis vetula, até o sul do Uruguai e norte da Argentina, com Penelope obscura. Segundo FrankHoeflich et al. (2007), atualmente nove são os gêneros considerados como válidos dentro da família Cracidae:

Ortalis Merrem, 1786

Penelope Merrem, 1786

Penelopina Reichenbach, 1861

Aburria Reichenbach, 1853

Chamaepetes Wagler, 1832

Oreophasis Gray GR, 1844

Nothocrax Burmeister, 1856

Crax Linnaeus, 1758

Pauxi Temminck, 1813

De acordo com a última Lista das Aves publicada pelo Comitê Brasileiro de Registros Ornitológicos (CBRO), a família Cracidae registra atualmente um total de 6 
gêneros que incluem 24 espécies e 41 subespécies que ocorrem no Brasil (Piacentini et al., 2015).

Os integrantes da família são comumente conhecidos na língua portuguesa como mutuns, jacus e aracuãs, dependendo do gênero científico. Morfologicamente eles podem ser de porte médio a grande, com cauda e asas longas e corpo de forma galinácea. Também possuem pernas e pés fortes, com o hálux bem desenvolvido e no mesmo nível que os três anteriores (Delacour \& Amadon, 2004), o que lhes permite empoleirar nos ramos com muita habilidade.

No aspecto ecológico eles são conhecidos por ser a única família da ordem Galliformes com hábitos predominantemente arborícolas (Delacour \& Amadon, 2004). A sua alimentação está baseada principalmente na ingesta de sementes e frutos, que podem ser coletados diretamente das árvores ou também recolhidas do chão (Brooks, 2001). Geralmente habitam florestas e matas abertas que vão desde o nível do mar até os 3900 metros de altitude, sendo ausentes em desertos e pradarias. Em geral, essa família é de grande importância para o meio ambiente por ter o papel de regenerar os florestas tropicais mediante a dispersão de sementes e assegurando que as plantas que eles consomem com preferência se regenerem naqueles habitats que são adequados para sua sobrevivência (Guix \& Ruiz, 1997; Sedaghatkish et al., 1999), especialmente certas espécies de plantas que têm sementes grandes e que habitam florestas maduras, tais como plantas das famílias Lauraceae, Arecaceae e Sapotaceae, sendo algumas delas utilizadas pelo homem (Sedaghatkish, 1996; Sedaghatkish et al., 1999). Além de sua importância ecológica como regeneradores de florestas, eles também são bons indicadores de qualidade das matas, por serem aves sensíveis às mudanças ambientais ou qualquer alteração do entorno. É por isso que, 
como consequência do desmatamento e a caça, os cracídeos são uma das famílias de aves com maior proporção de espécies ameaçadas na região Neotropical.

Do ponto de vista evolutivo, Vaurie (1968) menciona que alguns autores acreditam que os Cracidae se originaram na América do Norte e se retiraram para a América do Sul quando a América do Norte se tornou cada vez mais árida. Delacour \& Amadon (2004) sugerem que com base na distribuição atual, pode-se concluir que os Cracidae se originaram no sul da América do Norte e, após chegar à América do Sul, evoluíram mais rapidamente, como seria de esperar em uma área maior, porém a partir de registros fósseis foi evidenciada a ocorrência mais ao norte, no que foi o centro dos Estados Unidos há alguns milhões de anos atrás. Brodkorb (1964) reconhece fósseis da família do Eoceno Superior ao Mioceno Inferior no Velho Mundo, especificamente na França, mas esses registros são duvidosos. Haffer (1967) menciona que eles devem ter se originado ao sul da América do Norte no Eoceno, aproximadamente há uns 50 milhões de anos, quando ainda a maior parte dessa região era tropical, para depois migrar para a América do Sul antes do Pleistoceno.

Em geral, os Cracidae parecem ser a família de aves galináceas vivas mais primitiva, já que o fóssil mais antigo é de 50 milhões de anos atrás, exatamente do Eoceno Médio. Este fóssil sugere que as aves já possuíam hábitos arborícolas, sendo atualmente os cracídeos os únicos sobreviventes com esse comportamento, só que claramente bastante modificado (Delacour \& Amadon, 2004). 


\subsection{Gênero Penelope Merrem, 1786}

Os integrantes do gênero Penelope, comumente conhecidos como jacus, são considerados cracídeos típicos: de tamanho corporal de médio a grande, forma esbelta, com ambos sexos parecidos, de face com ausência de penas e cor apagada, e garganta total ou parcialmente nua de cor vermelho brilhante, que se projeta para formar uma membrana gular. A maioria de espécies do gênero têm uma crista escura, exceto $P$. pileata, e penas no peito e ombros com margens esbranquiçados que produzem um efeito escamado (Vaurie, 1968; Delacour \& Amadon, 2004). Dentro da família Cracidae esse é o gênero com maior número de espécies (15):

Penelope albipennis Taczanowski, 1878

Penelope argyrotis (Bonaparte, 1856)

Penelope barbata Chapman, 1921

Penelope superciliaris Temminck, 1815

Penelope pileata Wagler, 1830

Penelope ochrogaster Pelzeln, 1870

Penelope jacucaca Spix, 1825

Penelope dabbenei Hellmayr \& Conover, 1942

Penelope jacquacu Spix, 1825

Penelope ortoni Salvin, 1874

Penelope marail (Statius Muller, 1776)

Penelope montagnii (Bonaparte, 1856)

Penelope perspicax Bangs, 1911

Penelope purpurascens Wagler, 1830

Penelope obscura Temminck, 1815 
O gênero está amplamente distribuído, desde o México, com $P$. purpurascens, até o norte da Argentina e sul do Uruguai, com P. obscura. A lista de espécies do Comitê Brasileiro de Registros Ornitológicos (CBRO), considera que no Brasil ocorrem 16 subespécies em sete espécies: $P$. marail, $P$. superciliaris, $P$. jacquacu, $P$. obscura, P. pileata, P. ochrogaster e P. jacucaca (Piacentini et al., 2015).

Os jacus, diferente de outros integrantes da família, têm um comportamento arborícola, pois possuem o hábito de consumir frutos diretamente das árvores, embora as vezes possam se alimentar de frutos caídos no solo e para beber água durante os períodos secos provavelmente (Delacour \& Amadon, 2004). São uns dos poucos grupos de aves que procuram suplementos minerais a sua dieta, como Olivares (1962) menciona, sendo que algumas espécies em certas áreas frequentam até mesmo barreiros como fonte de consumo desses suplementos.

Quando eles se movimentam através da floresta, vão de árvore em árvore no sub-dosel, dando pulos de dois a três metros ou, se é necessário, voos curtos de seis a 20 metros (del Hoyo \& Motis, 2004). Em geral são aves altamente vocais que se destacam pela variedade e em ocasiões pela sonoridade de seus cantos e gritos (Delacour \& Amadon, 2004). Eles ocorrem em uma variedade de altitudes, mas estão restritas a florestas tanto montanas como de terras baixas, como a maioria de espécies de cracídeos.

Revisando o histórico do gênero, vemos que o registro mais antigo encontrado foi publicado no período Pre-Lineano no livro "Historia Naturalis Brasiliae" de Guilherme Piso e George Marcgrave, se referindo ao Iacupema (Iacv - pema; termo indígena), claramente um indivíduo do gênero Penelope que é comparado com faisães e galinhas, descrevendo algumas caraterísticas gerais além de fazer medições de dedos e pés. Eles mencionam que o nome que recebeu a ave foi pelos sons que ela 
emite: iacu, iacu, iacu. Essas observações foram feitas na faixa litorânea do nordeste do Brasil e foram originalmente publicadas em latim no ano de 1648.

No ano de 1758, na décima edição do Systema Naturae de Linnaeus, vemos a aparição de gêneros pertencentes a família Cracidae como Crax e Phasianus, mas não foi feita nenhuma referência sobre o gênero Penelope ou algum Jacu. Já no início do período Pós-Lineano, temos a série de livros do Conde de Buffon "Histoire Naturelle des Oiseaux", que no quarto volume (1772) menciona ao L'Yacou, mas sem utilizar o sistema de classificação de Linnaeus.

Foi Merrem quem deu o nome ao gênero como Penelope no ano de 1786, sendo P. marail (Statius Muller, 1776) designada como espécie-tipo do gênero, descrita originalmente como Phafianus marail (um gênero que parecia ser uma generalização dos faisões para aves chamadas como Marail, Caracara, Hoazin e outros). A localidade tipo foi designada posteriormente por Peters como "Cayenne $e x$ Buffon". 


\subsection{Penelope superciliaris}

\subsubsection{Distribuição}

Penelope superciliaris Temminck, 1815, conhecida comumente como jacupemba, é a espécie com a distribuição geográfica mais ampla dentro do gênero, sendo encontrada desde as planícies da floresta tropical da Amazônia Sul, ao norte do Brasil, oeste do Rio Madeira e seu afluente o Rio Guaporé, centro e nordeste do Brasil até o sul atingindo o leste do Paraguai, leste da Bolívia e o extremo norte da Argentina no departamento de Misiones (Delacour \& Amadon, 2004) (Fig. 3). Na Bolívia tem sido registrada só desde o oriente e sudeste do país, no estado de Santa Cruz (Remsen \& Traylor, 1989; Arribas et al., 1995; Hennessey et al., 2003). No Paraguai, só é conhecido para a região oriental, onde tem sido registrado nas regiões biogeográficas de Campos Cerrados, Paraguai Central e Alto Paraná, encontrando-se mais para o oeste até San Lázaro, Concepción (Hayes, 1995). 


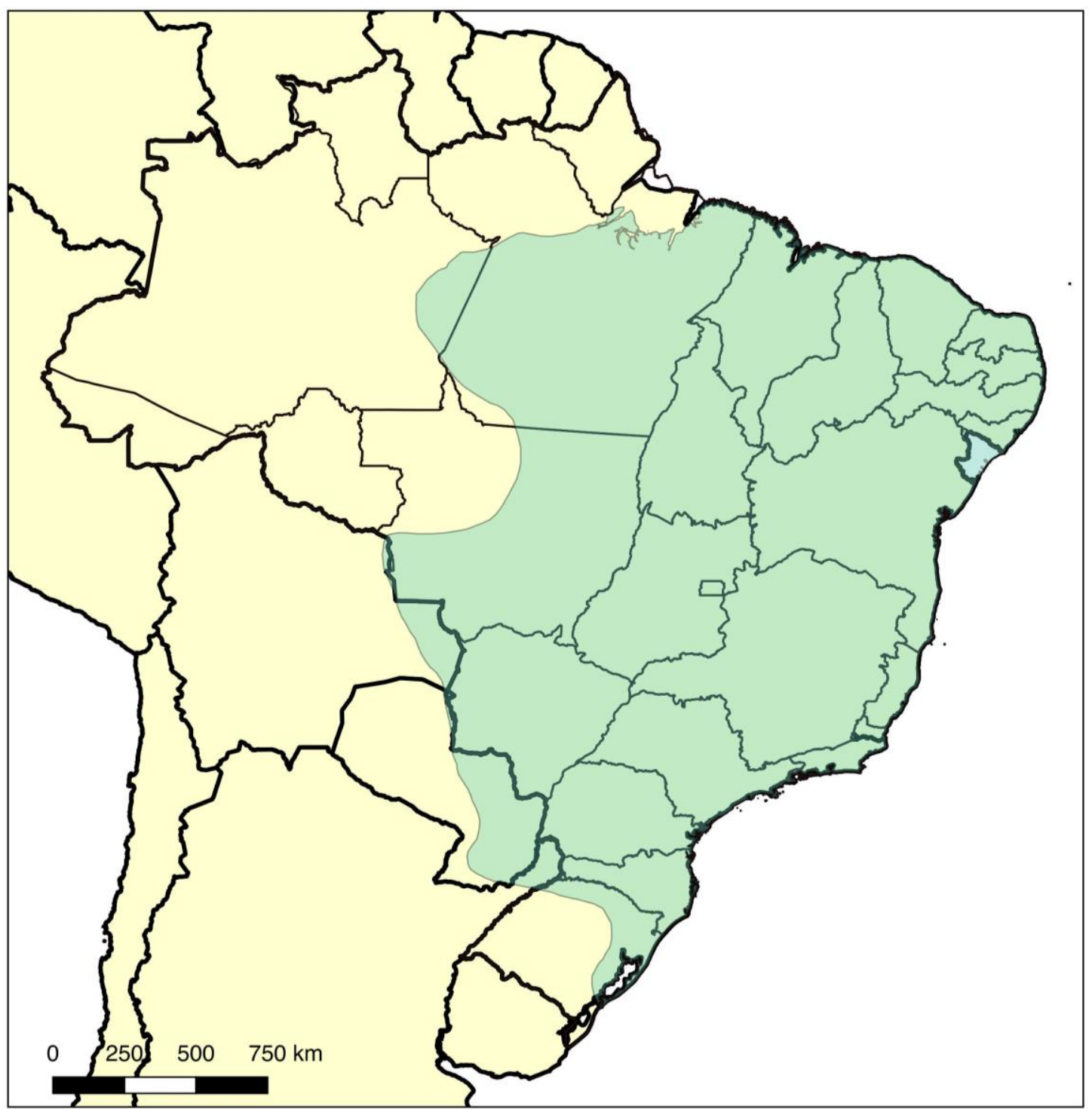

Figura 3. Distribuição global de Penelope superciliaris de acordo a BirdLife International \& NatureServe (2015).

\subsubsection{Ecologia}

Essa espécie ocorre na maioria dos biomas brasileiros e ocupa grande variedade de hábitats, incluindo a floresta úmida densa, caatinga, florestas de galeria, bordas de mata, capoeiras, manchas florestais em savanas abertas ou cerrados, e em margens de rios e lagos (Sick, 1993). Teixeira (1997) menciona que podem cruzar áreas abertas e de cultivo e que, portanto, podem chegar a bosques isolados, já que de 
outro modo seria impossível. No Estado de São Paulo, utilizam as florestas mais secas (subtropical semidecidual e decidual), floresta de transição (floresta subtropical floresta pluvial Atlântica), os cerrados e as restingas arbóreas e arbustivas do litoral (Guix, 1997).

\subsubsection{Morfologia}

P. superciliaris é diagnosticada pela cor das escápulas, as coberteiras superiores das asas e as secundárias com bordas conspicuamente coloridas que variam de ocre-avermelhado a castanho. Peculiarmente, a presença de uma linha superciliar não é exclusiva para esta espécie, já que esse caráter está também presente em outros integrantes do gênero. As bordas das penas das asas podem variar desde ferrugem até marrom avermelhado. Os pés são cinzas, a íris varia de vermelho a marrom e a face é cinza escuro. Não apresenta dimorfismo sexual e os jovens são similares aos adultos. Sick (1993) a diagnostica como: "De barbela nua e vermelha, mais proeminente (triangular) no macho; apresenta um rudimentar topete; asas com largas bordas ferrugíneas bem distintas; peito com desenho esbranquiçado; íris vermelha em ambos os sexos".

\subsubsection{Taxonomia}

A compreensão da variação morfológica e as implicações taxonômicas de $P$. superciliaris são complexas até hoje. Algumas populações foram descritas como subespécies baseadas principalmente na largura e coloração das bordas nas penas, na extensão e coloração da linha superciliar, o tamanho corporal, a coloração das penas em geral e cor das regiões nuas (Vaurie, 1966). 
Autores dos trabalhos que atualmente são as maiores referências na taxonomia do complexo P. superciliaris, como os de Charles Vaurie (1966), Josep del Hoyo et al. (1994) e Jean Delacour \& Dean Amadon (2004), reconhecem apenas três subespécies: Penelope s. superciliaris Temminck, 1815, P. s. jacupemba Spix, 1825 e P. s. major Bertoni, 1901. Das três raças geográficas propostas por Oscar Neumann em 1933 (P. s. pseudonyma, P. s. argyromitra e P. s. ochromitra), autores como Conover \& Hellmayr (1942) e Olivério Pinto (1964) reconheceram como válida a $P$. s. ochromitra Neumann, 1933, junto com as três primeiras subespécies. Na atualidade a maioria dos autores sinonimizam as raças ochromitra e argyromitra com jacupemba, e pseudonyma com a forma nominal (e.g. del Hoyo \& Kirwan, 2016), embora essas suposições careçam de comparação formal de material e claridade.

Mais recentemente, Nardelli (1993) adicionou mais dois táxons ao complexo P. superciliaris, descrevendo P. s. cyanosparius e P. s. alagoensis. Essas duas últimas subespécies foram descritas a partir de espécimes vivos mantidos em cativeiro, sem espécimes depositados em coleções científicas ou museus. As descrições são curtas, sem comparação com outros espécimes ou diagnoses, sendo acompanhadas por pranchas coloridas. Este procedimento, embora não usual, valida os nomes propostos, mas não há maneira objetiva de comparar os espécimes de coleções científicas com os táxons ou populações aqui descritas. Nenhum dos nomes introduzidos por Nardelli (1993) tem sido empregado na taxonomia de $P$. superciliaris por qualquer outro autor.

Descrevemos brevemente aqui cada um dos táxons, com a sua respectiva distribuição geográfica:

Penelope s. superciliaris Temminck, 1815 se caracteriza por ter a linha superciliar esbranquiçada; a parte posterior do pescoço e os ombros podem ser de cor oliva escuro ou marrom esverdeado, com bordas cinza-azuladas escuras. As penas do 
interior das asas e as coberteiras também das asas têm as suas bordas conspicuamente castanhas; as costas e coberteiras superiores da cauda são de cor castanho-pálido. O peito é cinza esverdeado escuro, com penas que têm bordas conspícuas de cor branco avermelhado pálido; o abdômen é cinza escuro, amplamente misturado e com bordas canela avermelhadas. Distribui-se ao norte do Brasil, ao sul da Amazônia, sul do Maranhão e desde o oeste do Pará até o Rio Madeira e seu afluente, o Rio Guaporé.

Penelope superciliaris jacupemba Spix, 1825 é mais pálido e apagado em tudo, com as bordas castanhas das penas do interior das asas mais pálidas como mais amplas. A linha superciliar é mais conspícua, com frequência castanha avermelhada. Esta subespécie substitui superciliaris no leste e centro do Brasil, desde o sul de Pernambuco até São Paulo e Paraná, ao oeste através de Minas Gerais e o sul de Goiás até Mato Grosso.

Penelope superciliaris major Bertoni, 1901 é uma subespécie de coloração mais escura que as duas anteriores, com bordas das penas de cor castanho pálidas nas asas; é um pouco maior no tamanho corporal em comparação ao resto de subespécies. A barbela é usualmente nua e não é tão pigmentada como nas duas primeiras subespécies mencionadas. Se distribui mais ao sul do Brasil, nos estados de Santa Catarina e Rio Grande do Sul. Também ao leste do Paraguai e ao nordeste da Argentina no departamento de Misiones.

Penelope superciliaris pseudonyma Neumann, 1933 difere de todas as outras raças geográficas de $P$. superciliaris por não apresentar linha superciliar, ou apenas uma estria branca fina mais ou menos marcada de cor cinza atrás do olho. Em geral é mais escura do que $P$. s. superciliaris Temminck. As bordas das penas são bem marcadas e de cor marrom escuro nas secundárias, uropígio e coberteiras superiores 
da cauda. Se distribui na margem direita do rio Madeira até a margem esquerda do Tapajós.

Penelope superciliaris argyromitra Neumann, 1933 possui uma muito ampla e bem marcada banda superciliar cinza claro unida na parte dianteira, por vezes, ligeiramente tingida de castanho. A cor geral é mais clara que $P$. s. pseudonyma, com pescoço, garganta e peito tingidos de cinza. Uropígio, coberteiras superiores da cauda e ventre rufo mais claro, assim como as bordas das secundarias em comparação com P. s. superciliaris e $P$. s. pseudonyma, que as vezes é ocre claro. Se distribui desde o centro de Goiás, ao leste, até pelo menos Bagagem, em Minas Gerais, co-ocorrendo com P. s. superciliaris perto do Rio Doce.

Penelope superciliaris ochromitra Neumann, 1933 é uma subespécie que segundo Hellmayr \& Conover (1942) é exatamente similar a $P$. s. jacupemba, mas com linha superciliar tingida fortemente de amarelo amarronzado claro, às vezes inclusive completamente amarelo amarronzado-ocráceo a marrom ocráceo. Distribuída pelo Nordeste do Brasil, nos estados de Maranhão, Piauí, e a seção adjacente do norte de Goiás (Boa Vista, interior de Tocantins).

Penelope superciliaris alagoensis Nardelli, 1993 se caracteriza por ter o supercílio de cor branca bem demarcado. O pescoço é negro e o dorso, coberteiras das asas, rêmiges e retrizes são de cor marrom-escuro, com discreto lustro verde-escuro. Últimas rêmiges secundárias e coberteiras intermediárias e maiores da asa com borda lateral das penas alaranjado-escuras. Peito negro, com borda lateral das penas de cor creme. Barriga com penas marrom-escuras, de borda lateral alaranjado-escura. Baixo ventre castanho-claro. Nas regiões nuas, a face é cinza-escura, o íris é vermelhoescura, e os tarsos e dedos são cinza-escuro-vináceos. Esta subespécie é endêmica da 
Mata Atlântica e ocorre só em uma faixa de floresta no Centro de Endemismo Pernambuco, no litoral entre os estados de Alagoas e Pernambuco.

Penelope superciliaris cyanosparius Nardelli, 1993 possui como característica a face nua que abrange uma área maior que nas outras subespécies, e se diferencia pela tonalidade cinza-escuro-azulada. Com supercílio branco quase imperceptível; a coloração do pescoço, dorso, coberteiras das asas, rêmiges e retrizes são similares às de $P$. s. alagoensis. Tarso e dedos cinza-escuro-vináceos. O que se conhecia sobre essa subespécie é que se distribui nas cabeceiras do rio Maués, no estado de Amazonas.

Charles Vaurie (1968) foi o último autor que fez uma revisão taxonômica completa do gênero Penelope no livro Taxonomy of the Cracidae. Esse trabalho, que está próximo a ter 50 anos de publicado, inclui informações bastante específicas sobre Penelope superciliaris, como a lista de espécies com as quais se sobrepõe, as variações na coloração da plumagem, estrutura, tamanho e proporções. Os mapas de distribuição propostos nesse trabalho ainda são utilizados como áreas onde as espécies do gênero ocorrem, um claro exemplo se vê nos mapas usados pela BirdLife International ou pela IUCN Red List of Threatened Species. Este autor considera que o complexo Penelope superciliaris possui três táxons subordinados: $P . \quad s$. superciliaris, P. s. jacupemba e P. s. major. Por outro lado, nenhuma revisão mais rigorosa deste grupo foi feita nas últimas décadas, e há um acúmulo de formas descritas e nomes disponíveis na literatura, além das descrições controversas feitas por Nardelli (1993). 


\section{JUSTIFICATIVA}

Os cracídeos são seriamente afetados pela caça e destruição de habitats, a consequência disso e por ter populações altamente sensíveis, podem ser efetivamente utilizadas como espécies indicadoras do estado das florestas e de áreas protegidas nos Neotrópicos (Strahl \& Grajal, 1991). Ao ser considerado como um grupo vulnerável ou em um maior perigo de extinção na Região Neotropical, o papel de bioindicadores requer a implementação de programas de gestão e conservação, é por isso que as incertezas taxonômicas das espécies pertencentes a essa família devem ser resolvidas, com o fim de tomar melhores decisões sobre a sua conservação. As revisões taxonômicas também são essenciais para o conhecimento da diversidade real e riqueza de aves, permitindo que estudos biogeográficos ou evolutivos sejam mais exatos depois de uma acertada delimitação dos táxons.

Devido à ampla distribuição geográfica e diversidade de habitats ocupados por $P$. superciliaris espera-se uma correspondente variação morfológica, que pode estar por trás do grande número de nomes propostos. No entanto, essa variação pode também ser o resultado do isolamento e processos históricos, o que, por sua vez, pode levar à existência de unidades evolutivamente diferentes e isoladas. Então, devido à incerteza quanto à validade de alguns táxons e das diferenças de tratamento entre os autores, uma revisão taxonômica deste complexo deve ser realizada, para conhecer os táxons válidos pertencentes ao complexo $P$. superciliaris, assim como suas distribuições geográficas. 


\section{OBJETIVOS}

O presente trabalho revisa a taxonomia do complexo Penelope superciliaris Temminck, 1815, com o objetivo de determinar quais são os táxons válidos, bem como delimitar suas respectivas distribuições geográficas, analisando caracteres morfológicos externos, como a coloração da plumagem, pigmentação das partes nuas e medidas corporais, tanto de espécimes depositados nas principais coleções ornitológicas como de indivíduos vivos. 


\section{MATERIAIS E MÉTODOS}

\subsection{Espécimes estudados e coleções científicas}

Foram examinados um total de 374 espécimes taxidermizados (peles) pertencentes ao complexo $P$. superciliaris, coletados ao longo de toda sua área de distribuição e depositados nas principais coleções ornitológicas do Brasil e do mundo (Fig. 4). Atualmente esse é o trabalho que emprega o maior número de exemplares do mencionado complexo, tendo também uma boa representatividade de amostras devido à ampla abrangência nas coletas por parte dos museus que foram visitados. Quando as coleções científicas foram visitadas pessoalmente, as fotografias dos espécimes foram tiradas sobre um pano branco de fundo e iluminadas com dois refletores de luzes LED de 10 watts, com a finalidade de uniformizar a superfície fotografada e assim ter padronizadas todas as imagens. As coleções que continham o material analisado estão organizadas a baixo em ordem alfabética, e daqui para frente serão citadas através dos seus acrônimos. Das seguintes instituições foram revisados pessoalmente 305 espécimes, fotografados sob os critérios acima mencionados, assim como medidos:

MACN - Museo Argentino de Ciencias Naturales "Bernardino Rivadavia", Buenos Aires, Argentina.

MHNCI - Museu de História Natural do Capão da Imbuia, Paraná, Brasil.

MNRJ - Museu Nacional da Universidade Federal de Rio de Janeiro, Rio de Janeiro, Brasil.

MPEG - Museu Paraense Emílio Goeldi, Pará, Brasil.

MZUSP - Museu de Zoologia da Universidade de São Paulo, São Paulo, Brasil. 
As seguintes coleções científicas não foram visitadas pessoalmente, mas 69 dos seus exemplares foram analisados através de fotografias fornecidas por pesquisadores colaboradores:

FMNH - Field Museum of Natural History, Chicago, Estados Unidos (27)

LSUMZ - Louisiana Museum of Natural History, Estados Unidos (2)

MFN - Museum für Naturkunde, Berlim, Alemanha (4)

RNHL - Rijksmuseum van Natuurlijke Historie, Leiden, Países Baixos (15)

ZSM - Zoologische Staatssammlung München, Munique, Alemanha (11).

\subsection{Localidades}

As localidades e coordenadas geográficas foram obtidas a partir dos dados anexados às etiquetas dos espécimes. Com exceção dos exemplares recentes, que tinham as coordenadas preenchidas na etiqueta, as coordenadas foram levantadas através da consulta aos gazetteers ornitológicos (Paynter, 1989; Paynter \& Traylor, 1991; Paynter, 1992; Vanzolini, 1992; Paynter, 1995) ou do sítio web de informação geográfica Google Earth, de acordo ao nome da localidade de coleta preenchida na etiqueta ou no livro de tombo. Alguns autores foram consultados sobre localidades históricas de coleta quando os nomes preenchidos nas etiquetas não eram mais conhecidos da mesma forma, como no caso de Fernando C. Straube que esclareceu dados de localidades do estado de Paraná; assim como para registros recentes de 
indivíduos da espécie e não houve coleta, por parte de Fabio Schunck e Vagner Cavarzere no estado de São Paulo.

Além de trabalhar com as localidades preenchidas nas etiquetas dos espécimes de museus, também foram empregadas algumas localidades citadas em literatura referencial, como as extraídas do livro "Aves do Estado de São Paulo" de Willis \& Oniki (2003), que apresentam dados do estado inteiro baseados em observações pessoais dos autores. Localidades citadas em literatura só foram empregadas quando tinham elevada importância no sentido geográfico, e quando tinha-se certeza que os autores conheciam e identificavam perfeitamente a espécie. Dados de campo foram empregados sempre que os registros foram confirmados, sendo próprios ou de outros ornitólogos que tenham claro o critério de identificação da espécie. Também foram empregadas bases de dados online como Wiki Aves (www.wikiaves.com) e Eco Registros (www.ecoregistros.org), com fotografias atuais publicadas de indivíduos silvestres da espécie, classificadas por localidades dentro de cada estado (Fig. 5). A primeira inclui dados do Brasil inteiro nas áreas onde ocorre essa espécie, e a outra inclui dados da Argentina. Ambas bases de dados foram consultadas até dezembro de 2016, com o objetivo de elucidar a atual ocorrência e distribuição geográfica da espécie em estudo. As imagens não passíveis de correta identificação foram descartadas. 


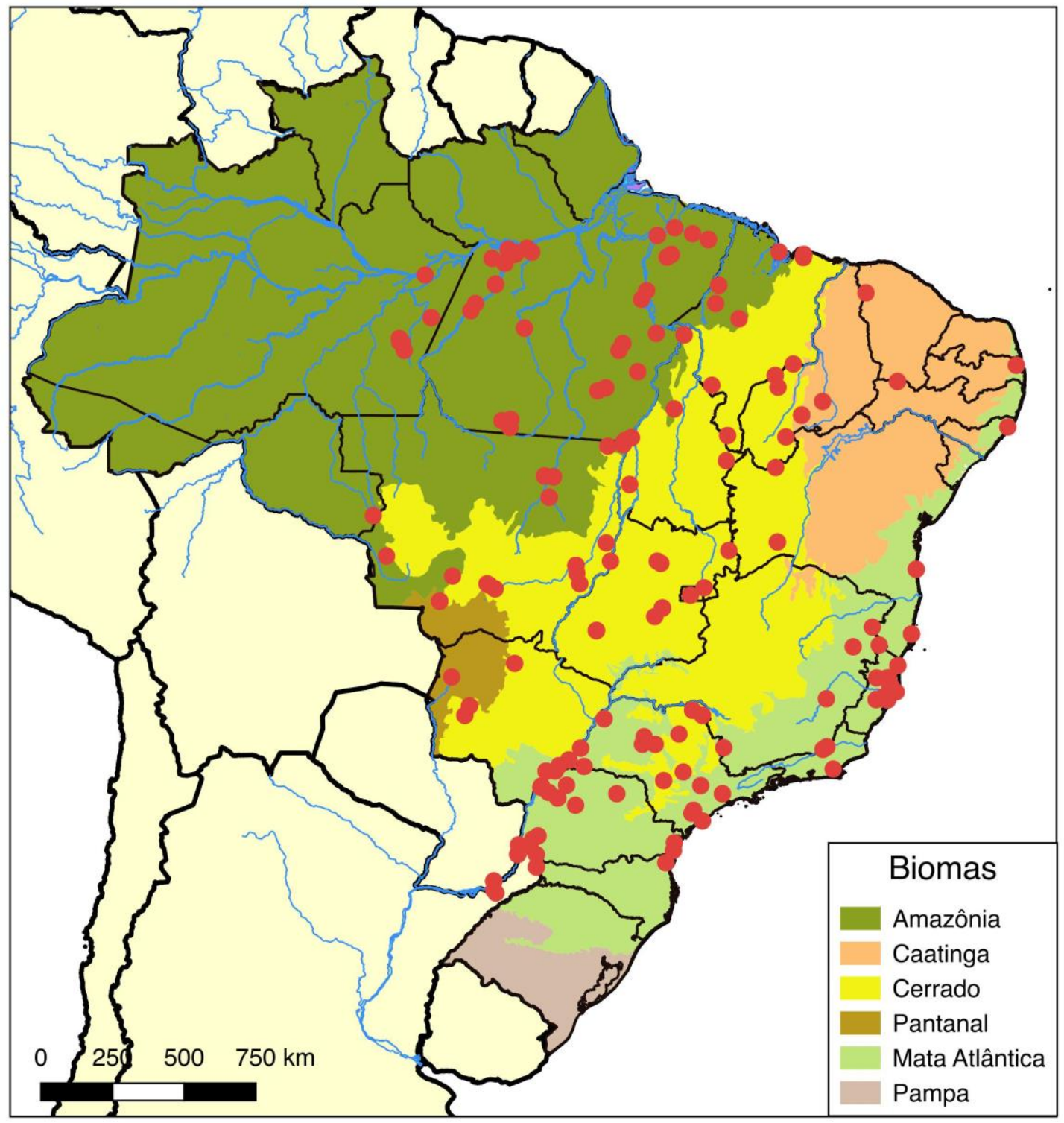

Figura 4. Localidades geográficas dos exemplares revisados de coleções científicas pertencentes ao complexo Penelope superciliaris, em um mapa separado por biomas. 


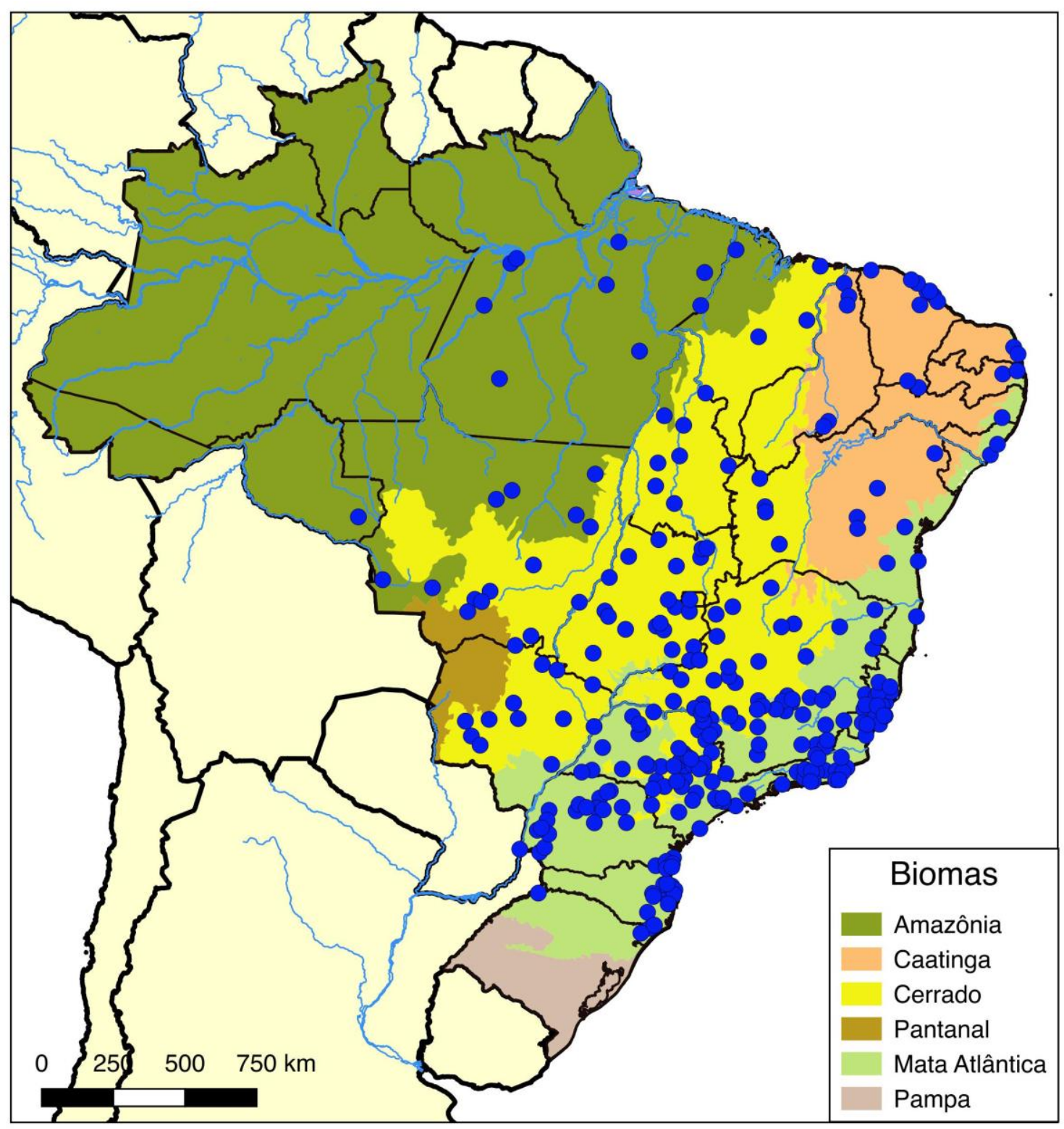

Figura 5. Localidades de fotografias revisadas de indivíduos vivos silvestres pertencentes ao complexo Penelope superciliaris, em um mapa separado por biomas.

A partir de todos os dados obtidos, foram elaborados mapas de ocorrência das populações e de distribuição geográfica no software de informação geográfica QGis for Windows (versão 2.14.3), e alguns itens adicionais foram editados no software de edição fotográfica Adobe Photoshop (versão CS5). Os mapas mostram as divisões dos países e os estados do Brasil, separados por biomas. 


\subsection{Definições de grupos geográficos}

Devido à ampla distribuição geográfica do complexo Penelope superciliaris, populações de localidades próximas foram agrupadas em grupo geográficos segundo os seguintes critérios: homogeneidade morfológica, proximidade geográfica, similaridade ecológica (pertencentes ao mesmo bioma) e ausência de barreiras geográficas significativas, como rios de grande extensão. Localidades geograficamente isoladas, impossíveis de juntar a outros grupos maiores, foram tratados separadamente, mesmo com baixo número de indivíduos. Os grupos geográficos formados são:

1. AM1: Interflúvio Madeira - Tapajós. Estados de Amazonas e Pará (BR).

2. AM2: Centro da Amazônia brasileira. Estado de Pará (BR).

3. AM3: Leste da Amazônia. Estados de Pará, Maranhão e Tocantins (BR).

4. AM4: Sul da Amazônia brasileira. Estados de Pará e Mato Grosso (BR).

5. AM5: Sudoeste da Amazônia brasileira. Estados de Rondônia e Mato Grosso (BR).

6. CA: Centro e Norte da Caatinga. Estados que compõem a Caatinga (BR).

7. PA: Leste do Pantanal. Estados de Mato Grosso, Mato Grosso do Sul (BR) e leste da Bolívia.

8. CE1: Norte do Cerrado próximo à Amazônia. Estados de Maranhão e Tocantins (BR).

9. CE2: Norte do Cerrado próximo à Caatinga. Estados de Maranhão, Piauí e Bahia (BR).

10. CE3: Cerrado Central no centro do Brasil. Estados de Mato Grosso, Goiás e Minas Gerais (BR). 
11. CE4: Cerrado Sul no sudeste do Brasil. Estados de Minas Gerais, São Paulo e Paraná (BR).

12. CE5: Sudoeste do Cerrado. Estados de Mato Grosso e Mato Grosso do Sul (BR).

13. MA1: Centro de Endemismo Pernambuco. Mata Atlântica dos estados nordestinos (BR).

14. MA2: Mata Atlântica do Centro-leste do Brasil. Estados de Bahia e Minas Gerais (BR).

15. MA3: Mata Atlântica do Sudeste do Brasil (1). Estados de Espirito Santo, Rio de Janeiro e Minas Gerais (BR).

16. MA4: Mata Atlântica de Sudeste do Brasil (2). Estados de Minas Gerais, São Paulo, Paraná e Santa Catarina (BR).

17. MA5: Sudoeste da Mata Atlântica. Estados de São Paulo, Paraná e Santa Catarina (BR).

18. MA6: Sul da Mata Atlântica. Sul do Brasil e nordeste da Argentina.

* AM=Amazônia, $\quad \mathrm{CE}=$ Cerrado, $\quad \mathrm{CA}=$ Caatinga, $\mathrm{MA}=$ Mata Atlântica, $\mathrm{PA}=$ Pantanal. 


\subsection{Análises qualitativas}

\subsubsection{Coloração de plumagem}

Para a análise de coloração de plumagem, cada padrão foi avaliado de acordo com o catálogo de cores de Munsell ® (Munsell Soil Color Chart, 1994), que foi empregado comparativamente dentro e entre os grupos geográficos. O Catálogo foi empregado com maior ênfase na análise da coloração das regiões consideradas diagnósticas por serem importantes para a identificação dos táxons considerados como válidos na atualidade. Essas regiões são a linha superciliar, a parte posterior do pescoço, os ombros, costas, peito, penas internas das asas, coberteiras das asas e coberteiras superiores da cauda.

\subsubsection{Pigmentação de regiões nuas}

A pigmentação das regiões nuas também é considerada como caráter diagnóstico, sendo analisadas as seguintes regiões: coloração e forma da membrana gular, coloração e extensão da região nua da face, coloração do tarso e dedos, e cor da íris. No caso dos espécimes de museu, foram considerados os dados preenchidos nas etiquetas, no caso estejam presentes. Apesar de os dados de coloração na etiqueta serem baseados em um critério subjetivo, devido ao fato de que cada coletor teve seu próprio ponto de vista para avaliar as cores, foram somente empregados como referência para algumas populações bem diferenciadas. Tanto para a coloração de plumagem como para a pigmentação das regiões nuas, foram testadas variações individuais e populacionais dentro e entre os grupos geográficos, para determinar se alguma população poderia ser diagnosticável por algum caráter morfológico externo. Também foram empregadas fotografias das bases de dados online já mencionadas 
(Wiki Aves e Eco Registros), onde apenas foram escolhidas as que não apresentaram dúvidas na identificação da cor, seja para a coloração das penas ou a pigmentação das regiões nuas. No caso que alguma das fotografias examinadas tenha sido tirada de uma longa distância, seja muito escura, retratada parcialmente ou erroneamente identificada, ela foi excluída.

\subsection{Análises quantitativas}

\subsubsection{Caracteres morfométricos}

Foram medidas seis estruturas, de acordo com Baldwin et al. (1931) e Baumel et al. (1993):

- Comprimento do cúlmen exposto: É comumente usado como comprimento total do bico, medido desde o ponto em que as pontas das penas da fronte tocam o cúlmen em posição natural, até a ponta do bico ou extremo anterior da maxila em linha reta. Se aproxima ao comprimento visível do cúlmen quando é visto de lado (Fig. 6A).

- Comprimento do bico-narina: Tomado desde o extremo anterior da narina até a ponta da maxila em linha reta (Fig. 6B).

- Largura do bico nas narinas: Medição feita no ponto da maxila que fecha com a mandíbula na região média da narina, desde o lado esquerdo até o direito.

- Altura do bico nas narinas: Medição feita na região média da narina, desde a cima da maxila até a base da mandíbula. 
- Comprimento do tarso: Medido desde o ponto da união entre a tíbia e o metatarso até a parte frontal da junção do metatarso com a base do dedo do meio, ou o meio dessa articulação quando tal é discernível (Fig. 6C).

- Comprimento do dedo do meio: O comprimento do terceiro dedo do pé é medido na superfície dorsal, a partir da sua própria base no meio da articulação com o metatarso, onde esta é discernível, até o seu extremo distal na base da garra. A garra não foi considerada (Fig. 7A). Quando o dedo tinha curvatura, se empregou uma cinta métrica.

- Comprimento de asa fechada: Esta é a medida de asa mais comumente usada, e geralmente é chamada de 'asa' ou 'comprimento de asa' nas descrições de aves. É preferencialmente tomada em linha reta desde o ponto anterior mais distante da corda até a ponta da primária mais longa, sem tentar achatar a curva desta pena. Em todos os casos foi medida a asa direita (Fig. 7B).

- Comprimento de cauda: O comprimento da cauda é medido no meio das duas retrizes centrais, desde o lugar onde as bases emergem a partir da pele em linha reta até a ponta da pena mais longa quando a cauda está fechada (Fig. 7C).

Foi utilizado um paquímetro com precisão de $0.05 \mathrm{~mm}$ para medir os quatros primeiros caracteres e uma régua com precisão de $0.10 \mathrm{~mm}$ para medir os dois últimos caracteres. Na medida do comprimento do dedo, quando a curvatura foi bastante pronunciada, se empregou uma cinta métrica com precisão de $0.10 \mathrm{~mm}$. 


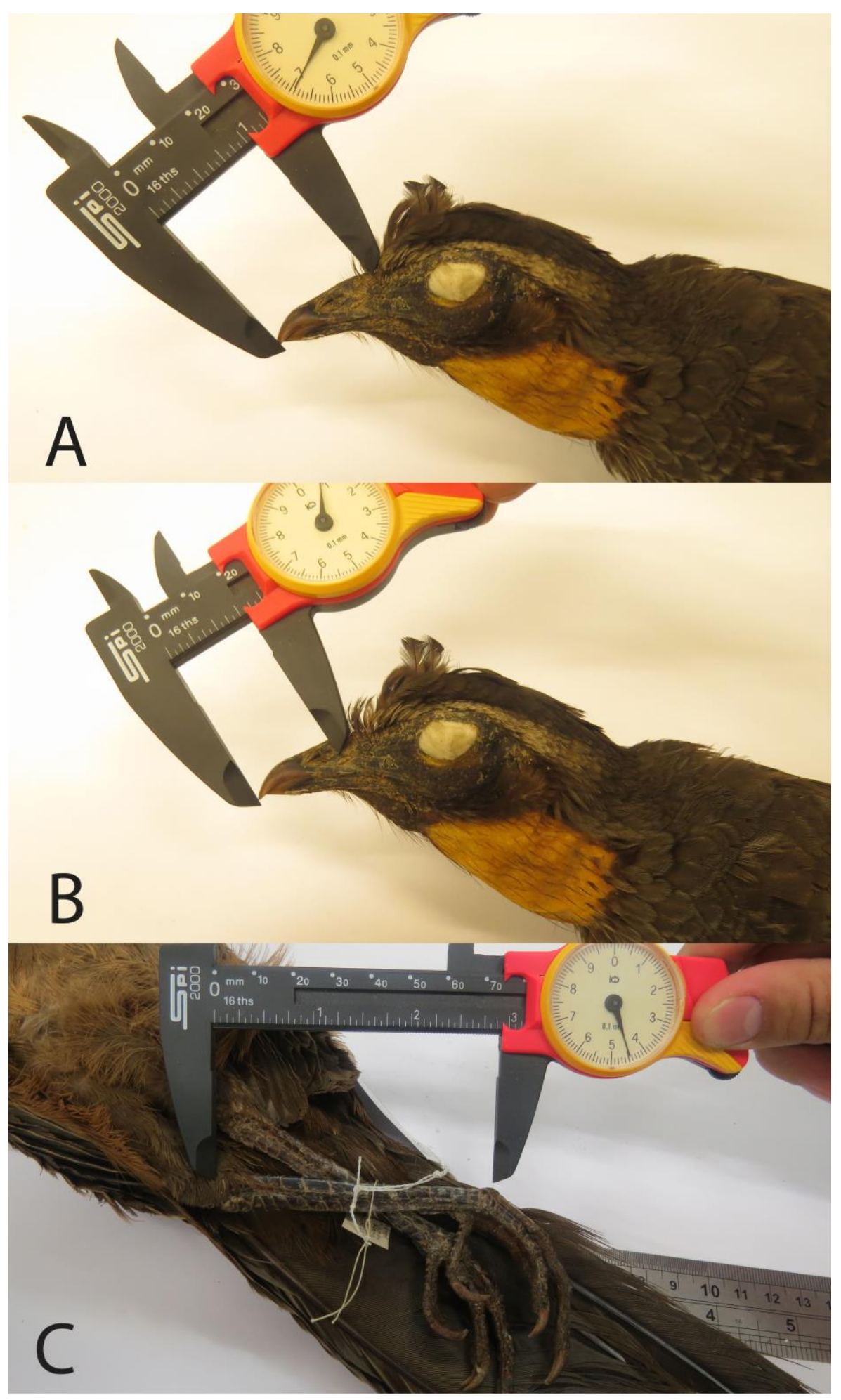

Figura 6. Medições empregadas para tomar o comprimento do cúlmen exposto (A), da ponta do bico até a narina (B) e tarso (C). 

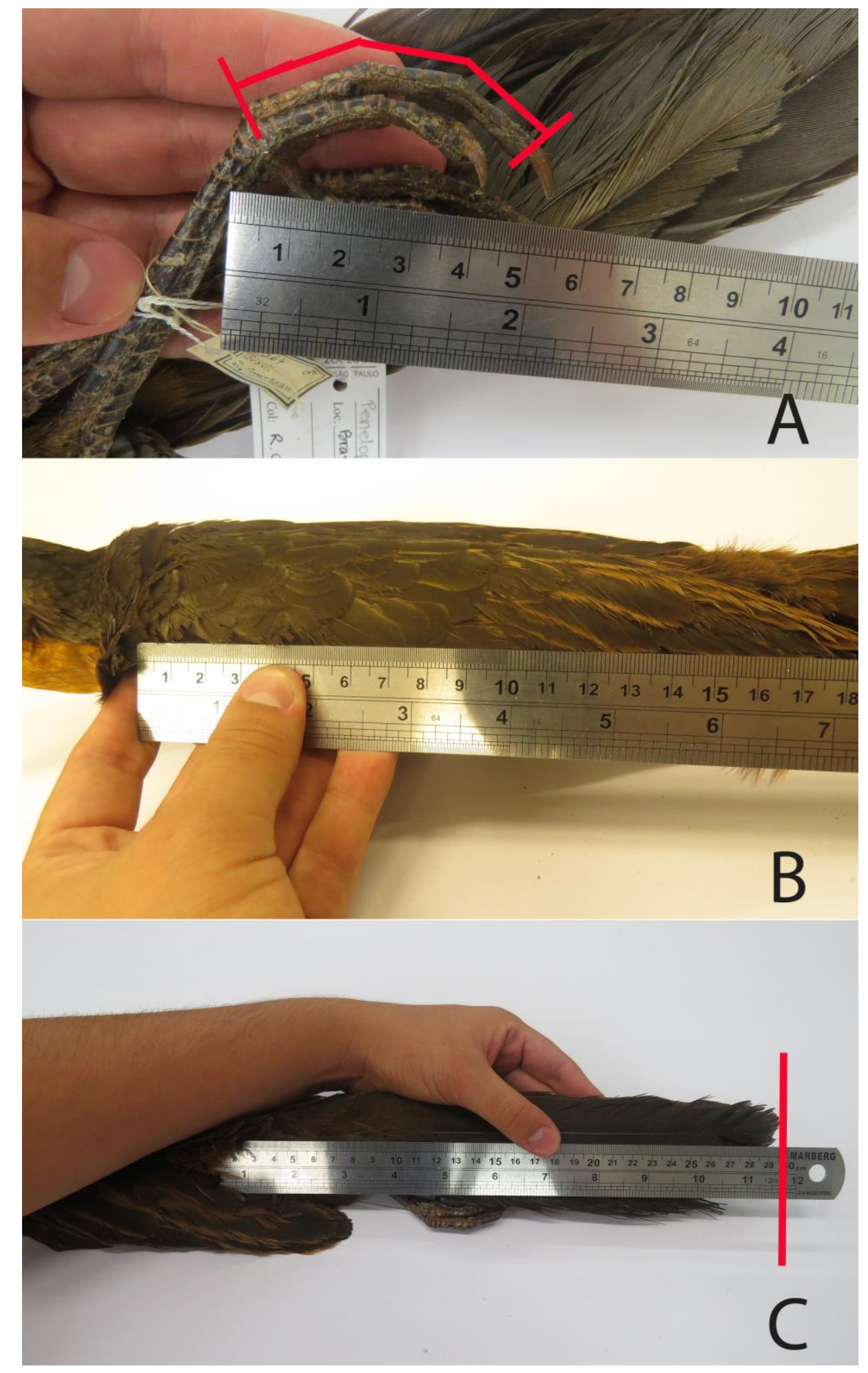

Figura 7. Medições empregadas para tomar o comprimento do dedo do meio (A), asa fechada (B) e cauda (C). 


\subsubsection{Análises estatísticas}

Como foi mencionado no item $\mathbf{4 . 3}$, indivíduos de localidades próximas foram classificados em grupos geográficos consistentes. Levando em conta esses grupos, foram feitas análises estatísticas de tipo Univariado e Multivariado utilizando os softwares R for Windows (R i386 versão 3.2.1) e Past (versão 2.15), a fim de testar as variações dos indivíduos e populações dentro e entre os grupos geográficos, assim como o dimorfismo sexual dentro deles.

Os indivíduos identificados como jovens, seja pela cor diferenciada da plumagem, por ter penas características de indivíduos jovens, por ser menores que o resto, ou por ter essa informação mencionada na etiqueta, foram excluídos das análises estatísticas e considerados apenas para fins geográficos.

\section{Analises Estatísticas Univariadas.}

A fim de testar a distribuição normal dos dados, foram usados os testes de ShapiroWilk e de Kolmogorov-Smirnov com a correção de Lilliefors. Os dois testes têm como hipótese nula que a variável avaliada satisfaz os critérios para o uso de testes paramétricos, isso quer dizer que quando p> 0.05 a variável tem distribuição normal. Para corroborar esses resultados também se aplicaram as medidas descritivas de assimetria e curtose.

Assimetria e curtose são medidas que permitem identificar a separação ou aglomeração dos valores de acordo com a frequência com que se distribuem, e permitem identificar numericamente caraterísticas da distribuição sem a necessidade de avaliar a normalidade dos dados através de gráficos. 
Assimetria ou obliquidade (em inglês skewness) nos permite definir se os dados forem distribuídos uniformemente ao redor do ponto central (média aritmética). Se divide em três categorias:

- Assimetria positiva: Quando a maioria dos dados se encontram acima do valor da média. G1 > 0 quando os valores tendem a se reunir mais no lado esquerdo da média.

- Assimetria negativa: Quando mais dados se encontram acima do valor da média. G1 < 0 quando os valores tendem a se reunir mais no lado direito da média.

- Curva simétrica: Quando se distribui aproximadamente a mesma quantidade de dados de cada lado da média. Tende a tomar os dados que são próximos de zero, sejam positivos ou negativos $( \pm 0.5)$. Quanto maior é o número, seja positivo ou negativo, maior é a distância que separa a aglomeração de valores em torno da média.

À diferença da assimetria, a curtose (em inglês kurtosis) determina o grau de concentração dos valores na região central da distribuição. Também está dividida em três categorias:

- Curva mesocúrtica: Se chama assim quando $\mathrm{G}=3$, então tem o mesmo achatamento que a distribuição normal.

- Curva leptocúrtica: Quando $\mathrm{G}>$ 3, então a distribuição em questão é mais alta (afunilada) e concentrada que a distribuição normal.

- Curva platicúrtica: Quando $G<3$, então a função de distribuição é menos concentrada (achatada) que a distribuição normal. 
Quando a distribuição dos dados tem um coeficiente de Assimetria de \pm 0.5 e o coeficiente de Curtose de \pm 0.5 , é chamado de curva normal, isso quer dizer que os dados têm uma distribuição normal.

Ao confirmar a hipótese, se utilizou o teste paramétrico $t$ de Student, para avaliar a diferença significativa entre as médias de duas mostras independentes, testando se existe dimorfismo sexual em cada grupo. Se o $t$ de student não mostra diferenças significativas nem sobreposição de valores, os sexos não seriam considerados por separado. O nível de significância para as provas foi de 0.05 .

\section{Analises Estatísticas Multivariadas.}

Se empregaram quando as variáveis de estudo são dependentes umas das outras. Como empregamos medidas de estruturas corporais, se considera que cada uma delas é dependente do resto porque um corpo tem desenvolvimento ou crescimento em conjunto. As análises multivariadas requerem que os dados de entrada sejam transformados na sua forma logarítmica para ser padronizados, e assim não dar um maior peso às estruturas de maior tamanho, como asas e cauda, com a finalidade de não interpretar os resultados de forma errada.

Para avaliar o dimorfismo sexual, foi usado o teste de Distribuição $T^{2}$ (Tquadrado) de Hotelling, a contraparte multivariada da prova $t$ de Student, testando as diferenças entre as médias multivariadas.

Para testar se os indivíduos de um grupo geográfico podem ser confundidos com outros por suas medidas corporais, se empregou a Análise Linear Discriminante (LDA), que é um teste que representa em porcentagens a possibilidade de indivíduos pertencerem ao grupo pré-determinado ou atingir o padrão de um outro grupo. Identifica todos os elementos que pertencem a cada grupo geográfico (incluindo cada 
medida para cada variável) e gera uma combinação linear de variáveis que podem encontrar um padrão dentro dos dados e efetivamente classifica-lo.

Com a finalidade de avaliar se os grupos geográficos tendem a se diferenciar por alguma das suas medidas corporais, a Análise de Variáveis Canônicas (CVA) verifica se os grupos formam aglomerados ou clusters significativamente distintos morfométricamente. Ela tenta modelar a diferença entre os grupos de dados por extração de fatores que maximizam a variação inter - grupos e minimizam a variação intra - grupos.

No caso que alguns grupos geográficos apresentem alguma tendência que possa sugerir que se ajustem a alguma regra biogeográfica, serão usadas análises de Regressão Linear para testar alguma variação gradual das estruturas corporais dentro ou entre cada grupo.

\subsection{Critérios para delimitação de espécies}

O Conceito Biológico de Espécie (Biological Species Concept - BSC) afirma que uma espécie é um grupo de populações naturais intercruzantes, isoladas reprodutivamente de outros grupos (Mayr, 1942); segundo isto, supõe-se que as populações reprodutivamente isoladas tenham atingido tal nível de divergência evolutiva que seus membros não reconhecem aos indivíduos de outras populações como parceiros reprodutivos.

Para a aplicação deste conceito existem muitos limitantes, como não propor critérios para verificar se duas populações que não estão em contato são coespecíficas ou não, o que torna subjetiva a determinação de status taxonômico de

populações alopátricas (Cracraft, 1983; McKitrick \& Zink, 1988; Zink, 1997). Também não leva em conta as relações filogenéticas entre as espécies. Como 
Donoghue (1985) menciona, um conceito de espécie consistente não deveria estar asociado ao isolamento reprodutivo, devido às dificuldades que este apresenta.

Ao BSC está associado o conceito de subespécie, que como Mayr (1963, 1982) define, é um agregado da população local de uma espécie, que habita uma subdivisão geográfica do total da distribuição, e que difere morfologicamente de outras populações da espécie. Este conceito deve ser utilizado para populações alopátricas que sejam muito bem definidas e separadas, e em situações onde ocorra contato secundário entre diferentes populações e a sua área de intergradação seja relativamente estreita (Monroe, 1982).

Ante as deficiências observadas no BSC, surgiram diversos conceitos que trataram de definir o que é uma espécie, destacando o Conceito Filogenético de Espécie (Phylogenetic Species Concept - PSC), que tem sido cada vez mais aceito entre os zoólogos, especialmente entre os que adotaram a metodologia cladista (Cracraft, 1983, 1989; McKitrick \& Zink, 1988). A base do PSC é de acordo às hipóteses históricas de diferenciação dos táxons, baseando-se principalmente na análise da variação geográfica e especiação. A utilização deste conceito implica em descartar a categoria de subespécie, porque se um trinômio representa uma população que é diagnosticável e monofilética, esta deve ser elevada à categoria de espécie; enquanto outros trinômios que não possuam valor taxonômico e evolutivo não seriam validos e deveriam ser eliminados (McKitrick \& Zink, 1988).

A falta de critérios no passado levou ao uso indiscriminado do conceito de subespécie, tornando-o menos confiável (Lanyon, 1982), e geralmente sem estudar a variação geográfica de maneira minuciosa (Barrowclough, 1982; Zusi, 1982; Bock, 2004). Como consequência surge a discriminação das populações reconhecidas como subespécies dos programas de proteção de fauna ou das listas de espécies ameaçadas 
(Silveira \& Olmos, 2007). Por todo o anteriormente exposto, o Conceito Filogenético de Espécie foi selecionado para ser aplicado no presente trabalho devido a sua melhor funcionalidade e aplicabilidade. Revisões taxonômicas que utilizam um maior número de caracteres possível demonstram de melhor maneira possível a diagnosticabilidade de cada táxon e são fundamentais para elaborar uma melhor taxonomia (Silveira \& Olmos, 2007). 


\section{RESULTADOS E DISCUSSÃO}

\subsection{Histórico do complexo Penelope superciliaris}

Sintetizo aqui o histórico do complexo Penelope superciliaris, incluindo as descrições originais e observações de todos os autores que descreveram alguma raça geográfica, tenham sido válidas ou não em algum momento.

A descrição de Penelope superciliaris Temminck, 1815 foi publicada em francês, e não foi acompanhada por alguma prancha que represente graficamente o espécime-tipo aos olhos do autor: "A nova espécie difere essencialmente dos guan (Penelope cristata Lath) e marail (Penelope marail Lath) não só no seu comprimento total, que não excede das vinte e três polegadas, difere também nas dimensões das outras regiões corporais. Este Penelope não tem crista, até mesmo no estado adulto; as suas penas da cabeça são curtas e arredondadas, o tarso é longo e fino, e a cauda é muito longa em proporção com o tamanho do corpo. As cores da plumagem também mostram diferenças marcantes, mas as partes nuas da cabeça e o pescoço são semelhantes como as das outras espécies. Há menos diferenças entre esta ave e o Yacuhu de Azara (Penelope obscura Temminck), diferindo cinco polegadas e meia no comprimento total, sendo essa a única diferença que parece ser bastante consistente, de modo de perceber isso antes de comparar totalmente os espécimes. Esta espécie é bastante parecida em volume corporal com o faisão tricolor da China, possuindo vinte e duas polegadas e meia de comprimento total, onze de cauda, três de tarso, duas e uma linha do dedo do meio com a unha, uma polegada e duas linhas de bico, e seis linhas desde o início das narinas até a ponta da maxila". Temminck (1815) ainda acrescenta: "Na parte superior da cabeça, onde as penas não são alargadas, a região occipital e a nuca são de cor marrom escuro, e pelos isolados aparecem na frente; 
uma faixa negra se estende a partir da mandíbula e cobre o ouvido, uma outra faixa composta de penas brancas que começa na base do bico passa sobre a região nua e também leva ao ouvido; na parte superior das costas as penas são cinza esverdeadas com bordas acinzentadas mais claras; as penas coberteiras e secundarias das asas $e$ as coberteiras da cauda têm uma sombra verde escura e borda larga de cor vermelho brilhante; a cauda é esverdeada de tom avermelhado; as penas do peito, ventre e base do pescoço são cinza amarronzadas e na borda esbranquiçadas; as coxas, abdômen e região uropigial são marrões, a garganta e a parte superior do pescoço têm a pele nua vermelha que é alongada na membrana flutuante e a região nua é pontilhada com alguns pelos; a pele que junta os lados da cabeça com o bico é negra púrpura. A íris é marrom avermelhada; as pernas chifre azul; e as unhas e o bico marrões".

Finalmente Temminck acrescenta que não achou alguma diferença entre ambos sexos, reconhecendo que um indivíduo jovem de 15 polegadas de comprimento que revisou possui iguais cores que os indivíduos adultos. Sobre a distribuição da espécie, Temminck diz que a espécie vive no Brasil, especialmente no estado de Pará, onde os índios chamam ela de Jacu-peoa.

Spix (1825) descreveu a Penelope jacupemba no livro Avium species novae, quas in itinere per Brasiliam annis (pag. 55), texto que estava acompanhado com um desenho do táxon (Fig. 8, prancha LXXII no livro). Um tempo depois o táxon passa a ser considerado como Penelope superciliaris jacupemba, tratamento que é seguido até hoje. Ele descreve: "Menor que a Penelope jacupeba (atualmente conhecida como P. marail jacupeba Spix, 1825) e de cor bronze escuro; cabeça preta de crista curta e sem raias brancas, com faixa rufescente sobre os olhos; penas da garganta, peito $e$ ombros com bordas brancas; retrizes das asas longas e rufas; abdômen, região 
uropigial, crisso e quadril rufos". Posteriormente acrescenta: "Magnitude do corpo é igual ao do faisão pintado, menor que Penelope jacupeba, com a parte superior do corpo de cor marrom bronze esverdeada, base das penas avermelhadas, e parte baixa do corpo cinérea; penas curtas na cabeça, 7"' de comprimento, erécteis, marrom enegrecidas e com estrias brancas; ao redor dos olhos, narinas e ouvidos a pele é nua de cor preto azulado; faixa dianteira sobre as narinas avermelhada ou cinzenta que vai até o occipital; queixo preto e garganta amarela carnuda; penas das retrizes do ombro bronze esverdeadas apenas com bordas cinéreas; clavícula, peito e esterno com penas de bordas brancas; retrizes das asas e uropígio bronze verdosos com margens de fibras vermelhas; rêmiges bronze esverdeadas reluzentes com margem exterior fulvescente; abdômen rufa e coxas avermelhadas escuras com penas que as vezes presentam margens avermelhados; cauda escura de cor bronze esverdeada não roxa brilhante e preta na parte baixa; rosto longo e marrom enegrecido, pés escuros e olhos marrões castanho. Comprimento do corpo $2^{\circ}$, cauda $1^{\circ}$, asas $9^{\prime}$, rosto $1.5^{\prime}$, tarso 2.75 ". Finalmente, Spix menciona que machos e fêmeas não são diferentes (de igual forma que Temminck quando se referiu a $P$. s. superciliaris), habitando nas florestas de Rio de Janeiro, indicando o "Prezidio de St. João", localizado na cidade de Rio de Janeiro - RJ, como localidade tipo (= cidade de Rio de Janeiro). 


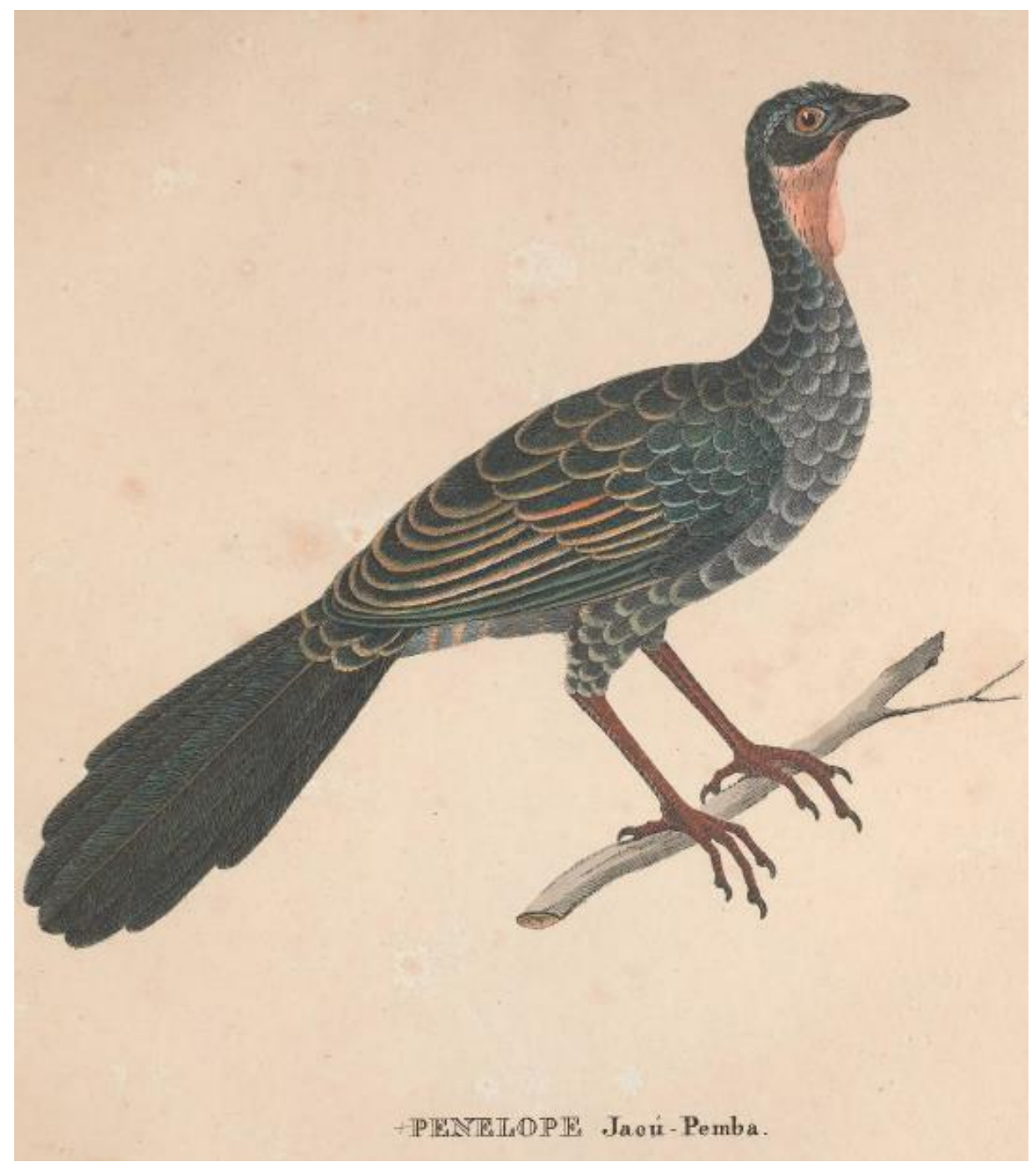

Figura 8. Prancha de Penelope superciliaris jacupemba que acompanha a descrição de Spix (1825).

Já em 1901, Arnaldo de Winkelried Bertoni descreveu Penelope purpurascens (not P. purpurascens Wagler, 1830) no livro Aves nuevas del Paraguay, Continuación á Azara- Extracto de la Historia Natural de las Aves del Paraguay (pag. 16 - 19), táxon que atualmente é conhecido como Penelope superciliaris major. Foi como parte das descrições de novas espécies paraguaias descobertas pelo autor, a partir de exemplares coletados desde 1890 até finais de 1900. A descrição foi feita em espanhol, minha língua nativa, mas incluso para mim o texto é confuso e prolixo, apesar de detalhado. 
$\mathrm{O}$ autor escreve: “Características: 24 rêmiges, $5^{\circ}$ e $6^{\circ}$ maiores, a primeira 70 milímetros mais curta que elas, as primeiras curvadas e aguçadas. Asa como nas outras espécies paranaenses. 12 retrizes, a externa é de $100 \mathrm{~mm}$ e seguinte $50 \mathrm{~mm}$ mais curta que a central, o resto em escadaria. Ventre, flancos, e dorso cobertos por penas curtas e densas de raques fortes. As asas dobradas cobrem totalmente o dorso até as subcaudais e ainda as últimas rêmiges de uma asa entram embaixo da outra. As penas do peito são bastante compridas. A região nua ao redor do olho e da membrana gular (como em P. obscura) apresenta pelos negros com finas e raras barbas. Com pestanas são compridas de $6 \mathrm{~mm}$ e pelos mais compridos na base do bico. A traqueia tem uma volta exterior sobre o peito, descendo $50 \mathrm{~mm}$ como em $P$. olivácea". "Cor: A região nua ao redor do olho e o rosto são de cor escuro azulado. A membrana e a garganta de cor vermelho não tão intenso. Iris marrom acanelado e pálpebra inferior esbranquiçada. Bico: escuro. Tarso e dedos escuros com algo de vermelho na frente. Do lado da mandíbula presenta uma área de pequenas penas negras, que vão alargando-se conforme vão subindo e que terminam cobrindo o ouvido. Outra faixa esbranquiçada pouco sensível sai da frente, passa sobre o olho e vai até o lado da nuca. Desde a cima da cabeça até o primeiro terço do pescoço a coloração é negra, desde aí até as costas, inclusive nas retrizes menores, a coloração é marrom escura com reflexos esverdeados e de bordas cinzentas. O resto da asa também é marrom, mas com reflexos esverdeados e arroxeados mais vivos; as retrizes e rêmiges do cotovelo e as escapulares são amplamente estriadas de canela forte ou avermelhado. A garganta toda e a região anterior do peito, xistáceo (cinzento-escuro opaco) muito escuro, com bordas cinzentas. O resto do peito, flanco e pernas, são escuros com as penas de bordas canela. As supra-e subcaudais são marrons com estrias e manchas avermelhadas; o dorso, região uropigial, pernas e 
ventre são inteiramente canela intenso, com estrias escuras pouco aparentes, mas com muita luz são perceptíveis outros paralelos azuis puros, que são mais ou menos visíveis de acordo a idade. A cauda é negra, mas pela cima tem vivas mudanças verdes em conjunção e arroxeados em oposição". O autor observou em 1893 que abunda muito pelos $25^{\circ}$ e $26^{\circ}$ graus no Alto Paraná, e menciona também algumas informações que não mencionaremos aqui, com relação aos costumes, alimentação e criação em cativeiro.

Posteriormente descreve Penelope purpurascens major (pag. 19, 20), o que ele chama de uma 'simples variedade' da anterior, dando assim o nome à subespécie de P. superciliaris: "É a ave de asa mais curta e arredondada que conheço, ou pelo menos nenhuma ultrapassará ela; a extremidade é perfeitamente redonda, bastante côncava em todos os sentidos. 23 rêmiges, a $7^{\circ}$ maior, a $6^{\circ}$ e $8^{\circ}$ são dois milímetros mais curtas, a $5^{\circ}$ e $9^{\circ}$ seis e a $1^{\circ}$ sete milímetros e meio mais curtos que a $7^{\circ}$, e a $2^{\circ}$, $3^{\circ}$ e $4^{\circ}$ em escada; as primeiras são curvadas e todas as da mão tem a barba maior bastante ondulada no terço médio, bastante arqueadas. A álula está composta por 5 penas fortes como remeiras e a $2^{\circ}$ é a maior. Todas as remeiras terminam em ângulo mais ou menos agudo e têm um espaço entre a $10^{\circ}$ e a $11^{\circ}$, formando aí um recesso na asa, porque aumentam por ambos lados depois do recesso. 12 retrizes, a externa 75 milímetros mais corta que a interna; a escadaria é muito mais forte nas 3 externas; todas são um pouco curvas para baixo. A região nua da cara e a membrana parecem algo mais extensas. O tarso tem na metade anterior duas fileiras de escamas mais ou menos quadradas, outra fileira no lado póstero-externo que termina de forma aguda antes chegar ao metatarso; uma zona estreita no lado exterior é de pele áspera e outra no lado póstero-interior é de escamas pequenas mais ou menos quadradas. $O$ dedo médio está unido aos demais por membranas, compostas de escamas de pele 
dura, até a primeira articulação. Unhas comprimidas e com duas bordas para baixo. Plumagem genérico. Parece ser mais robusto em todo. O caráter mais notável é a traqueia reta sem curvatura externa sobre o peito. É mais pesado do que os outros comuns. A maior parte dos caráteres indicados são comuns com às outras espécies, mas não deixa de ter alguns que são particulares".

Sobre a cor, ele acrescenta: “Desde a cabeça para trás é um preto esverdeado singular com reflexos metálicos ou escuro metálico com reflexos esverdeados, sem presença de bordas diferenciadas nem cabeça mais apagada. O mesmo na asa, mas nas rêmiges do braço tem bordas claras, nas maiores e as rêmiges do cotovelo tem bordas canela, sendo mais amplos e quase avermelhados nestes; as bordas desaparecem avançando pelas rêmiges do braço; as pontas todas e as barbas maiores são escuras com reflexos. Nas rêmiges do braço destaca-se uma pena branca pura, mas só existe na asa direita, como se quisesse se aproximar aos Pipile ou se conservasse um indício de suas prováveis antigas analogias. Retrizes pretas com fortes reflexos esverdeados metálicos. Membrana alaranjada débil. Garganta e extremo superior do peito são como o resto do pescoço, mas mais claro e algo xistáceo (cinzento-escuro opaco), de reflexos mais fracos e com notáveis bordas cinzentas. Peito e flancos são marrões escuro de bordas esbranquiçados sujas, que deixam a ponta livre. Pernas marrões escuras metálico, com pouco ou nada de canela nas pontas das penas. O resto como o outro. Bico escuro. Cara e horqueta idênticas (ou nuas). Iris vermelho. Pés pardos".

O exemplar no qual foi baseada a descrição, foi coletado em Mboká-ih quando estava comendo frutos de "Pindó". Seus costumes, como o autor observou, são as mesmas que das outras espécies. Foi coletado em junho de 1900 aos $25^{\circ} 43^{\prime}$ latitude Sul. Essa localidade parece ser atualmente Mbocayaty, do departamento de Guairá no 
Paraguai a 150 metros de altitude, a $5 \mathrm{~km}$ ao Nordeste de Villarrica $\left(25^{\circ} 45^{\prime} / 56^{\circ} 26^{\prime}\right)$. Vemos que as descrições feitas por Bertoni são as únicas dentro do complexo $P$. superciliaris que detalham bastante as diferenças com relação ao tamanho das penas.

Em 1933, Oscar Neumann, de Berlim (Alemanha), descreveu três novas subespécies de $P$. superciliaris: $P$. s. pseudonyma, $P . \quad s$. argyromitra e $P . s$. ochromitra. Ele descreve Penelope superciliaris pseudonyma como: "Subespécie que se diferença de todas as outras subespécies geográficas de Penelope superciliaris por ter (na maioria dos casos) faixa superciliar nenhuma, ou apenas uma fina linha branca cinzenta mais um menos marcada por trás do olho. Coloração geral é mais escura que em P. s. superciliaris Temminck. As bordas das penas são bem marcadas nas secundárias, na região uropigial e nas coberteiras superiores da cauda, que são de cor marrom escuro". Se distribui na margem direita do médio e baixo do Rio Amazonas, e as margens dos seus afluentes meridionais, desde o Rio Madeira até Pará. Não há holótipo designado, mas da série de sintipos, em Chicago encontra-se um espécime fêmea adulto na coleção cientifica do Mr. H. B. Conover, com localidade-tipo o Rio de Cumana, tendo a necessidade de designar um lectótipo.

Para Penelope superciliaris argyromitra ele descreve: "Enquanto para P. s. pseudonyma se encontra pouca ou nenhuma faixa superciliar, esta subespécie tem uma faixa superciliar bem ampla e marcada de cor cinza claro, as vezes ligeiramente tingida de marrom. As duas faixas superciliares estão unidas por uma barra frontal ampla da mesma cor, tendo como resultado um grande parecido na cabeça com $P$. jacucaca e P. argyrotis, etc. A coloração geral da ave é mais clara, sendo o pescoço, a garganta e a parte superior do peito tingidas de cinza. A região uropigial, as coberteiras superiores da cauda e o ventre são de cor castanho-avermelhado mais claro, com as bordas das secundarias mais claras que em P. s. superciliaris e P. s. 
pseudonyma, as vezes avelã clara ou ocre claro". O autor propõe uma distribuição desde o Centro de Goiás, para o leste pelo menos até Bagagem em Minas Gerais, com intergradação com $P$. s. superciliaris perto do Rio Doce. Um espécime fêmeo, coletado em Veadeiros ao noroeste de Forte no Centro de Goiás, foi designado como tipo da subespécie. Esse exemplar foi coletado o 2 de dezembro de 1929 por J. Blaser, e se encontrava depositado na coleção do autor. Foram revisados quatro espécimenes típicos, mas o autor não especificou a procedência dos outros três exemplares nem em qual coleção científica foram depositados.

Penelope superciliaris ochromitra foi descrito como: "Similar em todos os aspectos a P. s. argyromitra, mas as faixas superciliares e a barra frontal ampla não são de cor cinza prateado, mas são inteiramente de cor ocre". O autor acrescenta que só era conhecido para o estado de Piauí, e que o tipo foi coletado no Lago de Missão perto de Paragua (Piauí) o 26 de maio de 1903 por O. Reiser. Além disso, menciona que revisou três espécimenes típicos, mas novamente não menciona informação adicional que seja mais específica.

O. Neumann conclui que se absteve de dar medições de asa e cauda para cada uma das três subespécies porque as medições são quase as mesmas nelas, assim como também em P. s. superciliaris Temminck. As asas medem, tanto para machos como fêmeas adultos, 240-265 mm, e as caudas 290-330 mm.

Já muito anos depois, Pedro Mario Nardelli (1993) descreveu duas novas subespécies para Penelope superciliaris: P. s. alagoensis e P. s. cyanosparius, táxons que geraram o maior desacordo com relação a sua validade, por ser em ambos casos a descrição baseada a partir de exemplares vivos e mantidos em cativeiro, sem ter sido depositados em alguma coleção científica depois de mortos, tendo só pranchas de 
desenhos que acompanham a descrição das novas raças geográficas. Ambas descrições foram publicadas juntas em português e inglês.

Para Penelope superciliaris alagoensis Nardelli, 1993 (Fig. 9), o autor designou a um macho adulto como holótipo e uma fêmea adulta como parátipo (01, ZMN88 e 02, ZMN88; respectivamente), também acrescenta que outros "parátipos" compostos de aves se encontravam na Zôo-botânica Mário Nardelli e o criadouro Sete Cores (estado de Alagoas). Mas como já foi mencionado, esses exemplares não existem em nenhuma coleção científica. "Macho: Cabeça com supercílio branco, bem demarcado, formado por penas que apresentam a metade distal branca e a base negra. Vértice com penas negras erécteis. Pescoço negro, com borda lateral das penas da região anterior levemente esbranquiçada. Dorso, coberteiras da rêmiges e retrizes marrom-escuras, com discreto lustro verde-escuro. Últimas rêmiges secundárias e coberteiras intermediárias e maiores da asa com borda lateral das penas alaranjado-escuras, sendo que, nas rêmiges, ela abrange uma área maior das penas. Região dorsal marrom, com intensa vermiculação ferruginosa. Peito negro, com borda lateral das penas creme. Barriga com penas marrom-escuras, de borda lateral alaranjado-escura. Flanco castanho-claro, listrado com marrom. Coxas marrom-escuras, estriadas com ferrugem. Baixo ventre castanho-claro. Regiões nuas: Face cinza-escura. Íris vermelho-escura. Bico negro. Mento cinza-escuro. Barbela vermelha. Tarso e dedos cinza-escuro-vináceos. Peso 770 g. Medidas: cúlmen $27 \mathrm{~mm}$, tarso $78 \mathrm{~mm}$, asa $243 \mathrm{~mm}$, cauda $251 \mathrm{~mm}$. Fêmea: Apresenta uma coloração mais escura e menor tamanho. Peso 695 g. Medidas: cúlmen 26 mm, tarso $71 \mathrm{~mm}$, asa $231 \mathrm{~mm}$, cauda $238 \mathrm{~mm}$ ".

O autor também observou que, cotejando com outros representantes da subespécie, nota um tamanho menor, coloração geral mais escura e uma linha distinta 
de cor branca no supercílio. Se distribui no litoral dos estados de Alagoas e Pernambuco ao nordeste do Brasil.

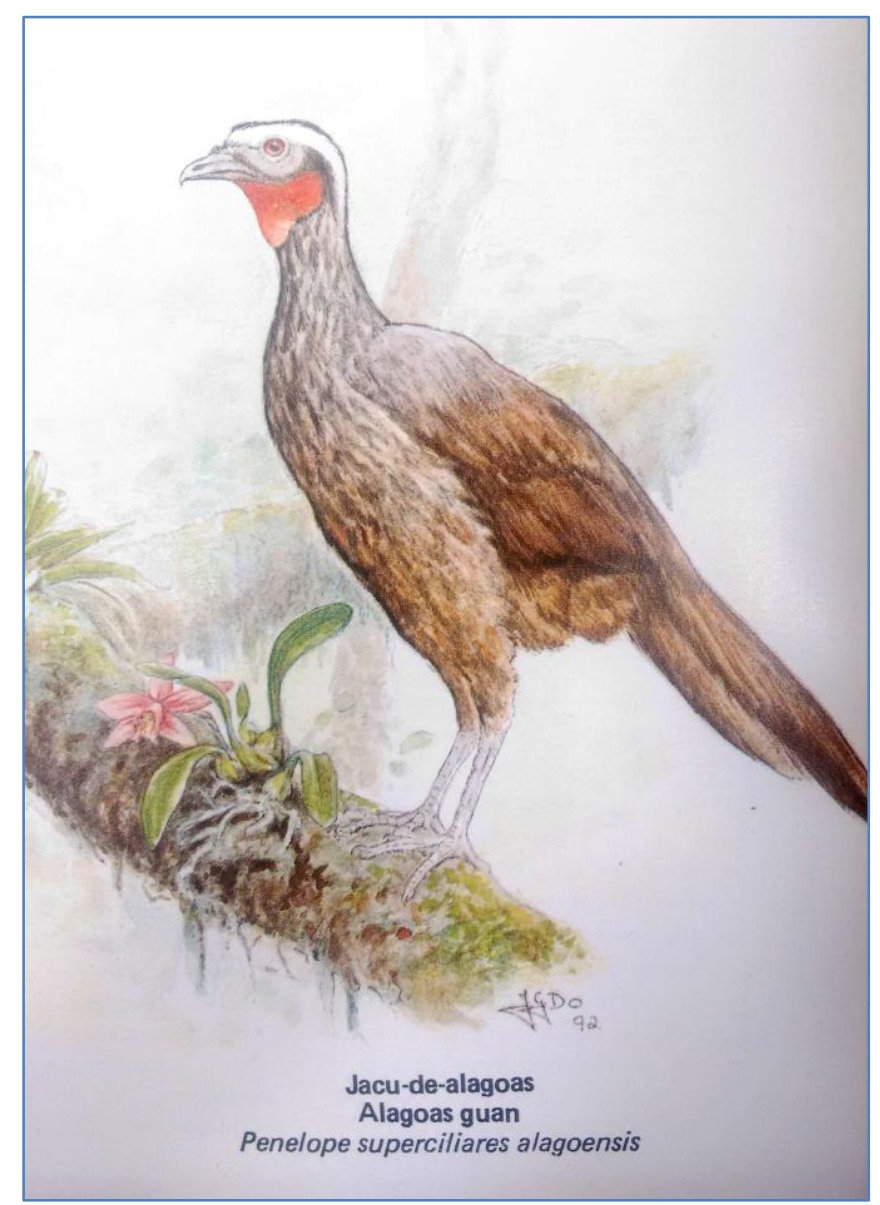

Figura 9. Desenho de Penelope superciliaris alagoensis que acompanha a descrição da subespécie. Extraído de Nardelli (1993).

Por outro lado, Penelope superciliaris cyanosparius Nardelli, 1993 (Fig. 10) é uma outra subespécie de P. superciliaris e se distribui nas cabeceiras do Rio Maués, no estado de Amazonas; um macho adulto foi designado como holótipo e uma fêmea adulta como parátipo (03, ZMN89 e 04, ZMN90; respectivamente), e diversos indivíduos vivos eram considerados como "parátipos" registrados nos criadouros Zôobotânica Mário Nardelli (Nilópolis, RJ) e o Chaparral (Recife, PE). Como no caso da 
anterior subespécie, na atualidade não existe nenhum desses exemplares em alguma coleção científica.

"Macho: Cabeça com supercílio branco quase imperceptível. Vértice com penas negras erécteis. Pescoço negro, com borda lateral das penas da região anterior levemente esbranquiçada. Dorso, coberteiras da asa, rêmiges e retrizes marrom-escuras com discreto lustro verde-escuro. Últimas rêmiges secundárias, coberteiras intermediárias e maiores da asa com borda lateral das penas alaranjadoescuras, sendo que, nas rêmiges, ela abrange uma área maior das penas. Região dorsal marrom com intensa vermiculação ferruginosa. Peito negro, com borda lateral das penas creme. Barriga com penas marrom-escuras, de borda lateral alaranjado-escura. Flanco castanho-claro listrado com marrom. Coxas marromescuras, estriadas com ferrugem. Baixo ventre castanho-escuro". Regiões nuas: Face com região nua, abrangendo uma área maior que nos outros indivíduos da espécie, de tonalidade cinza-escuro-azulada. Íris vermelho-tijolo, bico negro, mento cinza-escuro, barbela vermelha. Tarso e dedos cinza-escuro-vináceos. A tonalidade vinácea parece ser mais forte nos indivíduos jovens e menos intensa nos mais velhos. Peso 1080 g. Medidas: cúlmen $30 \mathrm{~mm}$, tarso $78 \mathrm{~mm}$, asa $250 \mathrm{~mm}$, cauda $272 \mathrm{~mm}$. Fêmea: Aspecto idêntico ao macho, porém ligeiramente menor. Peso $945 \mathrm{~g}$. Medidas: cúlmen $25 \mathrm{~mm}$, tarso $75 \mathrm{~mm}$, asa $249 \mathrm{~mm}$, cauda $261 \mathrm{~mm}$ ”.

O autor acrescenta que, comparando-se com as demais subespécies, ela apresenta substancial diferença na pele nua da face e o supercílio, os quais mostram uma coloração azulada. 


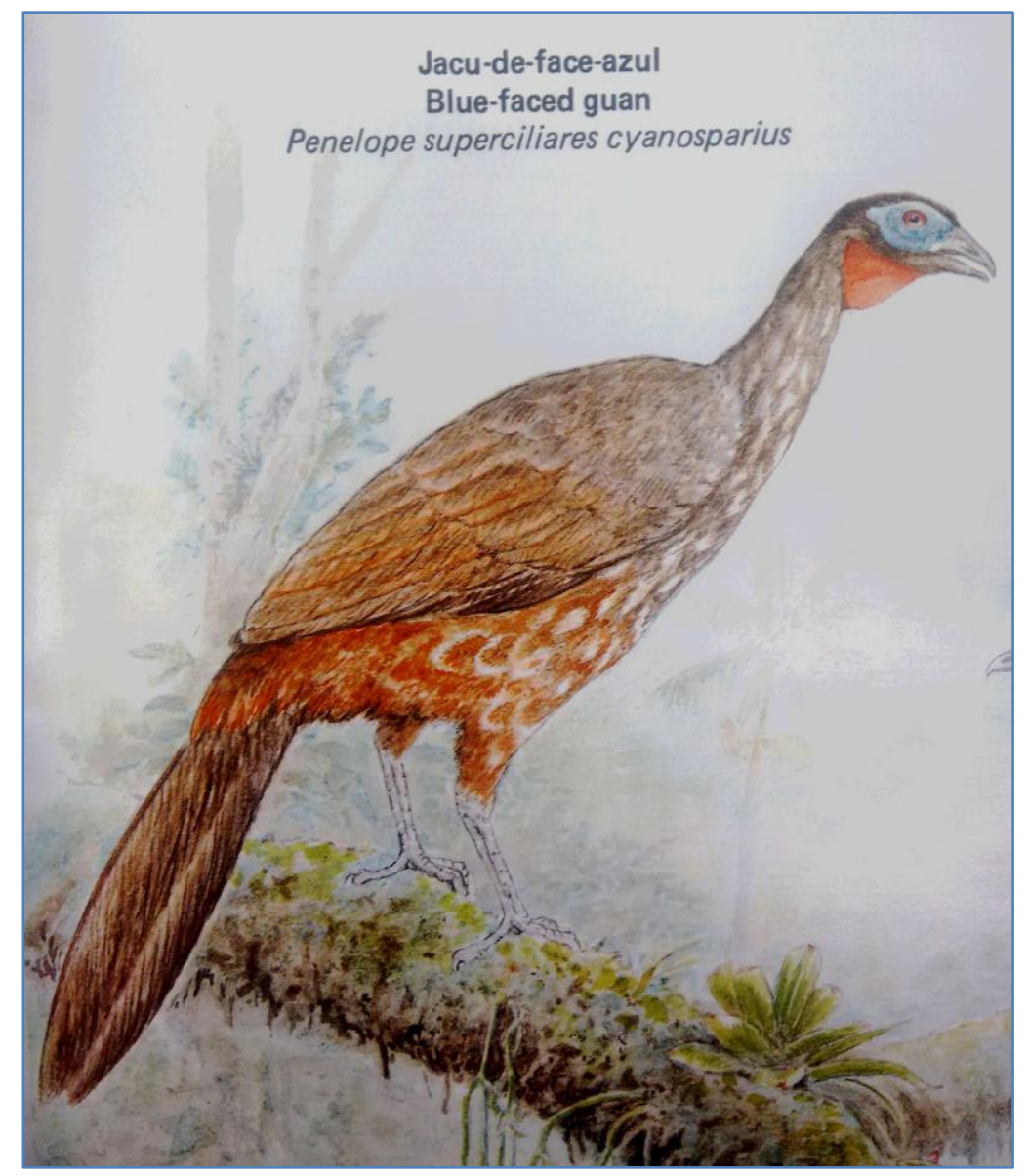

Figura 10. Desenho de Penelope superciliaris cyanosparius que acompanha a descrição da subespécie. Extraído de Nardelli (1993).

Um detalhe que foi importante no livro Preservação do Mutum de-Alagoas (1993), onde foram descritas as duas últimas subespécies, é que Nardelli menciona no texto inteiro a "Penelope superciliares" cada vez que se referia à espécie Penelope superciliaris. 


\subsection{ANÁLISE DA VARIAÇÃo GEOGRÁFICA}

Depois de ter conhecido mais a fundo às subespécies descritas pertencentes ao complexo $P$. superciliaris Temminck, 1815 e as características que fazem diagnosticáveis a cada população, se formaram grupos geográficos sem considerar aos indivíduos dentro de alguma das subespécies previamente conhecidas, com a finalidade de desenvolver as análises dentro e entre grupos mais restritos geograficamente separados com base em características morfológicas.

Foram delimitados um total de 18 grupos geográficos, a partir dos biomas brasileiros: Amazônia (5), Caatinga (1), Pantanal (1), Cerrado (5) e Mata Atlântica (6), dentro dos quais alguns grupos foram formados pela proximidade geográfica dos indivíduos, pela homogeneidade morfológica ou pela presencia de rios de grande extensão como barreira geográfica. Na tabela 2 e a figura 11 podemos identificar a localização de cada grupo geográfico, assim como o número total de indivíduos que cada um possui, e que foram medidos para ser analisados estatisticamente.

Tabela 2. Grupos geográficos formados e seus respectivos números de peles para as análises estatísticas.

\begin{tabular}{|c|c|c|}
\hline $\begin{array}{c}\text { Grupos } \\
\text { biogeográficos }\end{array}$ & $\begin{array}{c}\text { Número de peles e } \\
\text { gênero }\end{array}$ & Localização \\
\hline $\begin{array}{c}\text { 1. Amazônia 1 } \\
\text { (AM1) }\end{array}$ & $\begin{array}{c}\mathbf{n = 6} \text { (3 machos, 2 } \\
\text { fêmeas, 1 não definido) }\end{array}$ & $\begin{array}{c}\text { Interflúvio Madeira - Tapajós: Leste } \\
\text { do estado de Amazonas, no limite com } \\
\text { Pará. }\end{array}$ \\
\hline $\begin{array}{c}\text { 2. Amazônia 2 } \\
\text { (AM2) }\end{array}$ & $\begin{array}{c}\mathbf{n = 5 5} \text { (34 machos, 19 } \\
\text { fêmeas, 2 não definidos) }\end{array}$ & $\begin{array}{c}\text { Centro da Amazônia brasileira: Oeste } \\
\text { do estado de Pará, ao leste do Rio } \\
\text { Tapajós. }\end{array}$ \\
\hline $\begin{array}{c}\text { 3. Amazônia 3 } \\
\text { (AM3) }\end{array}$ & $\begin{array}{c}\mathbf{n = 2 5} \text { (11 machos, 10 } \\
\text { fêmeas, 4 não definidos) }\end{array}$ & $\begin{array}{c}\text { Leste da Amazônia: Leste do estado } \\
\text { de Pará e noroeste de Maranhão. }\end{array}$ \\
\hline $\begin{array}{c}\text { 4. Amazônia 4 } \\
\text { (AM4) }\end{array}$ & $\begin{array}{c}\text { n=27 (14 machos, 12 } \\
\text { fêmeas, 1 não definido) }\end{array}$ & $\begin{array}{c}\text { Sul da Amazônia brasileira: Sul do } \\
\text { estado de Pará e norte de Mato } \\
\text { Grosso. }\end{array}$ \\
\hline
\end{tabular}




\begin{tabular}{|c|c|c|}
\hline $\begin{array}{l}\text { 5. Amazônia } 5 \\
\text { (AM5) }\end{array}$ & $\mathbf{n}=\mathbf{3}$ (2 machos, 1 fêmea $)$ & $\begin{array}{l}\text { Sudoeste da Amazônia brasileira: Sul } \\
\text { de Rondônia e oeste de Mato Grosso. }\end{array}$ \\
\hline $\begin{array}{l}\text { 6. Caatinga } \\
\text { (CA) }\end{array}$ & $\begin{array}{c}\mathbf{n = 5} \text { (1 macho, } 2 \text { fêmeas, } \\
2 \text { não definidos) }\end{array}$ & $\begin{array}{c}\text { Centro e Norte da Caatinga: Nos } \\
\text { estados de Piauí, Ceará, Pernambuco e } \\
\text { Bahia. }\end{array}$ \\
\hline $\begin{array}{l}\text { 7. Pantanal } \\
\text { (PA) }\end{array}$ & $\begin{array}{l}\quad \mathbf{n}=\mathbf{6} \text { ( } 2 \text { machos, } 2 \\
\text { fêmeas, } 2 \text { não definidos) }\end{array}$ & $\begin{array}{l}\text { Leste do Pantanal: Sudoeste de Mato } \\
\text { Grosso, noroeste de Mato Grosso do } \\
\text { Sul no Brasil e leste da Bolívia. }\end{array}$ \\
\hline $\begin{array}{l}\text { 8. Cerrado } 1 \\
\text { (CE1) }\end{array}$ & $\begin{array}{l}\mathbf{n = 1 0} \text { (4 machos, } 5 \\
\text { fêmeas, } 1 \text { não definido) }\end{array}$ & $\begin{array}{c}\text { Norte do Cerrado próximo à } \\
\text { Amazônia: Centro de Maranhão e } \\
\text { oeste de Tocantins. }\end{array}$ \\
\hline $\begin{array}{l}\text { 9. Cerrado } 2 \\
\text { (CE2) }\end{array}$ & $\begin{array}{c}\mathbf{n = 1 4}(8 \text { machos, } 6 \\
\text { fêmeas })\end{array}$ & $\begin{array}{l}\text { Norte do Cerrado próximo à Caatinga: } \\
\text { Leste de Maranhão, oeste de Piauí e } \\
\text { oeste de Bahia. }\end{array}$ \\
\hline $\begin{array}{l}\text { 10. Cerrado } 3 \\
(\mathrm{CEB})\end{array}$ & $\begin{array}{l}\mathbf{n = 3 3} \text { (15 machos, } 14 \\
\text { fêmeas, } 4 \text { não definidos) }\end{array}$ & $\begin{array}{l}\text { Cerrado Central no centro do Brasil: } \\
\text { Leste de Mato Grosso, Goiás e oeste } \\
\text { de Minas Gerais. }\end{array}$ \\
\hline $\begin{array}{l}\text { 11. Cerrado } 4 \\
\text { (CE4) }\end{array}$ & $\begin{array}{l}\mathbf{n = 7} \text { ( } 2 \text { machos, } 4 \\
\text { fêmeas, } 1 \text { não definido) }\end{array}$ & $\begin{array}{l}\text { Cerrado Sul no sudeste do Brasil: } \\
\text { Cerrado rodeado por Mata Atlântica } \\
\text { no Sul de Minas Gerais, centro de São } \\
\text { Paulo e norte de Paraná. }\end{array}$ \\
\hline $\begin{array}{l}\text { 12. Cerrado } 5 \\
\text { (CE5) }\end{array}$ & $\begin{array}{r}\mathbf{n = 9}(4 \mathrm{~m} \\
\text { fême }\end{array}$ & $\begin{array}{l}\text { Sudoeste do Cerrado: Centro e Sul de } \\
\text { Mato Grosso e Mato Grosso do Sul. }\end{array}$ \\
\hline $\begin{array}{l}\text { 13. Mata } \\
\text { Atlântica } 1 \\
\text { (MA1) }\end{array}$ & $\begin{array}{c}\mathbf{n = 3} \text { (1 macho, } 1 \text { fêmea, } \\
1 \text { não definido })\end{array}$ & $\begin{array}{c}\text { Centro de Endemismo Pernambuco: } \\
\text { Mata Atlântica de Paraíba, } \\
\text { Pernambuco e Alagoas. }\end{array}$ \\
\hline $\begin{array}{c}\text { 14. Mata } \\
\text { Atlântica } 2 \\
\text { (MA2) }\end{array}$ & $\mathbf{n}=\mathbf{8}$ (7 machos, 1 fêmea $)$ & $\begin{array}{c}\text { Mata Atlântica do Centro-leste do } \\
\text { Brasil: Sul de Bahia e nordeste de } \\
\text { Minas Gerais. }\end{array}$ \\
\hline $\begin{array}{l}\text { 15. Mata } \\
\text { Atlântica } 3 \\
\text { (MA3) }\end{array}$ & $\begin{array}{l}\mathbf{n = 2 6} \text { (10 machos, } 11 \\
\text { fêmeas, } 5 \text { não definidos) }\end{array}$ & $\begin{array}{l}\text { Mata Atlântica do Sudeste do Brasil } \\
\text { (1): Espirito Santo, Rio de Janeiro e } \\
\text { sudeste de Minas Gerais. }\end{array}$ \\
\hline $\begin{array}{l}\text { 16. Mata } \\
\text { Atlântica } 4 \\
\text { (MA4) }\end{array}$ & $\begin{array}{l}\mathbf{n = 1 3} \text { (4 machos, } 4 \\
\text { fêmeas, } 5 \text { não definidos) }\end{array}$ & $\begin{array}{l}\text { Mata Atlântica do Sudeste do Brasil } \\
\text { (2): Ao leste do Cerrado no sul de } \\
\text { Minas Gerais, leste de São Paulo, leste } \\
\text { de Paraná e leste de Santa Catarina. }\end{array}$ \\
\hline $\begin{array}{l}\text { 17. Mata } \\
\text { Atlântica } 5 \\
\text { (MA5) }\end{array}$ & $\begin{array}{c}\mathbf{n}=\mathbf{3 1} \text { (21 machos, } 10 \\
\text { fêmeas })\end{array}$ & $\begin{array}{c}\text { Sudoeste da Mata Atlântica: Ao oeste } \\
\text { do Cerrado no oeste de São Paulo e } \\
\text { Paraná. }\end{array}$ \\
\hline $\begin{array}{c}\text { 18. Mata } \\
\text { Atlântica } 6 \\
\text { (MA6) }\end{array}$ & $\begin{array}{c}\mathrm{n}=\mathbf{2 4} \text { (12 machos, } 5 \\
\text { fêmeas, } 7 \text { não definidos) }\end{array}$ & $\begin{array}{c}\text { Sul da Mata Atlântica: Sul do Brasil e } \\
\text { nordeste da Argentina. }\end{array}$ \\
\hline
\end{tabular}

* AM=Amazônia, $\mathrm{CE}=$ Cerrado, $\mathrm{CA}=$ Caatinga, MA=Mata Atlântica, PA=Pantanal. 


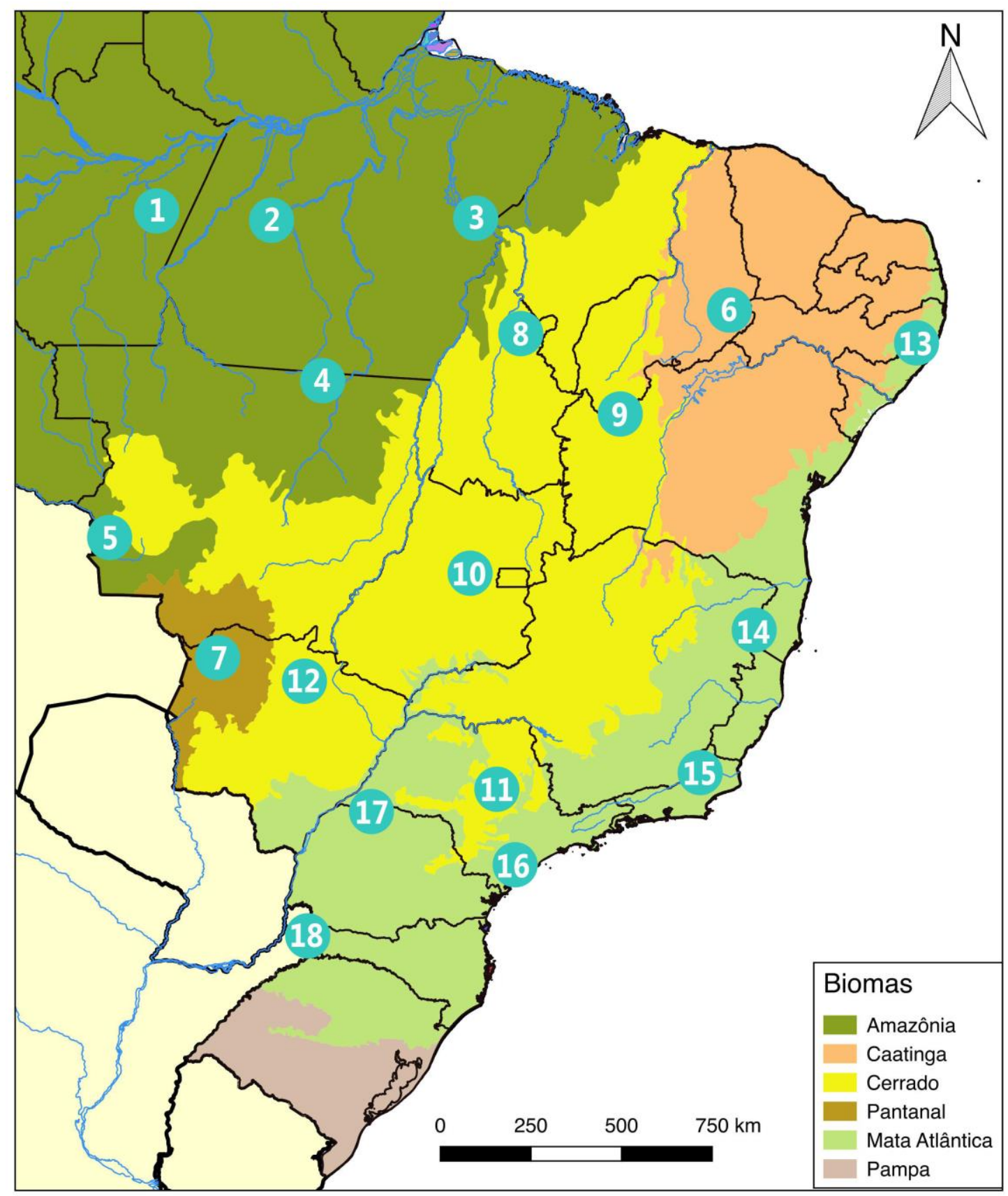

Figura 11. Grupos geográficos do complexo Penelope superciliaris divididos por biomas: Amazônia (1-5), Caatinga (6), Pantanal (7), Cerrado (8-12) e Mata Atlântica (13-18). 


\subsubsection{Variações geográficas}

As diagnoses das três subespécies do complexo $P$. superciliaris que atualmente são reconhecidas pela maioria de autores explicam basicamente que $P$. $s$. superciliaris, distribuída ao sul da Amazônia, tem coloração geral escura e com bordas das penas das asas avermelhadas escuras; P. s. jacupemba do centro do Brasil, ao sul da distribuição do anterior, tem coloração geral mais cinzenta e com bordas das penas das asas alaranjadas; e $P$. s. major de mais ao sul, atingindo os estados do sul do Brasil e estados de Bolívia, Paraguai e Argentina que limitam com o Brasil, é de coloração menos escura que a primeira mas mais escura que a segunda com as bordas das penas das asas bastante reduzidas. Por outro lado, nossa análise mostrou que em cada grupo geográfico os caracteres mencionados como diagnósticos de cada subespécie não são restritos às suas mencionadas áreas de distribuição, porque é possível encontrar indivíduos que pela morfologia externa seriam considerados de uma subespécie ocorrendo dentro da área de distribuição de uma outra subespécie. É também possível encontrar indivíduos coletados em uma mesma localidade com diferentes padrões de plumagem, e que poderiam ser identificados como subespécies diferentes. Um claro exemplo disso, são os espécimes da coleção do MZUSP coletados em Santana de Araguaia - PA, alguns deles foram identificados como P. s. superciliaris e outros como $P$. s. jacupemba, seguindo os caracteres diagnósticos de ambas subespécies, mostrando que dentro uma localidade existe um alto grau de variação individual. É importante comentar que cada que menciono à cor da borda das penas as asas, estou me referindo as coberteiras e rêmiges.

Para separar cada um dos 18 grupos geográficos mencionados, se revisaram as variações na coloração da plumagem e a pigmentação das regiões nuas indivíduo por 
indivíduo de cada localidade. Isso quer dizer que se foi encontrado algum indivíduo com uma característica em particular, esse seria agrupado com outros indivíduos que apresentem a mesma característica. Por exemplo, indivíduos que apresentem a pele da cara com pigmentação azul serão agrupados com outros que tenham a mesma característica e sejam geograficamente próximos.

Apesar dos exemplares terem sido agrupados pela proximidade geográfica e por pertencerem ao mesmo bioma, observamos que na maioria dos grupos existe um alto grau de variação individual.

Dentro dos mesmos grupos geográficos também foram considerados os registros fotográficos de indivíduos silvestres, obtidos a partir da base de dados online Wiki Aves. Essas fotos foram empregadas para confirmar a minha hipótese da alta variação individual dentro das populações, assim como para ter uma melhor delimitação geográfica do complexo baseado em registros recentes. Os registros fotográficos foram usados quando se teve certeza que não eram de animais de soltura, ou que fugiram do cativeiro (quando era próximo a um zoológico ou um criadouro, os registros foram excluídos). Foram analisados cada um dos indivíduos dos 18 grupos geográficos, e quando se encontrou similaridades entre as populações, foram agrupadas para interpretar elas juntas, com a finalidade de entender melhor as variações que existem dentro do complexo: 


\section{a. Amazônia 1:}

Este grupo inclui os exemplares que coletados no Interflúvio MadeiraTapajós, próximo ao limite do leste do estado de Amazonas e o oeste de Pará, no centro da Amazônia ao norte do Brasil. Se consideraram os 6 exemplares do MZUSP usados nas provas estatísticas, os 2 exemplares do LSUMZ, o holótipo de Penelope superciliaris pseudonyma, e a descrição de P. s. cyanosparius de Nardelli (1993).

Os espécimes desta região apresentam uma coloração geral bem escura, coloração que é mais frequente na Amazônia em comparação dos outros biomas, só que nesta população essa coloração é mais constante entre os indivíduos que nas outras (Fig. 12). Nas asas, as penas coberteiras e rêmiges tem bordas ferrugíneas fortes bastante contrastantes com o dorso mas o que realmente diferença morfologicamente esta população de todas as outras é a pigmentação azul intensa na região nua do rosto, caráter que não se apresenta em nenhuma outra população do complexo Penelope superciliaris, e faz ela diagnosticável (Fig. 13).

Os caracteres mencionados por Nardelli (1993) na descrição da subespécie $P$. s. cyanosparius correspondem com a presente população, só que uma outra subespécie descrita por Neumann (1933), P. s. pseudonyma, ocorre também dentro do interflúvio Madeira-Tapajós. 


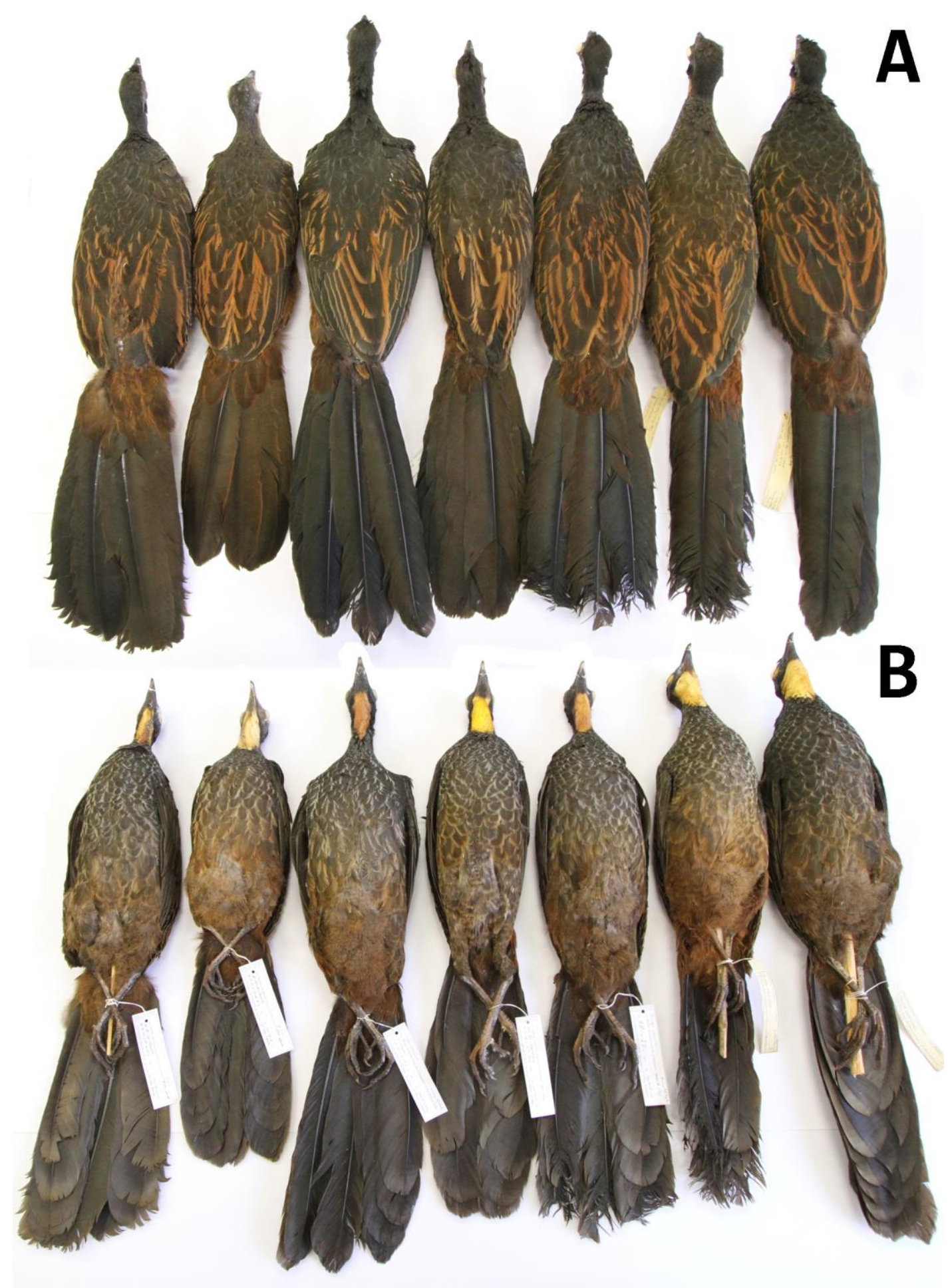

Figura 12. Vista dorsal (A) e ventral (B) dos sete exemplares coletados no interflúvio Madeira-Tapajós. De esquerda à direita: LSUMZ B-86475, MZUSP 97239, MUZSP 95762, LSUMZ B-80658, MZUSP 95764, MZUSP 86399 e MZUSP 86400. Foto:

Fabio Schunck. 


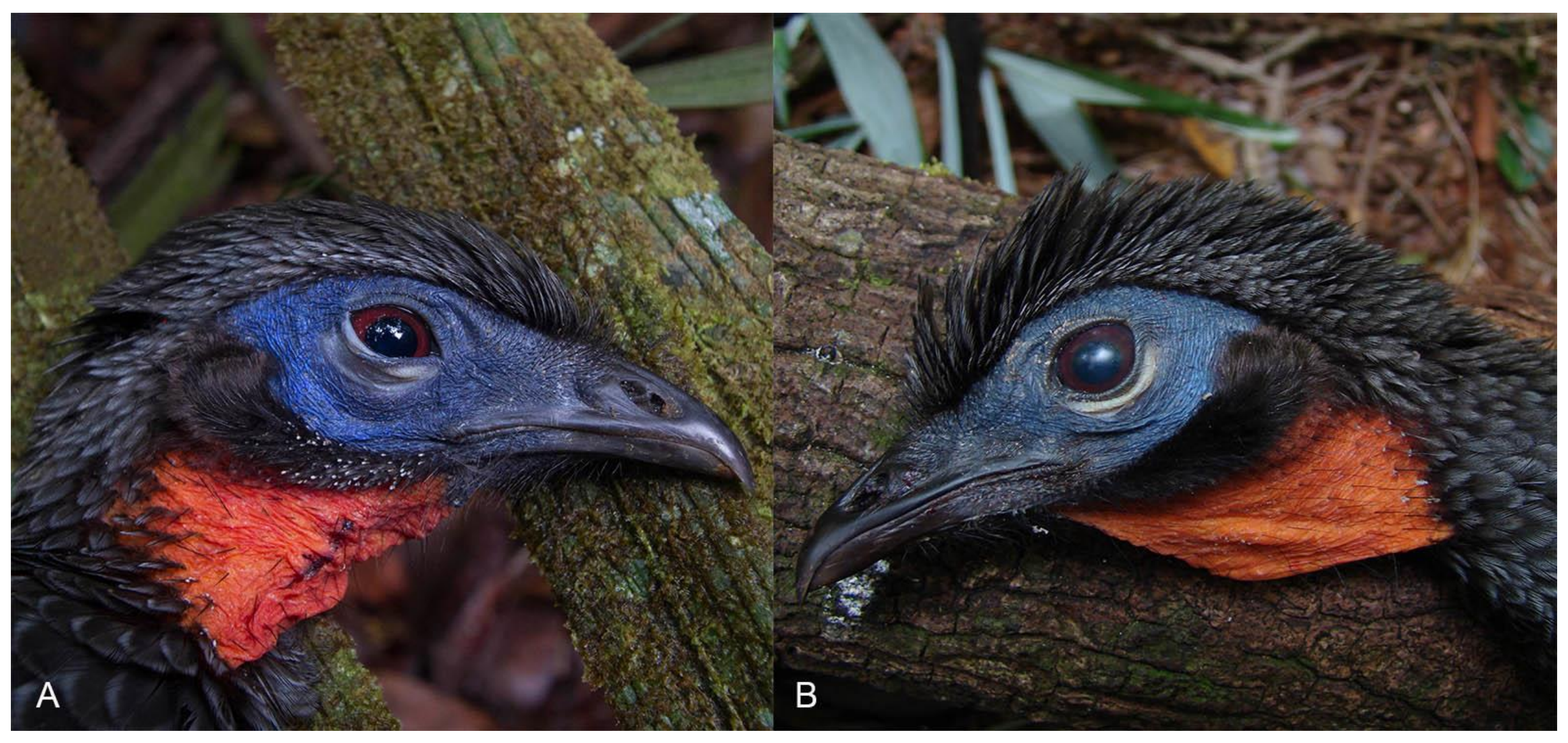

Figura 13. Pele azul da face em indivíduos machos imediatamente depois de coletados: LSUMZ B-86475 segundos (A) e MZUSP 86400 minutos (B) depois de coletados, mostrando a rápida perda do tom azulado. Foto: Fabio Schunck. 


\section{b. Amazônia 2, 3 e 4:}

Como se mencionou na Tabela 2, a população AM2 agrupa os exemplares do oeste de Pará, desde o Rio Tapajós; a população AM3, do leste da Amazônia brasileira, que inclui os exemplares do leste do estado de Pará e o noroeste de Maranhão; e a AM4, do sudeste da Amazônia brasileira, do sul de Pará e norte de Mato Grosso. Das quatro populações se revisaram 110 espécimes de coleções científicas em total, os quais mostraram que os indivíduos da Amazônia apresentam com maior frequência uma coloração geral bem escura em comparação com os indivíduos de outros biomas, só que essa coloração é menos frequente em comparação com o grupo AM1. É bom mencionar que, a pesar que este bioma inclui predominantemente espécimes mais escuros (Fig. 14 E, F), é também possível encontrar espécimes mais claros e com bordas das penas das asas mais alaranjadas em algumas localidades (Fig. 14 G, H), frequência que aumenta na população do sul da Amazônia (AM4). Também se encontraram espécimes de colorações totalmente diferentes na mesma localidade, como os exemplares MZUSP 20818 e MZUSP 21939 de Piquiatuba - PA (Fig. A-D).

Atualmente se considera que os indivíduos desta região da Amazônia pertencem à subespécie nominal, mas não sempre eles são tão escuros nem com bordas das penas das asas ferrugíneas fortes. 

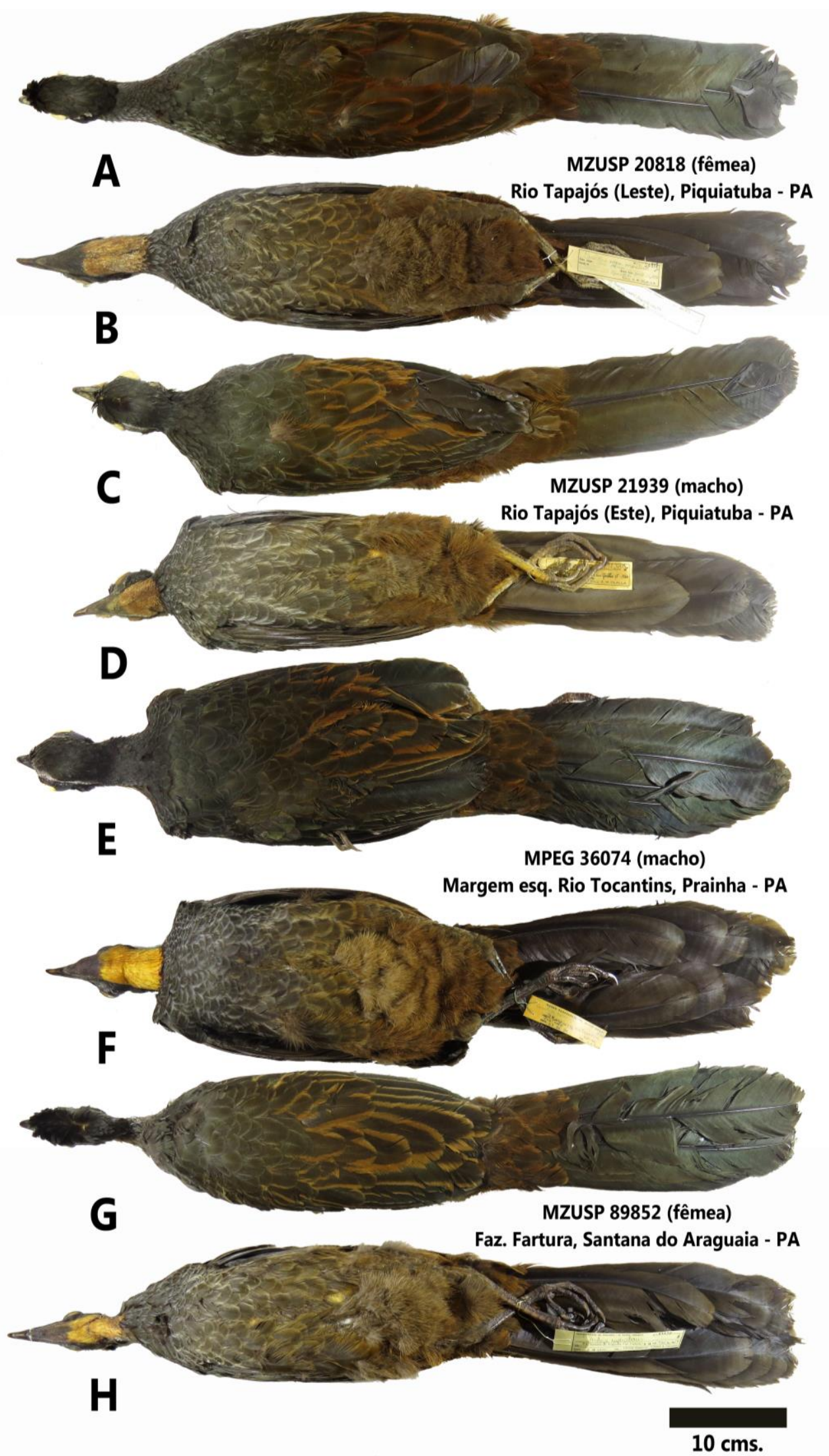

Figura 14: Espécimes revisados dos grupos geográficos da Amazônia: AM2 (MZUSP 20818, MZUSP 21939), AM3 (MPEG 36074), e AM4 (MZUSP 89852). 


\section{c. Caatinga e Cerrado 2}

Os espécimes de ambos os grupos apresentam os mesmos caracteres e são claramente diferenciáveis dos demais grupos geográficos do complexo. Na população CA se incluem os exemplares do centro e norte da Caatinga, que ocorrem nos estados de Piauí, oeste de Ceará e oeste de Pernambuco; e na população CE2, os exemplares da área do Cerrado que fica mais próxima ao limite com a Caatinga, que ocorrem no Piauí, sudeste de Maranhão, este de Tocantins e oeste de Bahia.

Foram analisados 19 indivíduos ( 9 machos, 8 fêmeas e 2 não determinados) para as duas populações, e mostraram que são notoriamente menos escuras que os outros grupos geográficos. Se os exemplares dos outros grupos são mais escuros ou de brilho esverdeado, os grupos CA e CE2 são bem diferenciados por apresentar algumas das seguintes caraterísticas: (1) o corpo em geral tem um matiz cinza claro e sem brilho verdoso na maioria dos seus integrantes, (Fig. 17 A,B) (2) borda das penas do peito são bem brancas e contrastantes com peito cinza, (3) linha superciliar de cor que varia entre ocre e laranja, podendo variar na intensidade (Fig. 15), (4) bordas das penas das asas extensas que variam de cor laranja amarelado a ocre (Fig. 17 C,D), e (5) aparentemente são menores que o resto de grupos geográficos.

As características mencionadas são exclusivas para estes grupos geográficos. 

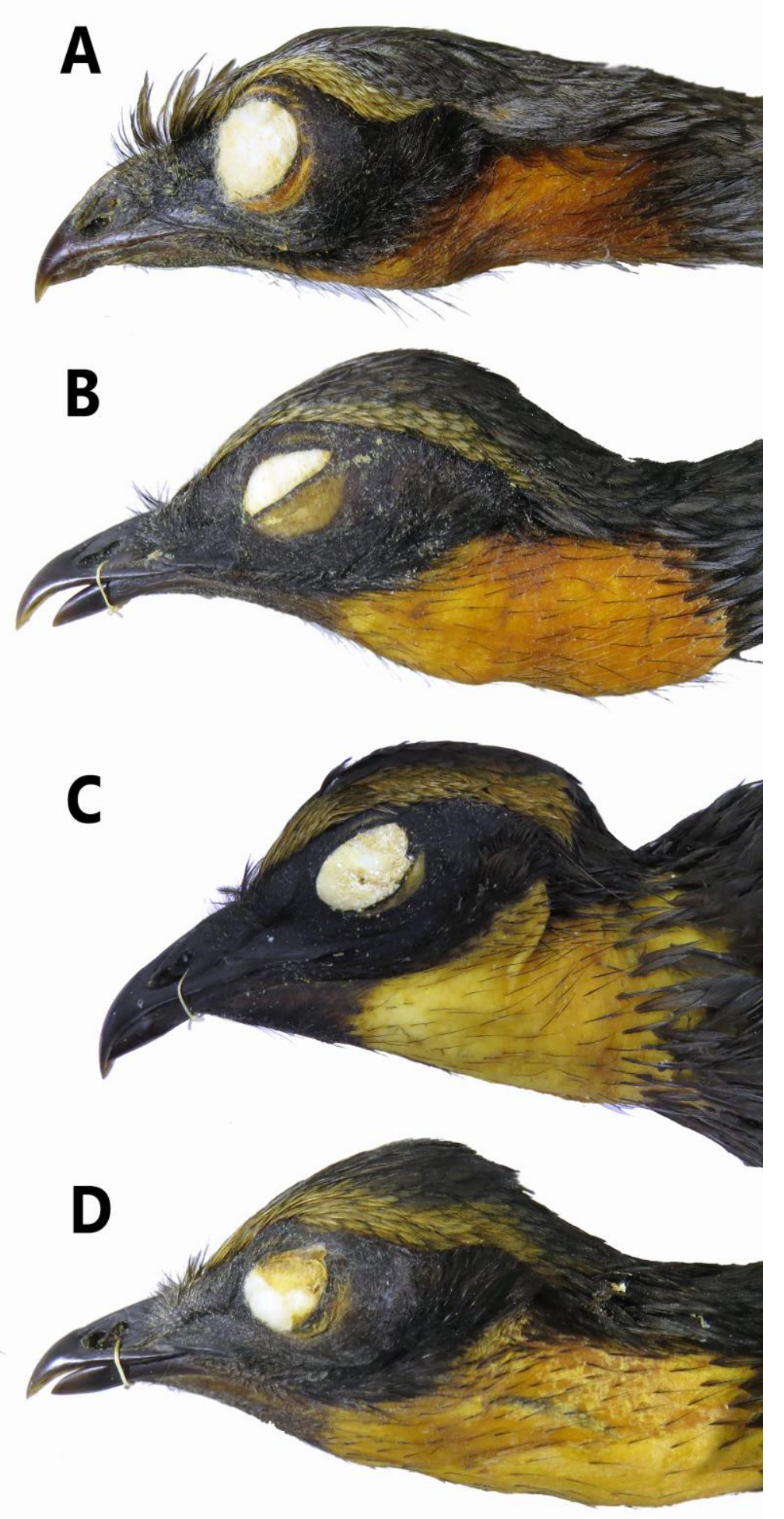

Figura 15. Linhas superciliares ocre características dos grupos geográficos CE2 e CA: MPEG 45080 (A; fêmea da Colônia do Formoso - BA), MNRJ 36284 (B; fêmea da Flona Araripe, Crato - CE), MZUSP 79473 (C; macho de ESEC Serra Geral de Tocantins - TO), e MNRJ 36285 (D; macho da Flona Araripe, Crato - CE). 


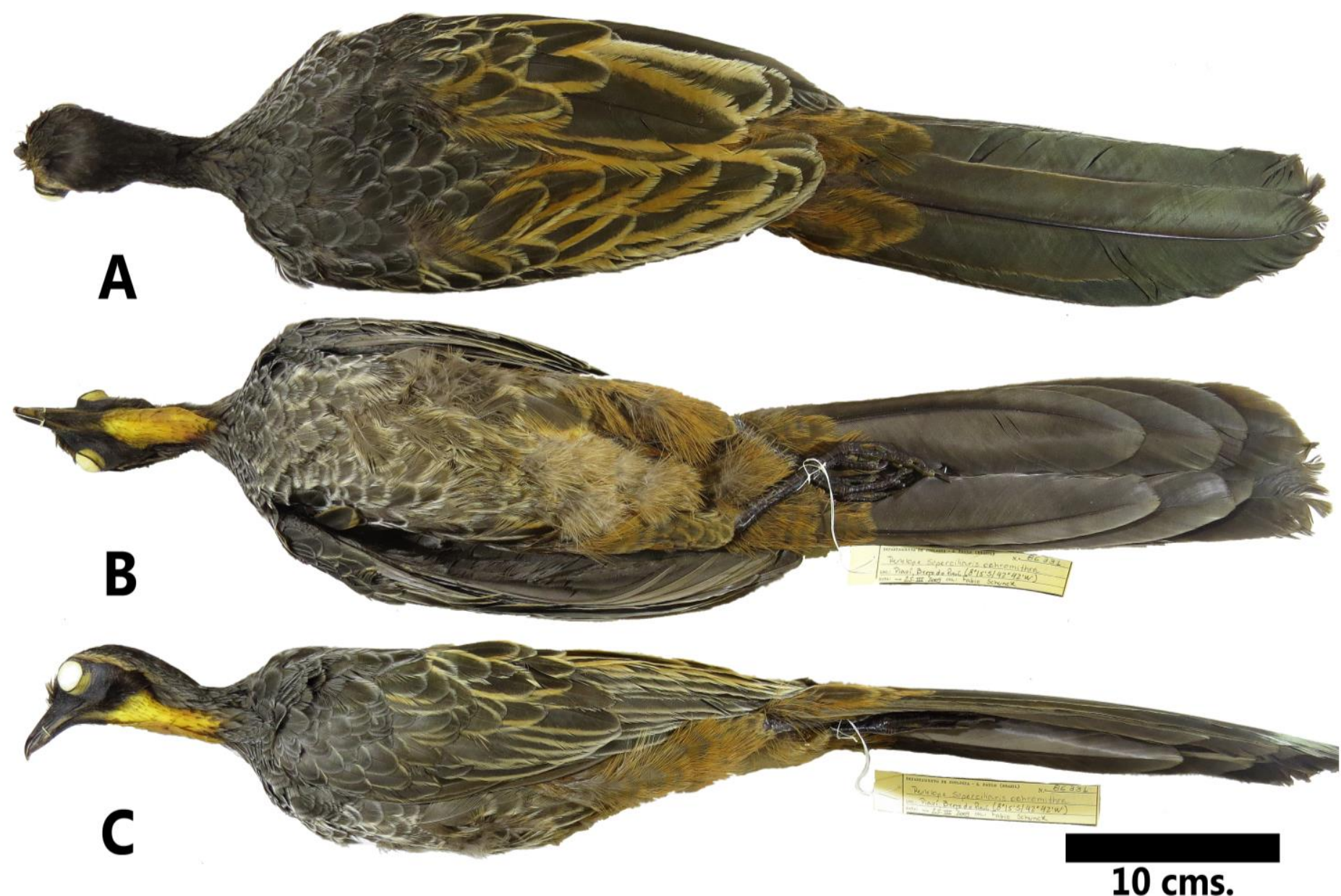

Figura 16. Vista dorsal (A), ventral (B) e lateral (C) do exemplar MZUSP 86331 (Brejo do Piauí - PI), típico da Caatinga pela linha superciliar ocre e as bordas extensas das penas das asas de cor laranja amarelada. 


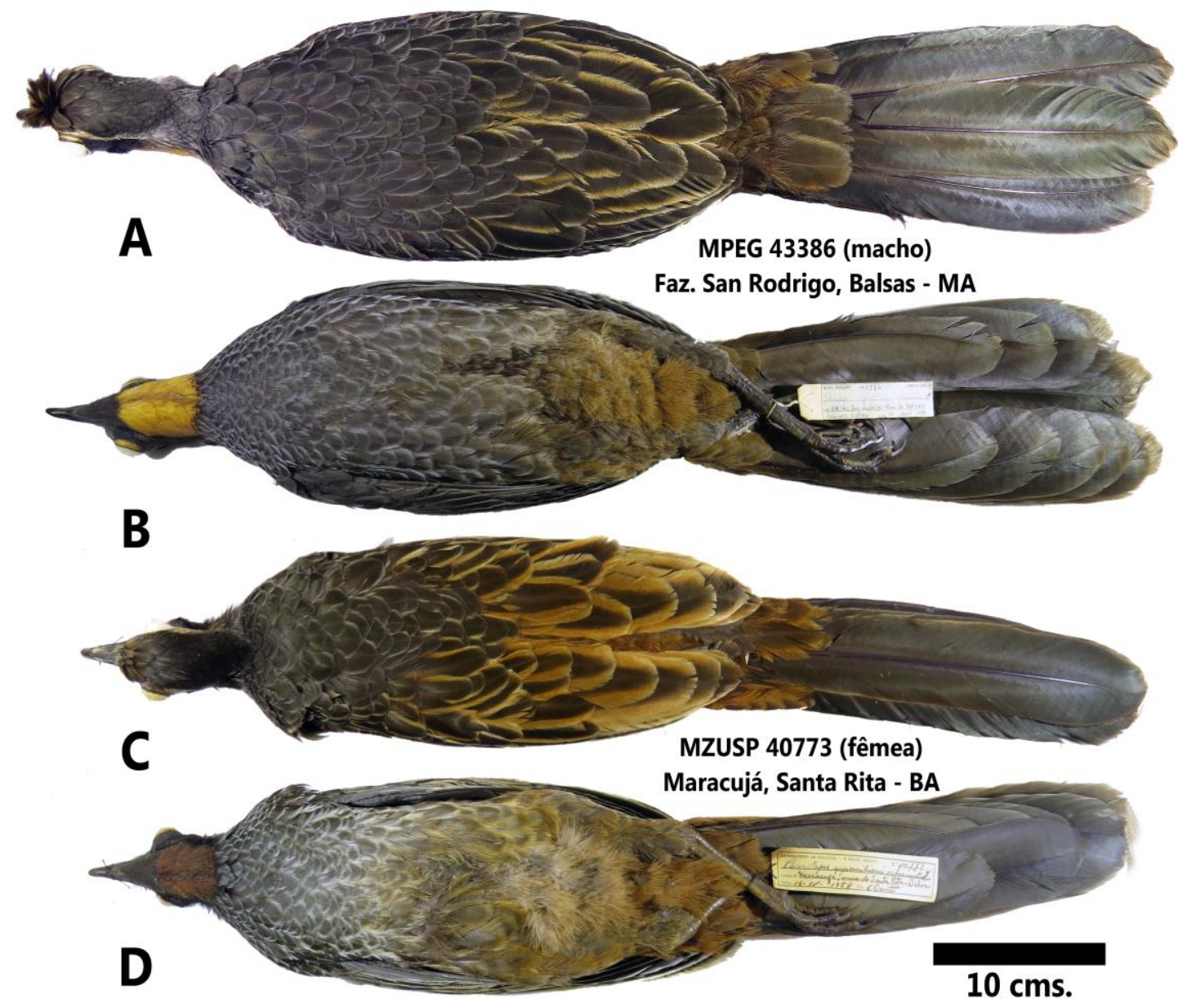

Figura 17. Exemplares típicos da área do Cerrado que limita com a Caatinga (CE2): MPEG 43386 de Maranhão (A, B) e MZUSP 40773 de Bahia (C, D). 


\section{d. Amazônia 5, Pantanal e Cerrado 5:}

Os espécimes destes três grupos geográficos são bastante variáveis em coloração geral: a população AM5 inclui os exemplares coletados na faixa de Amazônia no Sul de Rondônia e Oeste de Mato Grosso; PA, os espécimes do Pantanal no Sudoeste de Mato Grosso, noroeste de Mato Grosso do Sul e o leste da Bolívia; e a população CE5, do Sudoeste do Cerrado, abrange o Centro e Sul de Mato Grosso e o resto de Mato Grosso do Sul. Foram revisados um total de 18 exemplares entre os três grupos geográficos ( 8 machos, 8 fêmeas, 2 não determinados), e mostraram que também são bastante variáveis na coloração geral. Como se mencionou anteriormente, indivíduos de coloração mais escura são mais frequentes na Amazônia, mas não são exclusivos desse bioma, um claro exemplo disso é o espécimen MNRJ 18863 do Pantanal (Fig. 18 A, B), e da mesma localidade na qual foi coletado também temos o exemplar MNRJ 18899 (Fig. 18 C, D), que é totalmente diferente: bastante apagado e opaco, e com bordas das penas das asas e região uropigial de cor marrom apagado e não ferrugíneo intenso com o outro.

No Cerrado os espécimes são também bastante variáveis, como es exemplares MZUSP 12243 e MZUSP 36609 (Fig. 18 E-H), que apesar de ter um matiz algo escuro bastante parecido, têm as bordas das penas das asas bastante diferentes: no primeiro são ferrugíneas extensas, e no segundo são laranja apagadas e bastante finas.

Em resumo, a coloração geral, a cor e a extensão das bordas das penas das asas, a cor da região uropigial e o brilho do corpo, são bastante variáveis nos três grupos geográficos, e o sexo dos espécimes aparentemente não mostra diferença em esses caráteres. 


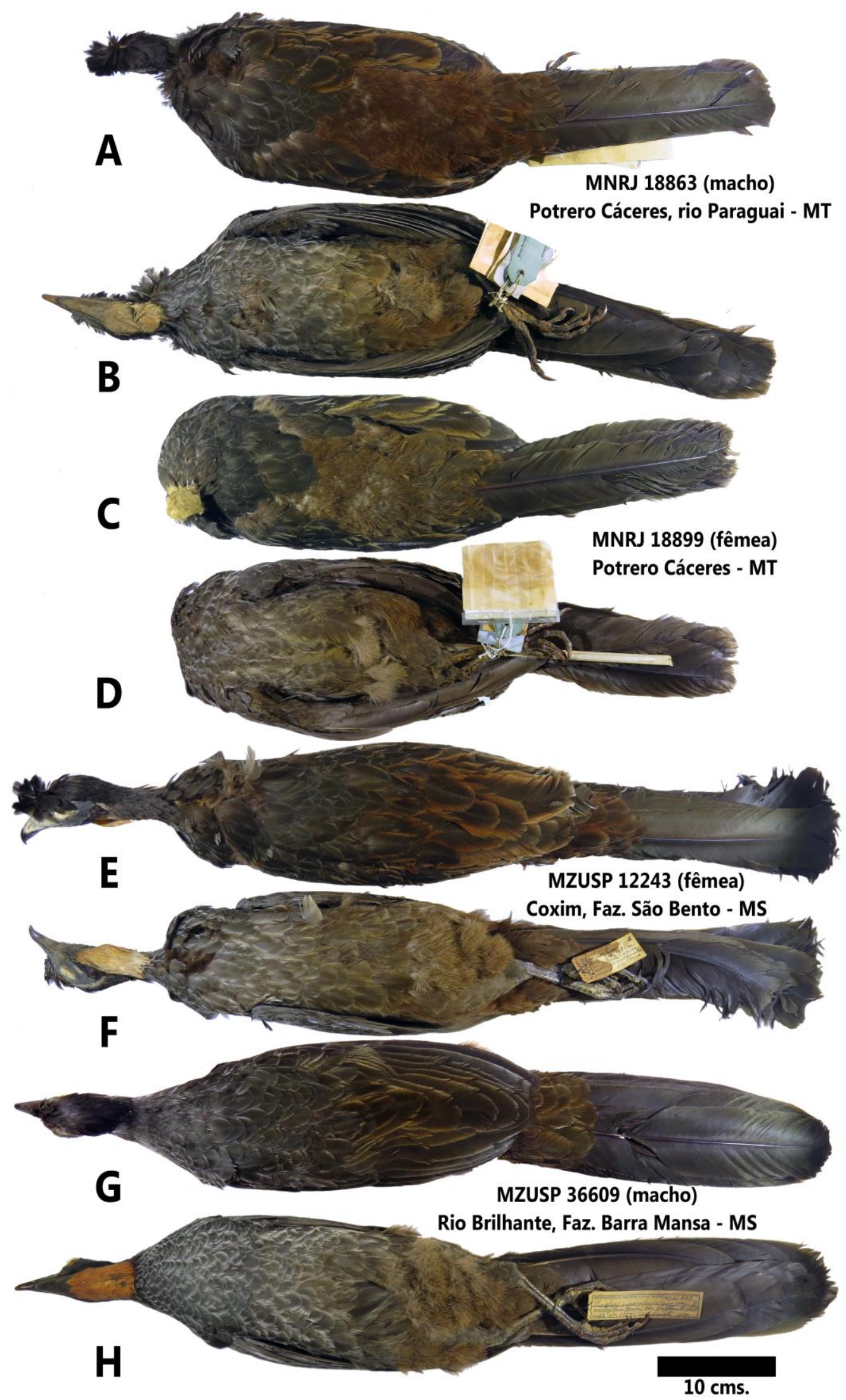

Figura 18: Espécimes revisados dos grupos geográficos do oeste do Brasil: PA (MNRJ 18863, MNRJ 18899) e CE5 (MZUSP 12243, MZUSP 36609). 


\section{e. Cerrado 1 e 3}

Aqui se juntam os grupos geográficos do Centro e Norte do Brasil (excluindo o grupo CE2 que limita com a Caatinga): o CE1, do Norte do Cerrado próximo à Amazônia, abrange o Centro de Maranhão e Oeste de Tocantins; e o CE3, do Cerrado central no Centro do Brasil, inclui o Leste de Mato Grosso, Goiás e Oeste de Minas Gerais. Se consideraram 43 exemplares em total (19 machos, 19 fêmeas, 5 não determinados); os do grupo CE1, apesar de se distribuir na faixa que limita com o Este da Amazônia, não são escuros e têm um brilho verdoso, com bordas das penas das asas que variam de laranja escuro a marrom claro, um exemplo disso são os espécimes MNRJ 18896 (Fig. 19 A, B) e MPEG 42246 (Fig. 19 C, D). No grupo CE3, apesar de ter uma tendência de incluir indivíduos maiormente de coloração geral clara e brilho verdoso, também é possível encontrar espécimes algo escuros bem diferentes da maioria da população, como o exemplar MNRJ 36662 (Fig. 19 E, F), enquanto o resto é mais parecido a MNRJ 32542 (Fig. 19 G, H). 

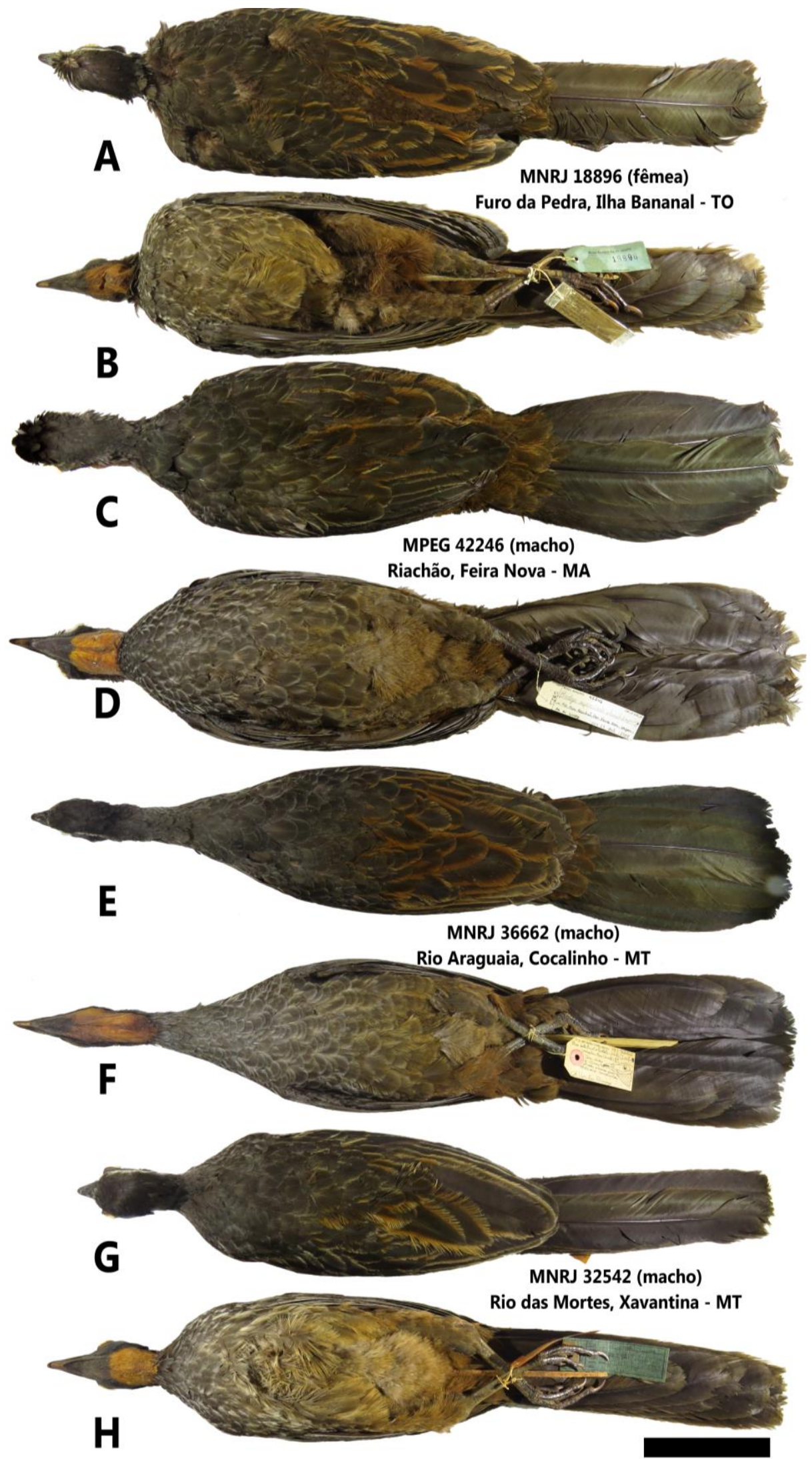

$10 \mathrm{cms}$.

Figura 19: Espécimes revisados dos grupos geográficos do centro do Brasil: CE1 (MNRJ 18896, MPEG 42246) e CE3 (MNRJ 36662, MNRJ 32542). 


\section{f. Cerrado 4, Mata Atlântica 4 e 5:}

Se revisou um total de 51 espécimes do Sudeste do Brasil (27 machos, 18 fêmeas, 6 não determinados), onde o Cerrado divide a Mata Atlântica do estado de São Paulo pelo meio e chega até Paraná, por isso selecionei os seguintes grupos geográficos: CE4, no extremo mais ao Sul do Cerrado, rodeado por Mata Atlântica no Sul de Minas Gerais, Centro de São Paulo e Norte de Paraná; MA4, da Mata Atlântica do litoral Sudeste, que inclui o Sul de Minas Gerais, e leste de São Paulo, Paraná e Santa Catarina; e MA5,da Mata Atlântica do interior do Sudeste, no oeste de São Paulo e Paraná.

Na Figura 20, mostro quatro exemplares de São Paulo, um do Cerrado no centro-norte do estado (C, D; MZUSP 2693), um da Mata Atlântica ao oeste do Cerrado no interior (A, B; MZUSP 26074), e dois da Mata Atlântica ao leste do Cerrado em localidades próximas ao litoral (E-H; MZUSP 54382, MZUSP 4861); aparentemente os exemplares do Cerrado são mais claros por causa do brilho verdoso mais claro e brilhante, além de ter bordas nas penas das asas mais claras que nos da Mata Atlântica. Em geral, os da Mata Atlântica parecem ser mais escuros, mas as bordas das penas da coberteiras e rêmiges das asas são bem variáveis em extensão e cor. A alta variação nas cores das três populações, não me permite discriminar elas pelo tipo de bioma no qual ocorrem, apesar de parecer que uns são mais escuros que outros na maioria dos casos. 


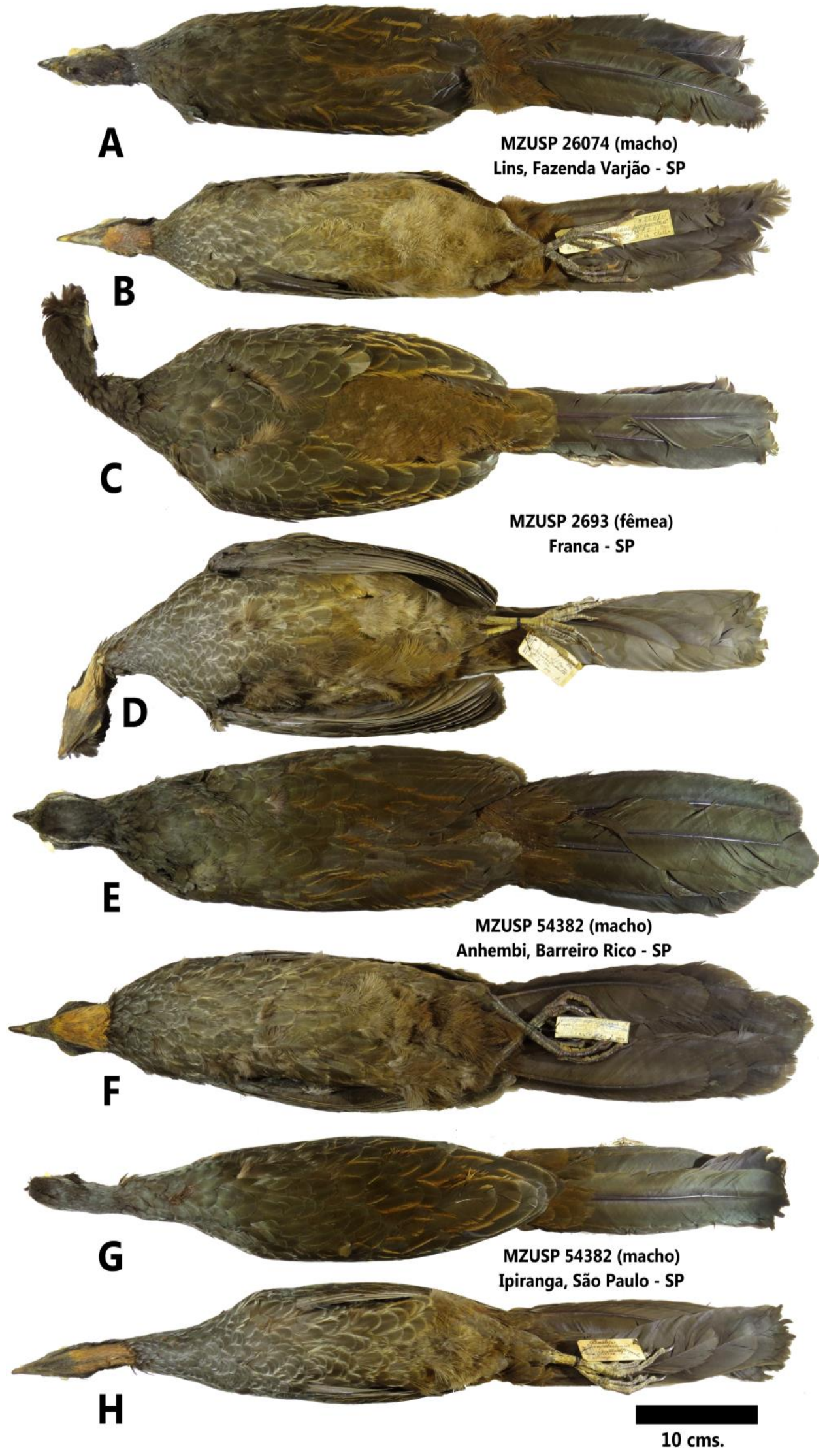

Figura 20: Espécimes revisados dos grupos geográficos do sudeste do Brasil: MA5 (MZUSP 26074), CE4 (MZUSP 2693) e MA4 (MZUSP 54382, MZUSP 4861). 


\section{g. Mata Atlântica 1:}

Este grupo geográfico se encontra isolado na Mata Atlântica do Nordeste, e devido ao baixo número de espécimes em coleções científicas (um de Paraíba, e dois de Alagoas), foram também usados dados de referências bibliográficas, como a descrição da subespécie endêmica do Centro de Endemismo Pernambuco Penelope superciliaris alagoensis proposta por Nardelli (1993), e os trabalhos feitos sobre essa área de Silveira et al. (2003), Silveira \& Olmos (2003), Silveira et al. (2008), e Silveira (2008).

Os indivíduos de Alagoas se diferenciam por (1) serem de coloração geral bem escura, (2) ter bordas das penas das asas ferrugíneas escuras, mais parecidas com as populações da Amazônia, e ter (3) uma linha superciliar larga, branca e brilhante. Tanto a descrição de Nardelli, como todas as identificações mencionadas nas referências, concordam com as caraterísticas desses espécimes. Das três características diagnosticáveis do grupo, o espécimen MZUSP 39439 de Paraíba (Fig. 21 A) só apresenta à da linha superciliar, enquanto a coloração do corpo é esverdeada brilhante, mais parecida com indivíduos de outras populações.

O Departamento de Zoologia do MZUSP fez expedições entre junho e julho de 1957, com coletas em Coremas e Mamanguape, interior e litoral de Paraíba, respectivamente. Os espécimes coletados em Coremas são típicos da Caatinga, como Xiphocolaptes falcirostris e Penelope jacucaca, enquanto os de Mamanguape mostram que esta é uma mata de transição entre o Cerrado e a Mata Atlântica com exemplares de Xenons minutus alagoanus, X. rutilans rutilans e Automolus leucophthalmus, entre outros. Isto explica a coloração do espécime MZUSP 39439 coletado nessa expedição em Mamanguape, que apesar de ter um superciliar largo e 
branco, tem uma coloração geral esverdeada brilhante mais parecida com indivíduos das populações do Cerrado e Mata Atlântica ao sul do Centro de Endemismo Pernambuco.

Então os caráteres diagnósticos do grupo geográfico MA1, são restritos aos fragmentos de Mata Atlântica do Centro de Endemismo Pernambuco nos estados de Alagoas e Pernambuco, que como já mencionei, inclui indivíduos que pela coloração geral do corpo e as bordas das penas das asas são mais parecidos como os indivíduos escuros que frequentemente ocorrem na Amazônia que com os da Mata Atlântica do Sudeste.

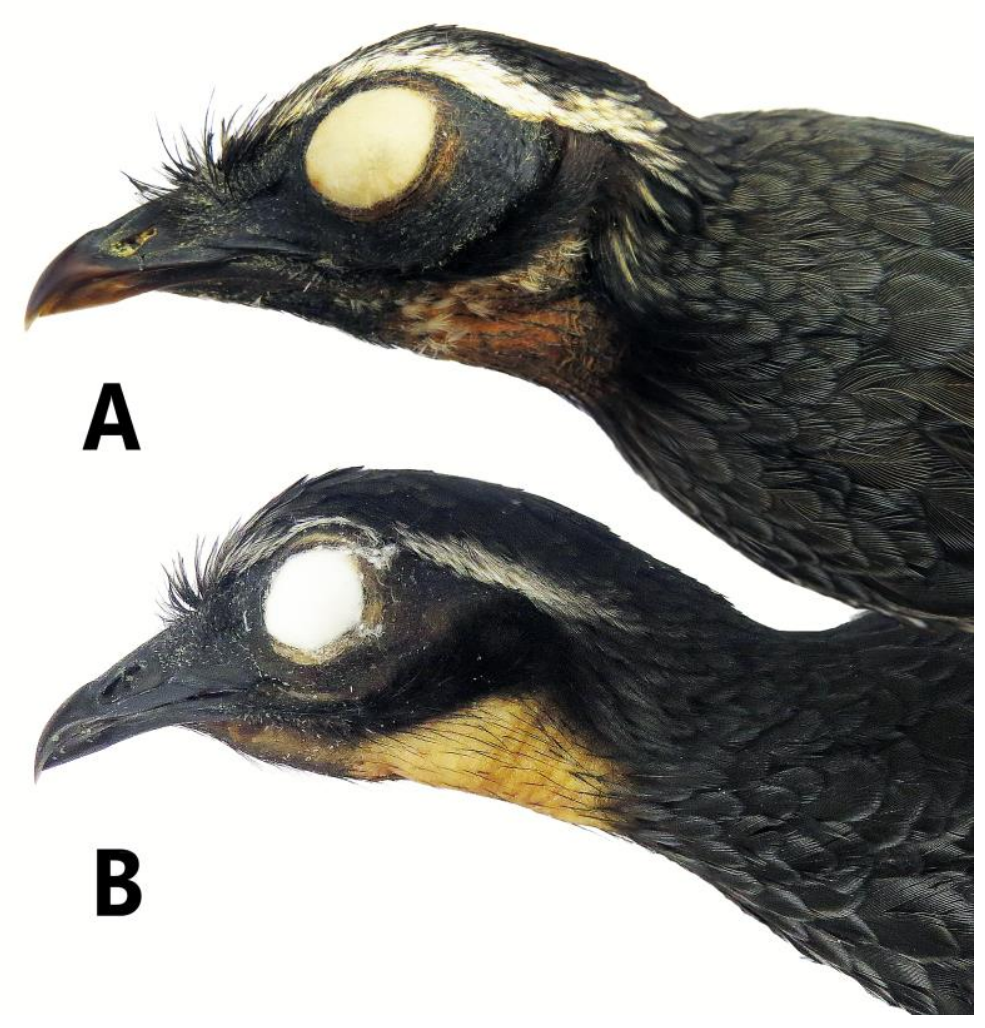

Figura 21. Linhas superciliares branco brilhantes do grupo geográfico MA1: MZUSP 39439 (A; não determinado de Mamanguape, Camaratuba - PB) e MZUSP SN (B; fêmea da Fazenda Santa Justina, Passo de Camaragibe - AL). 


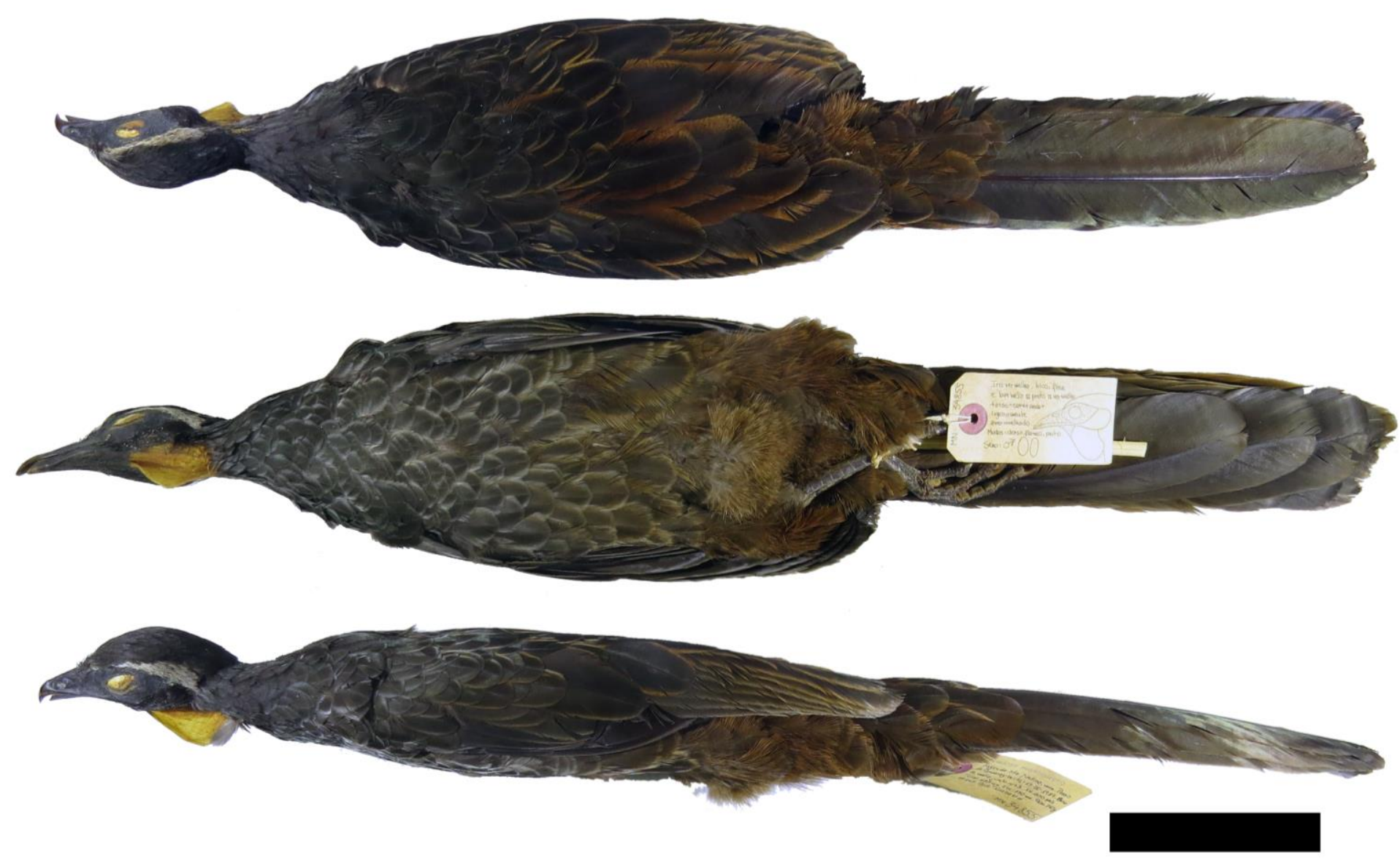

$10 \mathrm{cms}$.

Figura 22. Vista dorsal, ventral e lateral do exemplar MNRJ 34855 (Fazenda Santa Justina, Passo de Camaragibe - AL), típico do Centro de Endemismo Pernambuco (Mata Atlântica) pela linha superciliar branca brilhante e a coloração geral escura. 


\section{h. Mata Atlântica 2 e 3:}

Estes dois grupos juntam as populações da Mata Atlântica no Este do Brasil: MA2, do Sul de Bahia e nordeste de Minas Gerais; e MA3, de Espirito Santo, Rio de Janeiro e sudeste de Minas Gerais. Se revisou um total de 34 espécimes: 17 machos, 12 fêmeas e 5 não determinados.

Os exemplares desta região têm um brilho verdoso no dorso que vária em intensidade de forma independente para cada espécimen, que pode ser mais escuro como o MZUSP 14022 de Bahia (Fig. 23 A, B), ou mais claro como MZUSP 37826 de Minas Gerais (Fig. 23 C, D). Uma outra característica que varia bastante é a cor e extensão nas bordas das penas das asas, que por exemplo no espécimen MNRJ 31037 de Rio de Janeiro (Fig. 23 E, F) é medianamente larga e marrom claro, e em MNRJ 2674 de Espirito Santo (Fig. 23 G, H) é reduzida e marrom escura. Não se encontrou nenhuma caraterística que sugira a presença de dimorfismo sexual nos indivíduos desta região. 

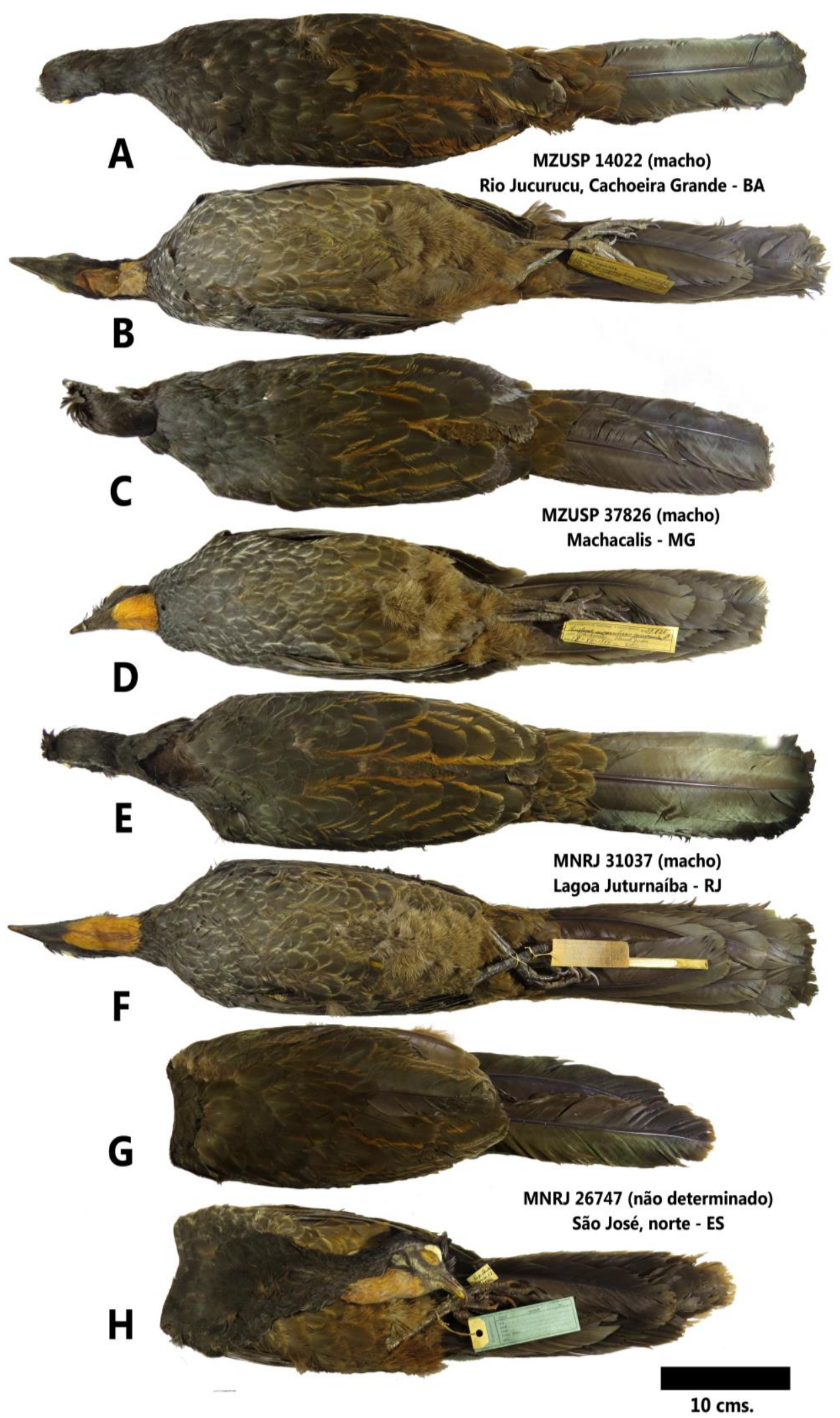

Figura 23. Espécimes revisados dos grupos geográficos do este do Brasil: MA2 (MZUSP 14022, MZUSP 37826) e MA3 (MNRJ 31037, MNRJ 26747). 


\section{i. Mata Atlântica 6:}

População mais ao sul da distribuição do complexo Penelope superciliaris, na Mata Atlântica que se distribui ao Sul do Brasil e nordeste da Argentina, de onde se revisaram um total de 24espécimes: 12 machos, 5 fêmeas e 7 não determinados.

A maioria dos espécimes deste grupo geográfico são bastante escuros, devido a que são mais opacos no corpo inteiro, com menos brilho verdoso no dorso e com bordas reduzidas nas penas das asas quase imperceptíveis, como o MACN 32895 (Fig. 24 E, F), ou de uma cor pouco contrastante com o centro da pena, como MACN 4608a (Fig. 24 G, H).

Alguns espécimes podem apresentam um brilho semelhante ao brilho de indivíduos que frequentemente ocorrem em grupos geográficos mais ao norte, como o MACN 31769 que é mais ferrugíneo intenso na região uropigial (Fig. 24 A, B), ou o MHNCI 4545 que é mais marrom escuro nessa região (Fig. 24 C, D). Em geral esta população parece ser mais opaca, mas não considero ela como totalmente diferençável das outras revisadas anteriormente, porque existe muita variação individual dentro dela. 

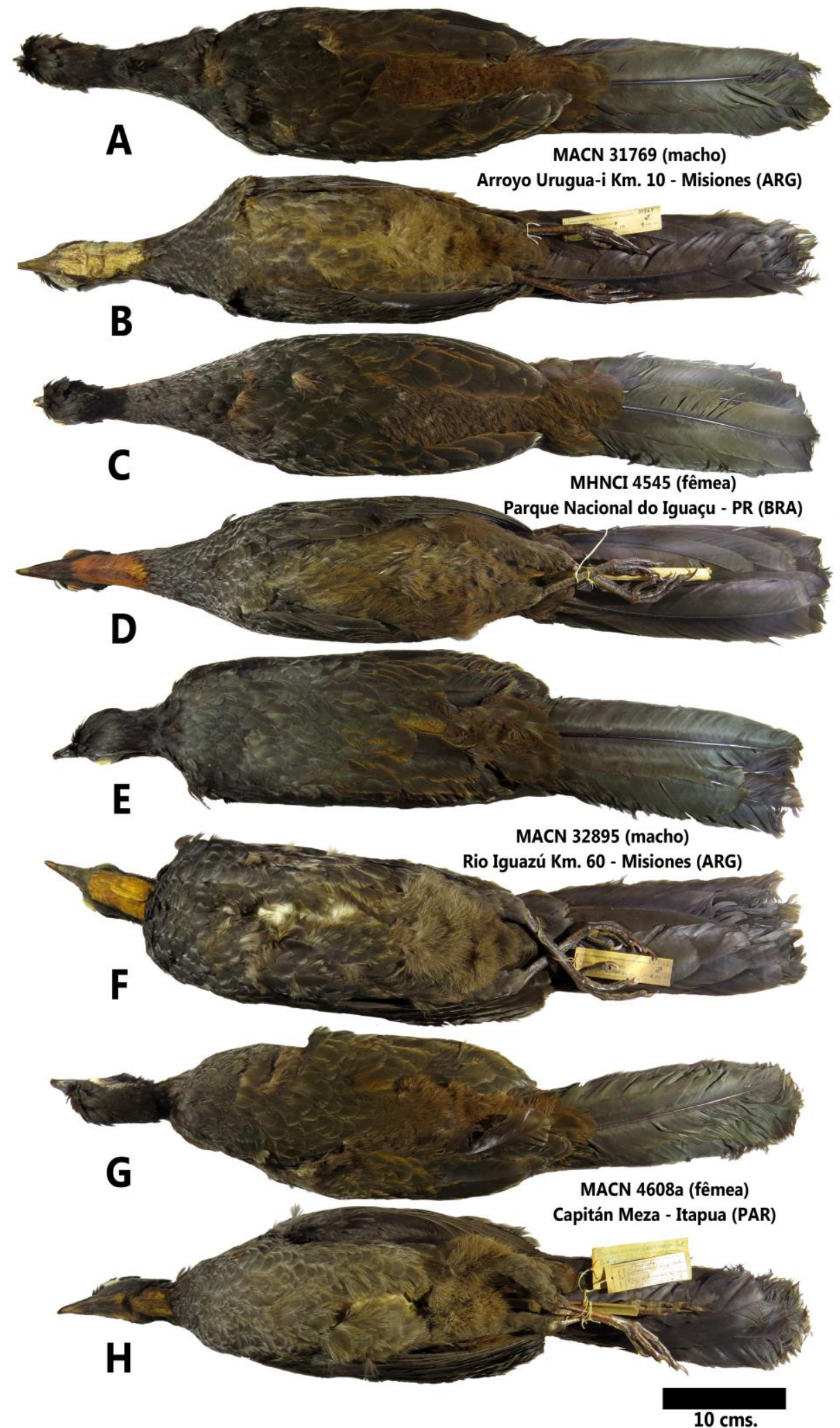

Figura 24: Espécimes revisados do grupo geográfico MA6 do limite entre Brasil, Paraguai e Argentina: MACN 31769 (ARG), MHNCI 4545 (BRA), MACN 32895 (ARG) e MACN 4608a (PAR). 
Depois de revisar todos os grupos geográficos, foi possível obter quatro grupos principais que se constituem em quatro unidades taxonômicas diagnosticáveis: (1) AM1, (2) CA + CE2, (3) MA1, e o (4) que inclui os demais grupos.

A primeira inclui o grupo AM1 do interflúvio Madeira-Tapajós, que compreende indivíduos de cor geral escura, diagnosticável pela pigmentação azul na pele nua do rosto. A segunda unidade inclui os grupos CA e CE2 da Caatinga e o Cerrado próximo a ela, diagnosticável por geralmente ter tom cinzento na coloração geral, bordas das penas coberteiras e rêmiges das asas extensas que variam de cor ocre a amarelo, e linha superciliar que varia de ocre a laranja. A terceira unidade agrupa os indivíduos do Centro de Endemismo Pernambuco (MA1), nos estados de Alagoas e Pernambuco, que se diferenciam por ser uma população isolada que é constantemente de tom bastante escuro, e uma linha superciliar larga, bem branca e brilhante. Os indivíduos da última unidade taxonômica ocorrem em toda a área de distribuição do complexo Penelope superciliaris, excluindo as áreas dos grupos geográficos já mencionados, e abrangendo a Amazônia, Cerrado, Pantanal e Mata Atlântica.

A análise qualitativa mostra que a cor geral do corpo, seja escura ou clara, a intensidade do brilho esverdeado no dorso, a cor e intensidade da região uropigial, ou as bordas das penas das asas, não influem na separação de unidades taxonômicas por biomas. Inicialmente eu acreditava que as três subespécies comumente reconhecidas (Vaurie, 1968; Delacour \& Amadon, 2004), poderiam ser delimitadas com base nos biomas nas quais elas ocorrem, mas apesar dos espécimes da Amazônia ter uma maior tendência a ser mais escuros, é também provável encontrar indivíduos com essas caraterísticas no Cerrado e na Mata Atlântica, assim como é possível encontrar indivíduos claros na Amazônia. Ressalta- 
se aqui a importância da coleta de séries, porque na quarta unidade taxonômica foram elas as que permitiram encontrar espécimes adultos que normalmente seriam identificados como subespécies geográficas diferentes e que ocorrem na mesma localidade, sem estar relacionados a alguma possível diferencia entre sexos.

Em nenhuma das quatro unidades taxonômicas se observou dimorfismo sexual ligado à coloração das penas nem à pigmentação da pele nas regiões nuas. Uma outra espécie do gênero, Penelope obscura, apresenta dimorfismo sexual na cor da íris, que em machos varia de vermelho a laranja e em fêmeas de marrom a marrom escuro, que se diferenciam desde o primeiro ano de vida (Sick, 1993; Chalukian, 1997; Nacinovic, 2012.

Uma importante observação feita nos exemplares de todos os grupos geográficos é que a coloração da região uropigial sempre varia com relação à cor das bordas das penas coberteiras e rêmiges nas asas, sendo geralmente do mesmo tom ou de intensidades bastante próximas. Quando os exemplares têm coloração geral mais escura, as bordas das penas coberteiras e rêmiges são ferrugíneas bastante intensas, mais escuras em uns que em outros; enquanto nos indivíduos menos escuros, amarronzados ou de brilho esverdeado, as bordas dessas penas não são ferrugíneas, elas variam de ocre a amarelo na segunda unidade taxonômica, e de marrom claro a marrom escuro na quarta unidade.

A quarta unidade taxonômica, a de mais ampla distribuição geográfica, é a que tem maior variação individual intra - populacional, e vemos que a aparente tendência a mudar de coloração entre diferentes regiões da sua distribuição não é totalmente delimitada. Frequentemente os indivíduos mais ao norte da distribuição são bem escuros e com bordas das penas das asas ferrugíneas intensas; no centro da distribuição são mais claros, 
amarronzados ou de brilho esverdeado, com bordas das penas das asas que variam de marrom claro a marrom escuro algo contrastantes; e bem no sul são mais escuros, com brilho quase ausente que dá um aspecto opaco e com bordas das penas das asas reduzidas que podem ser pouco notórias ou praticamente ausentes; essas três regiões não são bem delimitadas e as características mencionadas são possíveis de se observar em qualquer outra região, mas com uma frequência menor. 


\subsection{Análises Estatísticas}

Nas provas estatísticas foram analisados 305 exemplares adultos (155 machos, 114 fêmeas, 36 não identificados) divididos dentro dos 18 grupos geográficos. Os demais espécimes foram excluídos por ser jovens.

A Tabela 4apresenta as análises de estatística descritiva para cada um dos 18 grupos, que incluem a média, o desvio padrão, e o valores mínimos e máximo. Quando o N do grupo foi menor a $5(\mathrm{n}<5)$, só foi calculada a média e os valores mínimo e máximo. Brevemente cada um se define assim:

- Média: É o valor que mostra para onde se concentram os dados de uma distribuição, como o ponto de equilíbrio das frequências em um histograma.

- Desvio padrão: Também chamado de desvio padrão populacional, é uma medida de dispersão em torno da média populacional. Um baixo desvio padrão indica que os dados tendem a estar próximos da média, enquanto um alto desvio padrão indica que os dados estão espalhados por uma ampla gama de valores.

- Valores mínimo e máximo: São os valores extremos dentro da população avaliada, como referência do rango de dispersão. 
Tabela 4. Média \pm desvio padrão (primeira linha), e valores mínimo e máximo (segunda linha) das medidas corporais dos grupos geográficos do complexo Penelope superciliaris representados em milímetros.

\begin{tabular}{|c|c|c|c|c|c|c|c|c|}
\hline $\begin{array}{c}\text { Grupos } \\
\text { Geográficos }\end{array}$ & $\begin{array}{l}\text { Cúlmen } \\
\text { exposto }\end{array}$ & Bico - Narina & Largura & Altura & Tarso & $\begin{array}{c}\text { Dedo do } \\
\text { meio }\end{array}$ & Asa fechada & Cauda \\
\hline $\begin{array}{c}1 \text { (AM1) } \\
(n=6)\end{array}$ & $\begin{array}{l}28.35 \pm 1.06 \\
(26.6-29.8)\end{array}$ & $\begin{array}{l}20.76 \pm 0.86 \\
(19.9-21.9)\end{array}$ & $\begin{array}{l}10.56 \pm 0.63 \\
(10.1-11.6)\end{array}$ & $\begin{array}{l}11.16 \pm 0.48 \\
(10.7-11.7)\end{array}$ & $\begin{array}{c}74.6 \pm 2.38 \\
(72.8-79.0)\end{array}$ & $\begin{array}{c}56.33+4.08 \\
(51-61)\end{array}$ & $\begin{array}{c}262.83 \pm 12.06 \\
(241-274)\end{array}$ & $\begin{array}{c}314.5 \pm 32.75 \\
(265-347)\end{array}$ \\
\hline $\begin{array}{l}2 \text { (AM2) } \\
(n=55)\end{array}$ & $\begin{array}{l}28.37 \pm 1.64 \\
(25.4-33.1)\end{array}$ & $\begin{array}{l}21.02 \pm 1.35 \\
(18.0-24.7)\end{array}$ & $\begin{array}{l}9.60 \pm 0.55 \\
(8.6-11.2)\end{array}$ & $\begin{array}{c}10.55 \pm 0.85 \\
(8.6-12.2)\end{array}$ & $\begin{array}{l}73.58 \pm 2.98 \\
(64.5-79.2)\end{array}$ & $\begin{array}{c}55.45 \pm 2.39 \\
(49-62)\end{array}$ & $\begin{array}{c}254.44 \pm 9.81 \\
(232-282)\end{array}$ & $\begin{array}{c}301.65 \pm 17.35 \\
(255-347)\end{array}$ \\
\hline $\begin{array}{l}3 \text { (AM3) } \\
(n=25)\end{array}$ & $\begin{array}{l}27.91 \pm 1.29 \\
(24.4-30.4)\end{array}$ & $\begin{array}{l}20.42 \pm 1.15 \\
(17.6-22.5)\end{array}$ & $\begin{array}{l}9.84 \pm 0.71 \\
(8.3-11.5)\end{array}$ & $\begin{array}{c}10.60 \pm 0.91 \\
(9.0-12.3)\end{array}$ & $\begin{array}{l}73.76 \pm 2.93 \\
(64.9-77.0)\end{array}$ & $\begin{array}{c}56.96 \pm 2.07 \\
(53-60)\end{array}$ & $\begin{array}{c}251.88 \pm 13.05 \\
(228-279)\end{array}$ & $\begin{array}{c}302.56 \pm 15.46 \\
(271-341)\end{array}$ \\
\hline $\begin{array}{l}4 \text { (AM4) } \\
(n=27)\end{array}$ & $\begin{array}{c}28.1 \pm 2.00 \\
(23.6-32)\end{array}$ & $\begin{array}{c}21.75 \pm 1.21 \\
(18.9-24.4)\end{array}$ & $\begin{array}{c}10.02 \pm 0.64 \\
(8.8-11.4)\end{array}$ & $\begin{array}{c}10.59 \pm 0.61 \\
(9.5-12.2)\end{array}$ & $\begin{array}{l}72.12 \pm 4.56 \\
(63.8-79.7)\end{array}$ & $\begin{array}{c}55.46 \pm 3.16 \\
(51-62)\end{array}$ & $\begin{array}{c}254.42 \pm 10.57 \\
(231-270)\end{array}$ & $\begin{array}{c}307.84 \pm 18.74 \\
(264-335)\end{array}$ \\
\hline $\begin{array}{c}5 \text { (AM5) } \\
(n=3)\end{array}$ & $\begin{array}{c}27.8 \\
(27.1-28.4)\end{array}$ & $\begin{array}{c}22.13 \\
(21.5-22.6)\end{array}$ & $\begin{array}{c}9.97 \\
(9.5-10.2)\end{array}$ & $\begin{array}{c}10.5 \\
(9.7-11.2)\end{array}$ & $\begin{array}{c}68.87 \\
(63.5-73.3)\end{array}$ & $\begin{array}{c}55.33 \\
(53-58)\end{array}$ & $\begin{array}{c}242.66 \\
(238-248)\end{array}$ & $\begin{array}{c}315 \\
(309-322)\end{array}$ \\
\hline $\begin{array}{l}6 \text { (CA) } \\
(n=5)\end{array}$ & $\begin{array}{l}25.6 \pm 0.86 \\
(24.6-26.9)\end{array}$ & $\begin{array}{c}18.46 \pm 1.27 \\
(17.1-20.3)\end{array}$ & $\begin{array}{c}8.76 \pm 0.71 \\
(7.8-9.6)\end{array}$ & $\begin{array}{c}9.82 \pm 0.48 \\
(9.0-10.2)\end{array}$ & $\begin{array}{l}67.8 \pm 1.65 \\
(66.1-69.9)\end{array}$ & $\begin{array}{c}51.2 \pm 1.92 \\
(48-53)\end{array}$ & $\begin{array}{c}249.6 \pm 5.36 \\
(242-257)\end{array}$ & $\begin{array}{c}308.4 \pm 14.79 \\
(290-322)\end{array}$ \\
\hline $\begin{array}{l}7(P A) \\
(n=6)\end{array}$ & $\begin{array}{c}28.16 \pm 0.83 \\
(27.1-29.0)\end{array}$ & $\begin{array}{l}20.9 \pm 1.04 \\
(19.5-21.8)\end{array}$ & $\begin{array}{l}9.7 \pm 0.65 \\
(9.0-10.3)\end{array}$ & $\begin{array}{l}10.9 \pm 0.29 \\
(10.6-11.3)\end{array}$ & $\begin{array}{c}71.83 \pm 4.17 \\
(67.9-78.7)\end{array}$ & $\begin{array}{c}53.83 \pm 2.64 \\
(51-57)\end{array}$ & $\begin{array}{c}252.0 \pm 14.64 \\
(231-273)\end{array}$ & $\begin{array}{c}302.33 \pm 20.55 \\
(276-331)\end{array}$ \\
\hline $\begin{array}{l}8 \text { (CE1) } \\
(n=10)\end{array}$ & $\begin{array}{c}27.39 \pm 1.70 \\
(24.7-29.8)\end{array}$ & $\begin{array}{c}20.24 \pm 2.12 \\
(16.9-24.1)\end{array}$ & $\begin{array}{l}9.3 \pm 0.82 \\
(8.1-10.5)\end{array}$ & $\begin{array}{c}10.63 \pm 0.71 \\
(9.4-11.5)\end{array}$ & $\begin{array}{c}69.45 \pm 4.32 \\
(59.8-75.1)\end{array}$ & $\begin{array}{c}53.5 \pm 2.27 \\
(50-56)\end{array}$ & $\begin{array}{c}241.5 \pm 10.76 \\
(226-256)\end{array}$ & $\begin{array}{l}291.6 \pm 19.82 \\
\quad(255 \\
-324)\end{array}$ \\
\hline
\end{tabular}




\begin{tabular}{|c|c|c|c|c|c|c|c|c|}
\hline $\begin{array}{l}9 \text { (CE2) } \\
(n=14)\end{array}$ & $\begin{array}{c}27.04 \pm 2.02 \\
(23.5-31.1)\end{array}$ & $\begin{array}{c}19.61 \pm 1.55 \\
(17.9-23.0)\end{array}$ & $\begin{array}{c}9.35 \pm 0.52 \\
(8.5-10.1)\end{array}$ & $\begin{array}{c}10.71 \pm 0.67 \\
(9.7-11.7)\end{array}$ & $\begin{array}{l}70.5 \pm 2.92 \\
(66.6-75.7)\end{array}$ & $\begin{array}{c}53.28 \pm 3.91 \\
(42-59)\end{array}$ & $\begin{array}{c}249.07 \pm 9.82 \\
(226-261)\end{array}$ & $\begin{array}{c}308.28 \pm 13.47 \\
(294-339)\end{array}$ \\
\hline $\begin{array}{r}10 \text { (CE3) } \\
(n=33)\end{array}$ & $\begin{array}{c}27.31 \pm 1.98 \\
(22.1-32.0)\end{array}$ & $\begin{array}{c}20.02 \pm 1.28 \\
(18.1-23.2)\end{array}$ & $\begin{array}{c}9.77 \pm 0.65 \\
(8.4-11.4)\end{array}$ & $\begin{array}{c}10.54 \pm 0.83 \\
(8.9-12.6)\end{array}$ & $\begin{array}{c}70.23 \pm 4.10 \\
(61.4-79.6)\end{array}$ & $\begin{array}{c}53.51 \pm 2.70 \\
(47-58)\end{array}$ & $\begin{array}{c}243.15 \pm 14.27 \\
(203-273)\end{array}$ & $\begin{array}{c}294.61 \pm 16.86 \\
(264-334)\end{array}$ \\
\hline $\begin{array}{c}11 \text { (CE4) } \\
(n=7)\end{array}$ & $\begin{array}{c}26.53 \pm 0.46 \\
(25.7-27.2)\end{array}$ & $\begin{array}{c}20.14 \pm 0.37 \\
(19.5-20.6)\end{array}$ & $\begin{array}{c}9.64 \pm 0.58 \\
(8.8-10.5)\end{array}$ & $\begin{array}{c}10.3 \pm 0.36 \\
(9.9-10.8)\end{array}$ & $\begin{array}{l}71.8 \pm 3.26 \\
(68.5-78.4)\end{array}$ & $\begin{array}{c}54.71 \pm 3.15 \\
(52-61)\end{array}$ & $\begin{array}{c}248.28 \pm 9.18 \\
(230-258)\end{array}$ & $\begin{array}{c}294.86 \pm 7.17 \\
(283-306)\end{array}$ \\
\hline $\begin{array}{c}12 \text { (CE5) } \\
(n=9)\end{array}$ & $\begin{array}{c}27.26 \pm 2.26 \\
(22.7-29.6)\end{array}$ & $\begin{array}{c}20.14 \pm 1.76 \\
(17.2-22.2)\end{array}$ & $\begin{array}{l}9.98 \pm 0.94 \\
(7.9-11.0)\end{array}$ & $\begin{array}{c}10.46 \pm 0.75 \\
(9.0-11.5)\end{array}$ & $\begin{array}{c}68.42 \pm 8.67 \\
(50.0-76.6)\end{array}$ & $\begin{array}{c}54.78 \pm 5.40 \\
(45-61)\end{array}$ & $\begin{array}{c}249.89 \pm 21.02 \\
(208-275)\end{array}$ & $\begin{array}{c}296.55 \pm 33.03 \\
(247-343)\end{array}$ \\
\hline $\begin{array}{c}13 \text { (MA1) } \\
(n=3)\end{array}$ & $\begin{array}{c}26.5 \\
(21.2-29.3)\end{array}$ & $\begin{array}{c}19.76 \\
(15.6-22.0)\end{array}$ & $\begin{array}{c}8.75 \\
(7.6-9.9)\end{array}$ & $\begin{array}{c}9.5 \\
(7.8-11.2)\end{array}$ & $\begin{array}{c}66.26 \\
(59.0-72.5)\end{array}$ & $\begin{array}{c}51.66 \\
(47-56)\end{array}$ & $\begin{array}{c}239.66 \\
(210-255)\end{array}$ & $\begin{array}{c}286.66 \\
(251-309)\end{array}$ \\
\hline $\begin{array}{c}14 \text { (MA2) } \\
(n=8)\end{array}$ & $\begin{array}{c}29.21 \pm 1.63 \\
(27.2-32.4)\end{array}$ & $\begin{array}{c}21.54 \pm 1.16 \\
(20.2-23.9)\end{array}$ & $\begin{array}{c}9.64 \pm 0.45 \\
(9.1-10.4)\end{array}$ & $\begin{array}{c}10.94 \pm 0.58 \\
(10.2-12.1)\end{array}$ & $\begin{array}{c}74.01 \pm 2.46 \\
(70.8-77.8)\end{array}$ & $\begin{array}{c}58.12 \pm 2.53 \\
(54-61)\end{array}$ & $\begin{array}{c}266.25 \pm 9.97 \\
(251-279)\end{array}$ & $\begin{array}{c}312.62 \pm 14.69 \\
(295-336)\end{array}$ \\
\hline $\begin{array}{c}15 \text { (MA3) } \\
(n=26)\end{array}$ & $\begin{array}{c}26.14 \pm 2.07 \\
(22.6-29.0)\end{array}$ & $\begin{array}{c}20.32 \pm 1.33 \\
(17.5-23.3)\end{array}$ & $\begin{array}{c}9.57 \pm 0.73 \\
(7.7-10.8)\end{array}$ & $\begin{array}{c}10.39 \pm 0.73 \\
(9.2-12.4)\end{array}$ & $\begin{array}{c}69.23 \pm 3.88 \\
(62.6-79.4)\end{array}$ & $\begin{array}{c}55.35 \pm 3.33 \\
(51-63)\end{array}$ & $\begin{array}{c}253.73 \pm 10.42 \\
(235-275)\end{array}$ & $\begin{array}{c}297.85 \pm 24.68 \\
(225-353)\end{array}$ \\
\hline $\begin{array}{c}16 \text { (MA4) } \\
(n=13)\end{array}$ & $\begin{array}{c}27.49 \pm 1.49 \\
(25.2-29.9)\end{array}$ & $\begin{array}{c}20.65 \pm 1.16 \\
(18.5-23.1)\end{array}$ & $\begin{array}{l}9.1 \pm 0.74 \\
(8.3-11.1)\end{array}$ & $\begin{array}{c}10.08 \pm 0.79 \\
(9.3-12.0)\end{array}$ & $\begin{array}{c}72.19 \pm 2.46 \\
(68.2-75.4)\end{array}$ & $\begin{array}{c}55.92 \pm 2.32 \\
(52-60)\end{array}$ & $\begin{array}{c}252.54 \pm 12.15 \\
\quad(232-269)\end{array}$ & $\begin{array}{c}312.08 \pm 9.32 \\
(295-329)\end{array}$ \\
\hline $\begin{array}{c}17 \text { (MA5) } \\
(n=31)\end{array}$ & $\begin{array}{c}27.82 \pm 1.63 \\
(24.2-30.7)\end{array}$ & $\begin{array}{c}20.71 \pm 1.57 \\
(16.8-24.0)\end{array}$ & $\begin{array}{c}9.78 \pm 0.96 \\
(8.2-12.0)\end{array}$ & $\begin{array}{c}10.85 \pm 0.87 \\
(9.3-12.2)\end{array}$ & $\begin{array}{l}72.1 \pm 4.74 \\
(62.2-83.1)\end{array}$ & $\begin{array}{c}55.26 \pm 3.15 \\
(48-65)\end{array}$ & $\begin{array}{c}253.13 \pm 15.01 \\
\quad(215-283)\end{array}$ & $\begin{array}{c}304.19 \pm 23.92 \\
(253-345)\end{array}$ \\
\hline $\begin{array}{c}18 \text { (MA6) } \\
(n=24)\end{array}$ & $\begin{array}{c}26.93 \pm 1.47 \\
(24.0-28.9)\end{array}$ & $\begin{array}{c}20.41 \pm 1.37 \\
(18.5-23.2)\end{array}$ & $\begin{array}{c}10.4(n=2) \\
(10.3-10.5)\end{array}$ & $\begin{array}{l}10.45(n=2) \\
(10.2-10.7)\end{array}$ & $\begin{array}{c}75.54 \pm 3.33 \\
(66.1-80.8)\end{array}$ & $\begin{array}{c}57.79 \pm 3.54 \\
(49-63)\end{array}$ & $\begin{array}{c}268.58 \pm 10.55 \\
(246-290)\end{array}$ & $\begin{array}{c}311.12 \pm 20.70 \\
(246-334)\end{array}$ \\
\hline
\end{tabular}

* AM=Amazônia, $\mathrm{CA}=$ Caatinga, $\mathrm{PA}=$ Pantanal, $\mathrm{CE}=$ Cerrado, MA=Mata Atlântica. 
Com a finalidade de testar a normalidade para cada variável dentro de cada grupo geográfico, inicialmente se testou a assimetria e curtose, que são interpretados em conjunto para entender como os dados estão espalhados horizontal e verticalmente, respectivamente. Também se empregaram os testes de Shapiro-Wilk e Kolmogorov-Smirnov com a correção de Lilliefors, e para ambos casos quando $\mathrm{p}<0.05$, a distribuição não é normal. Na Tabela 5, quando os resultados de pelo menos dois testes mostraram que a distribuição não é normal, se interpretou com maior suporte que a variável não se distribui normalmente, obtendo assim mais de um critério para validar nossa interpretação.

Tabela 5. Resultados das provas empregadas para testar a Distribuição Normal de cada variável em cada grupo geográfico.

\begin{tabular}{|c|c|c|c|c|c|c|}
\hline Grupo & Estrutura & Assimetria & Curtose & Shapiro Wilk Test & Lilliefors Test & $\begin{array}{c}\text { Dist. } \\
\text { Normal }\end{array}$ \\
\hline \multirow{8}{*}{$\begin{array}{c}1 \\
\text { AM1 } \\
(n=6)\end{array}$} & Bico & -0.43 & 2.67 & $W=0.94 / P=0.67$ & $D=0.22 / P=0.46$ & $\mathrm{SI}$ \\
\hline & Narina & 0.52 & 1.52 & $W=0.84 / P=0.12$ & $D=0.29 / P=0.12$ & $\mathrm{SI}$ \\
\hline & Largura & 1.02 & 2.49 & $W=0.82 / P=0.11$ & $D=0.26 / P=0.32$ & $\mathrm{SI}$ \\
\hline & Altura & 0.12 & 1.27 & $W=0.85 / P=0.20$ & $D=0.23 / P=0.50$ & $\mathrm{SI}$ \\
\hline & Tarso & 1.20 & 2.96 & $W=0.80 / P=0.06$ & $D=0.28 / P=0.14$ & $\mathrm{SI}$ \\
\hline & Dedo & 0.05 & 1.62 & $W=0.90 / P=0.39$ & $D=0.21 / P=0.58$ & $\mathrm{SI}$ \\
\hline & Asa & -1.09 & 2.80 & $W=0.83 / P=0.11$ & $D=0.33 / P=0.04$ & NO \\
\hline & Cauda & -0.43 & 1.72 & $W=0.91 / P=0.44$ & $D=0.23 / P=0.38$ & $\mathrm{SI}$ \\
\hline \multirow{6}{*}{$\begin{array}{c}2 \\
\text { AM2 } \\
(n=55)\end{array}$} & Bico & 0.29 & 2.95 & $W=0.97 / P=0.29$ & $D=0.09 / P=0.27$ & SI \\
\hline & Narina & 0.23 & 2.87 & $W=0.99 / P=0.89$ & $D=0.06 / P=0.93$ & $\mathrm{SI}$ \\
\hline & Largura & 0.58 & 3.11 & $W=0.97 / P=0.19$ & $D=0.10 / P=0.16$ & $\mathrm{SI}$ \\
\hline & Altura & 0.03 & 2.26 & $W=0.98 / P=0.48$ & $D=0.06 / P=0.93$ & SI \\
\hline & Tarso & -0.72 & 3.63 & $W=0.96 / P=0.10$ & $D=0.10 / P=0.20$ & SI \\
\hline & Dedo & 0.25 & 4.06 & $W=0.95 / P=0.02$ & $D=0.19 / P=2.78^{-5}$ & NO \\
\hline
\end{tabular}




\begin{tabular}{|c|c|c|c|c|c|c|}
\hline & Asa & 0.31 & 2.88 & $W=0.98 / P=0.62$ & $D=0.07 / P=0.63$ & SI \\
\hline & Cauda & 0.008 & 2.92 & $W=0.98 / P=0.52$ & $D=0.08 / P=0.42$ & $\mathrm{SI}$ \\
\hline \multirow{8}{*}{$\begin{array}{c}3 \\
\text { AM3 } \\
(n=25)\end{array}$} & Bico & -0.52 & 3.64 & $W=0.97 / P=0.55$ & $D=0.14 / P=0.27$ & $\mathrm{SI}$ \\
\hline & Narina & -0.25 & 2.84 & $W=0.98 / P=0.90$ & $D=0.08 / P=0.94$ & $\mathrm{SI}$ \\
\hline & Largura & 0.09 & 3.26 & $W=0.98 / P=0.92$ & $D=0.12 / P=0.52$ & SI \\
\hline & Altura & 0.15 & 2.13 & $W=0.97 / P=0.59$ & $D=0.13 / P=0.32$ & $\mathrm{SI}$ \\
\hline & Tarso & -1.22 & 4.42 & $W=0.88 / P=0.009$ & $D=0.16 / P=0.09$ & NO \\
\hline & Dedo & -0.39 & 2.00 & $W=0.92 / P=0.07$ & $D=0.19 / P=0.02$ & NO \\
\hline & Asa & 0.07 & 2.52 & $W=0.98 / P=0.96$ & $D=0.09 / P=0.84$ & SI \\
\hline & Cauda & 0.46 & 3.57 & $W=0.94 / P=0.20$ & $D=0.20 / P=0.01$ & NO? \\
\hline \multirow{8}{*}{$\begin{array}{c}4 \\
\text { AM4 } \\
(n=27)\end{array}$} & Bico & -0.47 & 2.98 & $W=0.96 / P=0.46$ & $D=0.13 / P=0.32$ & $\mathrm{SI}$ \\
\hline & Narina & 0.03 & 3.22 & $W=0.98 / P=0.96$ & $D=0.09 / P=0.78$ & SI \\
\hline & Largura & 0.39 & 2.53 & $W=0.96 / P=0.37$ & $D=0.13 / P=0.24$ & SI \\
\hline & Altura & 0.19 & 3.26 & $W=0.95 / P=0.27$ & $D=0.12 / P=0.34$ & $\mathrm{SI}$ \\
\hline & Tarso & -0.13 & 1.88 & $W=0.96 / P=0.47$ & $D=0.14 / P=0.28$ & $\mathrm{SI}$ \\
\hline & Dedo & 0.40 & 2.26 & $W=0.95 / P=0.24$ & $D=0.14 / P=0.26$ & SI \\
\hline & Asa & -0.39 & 2.46 & $W=0.95 / P=0.32$ & $D=0.11 / P=0.57$ & SI \\
\hline & Cauda & -0.43 & 2.40 & $W=0.96 / P=0.35$ & $D=0.12 / P=0.39$ & SI \\
\hline \multirow{8}{*}{$\begin{array}{c}6 \\
C A \\
(n=5)\end{array}$} & Bico & 0.47 & 2.21 & $W=0.97 / P=0.85$ & $D=0.21 / P=0.67$ & SI \\
\hline & Narina & 0.41 & 1.90 & $W=0.96 / P=0.81$ & $D=0.17 / P=0.88$ & $\mathrm{SI}$ \\
\hline & Largura & -0.26 & 1.74 & $W=0.96 / P=0.80$ & $D=0.23 / P=0.50$ & $\mathrm{SI}$ \\
\hline & Altura & -1.17 & 2.79 & $W=0.81 / P=0.11$ & $D=0.28 / P=0.21$ & $\mathrm{SI}$ \\
\hline & Tarso & 0.35 & 1.39 & $W=0.88 / P=0.33$ & $D=0.29 / P=0.19$ & $\mathrm{SI}$ \\
\hline & Dedo & -1.02 & 2.65 & $W=0.86 / P=0.22$ & $D=0.26 / P=0.31$ & $\mathrm{SI}$ \\
\hline & Asa & -0.06 & 2.39 & $W=0.95 / P=0.72$ & $D=0.25 / P=0.35$ & $\mathrm{SI}$ \\
\hline & Cauda & -0.26 & 1.35 & $W=0.87 / P=0.25$ & $D=0.22 / P=0.58$ & $\mathrm{SI}$ \\
\hline \multirow{5}{*}{$\begin{array}{c}7 \\
\text { PA } \\
(n=6)\end{array}$} & Bico & -0.05 & 1.50 & $W=0.89 / P=0.39$ & $D=0.24 / P=0.42$ & SI \\
\hline & Narina & -0.47 & 1.45 & $W=0.85 / P=0.20$ & $D=0.28 / P=0.20$ & SI \\
\hline & Largura & -0.09 & 1.15 & $W=0.86 / P=0.27$ & $\mathrm{~N}<4$ & SI \\
\hline & Altura & 0.54 & 2 & $W=0.95 / P=0.73$ & $\mathrm{~N}<4$ & SI \\
\hline & Tarso & 0.67 & 2.15 & $W=0.91 / P=0.44$ & $D=0.17 / P=0.83$ & $\mathrm{SI}$ \\
\hline
\end{tabular}




\begin{tabular}{|c|c|c|c|c|c|c|}
\hline & Dedo & 0.34 & 1.42 & $W=0.85 / P=0.15$ & $D=0.26 / P=0.25$ & $\mathrm{SI}$ \\
\hline & Asa & 0.06 & 2.13 & $W=0.98 / P=0.95$ & $D=0.19 / P=0.68$ & $\mathrm{SI}$ \\
\hline & Cauda & -0.08 & 1.85 & $W=0.93 / P=0.55$ & $D=0.22 / P=0.49$ & $\mathrm{SI}$ \\
\hline \multirow{8}{*}{$\begin{array}{c}8 \\
\text { CE1 } \\
(n=10)\end{array}$} & Bico & -0.09 & 1.86 & $W=0.96 / P=0.78$ & $D=0.14 / P=0.82$ & $\mathrm{SI}$ \\
\hline & Narina & 0.47 & 2.66 & $W=0.94 / P=0.59$ & $D=0.23 / P=0.13$ & $\mathrm{SI}$ \\
\hline & Largura & -0.16 & 1.74 & $W=0.93 / P=0.51$ & $D=0.17 / P=0.59$ & $\mathrm{SI}$ \\
\hline & Altura & -0.21 & 1.89 & $W=0.93 / P=0.48$ & $D=0.16 / P=0.65$ & $\mathrm{SI}$ \\
\hline & Tarso & -1.02 & 3.63 & $W=0.91 / P=0.30$ & $D=0.24 / P=0.10$ & $\mathrm{SI}$ \\
\hline & Dedo & -0.24 & 1.62 & $W=0.89 / P=0.18$ & $D=0.16 / P=0.62$ & $\mathrm{SI}$ \\
\hline & Asa & 0.06 & 1.92 & $W=0.91 / P=0.26$ & $D=0.18 / P=0.46$ & $\mathrm{SI}$ \\
\hline & Cauda & -0.38 & 2.76 & $W=0.95 / P=0.68$ & $D=0.19 / P=0.40$ & $\mathrm{SI}$ \\
\hline \multirow{8}{*}{$\begin{array}{c}9 \\
\text { CE2 } \\
(n=14)\end{array}$} & Bico & 0.14 & 2.83 & $W=0.98 / P=0.99$ & $D=0.11 / P=0.95$ & $\mathrm{SI}$ \\
\hline & Narina & 0.95 & 2.79 & $W=0.89 / P=0.09$ & $D=0.22 / P=0.08$ & $\mathrm{SI}$ \\
\hline & Largura & -0.04 & 1.74 & $W=0.94 / P=0.49$ & $D=0.15 / P=0.62$ & $\mathrm{SI}$ \\
\hline & Altura & -0.23 & 1.88 & $W=0.94 / P=0.50$ & $D=0.12 / P=0.83$ & $\mathrm{SI}$ \\
\hline & Tarso & 0.40 & 1.89 & $W=0.93 / P=0.37$ & $D=0.20 / P=0.17$ & $\mathrm{SI}$ \\
\hline & Dedo & -1.61 & 6.20 & $W=0.83 / P=0.01$ & $D=0.21 / P=0.10$ & NO \\
\hline & Asa & -0.92 & 3.33 & $W=0.92 / P=0.23$ & $D=0.17 / P=0.32$ & $\mathrm{SI}$ \\
\hline & Cauda & 0.83 & 2.81 & $W=0.90 / P=0.12$ & $D=0.17 / P=0.35$ & $\mathrm{SI}$ \\
\hline \multirow{8}{*}{$\begin{array}{c}10 \\
\text { CE3 } \\
(n=33)\end{array}$} & Bico & -0.27 & 3.66 & $W=0.97 / P=0.59$ & $D=0.12 / P=0.27$ & $\mathrm{SI}$ \\
\hline & Narina & 0.69 & 2.88 & $W=0.95 / P=0.14$ & $D=0.11 / P=0.35$ & $\mathrm{SI}$ \\
\hline & Largura & 0.05 & 3.82 & $W=0.94 / P=0.05$ & $D=0.15 / P=0.04$ & NO \\
\hline & Altura & 0.24 & 3.12 & $W=0.96 / P=0.23$ & $D=0.14 / P=0.07$ & $\mathrm{SI}$ \\
\hline & Tarso & 0.29 & 2.99 & $W=0.98 / P=0.78$ & $D=0.09 / P=0.62$ & $\mathrm{SI}$ \\
\hline & Dedo & -0.23 & 2.44 & $W=0.95 / P=0.16$ & $D=0.13 / P=0.12$ & $\mathrm{SI}$ \\
\hline & Asa & -0.62 & 4.03 & $W=0.94 / P=0.09$ & $D=0.15 / P=0.05$ & $\mathrm{SI}$ \\
\hline & Cauda & 0.53 & 2.73 & $W=0.96 / P=0.27$ & $D=0.16 / P=0.03$ & NO \\
\hline \multirow{4}{*}{$\begin{array}{c}11 \\
\text { CE4 }\end{array}$} & Bico & -0.45 & 2.94 & $W=0.94 / P=0.69$ & $D=0.25 / P=0.22$ & $\mathrm{SI}$ \\
\hline & Narina & -0.45 & 2.43 & $W=0.94 / P=0.69$ & $D=0.21 / P=0.49$ & $\mathrm{SI}$ \\
\hline & Largura & 0.26 & 2.13 & $W=0.92 / P=0.45$ & $D=0.24 / P=0.23$ & $\mathrm{SI}$ \\
\hline & Altura & 0.02 & 1.44 & $W=0.89 / P=0.27$ & $D=0.22 / P=0.36$ & $\mathrm{SI}$ \\
\hline
\end{tabular}




\begin{tabular}{|c|c|c|c|c|c|c|}
\hline \multirow[t]{4}{*}{$(n=7)$} & Tarso & 1.22 & 3.51 & $W=0.86 / P=0.15$ & $D=0.24 / P=0.27$ & SI \\
\hline & Dedo & 1.18 & 3.33 & $W=0.85 / P=0.12$ & $D=0.20 / P=0.55$ & $\mathrm{SI}$ \\
\hline & Asa & -1.13 & 3.37 & $W=0.87 / P=0.20$ & $D=0.22 / P=0.40$ & SI \\
\hline & Cauda & -0.14 & 2.62 & $W=0.97 / P=0.89$ & $D=0.19 / P=0.64$ & $\mathrm{SI}$ \\
\hline \multirow{8}{*}{$\begin{array}{c}12 \\
\text { CE5 } \\
(n=9)\end{array}$} & Bico & -0.05 & 2.83 & $W=0.85 / P=0.08$ & $D=0.31 / P=0.01$ & NO \\
\hline & Narina & -0.75 & 2.15 & $W=0.87 / P=0.12$ & $D=0.22 / P=0.23$ & $\mathrm{SI}$ \\
\hline & Largura & -1.22 & 3.71 & $W=0.88 / P=0.14$ & $D=0.24 / P=0.12$ & $\mathrm{SI}$ \\
\hline & Altura & -0.55 & 2.72 & $W=0.96 / P=0.85$ & $D=0.14 / P=0.88$ & $\mathrm{SI}$ \\
\hline & Tarso & -0.31 & 3.32 & $W=0.79 / P=0.01$ & $D=0.32 / P=0.007$ & NO \\
\hline & Dedo & -0.62 & 2.36 & $W=0.91 / P=0.35$ & $D=0.18 / P=0.52$ & $\mathrm{SI}$ \\
\hline & Asa & -0.74 & 2.69 & $W=0.93 / P=0.49$ & $D=0.17 / P=0.56$ & $\mathrm{SI}$ \\
\hline & Cauda & -0.35 & 2.05 & $W=0.93 / P=0.48$ & $D=0.16 / P=0.69$ & $\mathrm{SI}$ \\
\hline \multirow{8}{*}{$\begin{array}{c}14 \\
\text { MA2 } \\
(n=8)\end{array}$} & Bico & 0.82 & 2. 85 & $W=0.94 / P=0.57$ & $D=0.18 / P=0.62$ & SI \\
\hline & Narina & 0.86 & 3.28 & $W=0.90 / P=0.29$ & $D=0.22 / P=0.30$ & SI \\
\hline & Largura & 0.57 & 2.01 & $W=0.92 / P=0.41$ & $D=0.24 / P=0.16$ & SI \\
\hline & Altura & 0.80 & 3.09 & $W=0.92 / P=0.44$ & $D=0.22 / P=0.32$ & SI \\
\hline & Tarso & 0.32 & 1.81 & $W=0.94 / P=0.64$ & $D=0.20 / P=0.43$ & SI \\
\hline & Dedo & -0.49 & 2.08 & $W=0.90 / P=0.30$ & $D=0.23 / P=0.24$ & SI \\
\hline & Asa & -0.46 & 1.95 & $W=0.92 / P=0.43$ & $D=0.23 / P=0.22$ & $\mathrm{SI}$ \\
\hline & Cauda & 0.39 & 1.75 & $W=0.94 / P=0.57$ & $D=0.20 / P=0.47$ & SI \\
\hline \multirow{8}{*}{$\begin{array}{c}15 \\
\text { MA3 } \\
(n=26)\end{array}$} & Bico & -0.68 & 2.03 & $W=0.85 / P=0.001$ & $D=0.26 / P=8.19^{-5}$ & NO \\
\hline & Narina & 0.13 & 2.82 & $W=0.98 / P=0.84$ & $D=0.10 / P=0.77$ & SI \\
\hline & Largura & -0.62 & 3.12 & $W=0.96 / P=0.40$ & $D=0.14 / P=0.19$ & $\mathrm{SI}$ \\
\hline & Altura & 0.67 & 3.65 & $W=0.95 / P=0.33$ & $D=0.13 / P=0.24$ & $\mathrm{SI}$ \\
\hline & Tarso & 0.68 & 3.87 & $W=0.93 / P=0.08$ & $D=0.17 / P=0.05$ & $\mathrm{SI}$ \\
\hline & Dedo & 0.74 & 2.63 & $W=0.92 / P=0.06$ & $D=0.16 / P=0.10$ & $\mathrm{SI}$ \\
\hline & Asa & 0.36 & 2.60 & $W=0.97 / P=0.54$ & $D=0.14 / P=0.18$ & $\mathrm{SI}$ \\
\hline & Cauda & -0.59 & 4.99 & $W=0.93 / P=0.11$ & $D=0.14 / P=0.17$ & SI \\
\hline \multirow[b]{3}{*}{16} & Bico & 0.15 & 1.94 & $W=0.93 / P=0.33$ & $D=0.21 / P=0.12$ & SI \\
\hline & Narina & 0.33 & 3.15 & $W=0.98 / P=0.96$ & $D=0.13 / P=0.76$ & $\mathrm{SI}$ \\
\hline & Largura & 1.54 & 5.21 & $W=0.84 / P=0.02$ & $D=0.21 / P=0.10$ & NO \\
\hline
\end{tabular}




\begin{tabular}{|c|c|c|c|c|c|c|}
\hline \multirow{5}{*}{$\begin{array}{c}\text { MA4 } \\
(n=13)\end{array}$} & Altura & 1.16 & 3.54 & $W=0.86 / P=0.03$ & $D=0.22 / P=0.07$ & NO \\
\hline & Tarso & -0.32 & 1.77 & $W=0.91 / P=0.22$ & $D=0.21 / P=0.11$ & $\mathrm{SI}$ \\
\hline & Dedo & 0.14 & 2.25 & $W=0.96 / P=0.85$ & $D=0.18 / P=0.30$ & SI \\
\hline & Asa & -0.17 & 1.96 & $W=0.94 / P=0.54$ & $D=0.12 / P=0.88$ & SI \\
\hline & Cauda & 0.05 & 2.39 & $W=0.97 / P=0.93$ & $D=0.17 / P=0.40$ & SI \\
\hline \multirow{8}{*}{$\begin{array}{c}17 \\
\text { MA5 } \\
(n=31)\end{array}$} & Bico & -0.35 & 2.43 & $W=0.96 / P=0.37$ & $D=0.18 / P=0.01$ & NO \\
\hline & Narina & -0.41 & 3.23 & $W=0.97 / P=0.68$ & $D=0.14 / P=0.14$ & $\mathrm{SI}$ \\
\hline & Largura & 0.49 & 2.67 & $W=0.96 / P=0.26$ & $D=0.14 / P=0.14$ & $\mathrm{SI}$ \\
\hline & Altura & -0.19 & 1.99 & $W=0.95 / P=0.15$ & $D=0.14 / P=0.15$ & SI \\
\hline & Tarso & -0.12 & 2.73 & $W=0.98 / P=0.79$ & $D=0.10 / P=0.55$ & $\mathrm{SI}$ \\
\hline & Dedo & 0.47 & 4.66 & $W=0.95 / P=0.14$ & $D=0.13 / P=0.22$ & $\mathrm{SI}$ \\
\hline & Asa & -0.36 & 3.00 & $W=0.98 / P=0.90$ & $D=0.08 / P=0.90$ & $\mathrm{SI}$ \\
\hline & Cauda & -0.50 & 2.67 & $W=0.96 / P=0.25$ & $D=0.11 / P=0.45$ & SI \\
\hline \multirow{6}{*}{$\begin{array}{c}18 \\
\text { MA6 } \\
(n=24)\end{array}$} & Bico & -0.53 & 2.19 & $W=0.93 / P=0.12$ & $D=0.10 / P=0.74$ & $\mathrm{SI}$ \\
\hline & Narina & 0.52 & 2.18 & $W=0.94 / P=0.17$ & $D=0.13 / P=0.38$ & $\mathrm{SI}$ \\
\hline & Tarso & -0.78 & 3.86 & $W=0.95 / P=0.24$ & $D=0.13 / P=0.34$ & $\mathrm{SI}$ \\
\hline & Dedo & -0.85 & 3.10 & $W=0.92 / P=0.05$ & $D=0.19 / P=0.02$ & NO \\
\hline & Asa & -0.14 & 2.82 & $W=0.98 / P=0.94$ & $D=0.12 / P=0.45$ & SI \\
\hline & Cauda & -1.35 & 5.04 & $W=0.87 / P=0.006$ & $D=0.15 / P=0.19$ & NO \\
\hline
\end{tabular}

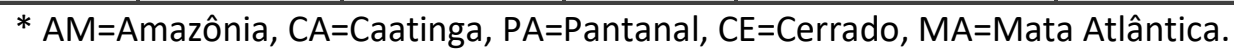


Os testes de normalidade sugerem que a maioria dos dados pertencentes às oito variáveis morfométricas satisfazem os critérios para o uso de testes paramétricos, é por isso que se empregou o teste $t$ de Student, com a finalidade de testar a existência dimorfismo sexual dentro dos grupos geográficos. O teste não foi realizado para os grupos com baixo número amostral, como mínimo foram empregadas populações com 4 indivíduos de cada sexo. Por esse motivo o teste não foi empregado para os grupos geográficos 1 (AM1), 5 (AM5), 6 (CA), 7 (PA), 11 (CE4), 13 (MA1), 14 (MA2).

A hipótese nula do teste é que o valor médio de machos e fêmeas não difere dentro da população, então aplicando isso para cada variável de cada grupo, na Tabela 6 vemos que a grande maioria das médias de ambos sexos não diferem significativamente. Os valores M e F são as médias de Machos e Fêmeas, e apenas em 16 casos de 86 (8 variáveis para cada um dos 11 grupos geográficos com número amostral suficiente) houve diferença significativa. Quando houve dimorfismo sexual, as variáveis foram sombreadas em cada um dos 16 casos, onde os machos eram claramente maiores que as fêmeas, sem exceção. 
Tabela 6. Prova $t$ de student comparando machos e fêmeas de cada grupo geográfico. Áreas sombreadas indicam diferencias significativas entre ambos sexos ( $\mathrm{p}$ < 0.05). T e P valores da prova $t$ de student, $\mathrm{M}$ e F médias de Machos e Fêmeas.

\begin{tabular}{|c|c|c|c|c|c|c|c|c|}
\hline $\begin{array}{c}\text { Grupos } \\
\text { Geográficos }\end{array}$ & $\begin{array}{l}\text { Cúlmen } \\
\text { exposto }\end{array}$ & Bico - Narina & Largura & Altura & Tarso & $\begin{array}{l}\text { Dedo do } \\
\text { meio }\end{array}$ & Asa fechada & Cauda \\
\hline $\begin{array}{c}2=\text { AM2 } \\
\left({ }^{\top}: 34,+: 19\right)\end{array}$ & $\begin{array}{c}\mathrm{T}=-2.409 \\
\mathbf{P}=\mathbf{0 . 0 1 9} \\
(M: 28.84 \\
F: 27.79)\end{array}$ & $\begin{array}{c}T=-1.686 \\
\mathbf{P}=\mathbf{0 . 1 0} \\
(M: 21.29 \\
F: 20.65)\end{array}$ & $\begin{array}{c}\mathrm{T}=-2.424 \\
\mathbf{P}=\mathbf{0 . 0 1 9} \\
(M: 9.76 \\
F: 9.39)\end{array}$ & $\begin{array}{c}T=-3.108 \\
\mathbf{P}=\mathbf{0 . 0 0 3} \\
(M: 10.79 \\
F: 10.10)\end{array}$ & $\begin{array}{c}T=-2.784 \\
\mathbf{P}=\mathbf{0 . 0 0 7} \\
(M: 74.45 \\
F: 72.21)\end{array}$ & $\begin{array}{c}T=-2.936 \\
\mathbf{P}=\mathbf{0 . 0 0 5} \\
(M: 56.20 \\
F: 54.31)\end{array}$ & $\begin{array}{c}T=-3.316 \\
\mathbf{P}=\mathbf{0 . 0 0 2} \\
(M: 258.00 \\
F: 249.89)\end{array}$ & $\begin{array}{c}T=-1.247 \\
\mathbf{P}=\mathbf{0} .218 \\
(M: 303.85 \\
F: 297.68)\end{array}$ \\
\hline $\begin{array}{c}3=\text { AM3 } \\
\left(0^{\top}: 11,+10\right)\end{array}$ & $\begin{array}{c}\mathrm{T}=-0.014 \\
\mathbf{P}=\mathbf{0 . 9 8 8} \\
(M: 27.91 \\
F: 27.90)\end{array}$ & $\begin{array}{c}T=-1.073 \\
\mathbf{P}=0.296 \\
(M: 20.69 \\
F: 20.13)\end{array}$ & $\begin{array}{c}\mathrm{T}=-0.400 \\
\mathbf{P}=0.693 \\
(M: 9.80 \\
F: 9.92)\end{array}$ & $\begin{array}{c}T=-2.843 \\
\mathbf{P}=\mathbf{0} .010 \\
(M: 11.16 \\
F: 10.19)\end{array}$ & $\begin{array}{c}\mathrm{T}=-0.609 \\
\mathbf{P}=\mathbf{0 . 5 5 0} \\
(M: 74.14 \\
F: 73.28)\end{array}$ & $\begin{array}{c}T=-0.771 \\
\mathbf{P}=\mathbf{0 . 4 5 0} \\
(M: 57.5 \\
F: 56.8)\end{array}$ & $\begin{array}{c}T=-1.497 \\
\mathbf{P}=\mathbf{0 . 1 5 1} \\
(M: 256.82 \\
F: 248.60)\end{array}$ & $\begin{array}{c}\mathrm{T}=-3.313 \\
\mathbf{P}=0.004 \\
(M: 311.82 \\
F: 292.30)\end{array}$ \\
\hline $\begin{array}{c}4=\text { AM4 } \\
(\hat{\jmath}: 14,+1: 12)\end{array}$ & $\begin{array}{c}\mathrm{T}=-0.053 \\
\mathbf{P}=\mathbf{0 . 9 5 8} \\
(M: 28.04 \\
F: 28.00)\end{array}$ & $\begin{array}{c}\mathrm{T}=-1.257 \\
\mathbf{P}=\mathbf{0 . 2 2 1} \\
(M: 22.06 \\
F: 21.46)\end{array}$ & $\begin{array}{c}\mathrm{T}=-1.004 \\
\mathbf{P}=\mathbf{0 . 3 2 5} \\
(M: 10.16 \\
F: 9.91)\end{array}$ & $\begin{array}{c}T=-1.808 \\
\mathbf{P}=\mathbf{0 . 0 8 3} \\
(M: 10.79 \\
F: 10.37)\end{array}$ & $\begin{array}{c}T=0.476 \\
\mathbf{P}=\mathbf{0 . 6 3 8} \\
(M: 71.77 \\
F: 72.72)\end{array}$ & $\begin{array}{c}T=0.099 \\
\mathbf{P}=\mathbf{0 . 9 2 1} \\
(M: 55.46 \\
F: 55.60)\end{array}$ & $\begin{array}{c}T=-2.813 \\
\mathbf{P}=0.009 \\
(M: 259.14 \\
F: 248.36)\end{array}$ & $\begin{array}{c}\mathrm{T}=-1.188 \\
\mathbf{P}=0.247 \\
(M: 312.31 \\
F: 303.09)\end{array}$ \\
\hline $\begin{array}{c}8=\text { CE1 } \\
(0: 4, \bigcirc: 5)\end{array}$ & $\begin{array}{c}\mathrm{T}=-1.437 \\
\mathbf{P}=0.194 \\
(M: 28.05 \\
F: 26.52)\end{array}$ & $\begin{array}{c}T=-1.900 \\
\mathbf{P}=0.099 \\
(M: 20.87 \\
F: 18.96)\end{array}$ & $\begin{array}{c}\mathrm{T}=-1.353 \\
\mathbf{P}=\mathbf{0 . 2 1 8} \\
(M: 9.52 \\
F: 8.88)\end{array}$ & $\begin{array}{c}T=-0.020 \\
\mathbf{P}=0.984 \\
(M: 10.55 \\
F: 10.54)\end{array}$ & $\begin{array}{c}T=-2.495 \\
\mathbf{P}=\mathbf{0 . 0 4 1} \\
(M: 72.57 \\
F: 68.88)\end{array}$ & $\begin{array}{c}T=-1.291 \\
\mathbf{P}=\mathbf{0} .238 \\
(M: 54.25 \\
F: 52.40)\end{array}$ & $\begin{array}{c}\mathrm{T}=-1.867 \\
\mathbf{P}=0.104 \\
(M: 246 \\
F: 235)\end{array}$ & $\begin{array}{c}T=-1.456 \\
\mathbf{P}=0.188 \\
(M: 296.75 \\
F: 281.00)\end{array}$ \\
\hline $\begin{array}{c}9=\text { CE2 } \\
\left(\bigcirc^{1}: 8,+9: 6\right)\end{array}$ & $\begin{array}{c}T=-1.546 \\
\mathbf{P}=\mathbf{0 . 1 5 0} \\
(M: 27.68 \\
F: 26.00)\end{array}$ & $\begin{array}{c}T=-1.525 \\
\mathbf{P}=\mathbf{0 . 1 5 5} \\
(M: 20.10 \\
F: 18.82)\end{array}$ & $\begin{array}{c}T=-1.575 \\
\mathbf{P}=\mathbf{0 . 1 4 3} \\
(M: 9.525 \\
F: 9.080)\end{array}$ & $\begin{array}{c}T=-0.391 \\
\mathbf{P}=0.703 \\
(M: 10.77 \\
F: 10.62)\end{array}$ & $\begin{array}{c}T=-2.399 \\
\mathbf{P}=\mathbf{0 . 0 3 5} \\
(M: 71.80 \\
F: 68.42)\end{array}$ & $\begin{array}{c}\mathrm{T}=0.171 \\
\mathbf{P}=\mathbf{0 . 8 6 7} \\
(M: 53.12 \\
F: 53.50)\end{array}$ & $\begin{array}{c}T=-1.074 \\
\mathbf{P}=\mathbf{0 . 3 0 4} \\
(M: 251.50 \\
F: 245.83)\end{array}$ & $\begin{array}{c}T=-0.990 \\
\mathbf{P}=0.342 \\
(M: 311.37 \\
F: 304.16)\end{array}$ \\
\hline
\end{tabular}




\begin{tabular}{|c|c|c|c|c|c|c|c|c|}
\hline $\begin{array}{c}10=\text { CE3 } \\
\left(\begin{array}{l}0 \\
: 15,\end{array}: 14\right)\end{array}$ & $\begin{array}{c}T=-0.147 \\
\mathbf{P}=0.884 \\
(M: 27.33 \\
F: 27.23)\end{array}$ & $\begin{array}{c}T=-1.743 \\
\mathbf{P}=\mathbf{0} .093 \\
(M: 20.40 \\
F: 19.62)\end{array}$ & $\begin{array}{c}\mathrm{T}=-2.382 \\
\mathbf{P}=\mathbf{0 . 0 2 4} \\
(M: 10.10 \\
F: 9.57)\end{array}$ & $\begin{array}{c}T=-2.199 \\
\mathbf{P}=0.036 \\
(M: 10.88 \\
F: 10.29)\end{array}$ & $\begin{array}{c}\mathrm{T}=-1.489 \\
\mathbf{P}=\mathbf{0 . 1 4 8} \\
(M: 71.31 \\
F: 69.28)\end{array}$ & $\begin{array}{c}T=-0.935 \\
\mathbf{P}=\mathbf{0 . 3 5 8} \\
(M: 54.13 \\
F: 53.14)\end{array}$ & $\begin{array}{c}T=-2.878 \\
P=0.007 \\
(M: 250.80 \\
F: 239.14)\end{array}$ & $\begin{array}{c}T=0.097 \\
\mathbf{P}=\mathbf{0 . 9 2 3} \\
(\mathrm{M}: 292.66 \\
F: 293.21)\end{array}$ \\
\hline $\begin{array}{c}12=\text { CE5 } \\
\left(0^{\lambda}: 4,+9: 5\right)\end{array}$ & $\begin{array}{c}T=-1.124 \\
P=0.298 \\
(M: 28.20 \\
F: 26.52)\end{array}$ & $\begin{array}{c}T=-0.955 \\
P=0.371 \\
(M: 20.77 \\
F: 19.64)\end{array}$ & $\begin{array}{c}\mathrm{T}=-0.909 \\
\mathrm{P}=\mathbf{0 . 3 9 3 4} \\
(\mathrm{M}: 10.30 \\
F: 9.72)\end{array}$ & $\begin{array}{c}T=-1.577 \\
\mathbf{P}=\mathbf{0 . 1 5 9} \\
(M: 10.87 \\
F: 10.14)\end{array}$ & $\begin{array}{c}\mathrm{T}=-1.279 \\
\mathbf{P}=\mathbf{0 . 2 4 2} \\
(M: 72.40 \\
F: 65.24)\end{array}$ & $\begin{array}{c}T=-2.575 \\
P=0.036 \\
(M: 58.75 \\
F: 51.60)\end{array}$ & $\begin{array}{c}T=-1.831 \\
\mathbf{P}=\mathbf{0 . 1 0 9} \\
(M: 262.5 \\
F: 239.8)\end{array}$ & $\begin{array}{c}T=-1.108 \\
P=0.305 \\
(M: 310.0 \\
F: 285.8)\end{array}$ \\
\hline $\begin{array}{c}15=\text { MA3 } \\
\left(\delta^{\prime}: 10, \varnothing: 11\right)\end{array}$ & $\begin{array}{c}T=-1.516 \\
P=0.146 \\
(M: 26.81 \\
F: 25.45)\end{array}$ & $\begin{array}{c}T=-1.415 \\
\mathbf{P}=\mathbf{0 . 1 7 3} \\
(M: 20.68 \\
F: 19.89)\end{array}$ & $\begin{array}{c}\mathrm{T}=-1.258 \\
\mathbf{P}=\mathbf{0 . 2 2 5} \\
(M: 9.88 \\
F: 9.46)\end{array}$ & $\begin{array}{c}T=-1.685 \\
\mathbf{P}=\mathbf{0 . 1 0 8} \\
(M: 10.66 \\
F: 10.13)\end{array}$ & $\begin{array}{c}\mathrm{T}=-0.925 \\
\mathbf{P}=0.366 \\
(M: 70.71 \\
F: 69.09)\end{array}$ & $\begin{array}{c}T=-1.717 \\
\mathbf{P}=\mathbf{0 . 1 0 2} \\
(M: 57.30 \\
F: 54.91)\end{array}$ & $\begin{array}{c}T=-1.639 \\
\mathbf{P}=\mathbf{0 . 1 1 7} \\
(\mathrm{M}: 257.40 \\
F: 249.91)\end{array}$ & $\begin{array}{c}T=-0.058 \\
P=0.954 \\
(M: 301.10 \\
F: 300.45)\end{array}$ \\
\hline $\begin{array}{l}16=\text { MA4 } \\
\left(0^{\top}: 4, \bigcirc: 4\right)\end{array}$ & $\begin{array}{c}T=-0.753 \\
P=0.480 \\
(M: 27.22 \\
F: 28.02)\end{array}$ & $\begin{array}{c}T=-0.029 \\
\mathbf{P}=\mathbf{0} .977 \\
(M: 20.47 \\
F: 20.45)\end{array}$ & $\begin{array}{c}T=0.082 \\
P=0.937 \\
(M: 8.95 \\
F: 8.97)\end{array}$ & $\begin{array}{l}T=0.331 \\
\mathbf{P}=\mathbf{0 . 7 5 2} \\
(M: 9.85 \\
F: 10.07)\end{array}$ & $\begin{array}{c}T=1.061 \\
P=0.329 \\
(M: 71.30 \\
F: 72.25)\end{array}$ & $\begin{array}{c}T=0.2 \\
\mathbf{P}=\mathbf{0 . 8 4 8} \\
(M: 55.75 \\
F: 56.00)\end{array}$ & $\begin{array}{c}T=-1.576 \\
P=0.166 \\
(M: 260.5 \\
F: 249.0)\end{array}$ & $\begin{array}{c}T=-0.865 \\
\mathbf{P}=\mathbf{0 . 4 2 0} \\
(\mathrm{M}: 315.75 \\
F: 308.75)\end{array}$ \\
\hline $\begin{array}{c}17=\text { MA5 } \\
(\overbrace{}^{7}: 21, \circ: 10)\end{array}$ & $\begin{array}{c}T=-0.957 \\
P=0.346 \\
(M: 28.01 \\
F: 27.41)\end{array}$ & $\begin{array}{c}T=-1.513 \\
P=0.141 \\
(M: 21.00 \\
F: 20.11)\end{array}$ & $\begin{array}{c}T=-0.596 \\
P=0.555 \\
(M: 9.85 \\
F: 9.63)\end{array}$ & $\begin{array}{c}T=-0.254 \\
P=0.801 \\
(M: 10.87 \\
F: 10.79)\end{array}$ & $\begin{array}{c}\mathrm{T}=-0.971 \\
\mathbf{P}=\mathbf{0 . 3 3 9} \\
(M: 72.67 \\
F: 70.90)\end{array}$ & $\begin{array}{c}T=-0.797 \\
\mathbf{P}=\mathbf{0 . 4 3 2} \\
(M: 55.57 \\
F: 54.60)\end{array}$ & $\begin{array}{c}T=-2.244 \\
P=\mathbf{0 . 0 3 2} \\
(M: 257.05 \\
F: 244.90)\end{array}$ & $\begin{array}{c}T=-0.994 \\
P=0.328 \\
(M: 307.14 \\
F: 298.00)\end{array}$ \\
\hline $\begin{array}{c}18=\text { MA6 } \\
\left(0^{\prime}: 12, q: 5\right)\end{array}$ & $\begin{array}{c}\mathrm{T}=-0.638 \\
\mathbf{P}=\mathbf{0} .533 \\
(M: 26.94 \\
F: 26.48)\end{array}$ & $\begin{array}{c}T=-1.495 \\
\mathbf{P}=\mathbf{0 . 1 5 6} \\
(M: 20.57 \\
F: 19.54)\end{array}$ & - & - & $\begin{array}{c}\mathrm{T}=-1.817 \\
\mathbf{P}=\mathbf{0 . 0 8 9} \\
(M: 75.95 \\
F: 72.78)\end{array}$ & $\begin{array}{c}T=-1.199 \\
\mathbf{P}=\mathbf{0 . 2 4 9} \\
(M: 58.33 \\
F: 56.20)\end{array}$ & $\begin{array}{c}T=-2.775 \\
P=0.014 \\
(M: 271.33 \\
F: 260.00)\end{array}$ & $\begin{array}{c}T=-0.173 \\
P=0.865 \\
(M: 308.83 \\
F: 306.80)\end{array}$ \\
\hline
\end{tabular}

* AM=Amazônia, CA=Caatinga, $\mathrm{PA}=$ Pantanal, $\mathrm{CE}=$ =Cerrado, MA=Mata Atlântica. 
Uma análise multivariada é baseada em múltiplas variáveis que são estruturas medidas em um mesmo indivíduo, estruturas dependentes umas das outras no crescimento, porque nenhuma delas vai crescer independente da outra. É por isso que, além de ter feito as análises estatísticas univariadas básicas, considero mais relevante também testar a morfologia geral do complexo Penelope superciliaris com todas as variáveis morfométricas tomadas em conjunto, como um todo, relacionadas umas com as outras. Então nos testes multivariados se analisaram os indivíduos e suas variáveis em conjunto entre os diferentes grupos geográficos.

O teste $T^{2}$ Hotelling, a contraparte multivariada do teste $\mathrm{t}$ de student, tem como hipótese nula que os vetores das médias dos sexos são iguais. Esse teste foi empregado nos mesmos grupos geográficos testados com o t de Student ( $p>0.05$ ), e mostra que não há dimorfismo sexual nos mesmos grupos.

As Tabelas 7 e 8apresentam os resultados da Análise Discriminante Linear (LDA) aplicado aos 18 grupos geográficos representados porcentual e numericamente, respectivamente. As colunas são os grupos geográficos originais com a totalidade dos indivíduos que eles agrupam, e as fileiras são os indivíduos assignados a cada grupo geográficos pelo LDA; então a diagonal, que tem a área sombreada, indica a frequência de indivíduos que foram reconhecidos como pertencentes ao mesmo grupo prédeterminado, enquanto tudo o que fica fora da diagonal são as frequências de indivíduos que também atendem ao padrão de outros grupos. Apenas 16.5\% (85 indivíduos de um total de 305) de indivíduos foram igualmente assignados dentro do grupo prédeterminado, isso significa que a possibilidade de diferenciar um indivíduo que pertence a um grupo dos outros, por suas medidas em conjunto, é bastante baixa. 
A Figura 7 é o gráfico da Análise de Variáveis Canônicas (CVA) aplicado para os 18 grupos geográficos, explicando as variações entre todos eles de acordo a um teste multivariado. Aproximadamente $97 \%$ da análise é explicada nos dois primeiros eixos (eixo $1=74.09 \%$, eixo $2=23.32 \%$ ). O gráfico mostra que os vetores explicam que as medidas de asa, dedo do meio, tarso e cauda (essa última com menor relevância) têm uma tendência a polarizar as populações do Cerrado e a Mata Atlântica, parecendo ser maiores as populações MA5 e MA6 e menores as populações CE3 e CE5, as duas primeiras do sul do Brasil e norte da Argentina, e as últimas do Centro do Brasil. Na área onde não se polarizam o Cerrado e a Mata Atlântica, também achamos as populações da Amazônia, Caatinga e Pantanal.

Os vetores das medidas do bico (largura, altura, bico-narina e cúlmen exposto), parecem não explicar diferenças entre as populações. Só a largura do bico parece confirmar que as populações MA5 e MA6 são bem polarizadas com as populações CE3 e CE5. 
Tabela 7. Frequência de indivíduos atribuídos a cada grupo geográfico a partir da Análise Discriminante Linear (LDA), representado em porcentagens.

\begin{tabular}{|c|c|c|c|c|c|c|c|c|c|c|c|c|c|c|c|c|c|c|}
\hline Original & $\begin{array}{c}1 \\
\text { AM1 } \\
(\%)\end{array}$ & $\begin{array}{c}2 \\
\text { AM2 } \\
(\%)\end{array}$ & $\begin{array}{c}3 \\
\text { AM3 } \\
(\%) \\
\end{array}$ & $\begin{array}{c}4 \\
\text { AM4 } \\
(\%) \\
\end{array}$ & $\begin{array}{c}5 \\
\text { AM5 } \\
(\%) \\
\end{array}$ & $\begin{array}{c}6 \\
C A \\
(\%) \\
\end{array}$ & $\begin{array}{c}7 \\
\text { PA } \\
(\%) \\
\end{array}$ & $\begin{array}{c}8 \\
\text { CE1 } \\
(\%) \\
\end{array}$ & $\begin{array}{c}9 \\
\text { CE2 } \\
(\%) \\
\end{array}$ & $\begin{array}{l}10 \\
\text { CE3 } \\
(\%) \\
\end{array}$ & $\begin{array}{l}11 \\
\text { CE4 } \\
(\%) \\
\end{array}$ & $\begin{array}{l}12 \\
\text { CE5 } \\
(\%) \\
\end{array}$ & $\begin{array}{c}13 \\
\text { MA1 } \\
(\%)\end{array}$ & $\begin{array}{c}14 \\
\text { MA2 } \\
(\%) \\
\end{array}$ & $\begin{array}{c}15 \\
\text { MA3 } \\
(\%) \\
\end{array}$ & $\begin{array}{c}16 \\
\text { MA4 } \\
(\%) \\
\end{array}$ & $\begin{array}{c}17 \\
\text { MA5 } \\
(\%) \\
\end{array}$ & $\begin{array}{c}18 \\
\text { MA6 } \\
(\%) \\
\end{array}$ \\
\hline $1=\mathrm{AM} 1$ & - & - & - & - & - & - & - & - & - & - & - & - & - & - & - & - & - & - \\
\hline 2 = AM2 & 33.3 & 60 & 40 & 51.9 & - & - & 49.9 & 40 & 14.3 & 18.2 & 42.8 & 22.2 & - & 87.5 & 26.9 & 54 & 38.7 & 16.7 \\
\hline $3=\mathrm{AM} 3$ & - & 9.1 & 16 & 3.7 & - & - & - & - & - & 6.1 & 14.3 & 11.1 & - & - & 3.8 & - & 6.4 & 12.5 \\
\hline 4 = AM4 & - & 9.1 & - & 14.8 & 100 & - & 16.7 & - & - & 3 & - & 11.1 & 33.3 & - & 3.8 & 7.7 & 3.2 & 8.3 \\
\hline 5 = AM5 & - & - & - & 3.7 & - & - & - & 10 & - & 6.1 & - & - & - & - & - & - & - & - \\
\hline $6=C A$ & - & - & - & - & - & 20 & - & - & 7.2 & 3 & - & - & 33.3 & - & 3.8 & - & - & - \\
\hline $7=P A$ & - & - & - & - & - & - & - & - & - & - & - & - & - & - & - & - & - & - \\
\hline $8=\mathrm{CE} 1$ & - & 1.8 & - & - & - & - & 16.7 & - & - & - & - & - & - & - & - & 7.7 & - & - \\
\hline $9=$ CE2 & - & - & 4 & - & - & 60 & 16.7 & - & 21.4 & 3 & - & - & - & - & - & - & - & - \\
\hline $10=$ CE3 & - & - & 8 & - & - & 20 & - & 40 & 14.3 & 42.4 & 28.6 & 22.2 & - & - & 11.5 & - & 16.1 & 4.2 \\
\hline $11=$ CE4 & - & - & - & - & - & - & - & - & - & - & - & - & - & - & - & - & - & - \\
\hline $12=$ CE5 & - & - & 4 & 3.7 & - & - & - & - & - & 3 & - & - & - & - & 3.8 & - & 3.2 & - \\
\hline $13=$ MA1 & - & - & - & - & - & - & - & - & - & 3 & - & 11.1 & - & - & - & - & - & - \\
\hline $14=$ MA2 & - & - & - & - & - & - & - & - & - & - & - & - & - & 12.5 & - & - & - & 4.2 \\
\hline $15=\mathrm{MA} 3$ & - & 1.8 & - & 14.8 & - & - & - & - & 14.3 & 9.1 & - & 11.1 & - & - & 30.8 & 7.7 & 9.7 & 4.2 \\
\hline $16=$ MA4 & - & 3.6 & 4 & - & - & - & - & - & - & - & - & - & - & - & - & 23 & 9.7 & - \\
\hline $17=$ MA5 & 16.7 & 5.5 & 16 & 3.7 & - & - & - & 10 & 21.4 & 3 & 14.3 & - & 33.3 & - & 11.5 & - & 6.4 & - \\
\hline $18=$ MA6 & 50 & 1.8 & 8 & 3.7 & - & - & - & - & 7.1 & - & - & 11.1 & - & - & 3.8 & - & 6.4 & 50 \\
\hline
\end{tabular}

*AM=Amazônia, CA=Caatinga, PA=Pantanal, CE=Cerrado, MA=Mata Atlântica. 
Tabela 8. Número de indivíduos atribuídos a cada grupo geográfico a partir da Análise Discriminante Linear (LDA).

\begin{tabular}{|c|c|c|c|c|c|c|c|c|c|c|c|c|c|c|c|c|c|c|}
\hline $\begin{array}{l}\text { Original } \\
\text { Atribuído }\end{array}$ & $\begin{array}{c}1 \\
\text { AM1 }\end{array}$ & $\begin{array}{c}2 \\
\mathrm{AM} 2\end{array}$ & $\begin{array}{c}3 \\
\text { AM3 }\end{array}$ & $\begin{array}{c}4 \\
\text { AM4 }\end{array}$ & $\begin{array}{c}5 \\
\text { AM5 }\end{array}$ & $\begin{array}{c}6 \\
C A\end{array}$ & $\begin{array}{c}7 \\
\text { PA }\end{array}$ & $\begin{array}{c}8 \\
\text { CE1 }\end{array}$ & $\begin{array}{c}9 \\
\text { CE2 }\end{array}$ & $\begin{array}{c}10 \\
C E 3\end{array}$ & $\begin{array}{c}11 \\
\text { CE4 }\end{array}$ & $\begin{array}{c}12 \\
\text { CE5 }\end{array}$ & $\begin{array}{c}13 \\
\text { MA1 }\end{array}$ & $\begin{array}{c}14 \\
\text { MA2 }\end{array}$ & $\begin{array}{c}15 \\
\text { MA3 }\end{array}$ & $\begin{array}{c}16 \\
\text { MA4 }\end{array}$ & $\begin{array}{c}17 \\
\text { MA5 }\end{array}$ & $\begin{array}{c}18 \\
\text { MA6 }\end{array}$ \\
\hline 1 = AM1 & - & - & - & - & - & - & - & - & - & - & - & - & -- & - & - & - & - & - \\
\hline 2 = AM2 & 2 & 33 & 10 & 14 & - & - & 3 & 4 & 2 & 6 & 3 & 2 & - & 7 & 7 & 7 & 12 & 4 \\
\hline $3=A M 3$ & - & 5 & 4 & 1 & - & - & - & - & - & 2 & 1 & 1 & - & - & 1 & - & 2 & 3 \\
\hline 4 = AM4 & - & 5 & - & 4 & 3 & - & 1 & - & - & 1 & - & 1 & 1 & - & 1 & 1 & 1 & 2 \\
\hline 5 = AM5 & - & - & - & 1 & - & - & - & 1 & - & 2 & - & - & - & - & - & - & - & - \\
\hline $6=C A$ & - & - & - & - & - & 1 & - & - & 1 & 1 & - & - & 1 & - & 1 & - & - & - \\
\hline $7=P A$ & - & - & - & - & - & - & - & - & - & - & - & - & - & - & - & - & - & - \\
\hline 8 = CE1 & - & 1 & - & - & - & - & 1 & - & - & - & - & - & - & - & - & 1 & - & - \\
\hline $9=$ CE2 & - & - & 1 & - & - & 3 & 1 & - & 3 & 1 & - & - & - & - & - & - & - & - \\
\hline $10=$ CE 3 & - & 4 & 2 & - & - & 1 & - & 4 & 2 & 14 & 2 & 2 & - & - & 3 & - & 5 & 1 \\
\hline $11=$ CE4 & - & - & - & - & - & - & - & - & - & - & - & - & - & - & - & - & - & - \\
\hline 12 = CE5 & - & - & 1 & 1 & - & - & - & - & - & 1 & - & - & - & - & 1 & - & 1 & - \\
\hline $13=$ MA1 & - & - & - & - & - & - & - & - & - & 1 & - & 1 & - & - & - & - & - & - \\
\hline $14=$ MA2 & - & - & - & - & - & - & - & - & - & - & - & - & - & 1 & - & - & - & 1 \\
\hline $15=$ MA3 & - & 1 & - & 4 & - & - & - & - & 2 & 3 & - & 1 & - & - & 8 & 1 & 3 & 1 \\
\hline $16=$ MA4 & - & 2 & 1 & - & - & - & - & - & - & - & - & - & - & - & - & 3 & 3 & - \\
\hline 17 = MA5 & 1 & 3 & 4 & 1 & - & - & - & 1 & 3 & 1 & 1 & - & 1 & - & 3 & - & 2 & - \\
\hline $18=$ MA6 & 3 & 1 & 2 & 1 & - & - & - & - & 1 & - & - & 1 & - & - & 1 & - & 2 & 12 \\
\hline TOTAL & 6 & 55 & 25 & 27 & 3 & 5 & 6 & 10 & 14 & 33 & 7 & 9 & 3 & 8 & 26 & 13 & 31 & 24 \\
\hline
\end{tabular}

* AM=Amazônia, CA=Caatinga, PA=Pantanal, CE=Cerrado, MA=Mata Atlântica. 


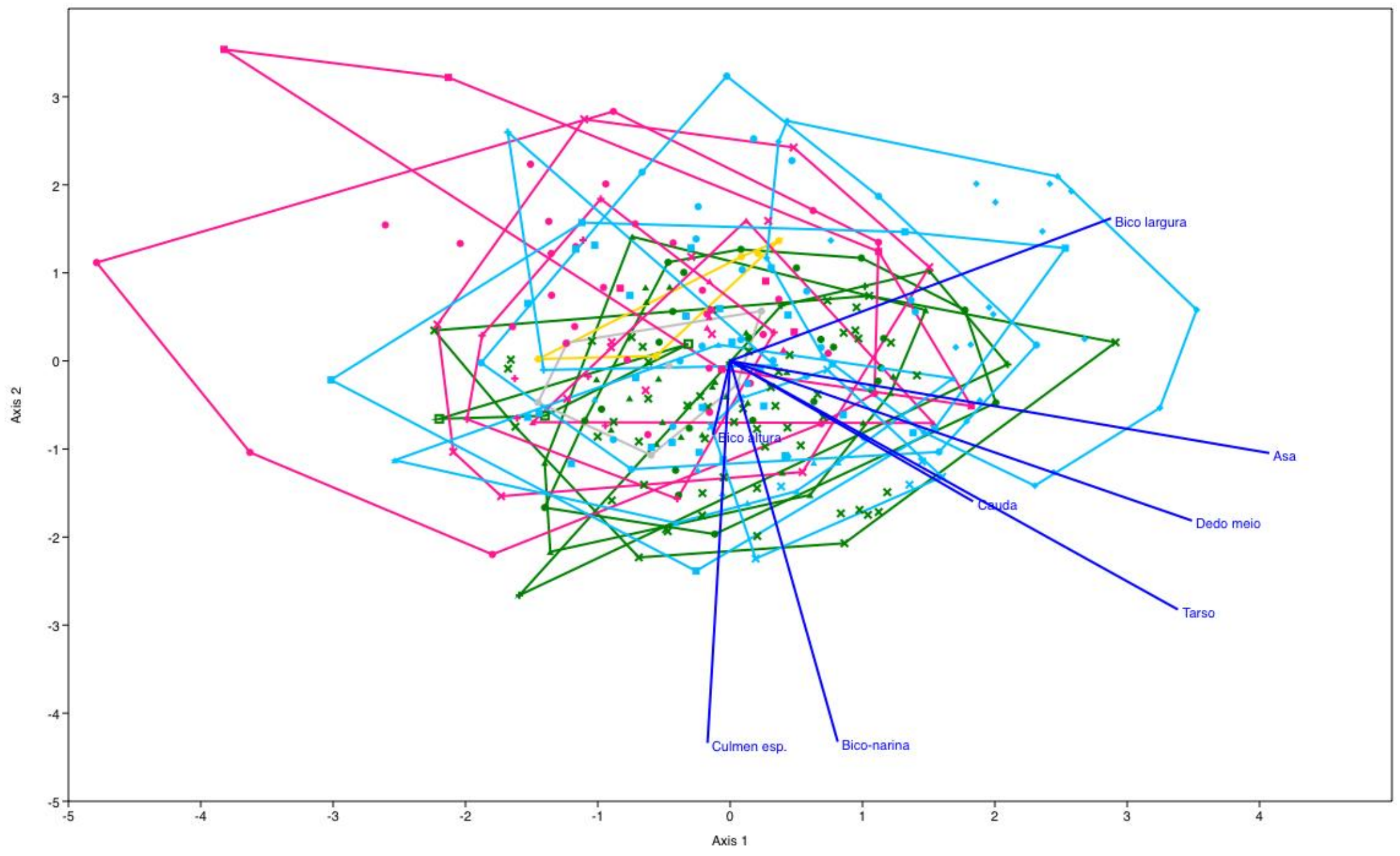

Figura 25. Análise de Variáveis Canônicas (CVA) com vectores que diferenciam os indivíduos dos grupos geográficos por suas diferenças morfométricas. Amazônia, verde (AM1, X; AM2, +; AM3, O; AM4, $\triangle$; AM5, $\square$ ); Caatinga, O amarelo; Pantanal, $\mathbf{O}$ cinza; Cerrado, rosa (CE1, X; CE2, +; CE3, O; CE4, $\Delta$; CE5, $\square$ ); Mata Atlântica, azul (MA1, $X$; MA2, +; MA3, O; MA4, $\Delta$; MA5, $\square$; MA6, 
Conforme visto na Figura 7 os grupos geográficos tendem a se juntar pelo tipo de bioma que ocupam. Assim, se testou o LDA para os indivíduos agrupados pelo tipo de bioma: Amazônia, Caatinga, Pantanal, Cerrado e Mata Atlântica.

As Tabelas 9 e 10, assim como as $\mathbf{7}$ e $\mathbf{8}$, apresentam os resultados do LDA aplicado aos cinco biomas onde ocorre o complexo Penelope superciliaris, e estão representados porcentual e numericamente. As colunas incluem os indivíduos dos biomas originais, e as fileiras os indivíduos assignados pelo LDA; a diagonal sombreada com a frequência de indivíduos reconhecidos como pertencentes ao mesmo grupo pré-determinado tem 149 de um total de 305 indivíduos (33.02\%). A possibilidade de diferenciar um indivíduo que pertence a um grupo dos outros, por suas medidas em conjunto, é bastante baixa.

A Figura 8 que representa o CVA para os biomas, explica aproximadamente 90\% da análise nos dois primeiros eixos (eixo $1=54.81 \%$, eixo $2=34.78 \%$, eixo $3=8.66$ ). No gráfico vemos que as populações estão um pouco mais aglomeradas, que os 5 grupos de biomas se sobrepõem uns aos outros no centro dos eixos. Os indivíduos do Cerrado e a Mata Atlântica estão levemente polarizados pelos vetores da asa e a cauda (em menor relevância), mas não tanto como quando estavam separados nos 18 grupos geográficos. $\mathrm{O}$ vector do dedo do meio parece reforçar que existe uma leve polaridade entre o Cerrado e a Mata Atlântica, mas não tão notoriamente. 
Tabela 9. Frequência de indivíduos atribuídos a cada bioma brasileiro a partir da Análise Discriminante Linear (LDA), representado em porcentagens.

\begin{tabular}{|c|c|c|c|c|c|}
\hline Original & $\begin{array}{c}\text { Amazônia } \\
\text { (\%) }\end{array}$ & $\begin{array}{c}\text { Caatinga } \\
\text { (\%) }\end{array}$ & $\begin{array}{c}\text { Cerrado } \\
\text { (\%) }\end{array}$ & $\begin{array}{c}\text { Mata } \\
\text { Atlântica (\%) }\end{array}$ & $\begin{array}{c}\text { Pantanal } \\
\text { (\%) }\end{array}$ \\
\hline Amazônia & 64.7 & - & 28.8 & 38.1 & 50 \\
\hline Caatinga & - & 20 & 5.5 & 1.9 & - \\
\hline Cerrado & 8.6 & 20 & 35.6 & 15.2 & 33.3 \\
\hline $\begin{array}{c}\text { Mata } \\
\text { Atlântica }\end{array}$ & 26.7 & 60 & 30.1 & 44.8 & 16.7 \\
\hline Pantanal & - & - & - & - & - \\
\hline
\end{tabular}

Tabela 10. Número de indivíduos atribuídos a cada bioma brasileiro a partir da Análise Discriminante Linear (LDA).

\begin{tabular}{|c|c|c|c|c|c|}
\hline Original & Amazônia & Caatinga & Cerrado & $\begin{array}{c}\text { Mata } \\
\text { Atlântica }\end{array}$ & Pantanal \\
\hline Amazốnia & 75 & - & 21 & 40 & 3 \\
\hline Caatinga & - & 1 & 4 & 2 & - \\
\hline Cerrado & 10 & 1 & 26 & 16 & 2 \\
\hline $\begin{array}{c}\text { Mata } \\
\text { Atlântica }\end{array}$ & 31 & 3 & 22 & 47 & 1 \\
\hline Pantanal & 0 & - & - & - & - \\
\hline TOTAL & $\mathbf{1 1 6}$ & $\mathbf{5}$ & $\mathbf{7 3}$ & $\mathbf{1 0 5}$ & $\mathbf{6}$ \\
\hline
\end{tabular}




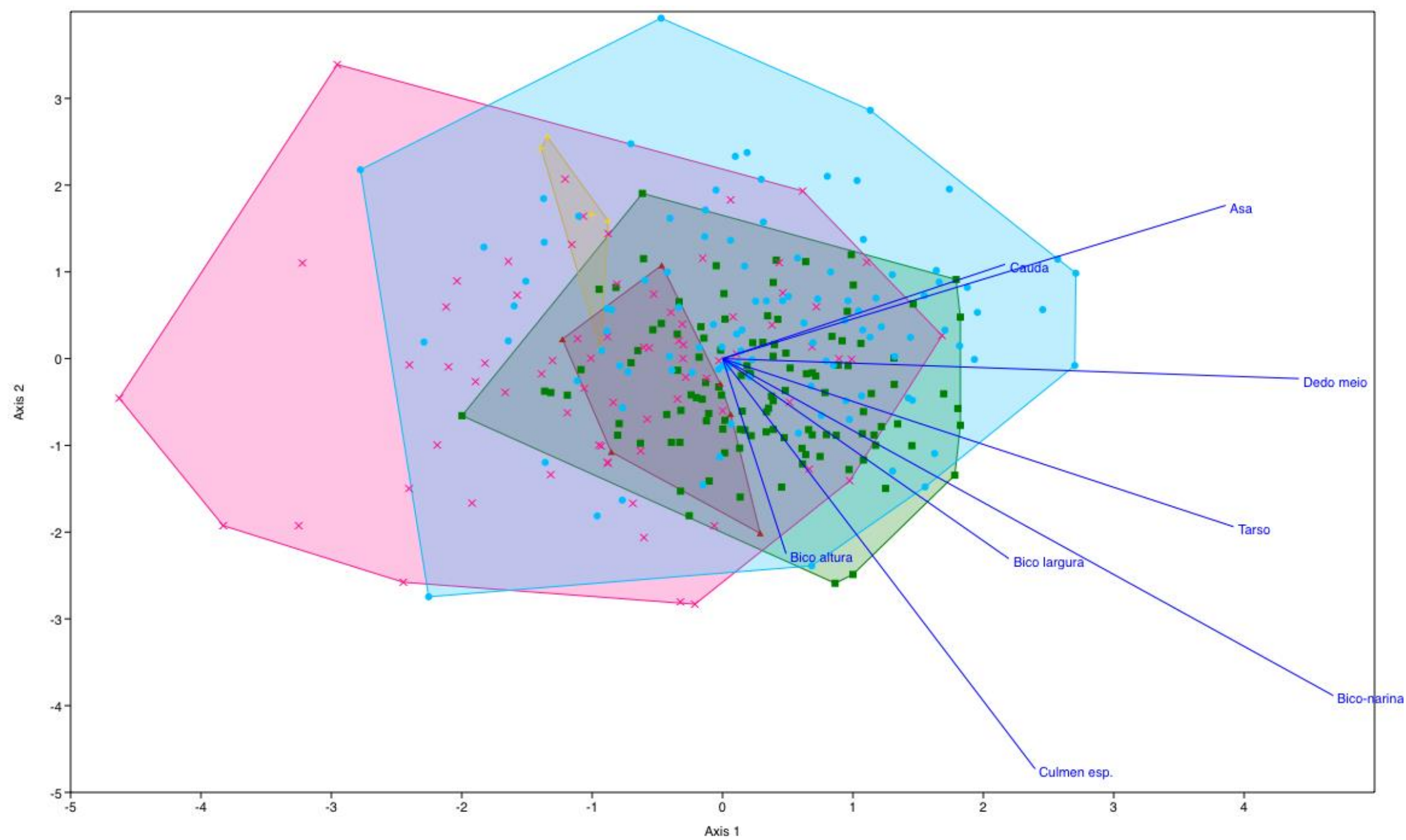

Figura 26. Análise de Variáveis Canônicas (CVA) com vectores que diferenciam os indivíduos dos biomas brasileiros por suas diferenças morfométricas. Cerrado, $\times \quad$ rosa; Amazônia, $\square$ verde; Mata atlântica, Oazul; Caatinga, + amarelo; Pantanal, $\Delta$ marrom. 
Assim, como foram quatro as unidades taxonômicas determinadas pela análise qualitativa, pode-se testar estatisticamente se existem diferenças entre eles $(1=\mathrm{AM} 1,2=$ MA1, 3 = CA+CE2, e 4 = os demais grupos geográficos $).$

Nas Tabelas 11 e 12, novamente as colunas incluem os indivíduos originalmente categorizados como pertencentes as unidades taxonômicas, as linhas os indivíduos assignados pelo LDA, e a diagonal sombreada apresenta a frequência de indivíduos reconhecidos como pertencentes ao mesmo grupo pré-determinado. Os resultados mostram que, apesar de ter poucos exemplares das unidades 1, 2 e 3, eles são facilmente confundíveis com a unidade 4.

Na Figura 9, onde o eixo 1 representa $90 \%$ dos resultados da análise, vemos que pelas medições das estruturas corporais em conjunto não é possível diferenciar os táxons. Só os indivíduos da unidade 1(AM1, verde) mostram uma notória separação com os indivíduos da unidade 2(MA1, azul), isto baseado no tamanho da asa e a altura do bico, e em menor relevância pela cauda e o tarso. Seria bom em um futuro repetir essa prova estatística quando seja possível trabalhar com um $\mathrm{N}$ maior para ambas unidades, para assim confirmar se efetivamente essas duas populações são diferenciáveis entre si. 
Tabela11. Frequência de indivíduos atribuídos a cada unidade taxonômica identificada a partir da Análise Discriminante Linear (LDA), representado em porcentagens.

\begin{tabular}{|c|c|c|c|c|}
\hline $\begin{array}{c}\text { Original } \\
\text { Atribuído }\end{array}$ & $\begin{array}{c}\mathbf{2} \\
(\mathbf{\%})\end{array}$ & $\begin{array}{c}\mathbf{3} \\
\mathbf{( \% )}\end{array}$ & $\begin{array}{c}\mathbf{1} \\
(\mathbf{\%})\end{array}$ & $\begin{array}{c}\mathbf{4} \\
(\mathbf{\%})\end{array}$ \\
\hline $\mathbf{2}$ & - & - & - & 0.4 \\
\hline $\mathbf{3}$ & - & 15.8 & - & 0.7 \\
\hline $\mathbf{1}$ & - & - & - & - \\
\hline $\mathbf{4}$ & 100 & 84.2 & 100 & 98.9 \\
\hline
\end{tabular}

* Grupos geográficos que inclui cada unidade taxonômica: 1 (AM1), 2 (MA1), 3 (CA+CE2) e 4 (com os demais grupos).

Tabela 12. Número de indivíduos atribuídos a cada unidade taxonômica identificada a partir da Análise Discriminante Linear (LDA).

\begin{tabular}{|c|c|c|c|c|}
\hline Original & $\begin{array}{c}\mathbf{2} \\
\text { Atribuído }\end{array}$ & $\begin{array}{c}\mathbf{3} \\
\mathbf{( \% )}\end{array}$ & $\begin{array}{c}\mathbf{1} \\
(\mathbf{\%})\end{array}$ & $\begin{array}{c}\mathbf{4} \\
\mathbf{( \% )}\end{array}$ \\
\hline $\mathbf{2}$ & - & - & - & 1 \\
\hline $\mathbf{3}$ & - & 3 & - & 2 \\
\hline $\mathbf{1}$ & - & - & - & - \\
\hline $\mathbf{4}$ & 3 & 16 & 6 & 274 \\
\hline TOTAL & $\mathbf{3}$ & 19 & $\mathbf{6}$ & $\mathbf{2 7 7}$ \\
\hline
\end{tabular}

* Grupos geográficos que inclui cada unidade taxonômica: 1 (AM1), 2 (MA1), 3 (CA+CE2) e 4 (com os demais grupos). 


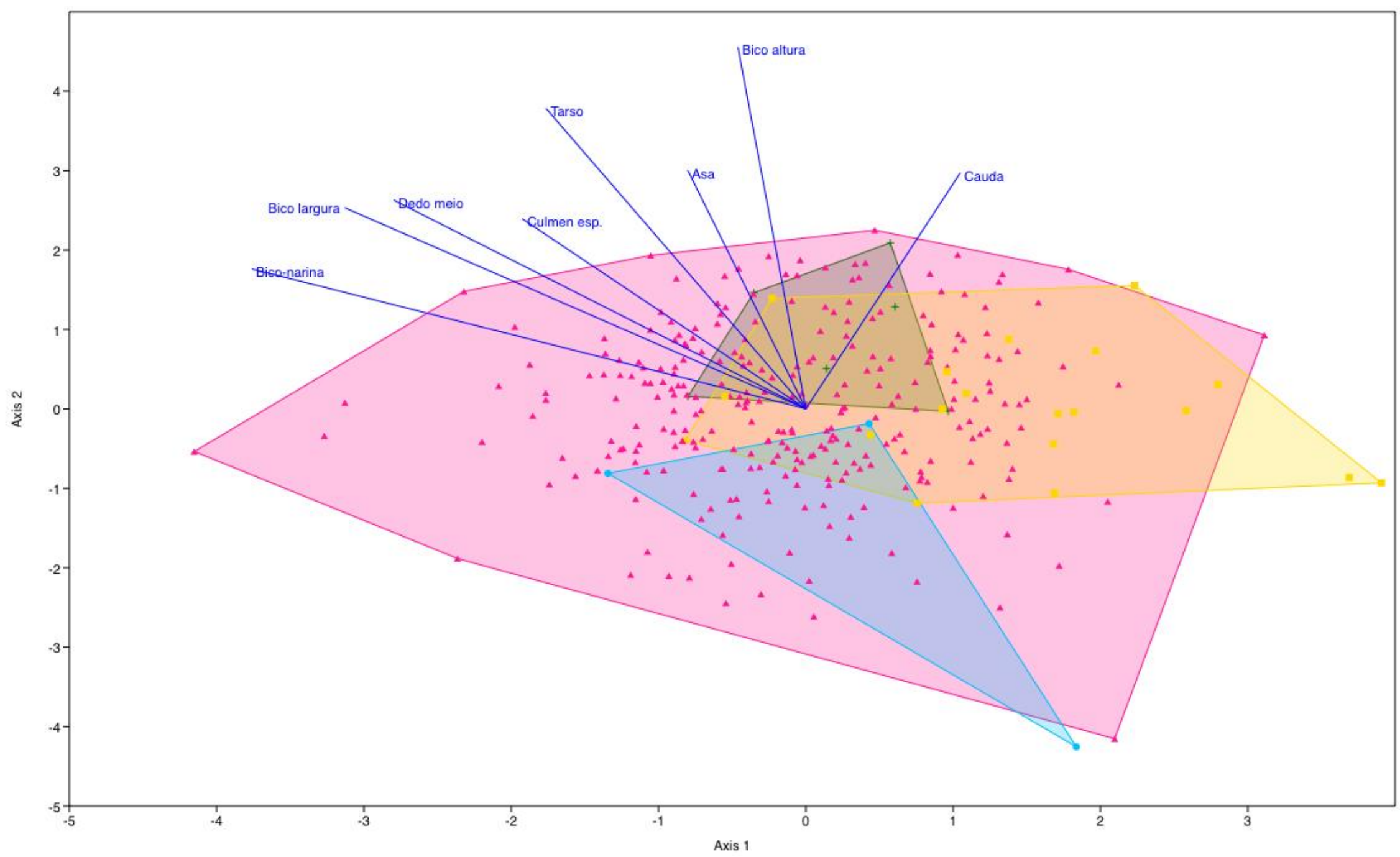

Figura 27. Análise de Variáveis Canônicas (CVA) com vectores que diferenciam morfométricamente os indivíduos das unidades taxonômicas identificadas.; 1 (AM1), + verde; 2 (MA1), $\mathbf{O}$ azul; 3 (CA+CE2), $\square$ amarelo; 4 (demais grupos), $\Delta$ rosa. 


\subsection{Demais dados morfométricos}

Alguns exemplares apresentaram dados adicionais de medidas (Tabela 13). Os dados da tabela foram separados por grupos geográficos, dentro deles por sexo (machos, fêmeas e não determinados), e ordenados de forma decrescente pelo comprimento total. De acordo ao tamanho total, em alguns grupos os machos são maiores que as fêmeas, como em AM1; enquanto na maioria dos outros grupos, apesar de um macho ser maior que a maioria das fêmeas, alguma fêmea pode ser maior que alguns do resto de machos, como no grupo AM4; de acordo a isso podemos dizer que só a primeira unidade taxonômica (AM1, do interflúvio Madeira-Tapajós) é a que aparentemente mostra que os machos são maiores que as fêmeas pelo comprimento total do corpo, enquanto as outras unidades taxonômicas não mostram exclusão suficiente para dizer que os machos são maiores que fêmeas ou viceversa.

A hipótese que eu tinha sobre a segunda unidade taxonômica, que inclui os grupos CA e CE2 da Caatinga e o Cerrado próximo a ela, de que seus integrantes são aparentemente menores que os demais não foi confirmada pela informação apresentada na

Tabela 13. Quando revisei os espécimes de museus, as peles dos indivíduos dessa região davam a impressão de ser menores, mas as poucas medidas corporais não confirmaram essa hipótese.

$\mathrm{O}$ peso não tem relação nenhuma com o sexo dos espécimes, em algumas populações os machos foram mais pesados, em outras as fêmeas, mas sempre com valores bastante próximos; além disso, o peso é totalmente independente do tamanho, porque em 
alguns casos indivíduos de menor comprimento total parecem ser mais pesados que indivíduos maiores, e vice-versa.

Tabela 13. Medidas corporais preenchidas na etiqueta de espécimes de museu revisados, separados por machos ( $\mathrm{M}$, azul), fêmeas ( $\mathrm{F}$, rosa) e não determinados (ND, cinza).

\begin{tabular}{|c|c|c|c|c|c|c|}
\hline GG & Sexo & Número & Peso & $\begin{array}{c}\text { Comp. } \\
\text { total }\end{array}$ & Enverg. & Dados adicionais \\
\hline \multirow{4}{*}{$\begin{array}{c}1 \\
\text { (AM1) }\end{array}$} & $\mathrm{M}$ & MZUSP 86400 & $800 \mathrm{~g}$. & $708 \mathrm{~mm}$ & - & \\
\hline & M & MZUSP 95764 & $850 \mathrm{~g}$. & $702 \mathrm{~mm}$ & - & \\
\hline & $\mathrm{F}$ & MZUSP 86399 & $800 \mathrm{~g}$. & $688 \mathrm{~mm}$ & - & \\
\hline & $\mathrm{F}$ & MZUSP 97239 & $650 \mathrm{~g}$. & $619 \mathrm{~mm}$ & $704 \mathrm{~mm}$ & \\
\hline \multirow{2}{*}{$\begin{array}{c}2 \\
\text { (AM2) }\end{array}$} & $M$ & MZUSP 95546 & - & $665 \mathrm{~mm}$ & - & \\
\hline & M & MZUSP 102973 & - & $613 \mathrm{~mm}$ & - & \\
\hline \multirow{9}{*}{$\begin{array}{c}3 \\
\text { (AM3) }\end{array}$} & $M$ & MPEG 36074 & $976 \mathrm{~g}$. & $630 \mathrm{~mm}$ & - & \\
\hline & $M$ & MPEG 34728 & $850 \mathrm{~g}$. & - & - & \\
\hline & $M$ & MPEG 77030 & $635 \mathrm{~g}$. & $653 \mathrm{~mm}$ & - & \\
\hline & $\mathrm{F}$ & MPEG 37325 & $795 \mathrm{~g}$. & $631 \mathrm{~mm}$ & - & \\
\hline & $\mathrm{F}$ & MPEG 37967 & $760 \mathrm{~g}$. & $625 \mathrm{~mm}$ & - & \\
\hline & $\mathrm{F}$ & MPEG 36476 & - & $610 \mathrm{~mm}$ & - & \\
\hline & $\mathrm{F}$ & MPEG 36716 & - & $610 \mathrm{~mm}$ & - & \\
\hline & ND & MPEG 77031 & $803,1 \mathrm{~g}$. & $645 \mathrm{~mm}$ & - & \\
\hline & ND & MZUSP 77114 & $720 \mathrm{~g}$. & $623 \mathrm{~mm}$ & - & \\
\hline \multirow{10}{*}{$\begin{array}{c}4 \\
\text { (AM4) }\end{array}$} & $M$ & MPEG 48493 & $910 \mathrm{~g}$. & $720 \mathrm{~mm}$ & - & \\
\hline & $M$ & MPEG 48492 & $910 \mathrm{~g}$. & $694 \mathrm{~mm}$ & - & \\
\hline & $\mathrm{M}$ & MZUSP 89851 & $900 \mathrm{~g}$. & $678 \mathrm{~mm}$ & - & \\
\hline & $M$ & MZUSP 81976 & $900 \mathrm{~g}$. & $670 \mathrm{~mm}$ & - & \\
\hline & M & MPEG 57299 & $700 \mathrm{~g}$. & $660 \mathrm{~mm}$ & - & \\
\hline & $\mathrm{F}$ & MZUSP 83731 & $985 \mathrm{~g}$. & $700 \mathrm{~mm}$ & - & \\
\hline & $\mathrm{F}$ & MZUSP 89852 & $780 \mathrm{~g}$. & $675 \mathrm{~mm}$ & - & \\
\hline & $\mathrm{F}$ & MPEG 57300 & $650 \mathrm{~g}$. & $640 \mathrm{~mm}$ & - & \\
\hline & ND & MZUSP 98999 & $800 \mathrm{~g}$. & $615 \mathrm{~mm}$ & $760 \mathrm{~mm}$ & \\
\hline & ND & MPEG 57924 & $620 \mathrm{~g}$. & $610 \mathrm{~mm}$ & - & \\
\hline \multirow{2}{*}{$\begin{array}{c}5 \\
\text { (AM5) }\end{array}$} & $M$ & MNRJ 45027 & $667 \mathrm{~g}$. & $630 \mathrm{~mm}$ & $730 \mathrm{~mm}$ & \\
\hline & $\mathrm{F}$ & MNRJ 36177 & $800 \mathrm{~g}$. & $655 \mathrm{~mm}$ & $740 \mathrm{~mm}$ & \\
\hline \multirow{3}{*}{$\begin{array}{c}6 \\
\text { (CA) }\end{array}$} & $\mathrm{M}$ & MNRJ 36285 & $750 \mathrm{~g}$. & $680 \mathrm{~mm}$ & $780 \mathrm{~mm}$ & \\
\hline & $\mathrm{F}$ & MPEG 67785 & $710 \mathrm{~g}$. & $655 \mathrm{~mm}$ & $710 \mathrm{~mm}$ & \\
\hline & $\mathrm{F}$ & MNRJ 36284 & $690 \mathrm{~g}$. & $620 \mathrm{~mm}$ & $725 \mathrm{~mm}$ & \\
\hline
\end{tabular}




\begin{tabular}{|c|c|c|c|c|c|c|}
\hline & ND & MZUSP 86331 & $650 \mathrm{~g}$. & $652 \mathrm{~mm}$ & $650 \mathrm{~mm}$ & \\
\hline \multirow{2}{*}{$\begin{array}{c}8 \\
\text { (CE1) }\end{array}$} & $\mathrm{M}$ & MPEG 42246 & $760 \mathrm{~g}$. & $657 \mathrm{~mm}$ & - & \\
\hline & ND & MNRJ 47660 & - & $702 \mathrm{~mm}$ & $800 \mathrm{~mm}$ & \\
\hline \multirow{9}{*}{$\begin{array}{c}9 \\
\text { (CE2) }\end{array}$} & $\mathrm{M}$ & MPEG 43386 & $940 \mathrm{~g}$. & $690 \mathrm{~mm}$ & - & \\
\hline & $\mathrm{M}$ & MZUSP 79473 & $750 \mathrm{~g}$. & $695 \mathrm{~mm}$ & - & \\
\hline & $\mathrm{M}$ & MPEG 67786 & $747 \mathrm{~g}$. & $667 \mathrm{~mm}$ & - & \\
\hline & $\mathrm{M}$ & MPEG 45079 & $670 \mathrm{~g}$. & $672 \mathrm{~mm}$ & - & \\
\hline & $\mathrm{M}$ & MZUSP 77637 & $660 \mathrm{~g}$. & $630 \mathrm{~mm}$ & - & \\
\hline & $\mathrm{F}$ & MPEG 43388 & $940 \mathrm{~g}$. & $670 \mathrm{~mm}$ & - & \\
\hline & $\mathrm{F}$ & MPEG 43387 & $704 \mathrm{~g}$. & $620 \mathrm{~mm}$ & - & \\
\hline & $F$ & MPEG 45080 & - & $612 \mathrm{~mm}$ & - & \\
\hline & $\mathrm{F}$ & MZUSP 77638 & $570 \mathrm{~g}$. & $595 \mathrm{~mm}$ & - & \\
\hline \multirow{7}{*}{$\begin{array}{c}10 \\
\text { (CE3) }\end{array}$} & $\mathrm{M}$ & MNRJ 36662 & $830 \mathrm{~g}$. & $680 \mathrm{~mm}$ & $680 \mathrm{~mm}$ & \\
\hline & $M$ & MNRJ 44230 & - & $660 \mathrm{~mm}$ & - & $\begin{array}{c}\text { Asa } 252 \text {, cauda } 280, \\
\text { tarso } 79, \text { bico } 31\end{array}$ \\
\hline & $\mathrm{M}$ & MNRJ 10331 & $775 \mathrm{~g}$. & $650 \mathrm{~mm}$ & - & $\begin{array}{l}\text { Asas } 760 \mathrm{~mm} \text {, } \\
\text { cauda } 280 \mathrm{~mm}\end{array}$ \\
\hline & $\mathrm{F}$ & MNRJ 21749 & $690 \mathrm{~g}$. & $700 \mathrm{~mm}$ & - & Asas $770 \mathrm{~mm}$ \\
\hline & $\mathrm{F}$ & MNRJ 21747 & $660 \mathrm{~g}$. & $660 \mathrm{~mm}$ & - & Asas $750 \mathrm{~mm}$ \\
\hline & $\mathrm{F}$ & MNRJ 21746 & $630 \mathrm{~g}$. & $650 \mathrm{~mm}$ & - & $\begin{array}{l}\text { Asas } 750 \mathrm{~mm} \text {, } \\
\text { cauda } 280 \mathrm{~mm}\end{array}$ \\
\hline & $\mathrm{F}$ & MNRJ 21745 & $590 \mathrm{~g}$. & $630 \mathrm{~mm}$ & - & $\begin{array}{l}\text { Asas } 730 \mathrm{~mm} \text {, } \\
\text { cauda } 270 \mathrm{~mm}\end{array}$ \\
\hline \multirow{3}{*}{$\begin{array}{c}11 \\
(\mathrm{CE} 4)\end{array}$} & $\mathrm{F}$ & MZUSP 3148 & - & $720 \mathrm{~mm}$ & - & \\
\hline & $\mathrm{F}$ & MZUSP 2693 & - & $665 \mathrm{~mm}$ & - & \\
\hline & $\mathrm{F}$ & & - & $37 \mathrm{~cm}$ & - & \\
\hline $\begin{array}{c}12 \\
\text { (CE5) }\end{array}$ & $\mathrm{F}$ & MZUSP 12243 & - & $650 \mathrm{~mm}$ & - & \\
\hline $\begin{array}{c}13 \\
\text { (MA1) } \\
\end{array}$ & $\mathrm{M}$ & MNRJ 34855 & $740 \mathrm{~g}$. & $685 \mathrm{~mm}$ & $750 \mathrm{~mm}$ & \\
\hline \multirow{2}{*}{$\begin{array}{c}14 \\
(\mathrm{MA2})\end{array}$} & $\mathrm{M}$ & MZUSP 7802 & - & - & - & long. T. 66.16 .22 \\
\hline & $\mathrm{M}$ & MZUSP 7801 & - & - & - & long. T. 63.17 .22 \\
\hline \multirow{8}{*}{$\begin{array}{c}15 \\
\text { (MA3) }\end{array}$} & $\mathrm{M}$ & MZUSP 6767 & - & - & - & long. T. 86.19.23 \\
\hline & $M$ & MNRJ 44227 & - & $725 \mathrm{~mm}$ & - & $\begin{array}{c}\text { Asa } 260, \text { cauda } 315, \\
\text { tarso } 84, \text { bico } 35 \\
\text { mm }\end{array}$ \\
\hline & $\mathrm{M}$ & MNRJ 23274 & $830 \mathrm{~g}$. & $710 \mathrm{~mm}$ & - & Asa 320 , asas 790 \\
\hline & $\mathrm{M}$ & MNRJ 23998 & - & $706 \mathrm{~mm}$ & - & \\
\hline & M & MNRJ 23572 & $720 \mathrm{~g}$. & $680 \mathrm{~mm}$ & - & $\begin{array}{c}\text { Asa 300-360, asas } \\
\text { 790, tarso 90, bico } \\
40 .\end{array}$ \\
\hline & $M$ & MNRJ 44228 & - & $660 \mathrm{~mm}$ & - & $\begin{array}{c}\text { Asa } 255 \text {, cauda } 290, \\
\text { tarso } 83, \text { bico } 30 \\
\text { mm }\end{array}$ \\
\hline & $\mathrm{M}$ & MZUSP 7802 & - & - & - & long. T. 66.16 .22 \\
\hline & $\mathrm{M}$ & MZUSP 7801 & - & - & - & long. T. 63.17 .22 \\
\hline
\end{tabular}




\begin{tabular}{|c|c|c|c|c|c|c|}
\hline & $M$ & MNRJ 44231 & $900 \mathrm{~g}$. & $600 \mathrm{~mm}$ & - & $\begin{array}{c}\text { Asa } 255 \text {, cauda } 290, \\
\text { tarso } 89, \text { bico } 30 \\
\mathrm{~mm}\end{array}$ \\
\hline & $\mathrm{F}$ & MNRJ 23999 & - & $705 \mathrm{~mm}$ & - & \\
\hline & $\mathrm{F}$ & MZUSP 24544 & $820 \mathrm{~g}$. & $650 \mathrm{~mm}$ & - & Asa 310 , asas 740 \\
\hline & $\mathrm{F}$ & MNRJ 26745 & $803 \mathrm{~g}$. & - & - & \\
\hline & $\mathrm{F}$ & MNRJ 26745 & $803 \mathrm{~g}$. & - & - & \\
\hline & $\mathrm{F}$ & MNRJ 26748 & $730 \mathrm{~g}$. & - & - & \\
\hline & $\mathrm{F}$ & MNRJ 26748 & $730 \mathrm{~g}$. & - & - & \\
\hline & ND & MNRJ 39566 & - & $707 \mathrm{~mm}$ & - & $\begin{array}{c}\text { Asa } 274 \text {, cauda } 315, \\
\text { tarso } 71, \text { bico } 30 \\
\mathrm{~mm}\end{array}$ \\
\hline & ND & MNRJ 19410 & $730 \mathrm{~g}$. & - & - & \\
\hline \multirow[t]{2}{*}{$\begin{array}{c}16 \\
(\mathrm{MA} 4)\end{array}$} & ND & MZUSP 70637 & - & $612 \mathrm{~mm}$ & - & $\begin{array}{c}\text { asa } 230, \text { cauda } 244, \\
\text { culmen } 29, \text { tarso } \\
81, \text { banpb } 13\end{array}$ \\
\hline & ND & MHNCI 2004 & - & - & - & Corpo $18 \mathrm{~cm}$ \\
\hline \multirow{7}{*}{$\begin{array}{c}17 \\
\text { (MA5) }\end{array}$} & $M$ & MZUSP 26076 & - & - & - & $\begin{array}{l}\text { Asa } 250, \text { cúlmen } \\
27, \text { cauda } 285, \\
\text { tarso } 70\end{array}$ \\
\hline & $\mathrm{M}$ & MHNCI 5370 & $800 \mathrm{~g}$. & $705 \mathrm{~mm}$ & $825 \mathrm{~mm}$ & \\
\hline & $\mathrm{M}$ & $\mathrm{MHNCl} 252$ & - & - & - & Corpo $20,5 \mathrm{~cm}$ \\
\hline & $\mathrm{M}$ & $\mathrm{MHNCl} 462$ & - & - & - & Corpo $20 \mathrm{~cm}$ \\
\hline & $M$ & MHNCI 2040 & - & - & - & Corpo $19,3 \mathrm{~cm}$ \\
\hline & $\mathrm{M}$ & MHNCl 400 & - & - & - & Corpo $17 \mathrm{~cm}$ \\
\hline & $\mathrm{F}$ & MHNCI 2002 & - & - & - & Corpo $19,5 \mathrm{~cm}$ \\
\hline \multirow{2}{*}{$\begin{array}{c}18 \\
\text { (MA6) }\end{array}$} & $\mathrm{M}$ & MACN 54670 & $1150 \mathrm{~g}$. & $702 \mathrm{~mm}$ & - & \\
\hline & $\mathrm{F}$ & MHNCl 4545 & $1700 \mathrm{~g}$. & $668 \mathrm{~mm}$ & $760 \mathrm{~mm}$ & \\
\hline
\end{tabular}

* GG: Grupos geográficos; Comp. Total: Comprimento total; Enverg.: Envergadura. 
Inicialmente as análises qualitativas, que incluem a revisão da coloração das penas e a pigmentação das regiões nuas, mostraram que os indivíduos dos 18 grupos geográficos do complexo Penelope superciliaris formados pela proximidade geográfica, o bioma no qual ocorrem e a semelhança morfológica, poderiam ser agrupados em quatro unidades taxonômicas bem diferenciadas. As análises quantitativas não mostram evidência suficiente para diferenciar os grupos geográficos dentro dos mesmos biomas ou entre diferentes biomas, nem evidências que separem notoriamente as unidades taxonômicas que sejam explicadas por alguma das oito variáveis morfométricas; só umas poucas populações se mostraram diferenciadas, mas isso não foi explicado por alguma regra biogeográfica ou alguma tendência que seja explicada por alguma variação geográfica.

A diagnosticabilidade das quatro unidades taxonômicas pode ser explicada pelas análises qualitativas. Segundo o Conceito Filogenético de Espécie (PSC), sugere-se que o complexo Penelope superciliaris Temminck, 1815 deve ser dividido em quatro táxons que sejam considerados como espécies válidas:

- Penelope pseudonyma Neumann, 1933, restrita ao interflúvio Madeira-Tapajós na floresta amazônica;

- Penelope ochromitra Neumann, 1933, táxon da Caatinga e Cerrado;

- Penelope alagoensis Nardelli, 1993, restrita ao Centro de Endemismo Pernambuco nos estados de Alagoas e Pernambuco;

- E Penelope superciliaris Temminck, 1815, que ocorre em todo o restante da distribuição do complexo. 


\title{
VI. TAXONOMIA DO COMPLEXO Penelope superciliaris
}

\section{Penelope superciliaris Temminck, 1815}

\author{
Penelope superciliaris Temminck, 1815
}

Penelope superciliaris Temminck, 1815:72(3). Localidade tipo "Brésil, et plus particulièrement dans le district de Pará"; restrito a Belém por Olivério Pinto (1964:106). Holótipo perdido, originalmente na coleção de C.J. Temminck.

Penelope marail: Wied, 1820:69(1). Not Phasianus marail Statius Müller, 1776. Rio de Janeiro (Fazenda Pitanga, próximo de Saquarama), Espirito Santo (Aldea Velha = Santa Cruz), e Bahia (Morro d'Arara, Rio Mucuri; Timicui, Rio Belmonte).

Penelope jacupemba Spix, 1825:55(2). Localidade tipo "Presidio de São João, próximo de Rio de Janeiro" (=Rio de Janeiro). Holótipo no Zoologische Staatssammlung Mûnchen (ZSM) de Munique.

Penelope superciliaris var.: Pelzeln, 1870:283(3). Rio Guaporé (Forte do Príncipe, RO) e Rio Madeira (Borba, AM).

Penelope purpurescens: Bertoni, 1901:16(1). Not Penelope purpurascens Wagler, 1830. Alto Paraná, entre as latitudes $25^{\circ}$ e $26^{\circ}$ sul, Paraguai. Holótipo originalmente na coleção de A. W. de Bertoni, atualmente desconhecido. 
Penelope purpurescens major Bertoni, 1901:19(1). Alto Paraná, entre as latitudes 25²3' sul, Paraguai. Holótipo originalmente na coleção de A. W. de Bertoni, atualmente desconhecido.

Penelope superciliaris jacupemba: Hellmayr, 1906:690(3). Presidio do São João (=Rio de Janeiro).

Penelope superciliaris superciliaris: Hellmayr, 1912:81(26). Peixe-Boi e Rio Acará, PA.

Penelope superciliaris argyromitra Neumann, 1933:94(53). Localidade tipo "Veadeiros, noroeste de Forte, Goyáz (=Goiás) ”. Holótipo no Museum of Comparative Zoology da Harvard University.

Penelope superciliaris major Neumann, 1933:187(20). Parte de Santa Catharina e Rio Grande do Sul. Holótipo na coleção de A. W. de Bertoni.

Nome comum: Português: jacupemba. Espanhol: Pava yacupemba. Inglês: Rusty-margined Guan.

Holótipo: O holótipo designado por C.J. Temminck pertencia a sua coleção pessoal, mas depois da transferência dessa coleção ao Museu de Leiden, esse espécimen está perdido (Neumann, 1933; Hellmayr \& Conover, 1942).

Localidade tipo: A localidade tipo designada por Temminck (1815: 74) foi "Brésil, et plus particulièrement dans le district de Para (Brasil, particularmente no estado de Pará) ", e posteriormente foi restrita à região de Belém por Olivério Pinto (1964: 106). 
Diagnose: Coloração geral bastante variável, com dorso de brilho esverdeado que varia em intensidade, desde forte que dá aparência escura, até amarronzado leve de aparência clara. Asas com bordas que variam em extensão, desde largas até reduzidas quase imperceptíveis e de cor ferrugínea forte até marrom claro. Supercilio de penas esbranquiçadas a cinzentas, que pode variar de extensa a reduzida. Peito com desenho escalado esbranquiçado. Barbela nua bicolorida, pés cinzas e íris que varia de vermelho a marrom claro.

Re-descrição: Sem dimorfismo sexual pela coloração da plumagem ou tamanho, e com indivíduos imaturos similares aos adultos. Padrões de plumagem altamente variáveis, que se apresentam aleatoriamente em qualquer parte do seu rango de distribuição. Com cabeça escura e linha superciliar geralmente contrastante, de penas esbranquiçadas a cinzentas, e que pode variar de extensa a reduzida. Borda branca nas penas do peito que contorna a totalmente a pena e varia em intensidade, dando uma aparência escalada. O dorso é de brilho esverdeado que varia em intensidade, desde forte que dá uma aparência escura, até amarronzada de aparência clara. Com bordas das penas coberteiras e rêmiges das asas que variam em extensão, desde largas até reduzidas quase imperceptíveis e de cor ferrugínea forte até marrom claro. Frequentemente os indivíduos da Amazônia são mais escuros com bordas das penas das asas ferrugíneas, do Cerrado mais claros com bordas marrões e do sul da distribuição opacos com bordas quase imperceptíveis, mas esse não é um padrão delimitado, existem muitas exceções. Em cada indivíduo o peito é quase do mesmo tom que o dorso, e o ventre é da mesma cor que a região uropigial, esta última relacionada com a cor da borda das penas das asas. A cauda é longa e com cor verde brilhante escura. É possível encontrar indivíduos de diferente padrão de coloração na mesma localidade. A barbela é 
nua e bicolorida, preta no extremo anterior e vermelho no resto, pele do rosto cinza escura, pés cinzas e a íris varia de vermelho a marrom independente do sexo.

Distribuição: Ocorre na Amazônia, Cerrado, Pantanal e Mata Atlântica. Ao norte ocorre no sul da Amazônia na margem direita do Rio Amazonas, desde a margem direita do rio Tapajós para o leste através do estado do Pará até o Cerrado que limita com a Amazônia no Maranhão e Tocantins. Leste do Paraguai e Bolívia, e por todo o centro do Brasil, chegando até a Mata Atlântica do sudeste, desde o litoral sul da Bahia até o sul, no Rio Grande do Sul e Misiones, no nordeste da Argentina.

\section{Material examinado pessoalmente $(n=277)$}

BRASIL. Pará: Rio Amazonas (Sul), foz do Rio Curuá (1 §ึ- MZUSP 22248); Curuatinga, afluente do Curuauma, margem direita do rio Amazonas, Prainha (1 §ิ- MNRJ 25244); Baixo Rio Tapajós, margem direita, Inumu (1 §̂- MPEG 28025); Santarém (2 ๆ- MNRJ 25240, MNRJ 25241); Ipanema, beira da rondagem à esquerda, Santarém (2 ð- MNRJ 25242, MNRJ 25243); Rio Arapiuns, Aruá (2 ㅇ- MZUSP 22093, MZUSP 22137, 2 MZUSP 22095, MZUSP 22140); Rio Tapajós (Leste), Caxiricatuba (4 §̊- MZUSP 17766, MZUSP 20468, MZUSP 21938, MZUSP 22142, 6 9- MZUSP 21937, MZUSP 22033, MZUSP 22087, MZUSP 22141, MZUSP 22174, MZUSP 28038, 1 ND- 22096); Rio Amazonas (Sul), foz do Rio Curuá (2 ๆ- MZUSP 21940, MZUSP 21941, 1 ๙- MZUSP 20817); Rio Tapajós (Leste), Forlândia (6 q- MZUSP 46262, MZUSP 58076, MZUSP 58078, MZUSP 58094, MZUSP 58095, MZUSP 72087, 11 ๙- MZUSP 46263, MZUSP 46264, MZUSP 58077, MZUSP 58090, MZUSP 58092, MZUSP 58093, MZUSP 58497, MZUSP 58498, MZUSP 71386, MZUSP 73192, MZUSP 73193, 1 ND- 58091); Vila 
Braga, rio Tapajós (1 đ̂- MNRJ 18893); Itaituba, Rio Tapajós, margem esquerda, Vila Braga (1 $\hat{0}$ - MPEG 6557); Rio Amazonas (Sul), foz do Rio Curuá (1 q- MZUSP 22136, 1 §ิ- MZUSP 22086); Rio Xingú (margem direita), Anapu, T7 (1 $\widehat{\delta}$ - MZUSP 95546); Rio Tapajós (Leste), Piquiatuba (6 $\widehat{0}$ - MZUSP 20818, MZUSP 21939, MZUSP 21942, MZUSP 21943, MZUSP 22139, MZUSP 22176); Urucurituba (1 1 - MZUSP 102973); Xingura, Rio Araguaia, Remanso dos Botos (1 $\widehat{\jmath}$ - MPEG 34728); Parauapebas, Serra dos Carajás, Manganês (2 q- MPEG 36476, MPEG 36716); Parauapebas, Serra dos Carajás, Serra Norte (1 q- MPEG 34901, 1 đ̊- MPEG 34902); Marabá, Rio Sororó, Reserva da CVRD (1 †- MPEG 37967); Tucuruí, Rio Tocantins, margem esquerda, Prainha (1 ô- MPEG 36074); Arumatema, rio Tocantins (1 9 - MNRJ 2942); Reserva Florestal de Agropalma, Tailândia (1 NA- MZUSP 77114); Acará, Rio Acará (2 ô- MPEG 1691, MPEG 1694);

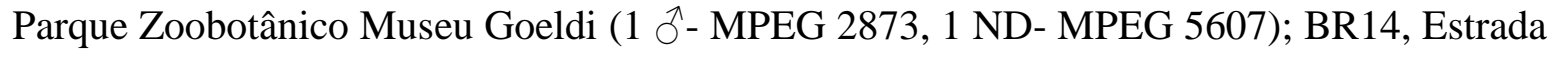
Belém-Brasília, km 93, Capim (1 ㅇ- MZUSP 43878); Ourém, Igarapé Pedral, afluente direito Rio Guamá, Sítio Fé em Deus (3 q- MPEG 32004, MPEG 32005, MPEG 32296, 1 $\widehat{\jmath}$ - MPEG 32006); Serra do Cachimbo (1 $\widehat{\partial}-$ MNRJ 31531); Cachimbo (1 $\widehat{\partial}-$ MZUSP 38440); Novo Progresso, Serra do Cachimbo, Base da Aeronáutica (1 ^- MPEG 57299, 2 ૧- MPEG 57299, MPEG 57300); Santana do Araguaia, Fazenda Fartura (2 $\widehat{\jmath}$ - MZUSP 81976, MZUSP 89851, 2 9- MZUSP 89852, MZUSP 83731, 1 ND- MZUSP 98899); Santana do Araguaia, Fazenda Barra das Princesas (1 9 - MPEG 48493, 1 $\widehat{\delta}$ - MPEG 48492); Nilo-Peçanha, Riosinho (afluente do Rio Fresco, afluente do Rio Xingú) (1 †. MZUSP 42226); Rio Fresco (afluente do Xingú), Gorotire (2 q- MZUSP 42223, MZUSP

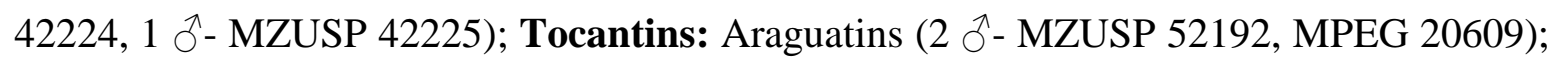
Presidente Kennedy (1 ND- MNRJ 47660); Furo da Pedra, Ilha Bananal (1 9 - MNRJ 18896, 1 §- MNRJ 18889); Maranhão: Centro Novo Maranhão, REBIO Gurupi (1 $\widehat{\delta}-$ 
MPEG 77030, 1 ND- MPEG 77031); Buriticupu, Floresta da Companhia Vale do Rio Doce (1 q-MPEG 37325); Arame, Pedra Preta (1 ND- MPEG 50724); Açailândia (1 $\widehat{\jmath}$ - MZUSP 75794); Primeira Cruz (2 ̊- MZUSP 6683, MPEG 46370, 1 ઈ- MZUSP 6682); Humberto de Campos (Miritiba) (1 q- MPEG 8326, 1 ○ิ- MPEG 8325); Miritiba (1 q- MZUSP 9138); Riachão, Povoado Feira Nova, Fazenda do Arroz (1 ઈ̂- MPEG 42246); Mato Grosso: Vila Rica, Fazenda Ipê (1 §ૈ- MZUSP 78126); rio Arraia (1 †- MNRJ 31528, 1

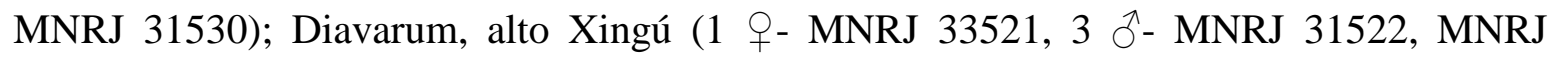
31523, MNRJ 31527); Jacaré, baixo kuluene, alto Xingú (2 ð̂- MNRJ 32544, MNRJ 33522, 2 q- MNRJ 31532, MNRJ 33523); Nova Lacerda (1 §̂- MNRJ 45027); Estação Ecológica de Serra das Araras, Barra do Bugre (1 ํ- MNRJ 36177); São Luiz de Cáceres (1 ND- MZUSP 10119); Potreiro Cáceres (1 q- MNRJ 18899, 1 đ̂- MNRJ 18863); Cáceres (1 ND- MACN 8083); Palmeiras (1 §ิ-MZUSP 30128); Salobra (1 †- MZUSP 27630); Xavantina, Rio das Mortes (5 §- MZUSP 32247, MZUSP 32248, MZUSP 32249, MNRJ 32542, MNRJ 32543, 1 - MNRJ 31529); Córrego dos Porcos, rodovia Xavantina-Xingu (1 ๆ- MNRJ 33276, 1 §- MNRJ 33275); Pindaíba (Rio das Mortes) (1 ND- MZUSP 34962); Vale dos Sonhos (1 ㅇ- MPEG 28026); Rio Araguaia, Cocalinho, Cocalinho (1 §MNRJ 36662); Dumba (1 ڤ̂- MZUSP 34961); Buriti, Chapada, Cuiabá (1 q- MNRJ 18895); Chapada (1 ๆ- MNRJ 9402, 2 ઈ- MZUSP 17030, MNRJ 9403); Morro Podre (Chapada) (2 9 - MNRJ 18901, MNRJ 18907); Mato Grosso do Sul: Coxim (1 $q$ - MZUSP 12243); Km 1221 da Estrada de Ferro Noroeste Brasil (prox. Bodoquena) (1 §ิ- MNRJ 20818); Fazenda Barra Mansa, Rio Brilhante (1 §- MZUSP 36609); Porto Primavera, Bataiporã, Rio Paraná (1 q- MNRJ 44229); rio Ivinheima, Porto 15 de agosto (5 §̂- MNRJ 21739, MNRJ 21740, MNRJ 21741, MNRJ 21742, MNRJ 21744); Rondônia: Comemoração de Floriano (1 đ̂- MNRJ 18904); Goiás: Rio Tocantins (margem esquerda), 
Campinaçu (1 +9- MZUSP 74230, 2 ND- MZUSP 74229, MZUSP 74231); Fazenda Transvaal, Município do Rio Verde (3 - MZUSP 27955, MZUSP 27956, MZUSP 27957, 2 హ- MZUSP 27958, MZUSP 27959); Uruaçu, Rio Maranhão (1 $\widehat{0}$ - MNRJ 44230); Rio das Almas, Fazenda Manuel Peixoto (1 ㅇ- MZUSP 14705, 1 §ิ- MZUSP 14704); Anápolis (4 ㅇ- MNRJ 21745, MNRJ 21746, MNRJ 21747, MNRJ 21750, 2 ○- MNRJ 10331, MNRJ 21749); Goiânia (1 ภ̂- MZUSP 52193); Formosa (1 q- MPEG 19343); Posse (1 NDMNRJ 18906); DF: Reserva Biológica do Roncador, Brasília (1 q- MNRJ 33247); Bahia:

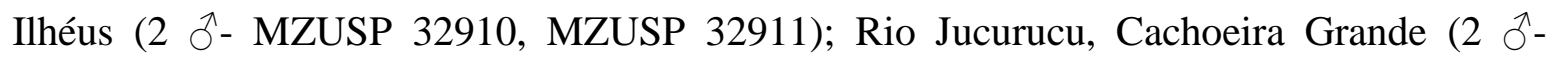
MZUSP 14022, MZUSP 14024, 1 q- MZUSP 14023); Minas Gerais: Machacalis (1 $\widehat{\emptyset}$ -

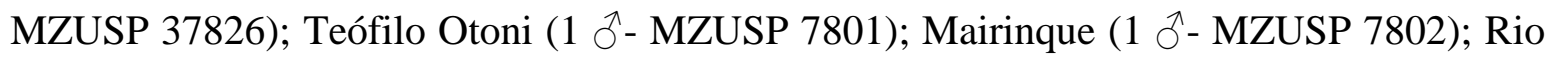
Matipo (1 $\widehat{\delta}$ - MZUSP 10348); Fazenda Paraíso Volta Grande (2 $\widehat{\sigma}$ - MNRJ 23274, MNRJ 23998, 1 ㅇ- MNRJ 23999); Além-Paraíba, Fazenda São Geraldo (1 +- MZUSP 24544); Poços de Caldas (1 ND- MZUSP 75479); Espirito Santo: Sem localidade específica (1 qMZUSP 6416); Fazenda Boa Lembrança, Rio Itaúnas, Conceição da Barra (1 $\widehat{\jmath}$ - MNRJ 44231); Córrego Cupido (REBIO Sooretama), Linhares (2 §- MNRJ 44227, MNRJ 44228, 1 ND- MNRJ 39566); Cupido (2 ㅇ- MNRJ 26745, MNRJ 26748, 2 ND- MNRJ 26044, MNRJ 26275); Faz. Europa, Linhares (1 O- MNRJ 26743, 1 ND- 26742); rio Pequeno, Linhares (1 †- MNRJ 26744); São José, norte (1 ND- MNRJ 26747); Rio Doce (1 §MZUSP 6727); Pau Gigante (1 q- MZUSP 32909); Suassú, Santa Cruz ( 1 §- MNRJ 19095); Santa Teresa (3 O- MNRJ 19410, MNRJ 21751, MNRJ 21752); Floresta da Capela, São Braz, Santa Teresa (1 §̂- MNRJ 23572); Rio de Janeiro: Lagoa Juturnaíba (1

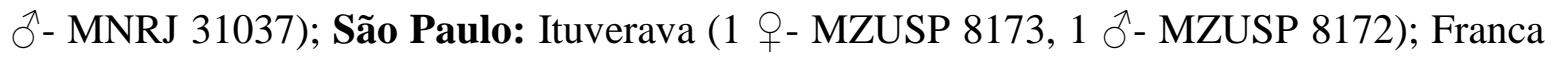
(2 ㅇ- MZUSP 2693, MZUSP 3148); Jaboticabal (1 q- MZUSP 1254); Fazenda Barreiro Rico, Anhembi (1 $\widehat{\jmath}$ - MZUSP 43362); Fazenda Santa Tereza, Avaré (1 ND- MZUSP 


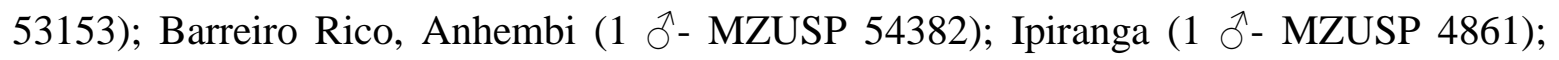
Horto Botânico do Museu Paulista (1 q- MZUSP 16058); Ribeirão Fundo (3 q- MZUSP 49341, MZUSP 49342, MZUSP 49343); Estrada Pariquera-açu - Iguape Km 36, Pariqueraaçu (1 ND- MZUSP 70637); Rio Juquiá, Fazenda Poço Grande (1 §̂- MZUSP 24381); Rio Ipiranga, Juquiá (1 ND- MZUSP 47505); Ilha Seca (1 ㅇ- MNRJ 20116, 1 §- MNRJ 20117); Barra do Rio Dourado (1 $\widehat{\alpha}$ - MZUSP 26075); Lins, Fazenda Varjão (2 $\widehat{\partial}$ - MZUSP

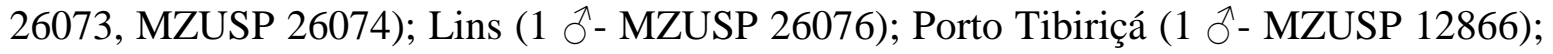
Porto Cabral, Rio Paraná (3 ㅇ- MZUSP 27488, MZUSP 27490, MZUSP 27491, 2 ภ-

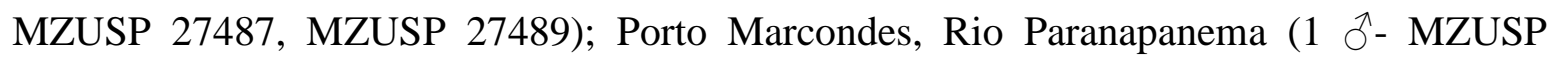
31865); Poço Grande (1 q- MZUSP 51); Paraná: Paranaguá (1 ND- MHNCI 2004);

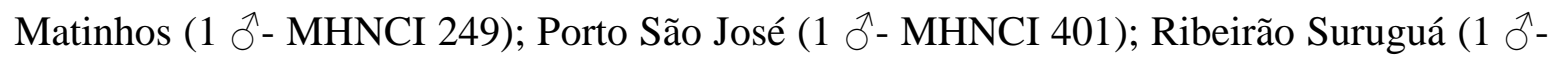
MHNCI 462); Rio Ivaí (1 §ิ-MHNCI 400, 1 q- MHNCI 1268); Porto Camargo, Rio Paraná (1 đ- MZUSP 36710, 2 ㅇ- MZUSP 36711, MZUSP 36712); Serra dos Dourados (1 ఏ- MHNCI 2040); Cruzeiro do Oeste (1 q- MHNCI 2002); Campo Mourão (1 §- MHNCI 5370); Serra Irati, Santa Barbara (1 §̂- MHNCI 252); Parque Nacional do Iguaçu (1 qMHNCI 4545, 1 ND- MNRJ 21227); Santa Catarina: Joinville (1 ND- MZUSP 4862). ARGENTINA. Misiones: Parque Nacional Iguazú (1 đ- MACN 54670); Rio Iguazú Km.

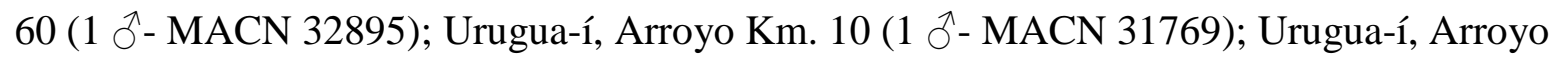
Km. 30 (3 §- MACN 36589, MACN 36590, MACN 38213, 2 q- MACN 31770, MACN

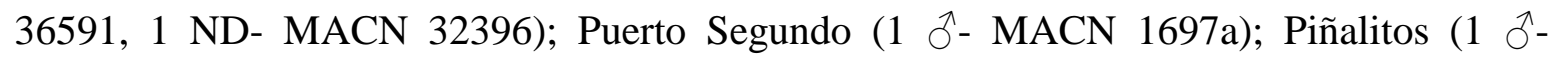
MACN 36593, 1 ND- MACN 36592); Tobuna (1 ڤึ- MACN 33460, 1 ND- MACN 34102); Santa Ana (1 q- MACN 9631, 1 ND- MACN 9962); Bondpland (1 ND- 7686). PARAGUAI. Itapúa: Capitán Meza (3 đ- MACN 471067, MACN 4778, MACN 47751, 1 - MACN 4608a, 1 ND- MACN 47750). 
Material examinado por fotografias $(n=59)$

BRASIL. Pará: Ipomonga, Rio Campio, L bank about 90 mi above mouth (1 ڤ̂- FMNH 411171); Fordlândia, Rio Tapajós (1 †- FMNH 422547); Peixe-boi (1 †- ZSM 101105), Rio Acará (2 ND- ZSM 102588, ZSM 102587); Boim Rio Tapajós (2 q- MFN 8900, MFN 7493); Maranhão: Miritiba (5 ふొ- RNHL 3759, RNHL 5652-18, RNHL 9701-13, RNHL 5652-16, RNHL 5652-19, 1 †- RNHL 5652-17); Mato Grosso: Sem localidade (1 つRNHL SN); Serra da Chapada (4 §̋- BMNH SN, BMNH SN, BMNH 89.1.10.66, BMNH

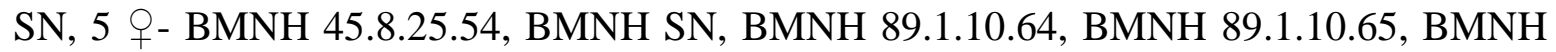
$\mathrm{SN}$ ); Minas Gerais: Bagagem (1 ND- ZSM SN); Rio de Janeiro: Rio de Janeiro (=Presidio de São João, Tipo de Penelope superciliaris jacupemba ND- ZSM SN); Ytararé (1 ๆ-RNHL 174); São Paulo: Fazenda Varjão, Município de Lins (1 ๆ- FMNH 415183, 1 §ิ- FMNH 415184); Barra do Rio Dourado (1 †- FMNH 415185); Victoria (1 §ิ- FMNH 400215); Santa Catarina: Sem localidade (2 - RNHL 5652-8, RNHL 9701-14, 2 NDRNHL 9701-10, RNHL 5652-20); Ararangua (1 §ิ- RNHL 9701-15, 2 q- RNHL 5652-9, RNHL 9701-11); Blumenau (1 ๆ-ZSM 26168, 1 ○ิ- MFN 29565); Rio Grande do Sul: Porto Alegre (1 ND- MFN b.295). ARGENTINA. Misiones: Puerto Segundo (1 ЉFMNH 404739, 1 ND- FMNH 404738). PARAGUAI. Amambay: Capitan Bado, 40km WSW, Cordillera de Amambay (3 ڤึ- FMNH 108705, FMNH 413701, FMNH 413702, 2 q- FMNH 413699, FMNH 413700); Capitan Bado, 45 km WSW (1 §ิ- FMNH 108704);

Concepción: Horqueta ( 2 ๙- FMNH 411019, FMNH 411718, 2 ○- FMNH 411516, FMNH 411719); Zanja Morotí (1 §̋- ZSM 3257); San Pedro: Col. Nueva Germania (1 qZSM 3258); Caaguazú: Caaguazú (1 ND- ZSM 59555); Itapuá: Cambyretá (1 đ̂- ZSM 
3725); Alto Paraná: Capitan Maza (1 q- ZSM ND). BOLÍVIA. Santa Cruz: Chiquitos, Serrania de Santiago (1 §̊- FMNH 295965, 1 q- FMNH 295966).

\subsubsection{Notas taxonômicas}

\section{Penelope superciliaris Illiger ou Penelope superciliaris Temminck?}

Como parte da revisão histórica do nome Penelope superciliaris, vimos que os autores mais antigos, especificamente no século XIX, citavam Johann Karl Wilhelm Illiger como o autor da descrição (e.g. Penelope superciliaris Illiger). É comum encontrar o nome de Illiger associado a esta espécie nos textos mais antigos, assim como em etiquetas de exemplares coletados nesse século, tal e como foi encontrado em alguns dos exemplares revisados. Por que antigamente essa espécie era associada a um outro autor que não fosse o Temminck? Aparentemente Illiger foi quem deu o nome à espécie mas sem ter publicado os resultados, quem se encarregou posteriormente disso foi Temminck. Para esclarecer essa história, escrevo brevemente o que aconteceu com esses autores e a descrição da espécie.

Coenraad Jacob Temminck (1778-1858) foi um zoólogo que publicou o livro intitulado "Histoire naturelle generale des pigeons et des gallinaces" em três volumes: os dois primeiros em 1813 e o terceiro em 1815, nesse último encontramos a descrição de “Penélope peoa: Penelope superciliaris Illiger" (p. 72-75). Essa é a primeira publicação que menciona o nome científico da espécie, e não existe alguma outra publicação que seja mais antiga e que tenha sido publicada por Illiger. Foi encontrada uma referência publicada como de autoria de Illiger que menciona a Penelope superciliaris, dentro de uma lista de 
espécies publicada no livro "Verz. Ausgestop. Säug. Vög." de Lichtenstein do ano 1818, três anos depois da descrição do Temminck.

Se revisamos a descrição de Temminck (1815), ele menciona: "Esta espécie vive no Brasil, especialmente no estado de Pará, onde os índios chamam ele de Jacu-peoa. Devo ao Conde de Hoffmannsegg o indivíduo que faz parte do meu gabinete; os dois indivíduos adultos, e as aves jovens que são parte do Museu de Berlim, também são produto das expedições, já que o Conde tem feito suas coletas no Brasil" (Traduzido do francês). O mencionado Conde Johann Centurius von Hoffmannsegg era um zoólogo naturalista experiente, famoso por suas viagens de coleta pelo mundo, possuía uma coleção particular muito importante e em 1810 faz parte da fundação do Museu Zoológico de Berlim, em uma época de profundos problemas políticos. Ele junto a outros gestores, nomearam o entomologista Johann Karl Wilhelm Illiger como diretor do "Museu Zoológico", como era chamada a instituição naquele tempo. O Conde também no primeiro ano, através de doações, ajudou em aumentar consideravelmente o acervo da coleção ornitológica. Até então as coleções de aves se encontravam espalhadas em vários edifícios associados com a Universidade de Berlim, que albergavam as peças anatômicas, assim como tesouros naturais (Stresemann, 1922).

As doações beneficiaram muito o Museu Zoológico, e em consequência Illiger focou seu trabalho ao estudo das Aves de América do Sul. Ele não chegou a publicar os resultados do seu trabalho no Museu porque em apenas dois anos de serviço, ele contraiu tuberculose e morreu em 1813 (Stresemann, 1922). O último livro publicado por Illiger foi "Systematis Mammalium et Avium" (1811), onde lista nomes de espécies novas de aves, mas sem incluir em parte nenhuma o nome de Penelope superciliaris. 
Depois de Illiger morrer, o Dr. Hinrich Lichtenstein foi nomeado como seu sucessor na direção do Museu de Berlim. Lichtenstein lutou com grandes dificuldades nos tempos turbulentos e conseguiu promover o aumento de exemplares na coleção, e em todas as direções ele foi capaz de construir relacionamentos (Stresemann, 1922). Ele como novo diretor, se encarregou de publicar em 1818 a lista de Illiger que inclui a Penelope superciliaris (três anos depois da publicação de Temminck). Parece que era bem sabido entre os ornitólogos da época que Illiger foi quem deu o nome a Penelope superciliaris, mas como consequência da sua morte, foi Temminck quem descreveu a espécie em 1815, e apesar da descrição ter sido publicada com o nome de Illiger, a posterior aplicação do Código de Nomenclatura Zoológica determina que Temminck é o autor do nome Penelope superciliaris.

\section{O tipo de Penelope superciliaris foi coletado no Pará ou na Bahia?}

Como já foi mencionado anteriormente, quando Temminck (1815) fez a descrição da espécie, escreveu em francês: "Brésil, et plus particulièrement dans le district de Parâ", o que seria interpretado em português como "Esta espécie vive no Brasil, particularmente no estado de Pará". Apesar de ter especificado isso, Oscar Neumann (1933), no mesmo texto que descreveu $P$. s. pseudonyma, $P$. s. ochromitra e $P$. s. argyromitra, menciona no final com bastante segurança que o tipo de Penelope superciliaris não veio do estado de Pará, acrescentando que foi uma suposição errada de Temminck, por ter sido provavelmente um exemplar coletado por Gomes no estado de Bahia para o Conde Hoffmannsegg, e que está depositado no Museu de Berlim (cf. Stresemann, Jorn. f. Ornith. 1922, p. 499). Ele justifica sua hipótese dizendo que o Dr. Van Oort havia reportado que o tipo de Temminck não está depositado no Museu de Leiden (Países Baixos) e que Sieber, o 
coletor do espécime tipo citado por Temminck, não coletou essa espécie porque não encontrou a informação nos velhos catálogos do Museu de Berlim.

De acordo com o publicado por Stresemann (1822), sabemos que o Conde Hoffmannsegg, trabalhou desde 1802 com Antônio Gomes, o principal coletor de aves no estado brasileiro de Bahia; alguns anos depois ele conta com a colaboração do jovem Franz Sieber (nascido em 1789, em Praga), designado para coletar no estado do Pará, principalmente nos rios Tocantins (Cametá) e Tapajós, voltando para Europa no ano 1810 (ou 1811) com uma fantástica coleção de aves. Com essa informação, vemos que a hipótese de Neumann (1933) perde sustento, e não exclui a de Sieber de ser o coletor do tipo.

Hellmayr \& Conover (1942) não concordaram com o mencionado por Neumann (1933), porque afirmam que tudo não passa de suposição. Ele não só não conseguiu provar seu ponto, até publicou as evidências que tendem a mostrar a sua falácia. Como Temminck diz na descrição: “Devo o Conde Hoffmannsegg o indivíduo que é parte de minha coleção, e também os dois indivíduos adultos e a ave jovem que fazem parte do Museu de Berlim, que também são produto de viagens da sua despesa no Brasill'. Essa declaração descarta de imediato a suposição de Neumann de que havia apenas um espécime, e também fornece dois fatos importantes: (1) o tipo estava na coleção privada de Temminck, (2) e os três exemplares adicionais foram para o Museu de Berlim. Então o espécime examinado por Neumann, seria um dos outros mencionados por Temminck como aqueles que estavam naquele momento na coleção.

Vale a pena mencionar que os exemplares pertencentes à coleção particular de Temminck foram posteriormente incorporados ao Museu de Leiden, mas o holótipo de 
Penelope superciliaris, assim como vários outros espécimes, desapareceram e não se encontram em essa nem em outra coleção científica.

Depois de um amplo seguimento das peles de Penelope superciliaris nas coleções do Brasil e o mundo, foi achado um único exemplar no museu de Berlim que aparentemente é uma das duas peles dessa espécie revisadas pelo Temminck nesse museu. O exemplar é um indivíduo adulto de sexo indeterminado coletado para o Conde de Hoffmannsegg por Francisco Agostinho Gomes entre 1801 e 1803, no estado da Bahia, Brasil, depositado no Museu de Berlim com o número tombo ZMB 11882 (Fig. 28). As informações preenchidas na etiqueta do exemplar indicam que esse foi um dos dois indivíduos adultos revisados por Temminck no Museu de Berlim. Os outros dois indivíduos (o adulto e o jovem), também mencionados por Temminck, e que também se encontravam depositados nesse museu, não foram encontrados.

Atualmente esse seria o exemplar mais antigo da espécie depositado em uma coleção científica, pelo fato do holótipo se encontrar perdido, e não ter referência alguma sobre os outros dois exemplares que estavam depositados no Museu de Berlim. Esse exemplar possui apenas valor histórico como o exemplar mais antigo e por ter sido revisado pelo autor que descreveu a espécie, Temminck. 


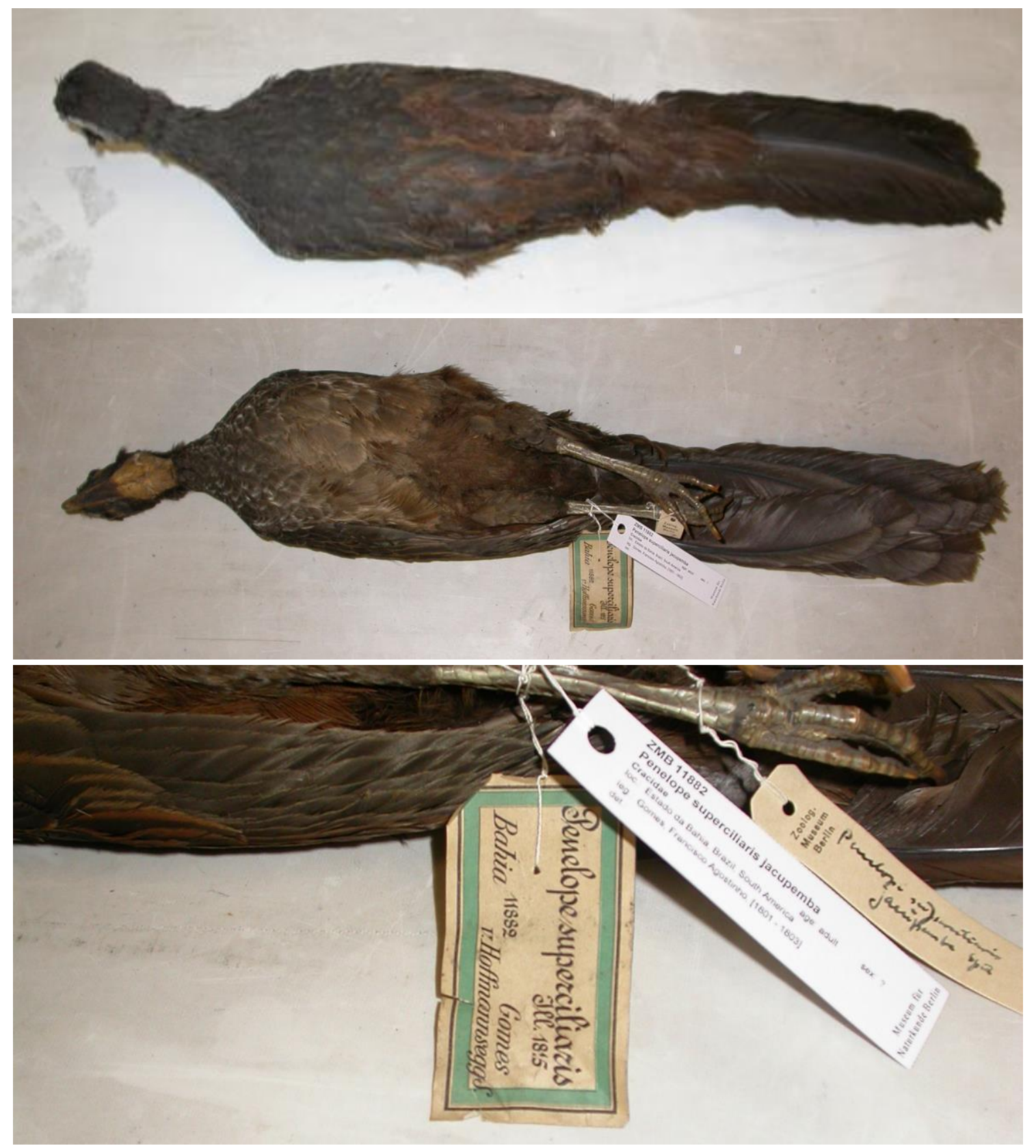

Figura 28. Exemplar de Penelope superciliaris mais antigo (ZMB 11882 - Museu de Berlim), coletado por Gomes para o Conde de Hoffmannsegg entre 1801-1803. Fotos: Sylke Frahnert.

Em 1929, Hellmayr no seu estudo sobre a diversidade ornitológica do nordeste brasileiro, menciona que $P$. s. jacupemba Spix que até o momento se considerava que 
ocorresse nos estados de Maranhão, Goiás e Piauí. Aqui ele propõe unir, sob o nome dado por Spix, as aves do leste do Brasil, desde Maranhão até Rio Grande do Sul e Mato Grosso, edo departamento de Misiones na Argentina, restringindo a subespécie nominal ao Vale do Amazonas, desde Pará até o Rio Madeira, dando a entender que só eram consideradas duas subespécies de P. superciliaris.

Peters (1934) considerava três subespécies para P. superciliaris: a subespécie nominal, no extremo sul do vale do Amazonas desde o Rio Madeira até Pará; $P$. $s$. jacupemba, do este do Brasil desde Maranhão até Mato Grosso e São Paulo; e P. s. major, no Paraguai e nordeste da Argentina, provavelmente sul de Mato Grosso e Paraná.

Olivério Pinto no Catalogo das Aves do Brasil (1938) inicialmente considera que três subespécies de Penelope superciliaris ocorrem no Brasil: P. s. superciliaris, da margem direita do Rio Amazonas e afluentes; P. s. jacupemba, ocorrendo no Brasil central e oriental e P. s. jacucaca, atualmente considerada como uma espécie separada.

Hellmayr \& Conover (1942), diferentemente de Pinto (1938), consideraram $P$. jacucaca como uma espécie distinta, e dividem $P$. superciliaris em quatro subespécies: $P$. s. superciliaris; P. s. ochromitra; P. s. jacupemba e P. s. major. Vaurie (1968) sinonimiza a P. s. ochromitra com P. s. jacupemba. Pinto (1978) continua considerando P. s. ochromitra como uma subespécie válida, no nordeste de Brasil, assim como as outras três subespécies: P. s. superciliaris, P. s. jacupemba e P. s. major, com a mesma distribuição que consideraram Hellmayr \& Conover (1942). 


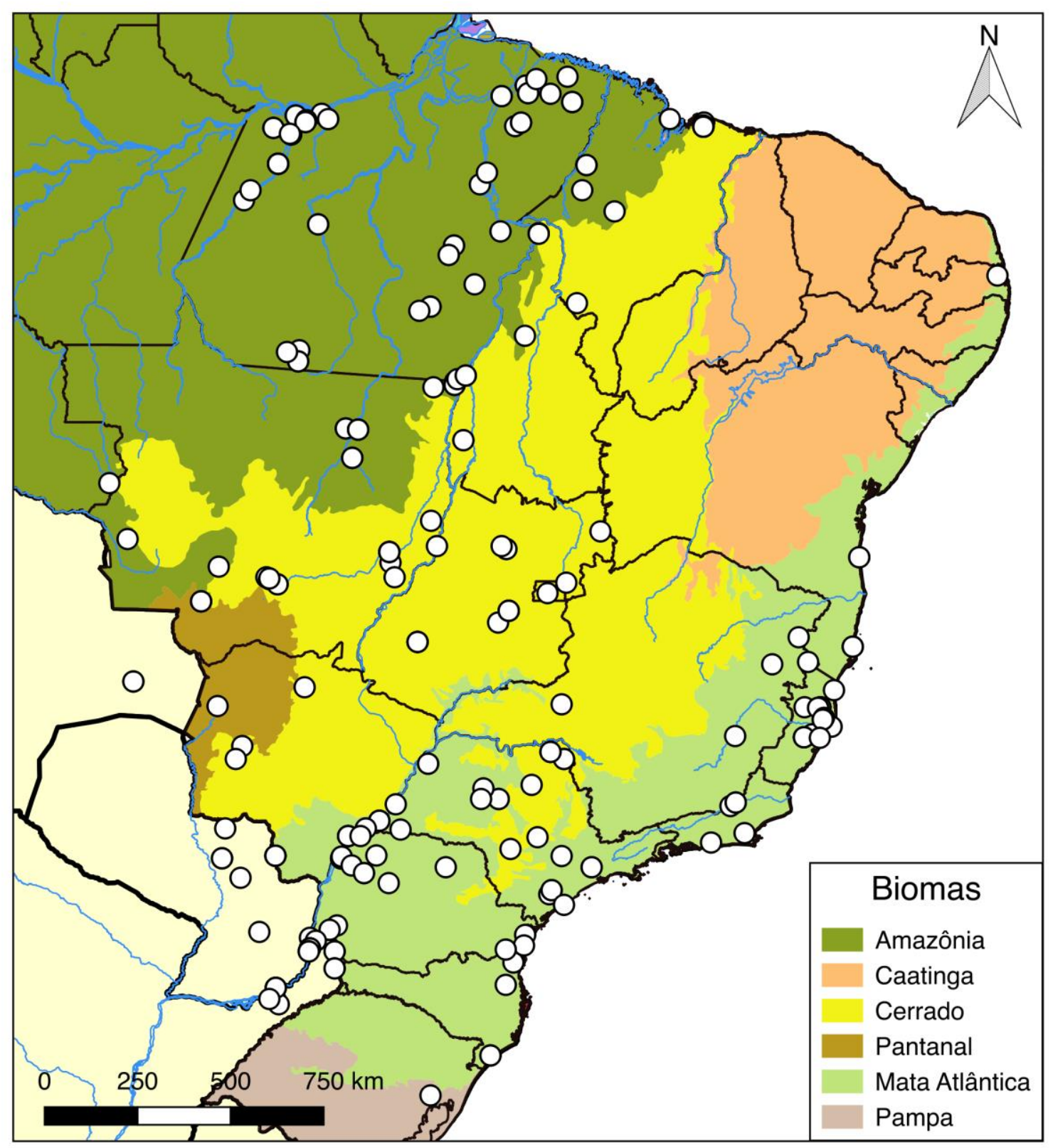

Figura 29. Espécimes de museus de Penelope superciliaris Temminck, 1815 , identificados com base no presente estudo. 


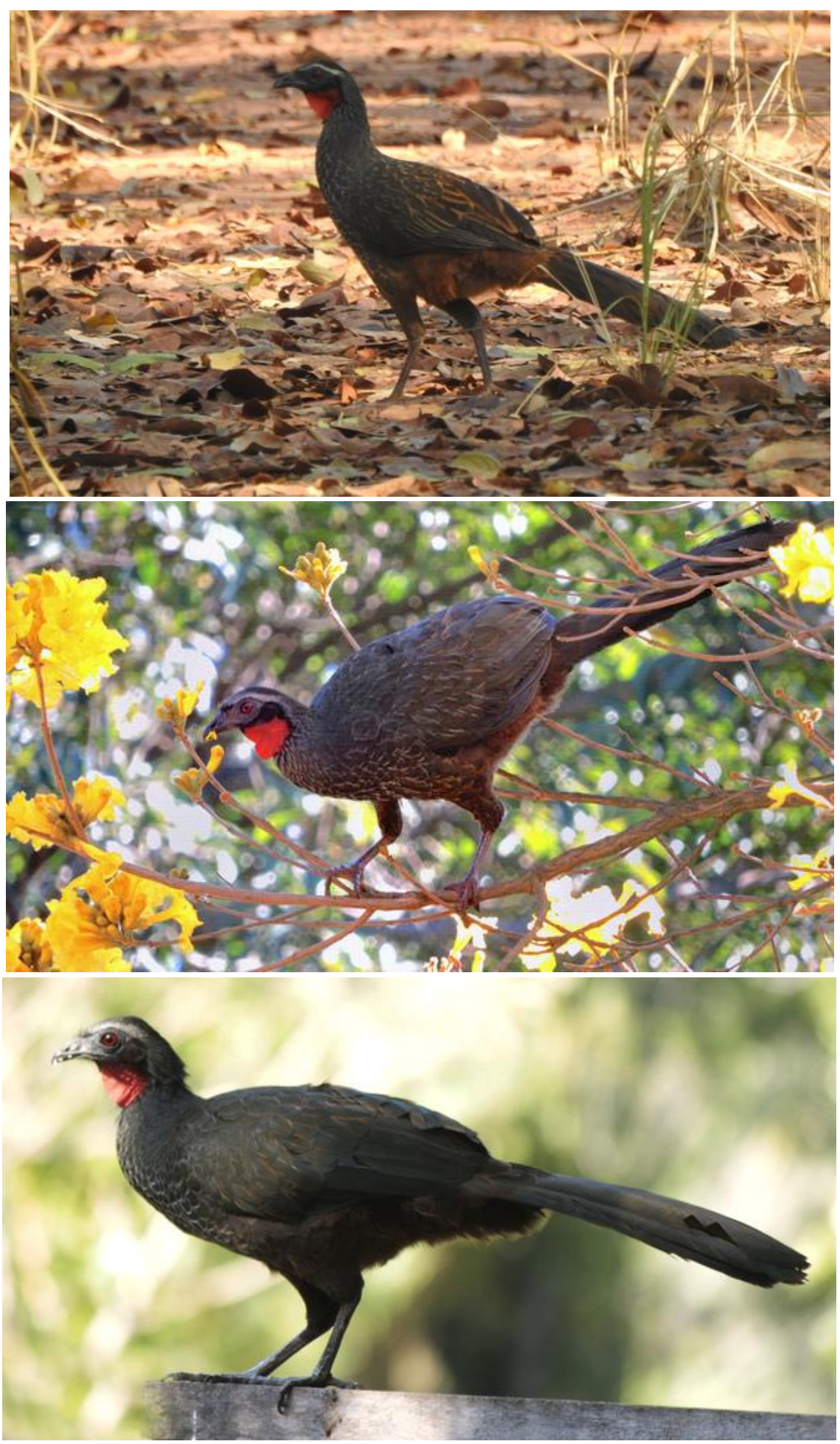

Figura 30. Indivíduos de Penelope superciliaris Temminck, 1815, identificados com base no presente estudo. Arriba: Ponta do Araguaia - MT (autor: Guilherme Carrano); Médio: Belo Horizonte - MG (autor: Zeafonso); embaixo: Peruíbe - SP (autor: Bruno Neri Peruibisbird). 


\title{
6.2. Penelope pseudonyma Neumann, 1933
}

\author{
Penelope pseudonyma Neumann, 1933
}

Penelope superciliaris superciliaris: Hellmayr, 1907:418(14). Not Penelope superciliaris superciliaris Temminck, 1815. Borba, Rio Madeira, AM.

Penelope superciliaris pseudonyma Neumann, 1933:93(53). Localidade tipo "Rio de Cumana"; correção de Rio Canumã, um tributário da margem direito do Rio Madeira, Brasil. Holótipo na Conover Collection do Field Museum of Natural History.

Penelope superciliaris cyanosparius Nardelli, 1993:9. Localidade tipo "Cabeceira do Rio Maués, AM". Baseado em espécimes vivos, espécime tipo não existe.

Espécime tipo: Quando Neumann (1933) descreveu Penelope superciliaris pseudonyma, ele se baseou em sete espécimes sem ter designado um holótipo. Mas é claro que o sexo do espécime, o coletor, bem como a data e a localidade de coleta (após a correção de erros óbvios de interpretação da escritura na etiqueta), deixam claro qual foi o espécime que ele tinha para a descrição. O espécime estava na coleção privada do Mr. H. B. Conover, posteriormente depositado no Field Museum of Natural History (Chicago, EEUU) sob o número FMNH 407458 (Fig. 30). Por tanto, se designa este espécime como o lectótipo de Penelope pseudonyma Neumann, 1933, ação que fixa o nome a este espécime da série de sete sintipos.

Localidade-tipo: A descrição original de $P$. s. pseudonyma tem o "Rio de Cumana" como localidade-tipo, que Vanzolini (1992) incorretamente interpretou como uma leitura 
errada de "Curuá-Una" no estado de Pará. As duas etiquetas associadas ao lectótipo, coletado por H. Lako em 12 de junho de 1929 (não “janeiro”, como foi interpretado por Neumann, 1933), têm como localidade "Rio Canuma", tributário da margem direita do baixo Rio Madeira, como foi previamente observado por Vaurie (1966). A localidade-tipo e a data de coleta foram incorretamente designadas por Neumann (1933), devido à má interpretação descrito à mão nas etiquetas antigas anexadas ao espécime (Fig. 29).

Nome comum: Português: jacu-de-face-azul. Espanhol: Pava de cara azul. Inglês: Bluefaced guan.

Diagnose: Pouco variáveis na coloração geral, tão escuros como a maioria dos indivíduos de $P$. superciliaris da Amazônia e todos os de P. alagoensis. Bordas das penas das asas largas e ferrugíneas de intensidade forte ou media. Linha superciliar fina e branca. Pele nua da face azul brilhante.

Re-descrição: Sem dimorfismo sexual pela coloração da plumagem ou tamanho. Padrões de plumagem pouco variável. Com cabeça escura e linha superciliar fina e branca, menos contrastante que nas outras espécies. Borda branca nas penas do peito que também contorna a totalmente a pena, dando uma aparência escalada. Dorso de brilho esverdeado forte que dá uma aparência escura. Bordas das penas coberteiras e rêmiges são largas de cor ferrugíneo de intensidade forte ou media. Em todos os indivíduos o peito é quase tão escuro como o dorso, e o ventre é da mesma cor que a região uropigial, esta última relacionada com a cor da borda das penas das asas. A cauda é longa, esverdeada e com brilho laranja. Aparentemente em alguns indivíduos a barbela é bicolor, com extremo anterior preto 
bastante reduzido e quase imperceptível, e todo o resto vermelho ou laranja avermelhado. Pés cinzas e a íris varia de vermelho a marrom independente do sexo. É a única das quatro espécies cujos indivíduos têm a pele nua do rosto de cor azul brilhante.

Distribuição: Penelope pseudonyma parece restrita ao interflúvio Madeira-Tapajós da Amazônia central brasileira.

\section{Material examinado $(n=9)$}

BRASIL. Amazonas: Rio Amazonas (Sul), Lago do Baptista (1 $\widehat{\jmath}$ - MZUSP 17765); Rio Parauari (margem esquerda), $5 \mathrm{~km}$ abaixo da Cachoeira Tambor (1 q- MZUSP 86399, $1 \hat{\jmath}-$ MZUSP 86400); Rio Sucunduri (margem direita), igarapé do Prego (1 §ิ- MZUSP 95764); Rio Sucunduri (margem direita), em frente a Ilha do Castanho (1 ND- MZUSP 95762); Rio Sucunduri (margem esquerda) 60km abaixo da BR-230, Ponto 08 (1 q- MZUSP 97239, 1

ڤึ- LSUMZ B-80658); Left bank Rio Sucunduri, right bank lower Rio Campinarana (1 ڤิLSUMZ B-86475), Rio Canumã, a tributary to the right bank of the lower Madeira River (1 १- FMNH 407458, Holótipo de Penelope superciliaris pseudonyma).

\subsubsection{Notas taxonômicas}

Penelope superciliaris pseudonyma foi uma das três novas subespécies propostas por Oscar Neumann (1933). Alguns anos depois, Hellmayr \& Conover (1942) o sinonimizaram com P. s. superciliaris. A maioria dos autores modernos continuam seguindo essa proposta (del Hoyo \& Kirwan, 2017), embora essas suposições careçam de comparação formal de material e uma clara razão. Mais recentemente, Nardelli (1993) descreveu $P . \quad s$. 
cyanosparius a partir de espécimes vivos mantidos em cativeiro, sem holótipo ou qualquer outro espécime depositado em coleções científicas ou museus. A descrição é curta com uma breve comparação com outros táxones, e seguidas apenas por uma prancha a cores. Este procedimento validou o nome proposto, mas não permitiu uma comparação objetiva entre esse táxon e os espécimes de outros táxons ou populações.

Neumann (1933) menciona que esta raça difere de todas as outras por ter na maioria dos casos nenhuma linha superciliar ou apenas uma fina linha branca, e cor geral mais escuro que $P$. s. superciliaris; centrando sua descrição na coloração da plumagem, curiosamente sem considerar a pigmentação das regiões nuas escritas por Lako no rótulo do espécime: "Iris carmine. Feet carmine. Naked skin about eye + under bill blue-black. Throat cinnabar red". Cerca de 60 anos depois, P. superciliaris cyanosparius foi descrita por Nardelli (1993) como um táxon da cabeceira do Rio Maués, no estado de Amazonas, e que em comparação com as outras subespécies se distingue pela cor azulada da pela nua na face. Os caracteres propostos para sustentar a validade de $P$. superciliaris cyanosparius Nardelli, 1993 são essencialmente os mesmos que os descritos por Neumann (1933) para $P$. s. pseudonyma, apesar de Neumann (1933) não incorporar na descrição as informações contidas no rótulo original em relação à coloração azulada do rosto considerada um caráter diagnóstico por Nardelli (1993). Além disso, a localidade-tipo dos dois táxons, Rio Canumã e Rio Maués, estão a apenas 200 km de distância. A coleta de sete espécimes do interflúvio Madeira-Tapajós por expedições lideradas pelo MZUSP em ambas margens do Rio Maués e no rio Canumã (que se torna o Rio Sucunduri acima de sua foz) confirmaram que as aves que habitam esta região possuem os caracteres atribuídos por ambos autores. Todos os espécimes possuíam a pele fácil azul brilhante no momento da coleta, que rapidamente 
desapareceu até um tom azulado muito mais sombrio. Em conclusão, Penelope pseudonyma é o nome disponível mais antigo para os jacus de cara azul do interflúvio Madeira-Tapajós (a oeste do rio Tapajós) e P. superciliaris cyanosparius Nardelli, 1993 deve ser tratado como um sinónimo júnior.

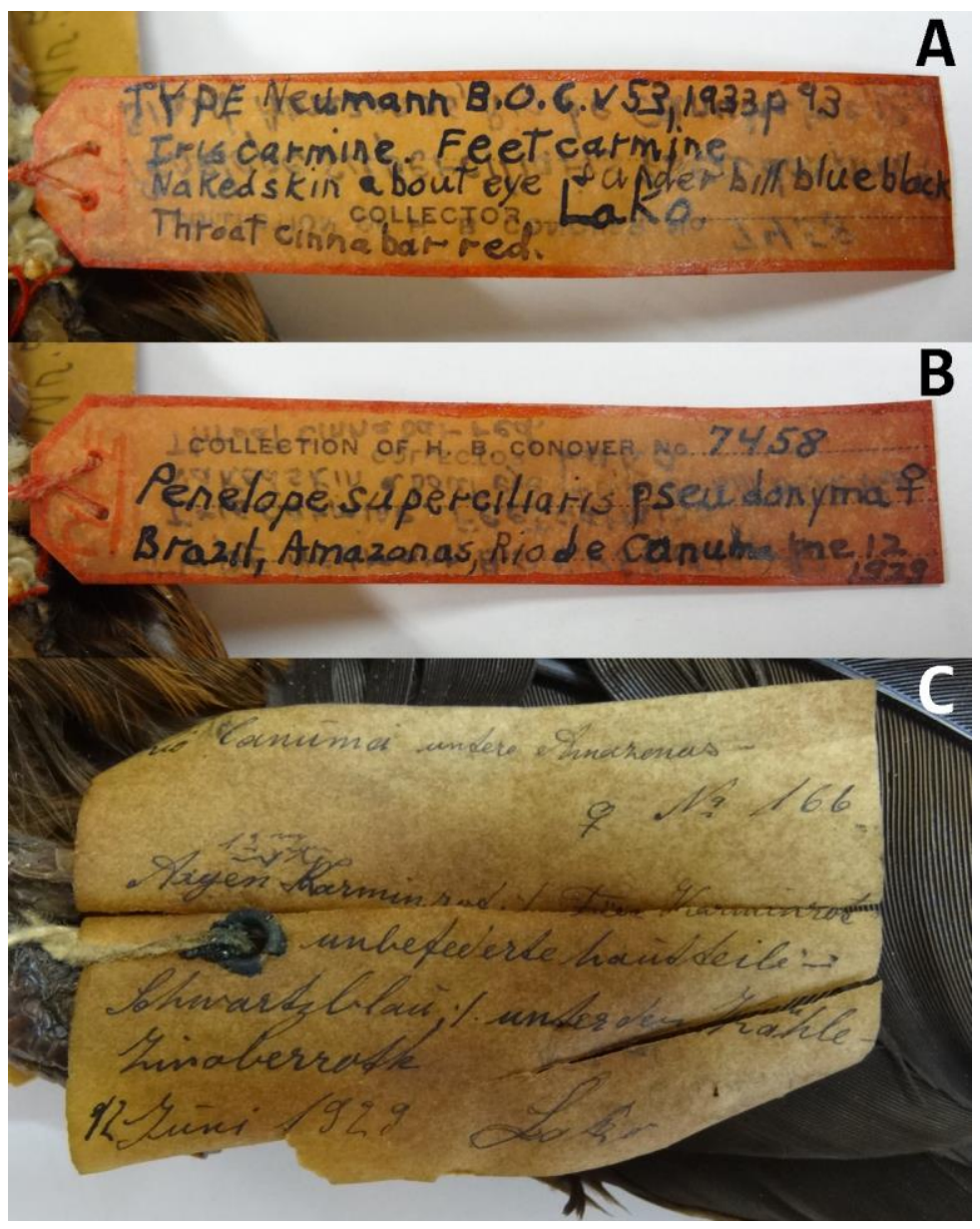

Figura 31. Ambos lados da etiqueta do exemplar FMNH 407458, traduzidos ao inglês (A e B); e etiqueta original de $\mathrm{H}$. Lako (C). Foto: Thiago V. V. Costa 


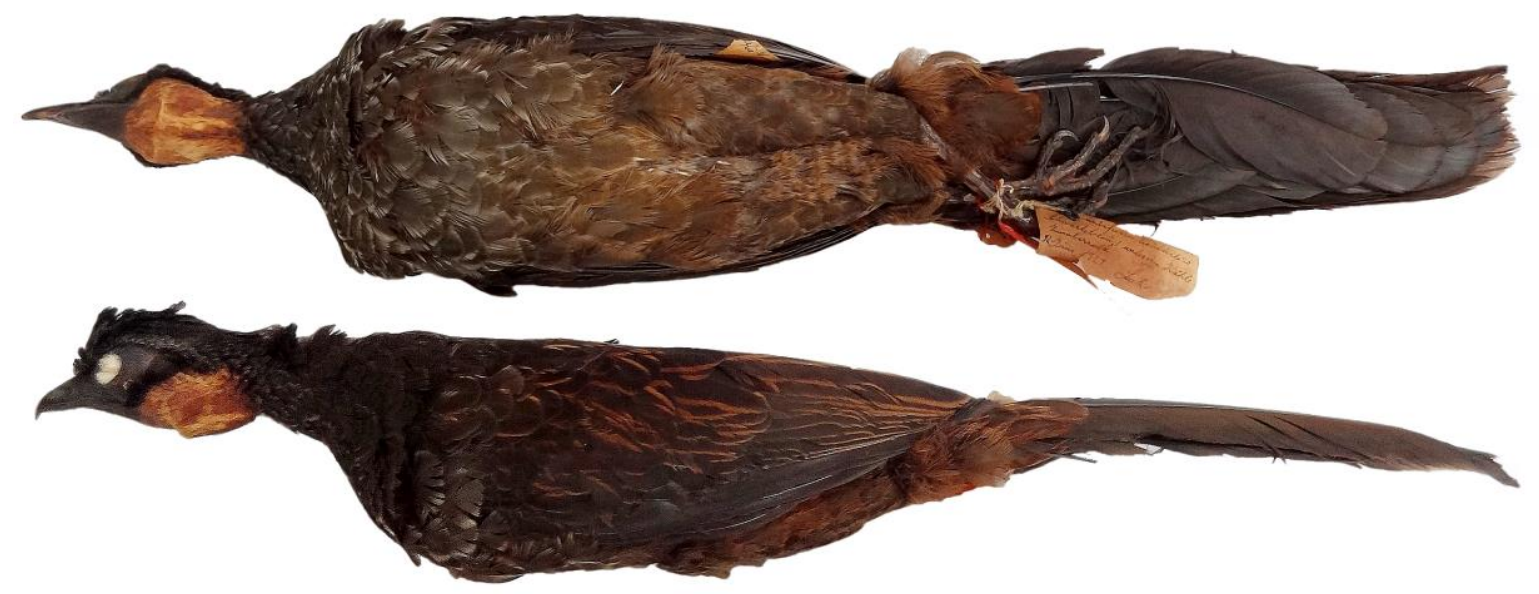

Figura 32. Exemplar FMNH 407458 designado como lectótipo de Penelope superciliaris pseudonyma. Foto: Thiago V. V. Costa

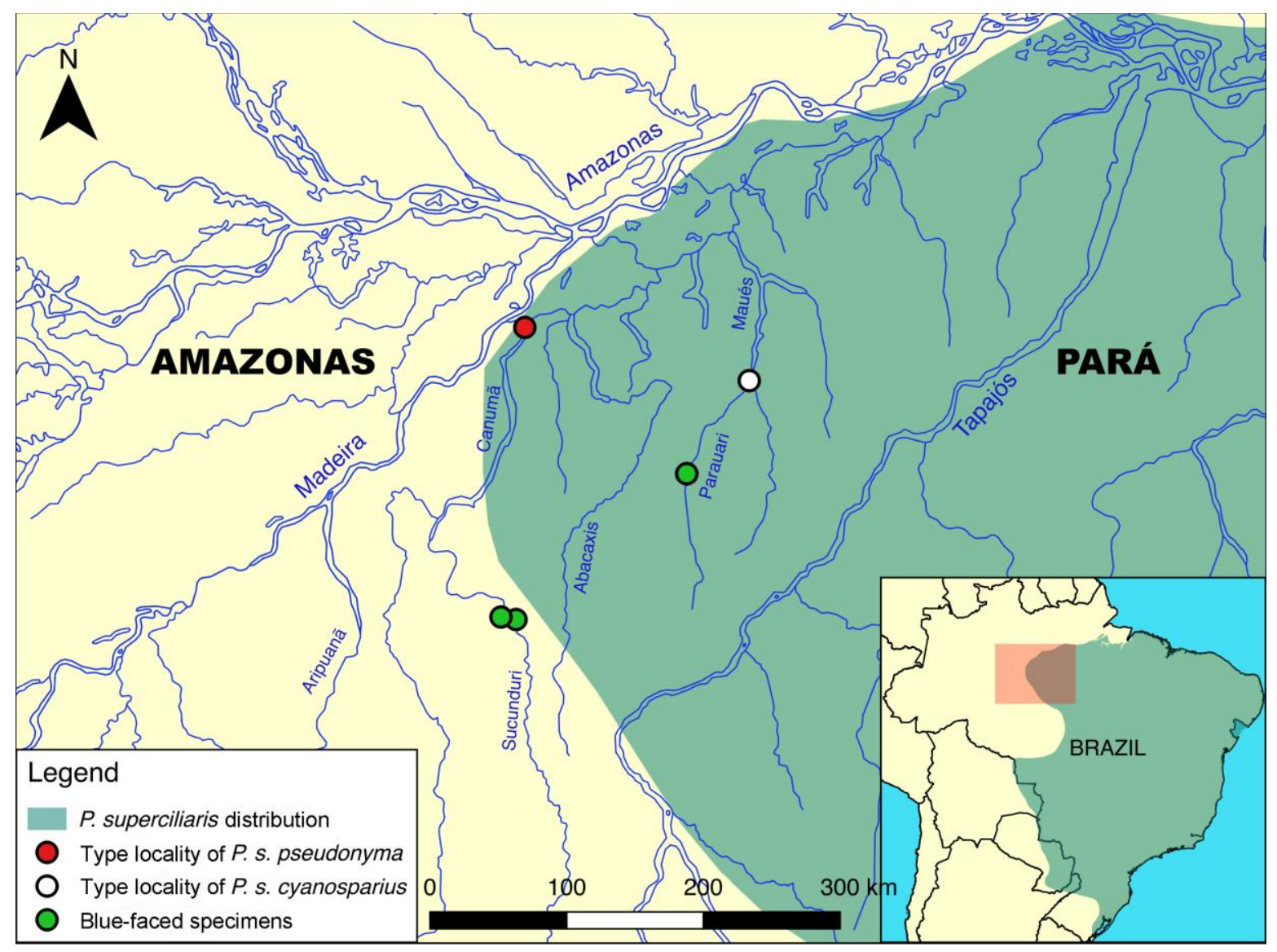

Figura 33. Localidades-tipo das subespécies propostas por Neumann (1933) e Nardelli (1993), espécimes revisados de cara azul, e distribuição geográfica conhecida do complexo Penelope superciliaris de acordo com BirdLife International \& NatureServe (2015). 


\title{
6.3. Penelope ochromitra Neumann, 1933
}

\author{
Penelope ochromitra Neumann, 1933
}

Penelope superciliaris: Sclater and Salvin, 1870:527. Not Penelope superciliaris Temminck, 1815. De Bahia até São Paulo.

Penelope superciliaris jacupemba: Hellmayr, 1906:690(22). Not Penelope superciliaris jacupemba Spix, 1825. Piauhy (=Piauí).

Penelope superciliaris ochromitra Neumann, 1933:94(53). Localidade tipo "Lagoa da Missão, próximo de Parnaguá, sul de Piauhy (=Piauí) ”. Holótipo no Museu de Viena.

Espécime tipo: Holótipo depositado no Naturhistorisches Museum Wien (Museu de História Natural de Viena) com número tombo NMW 37.972 (Schifter et al., 2007). Espécime macho coletado na Expedição de Steindachner \& Reiser o 26 de maio de 1903 por O. Reiser na Lagoa da Missão, próximo de Parnagua no sul de Piauí

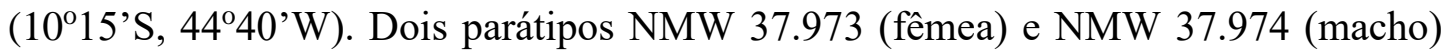
coletados na mesma localidade o 28 de maio de 1903.

Neumann (1933: 94) na sua descrição menciona que revisou três indivíduos, além disso específica quando e onde foi coletado o espécime que ele designa como holótipo, e em qual museu está depositado, mas não cita o número tombo do mesmo. É por isso que Schifter et al. (2007: 87), ao achar os três indivíduos da série no NMW, designa formalmente o exemplar NMW 37.972 como holótipo e os outros dois como parátipos, considerando o art. 72.4.5 do ICZN (1999). 
Localidade tipo: Lagoa da Missão, próximo de Paragua (= Parnaguá) no sul de Piauhy (=

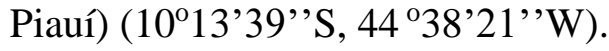

Nome comum: Português: jacu-de-supercílio-ocre. Espanhol: Pava de supercilio ocre. Inglês: Ochre-browed Guan.

Diagnose: Claramente diferenciáveis das outras espécies do complexo por ser menos escuras. São bastante variáveis, mas se diagnosticam quando seus indivíduos apresentam como mínimo duas das seguintes caraterísticas: corpo cinzento sem brilho verdoso, bordas brancas nas penas do peito bem contrastante com o peito cinza, linha superciliar ocre ou laranja e bordas largas das penas das asas que variam de laranja amarelado a ocre.

Re-descrição: Sem dimorfismo sexual pela coloração da plumagem ou tamanho. Plumagem em geral bastante variável mas com caracteres exclusivos da espécie, considero que os indivíduos são diagnosticáveis quando apresentam como mínimo duas das seguintes caraterísticas: (1) corpo em geral de matiz cinza claro e sem brilho verdoso na maioria dos seus integrantes, (2) bordas brancas nas penas do peito que contornam a totalidade da pena e que dão uma aparência escalada bastante contrastantes com peito de cor cinza claro ou algumas vezes escuro, (3) linha superciliar característica que varia desde ocre intenso até laranja claro leve, podendo também variar em largura, e (4) bordas das penas coberteiras e rêmiges das asas extensas ou medianamente largas que variam de cor laranja a ocre claro. Ventre entre marrom clara a laranja, da mesma cor que a região uropigial, que é mais escura que a cor da borda das penas das asas. A cauda é longa e de cor verde brilhante escura. É possível encontrar indivíduos de diferente padrão de coloração na mesma localidade. Aparentemente em alguns indivíduos a barbela é bicolor, com extremo anterior 
preto bastante reduzido e quase imperceptível, e todo o resto vermelho ou laranja avermelhado. Pele do rosto cinza escura, pés cinzas e a íris varia de vermelho a marrom independente do sexo.

Distribuição: Endêmica da Caatinga e das áreas de transição com o Cerrado. Se distribui na área de Caatinga dos estados de Ceará e Piauí, e no Cerrado próximo à Caatinga dos estados de Piauí, sul de Maranhão, este de Tocantins e oeste de Bahia.

\section{Material examinado pessoalmente $(n=19)$}

BRASIL. Ceará: Serra de Ibiapaba, São Paulo (1 ND- MNRJ 18891); Flona Araripe, Crato (1 †- MNRJ 36284, 1 $\precsim$ - MNRJ 36285); Piauí: Brejo do Piauí (1 ND- MZUSP 86331); Redenção do Gurguéia, Serra Vermelha (1 †- MPEG 67785); Guadalupe, Fazenda

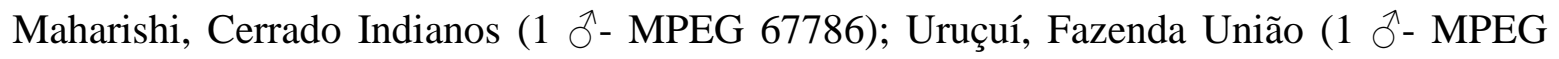
67784); Lagoa do Jacu/PN Serra das Confusões (1 q- MZUSP 77634, 1 ๙ิ- MZUSP 77635); Baixo da Casa do Pau/PN Serra das Confusões (1 q- MZUSP 77638, 2 - MZUSP 77636, MZUSP 77637); Maranhão: Balsas, Falha, Fazenda San Rodrigo (1 ๆ- MPEG 43388, 1 ๙- MPEG 43386); Alto Parnaíba, Estiva (1 q- MPEG 43387); Tocantins: ESEC Serra Geral do Tocantins (1 §̊- MZUSP 79473); Bahia: Maracujá, Santa Rita (1 qMZUSP 40773); Coribe, Colônia do Formoso (1 q- MPEG 45080, 1 §- MPEG 45079).

\section{Material examinado por fotografias $(n=7)$}

BRASIL. Piauí: Deserto (1 ઈ- FMNH 403202, 1 q- FMNH 403201); Goiás: Santo Antônio, Boa Vista (1 ふૈ- FMNH 404239); Maranhão: Fazenda Inhuma, Alto Rio Parnahyba (2 $q$ - FMNH 404241, FMNH 404240); Tranqueira, Alto Rio Parnaíba (2 qFMNH 404238, FMNH 64019). 


\subsubsection{Notas taxonômicas}

Hellmayr quando publicou seu estudo sobrea diversidade ornitológica do nordeste brasileiro (1929), mencionou que nesta região ocorre a subespécie $P$. superciliaris jacupemba. Também comentou que durante algum tempo considerou subdividir os indivíduos do leste do Brasil em duas formas com uma notória diferença: uma do norte com sobrancelhas de cor ocre, e outra do sul com sobrancelhas acinzentadas, mas não os dividiu porque não tinha visto espécimes dos estados do sul, então considerou necessário revisar mais material antes de alcançar alguma conclusão final. Ele tinha revisado o espécime tipo de $P$. jacupemba Spix, que era particularmente parecido a um macho adulto de Deserto no Piauí, só que esse último tinha a linha superciliar ligeiramente tingida de ocre escuro, e a maioria dos outros doze espécimes do sul do Brasil que revisou tinham a linha de cor cinza claro. Menciona também que outros espécimes do Museu de Viena coletados no Piauí e Goiás, também tinham conspícuas linhas superciliares desde ocre claro até ocre escuro, que se uniam na frente para frente uma linha superciliar continua. Hellmayr (1929) já tinha percebido que Penelope ochromitra era um táxon diferente de Penelope superciliaris jacupemba, mas não fez a sua separação formal. Apesar disso, provavelmente depois de ter lido o trabalho de Hellmayr, quatro anos depois Neumann (1933) descreveu P. superciliaris ochromitra, baseado em três espécimes do Museu de Viena.

Hellmayr \& Conover (1942) já consideravam P. s. ochromitra como uma subespécie válida que ocorre no nordeste do Brasil nos estados de Maranhão, Piauí e a seção adjacente ao norte de Goiás (Boa visto, baixo Tocantins). Olivério Pinto $(1964,1978)$ é um outro autor que considerou como válida esta subespécie de Penelope superciliaris no 
nordeste de Brasil, assegurando também que ocorre desde Maranhão ao oeste de Bahia, inclusive no norte de Goiás (baixo Tocantins).

Vaurie (1966) sinonimizou Penelope superciliaris ochromitra com P. superciliaris jacupemba Spix, 1825, mencionando que essa subespécie substituía à nominal desde Maranhão até o sul através do este e centro do Brasil, sem atingir os estados de Santa Catarina e Rio Grande do Sul onde era substituída por major, proposta taxonômica que é considerada válida até hoje (del Hoyo \& Kirwan, 2017).

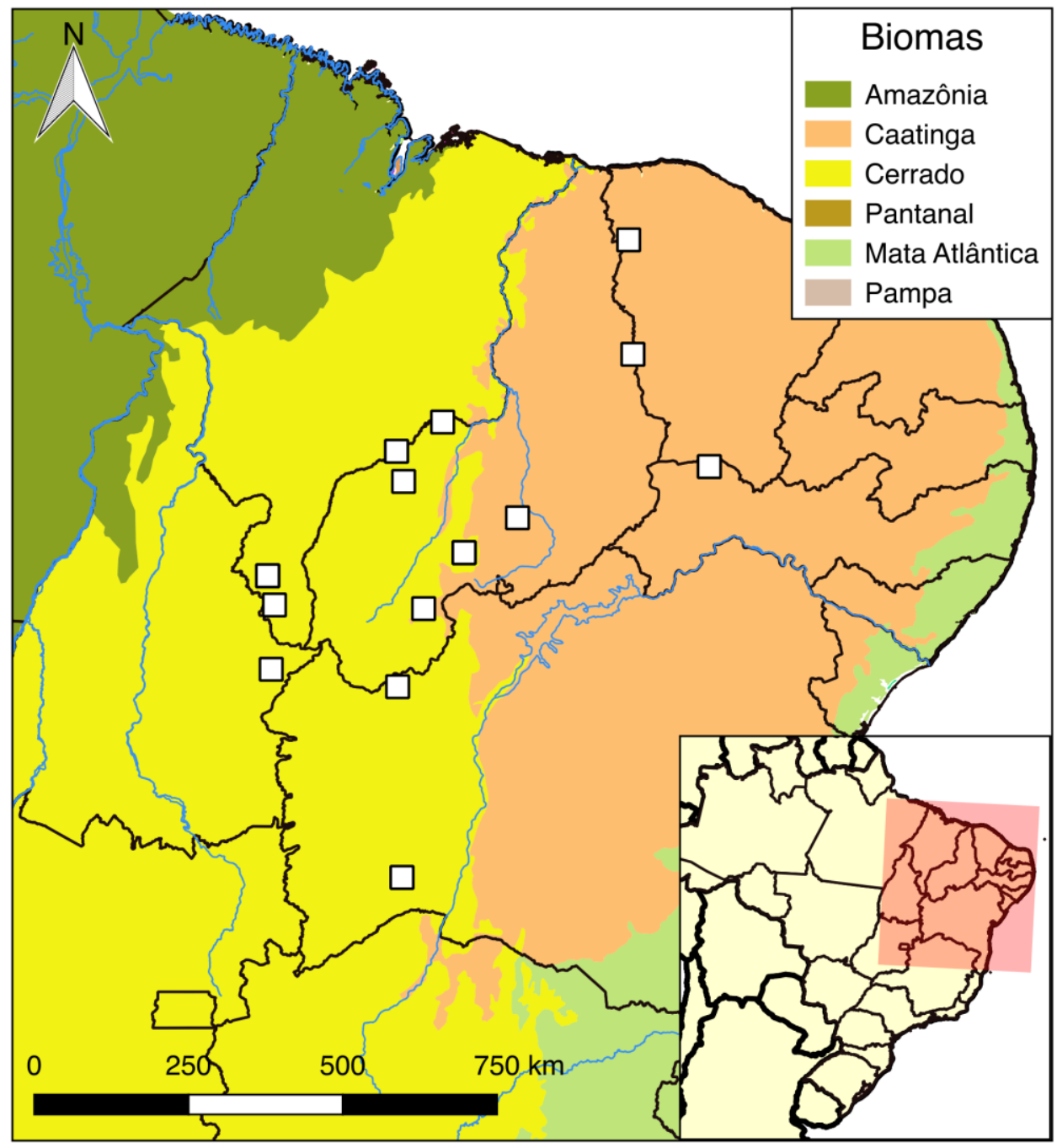

Figura 34. Espécimes de museus de Penelope ochromitra Neumann, 1933, identificados com base no presente estudo. 

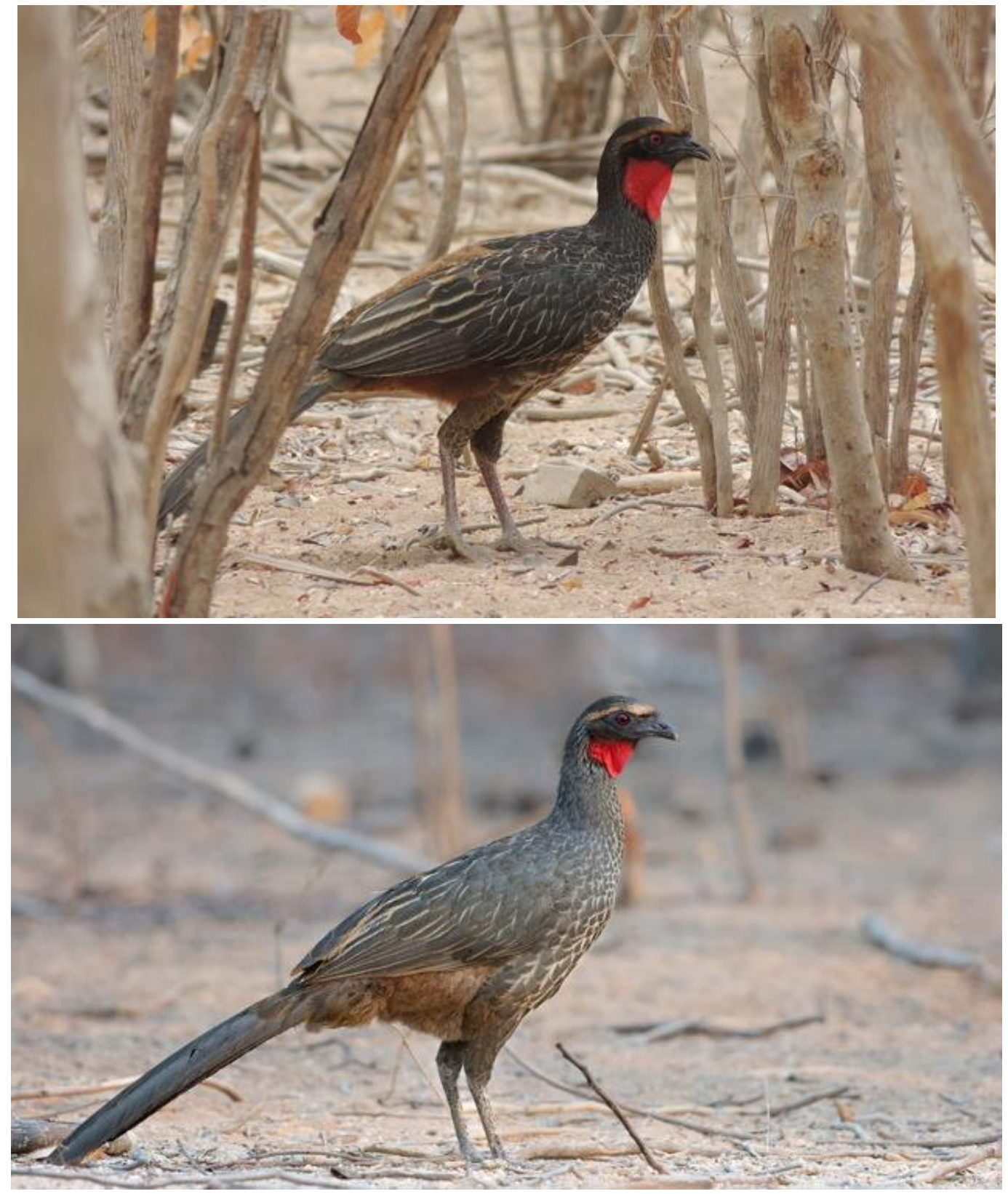

Figura 35. Indivíduos de Penelope ochromitra Neumann, 1933, identificados com base no presente estudo. Arriba: Coronel José Dias - Piauí (autor: Leandro Machado de Moura); embaixo: Coronel José Dias - Piauí (autor: Guto Balieiro). 


\title{
6.4. Penelope alagoensis Nardelli, 1933
}

\author{
Penelope alagoensis Nardelli, 1993
}

Penelope superciliaris: Forbes, 1881:357. Not Penelope superciliaris Temminck, 1815. Panellas, perto de Quipapá, Pernambuco.

Penelope superciliares alagoensis Nardelli, 1993:11. Pronunciação original errada de Penelope superciliaris alagoensis Nardelli, 1993. Localidade tipo "Região costeira dos estados de Alagoas e Pernambuco, Brasil". Baseado em espécimes vivos, espécime tipo não existe.

Penelope superciliaris alagoensis: Silveira, Olmos \& Long, 2003:33. Pronunciação certa de Penelope superciliares alagoensis Nardelli, 1993.

Espécime tipo: Quando Nardelli (1993) descreveu Penelope alagoensis acompanhado por uma ilustração do táxon, teve como base o estudo de exemplares de cativeiro, sem procedência e que não foram depositados em nenhuma coleção científica. Ele designou um macho como holótipo e uma fêmea como parátipo, só que o destino deles é desconhecido. É por isso que, seguindo o Artigo 73.1.4 do Código Internacional de Nomenclatura Zoológica (ICZN, 1999), o holótipo válido de Penelope alagoensis é a ilustração que acompanha a descrição original do táxon. O Artigo 73.1.4 diz: "A designação de uma ilustração de um único espécime como um holótipo deve ser tratada como designação do espécime ilustrado; o fato do espécime não existir mais ou não poder ser rastreado não invalida por si só a designação". 
Localidade-tipo: Nardelli (1993: 11) menciona como localidade-tipo o Litoral dos Estados de Alagoas e Pernambuco, - Brasil.

Nome comum: Português: jacu-de-Alagoas. Espanhol: Pava de Alagoas. Inglês: Alagoas Guan.

Diagnose: Coloração geral uniforme, é a menos variável das quatro espécies. São tão escuros como a maioria dos indivíduos de $P$. superciliaris da Amazônia e todos os de $P$. pseudonyma. Mais parecidos com os indivíduos da Amazônia que com os da Mata Atlântica ao sul do rio São Francisco. Bordas das penas das asas ferrugíneas bem escuras e pouco contrastantes com as asas. Linha superciliar larga de penas brancas brilhantes que se unem na frente.

Re-descrição: Não posso assegurar que não exista dimorfismo sexual, seja pela coloração da plumagem ou pelo tamanho, nem se os indivíduos imaturos são similares aos adultos devido ao baixo número de exemplares. Coloração geral uniforme, é a menos variável das quatro espécies. Com linha superciliar larga de penas brancas brilhantes que se unem na frente notoriamente contrastantes com a cabeça escura em todos os indivíduos. Borda branca nas penas do peito bastante contrastante que contorna totalmente a pena, dando uma aparência escalada. Dorso de brilho escuro que dá uma aparência bastante enegrecida. Bordas das penas coberteiras e rêmiges são largas de cor ferrugíneo bem escuro e contrastantes com as asas. Região uropigial da mesma tonalidade que as bordas das penas das asas. Coloração geral tão escura como a maioria dos indivíduos de $P$. superciliaris da Amazônia e todos os de $P$. pseudonyma. Notoriamente mais parecidos com os indivíduos da Amazônia que com os da Mata Atlântica ao sul do rio São Francisco. A cauda é longa de 
cor verde brilhante escura. Os poucos espécimes revisados tinham barbela bicolorida, com extremo anterior preto bastante reduzido e quase imperceptível, e todo o resto vermelho intenso. Os pés são marrões arroxados e íris marrom nos poucos espécimes revisados.

Distribuição: É endémica da Mata Atlântica, ocorrendo só em uma faixa de floresta no Centro de Endemismo Pernambuco, no litoral dos estados nordestinos de Alagoas e Pernambuco.

\section{Material examinado $(\mathbf{n}=3)$}

BRASIL. Alagoas: Faz. Santa Justina, Passo de Camaragibe (1 q- MZUSP Holótipo de Penelope alagoensis, 1 ઈ- MNRJ 34855). Paraíba: Mamanguape, Camaratuba (1 NDMZUSP 39439).

\subsubsection{Notas e taxonômicas}

As populações de Penelope alagoensis Nardelli, 1993 atualmente são consideradas como criticamente ameaçadas de extinção, por ser a caça uma atividade frequente na sua área de ocorrência (Teixeira, 1997; Silveira et al., 2008). No entanto, por ser atualmente tratada com uma subespécie de $P$. superciliaris, não está incluída em programas de conservação. O chamado Centro de Endemismo Pernambuco é um cinturão florestal ao norte do Rio São Francisco (Prance, 1982), e inclui tanto as florestas costeiras quanto a complexa área de transição entre elas e os habitats mais secos do interior (Silveira et al., 2003). É considerado uma área de intercâmbio entre as biotas das Matas Atlântica e 
Amazônica, com os animais tipicamente amazônicos ocorrendo junto com os táxones da Mata Atlântica (Coimbra-Filho \& Câmara, 1996).

É provável que os níveis de endemismo sejam ainda maiores no Centro Pernambuco, já que vários táxons atualmente considerados como subespécies poderiam ser espécies biológicas (BSC) ou filogenéticas (PSC) uma vez que sejam realizados estudos taxonômicos detalhados (Silveira et al., 2003). É por isso que, a partir do presente trabalho, proponho considerar a Penelope alagoensis como uma espécie válida que deve ser incluída em programas de conservação. A maioria de pesquisas que envolvem este táxon, são relacionadas com o tema da conservação dos cracídeos do Nordeste do Brasil, como os trabalhos de Silveira et al. (2003), Silveira \& Olmos (2003), Silveira et al. (2008) e Silveira (2008), que propõem urgentemente revisar a taxonomia do complexo Penelope superciliaris.

Olivério Pinto (1954) considerava relevante estudar a avifauna silvestre do estado de Alagoas, de transcendental importância por ser amaçada de desaparecimento em um futuro próximo, como consequência do progresso acelerado de deflorestação. Acrescentando que, essa é uma área com muitas formas ainda não conhecidas, e com laços zoogeográficos existentes entre a faixa atlântica meridional e a Amazônia em particular. Como resultado das duas expedições ao estado de Alagoas, de 1951 e 1952 (São Miguel e Mangabeira, respectivamente), encontrou bom número de formas estritamente nordestinas e até então conhecidas só para Pernambuco (Pinto, 1940), entre elas um único exemplar de Pauxi mitu, único representando dos cracídeos que encontrou.

Não foi até 1993 que Penelope alagoensis foi mencionada, quando Pedro Nardelli descreveu uma nova subespécie de Penelope superciliaris do litoral dos estados de Alagoas 
e Pernambuco, indicando que em comparação com outros representantes da espécie, notase um tamanho menor, coloração geral mais escura, e uma linha superciliar branca distinta.

Anos depois, Silveira \& Olmos (2003) indicaram que esta população é generalista, capaz de lidar com o desmatamento de habitat e até mesmo níveis bastante elevados de caça. Encontraram a espécie em cinco de 15 fragmentos florestais avaliados do estado de Alagoas, que variam desde florestas bem conservadas a muito degradadas. Também indicam que esta é a forma local do jacupemba em Alagoas, recentemente descrita por Nardelli mas ignorada, sem estar categorizada em algum status de ameaça e que merece uma especial atenção porque possivelmente representaria um novo táxon endémico do Centro Pernambuco, acrescentando que o complexo P. superciliaris está sob estudo deles, e planejam coletar material adicional desta população.

Silveira et al. (2008) listaram o táxon dentro das espécies ameaçadas na categoria em perigo, por ser ameaçado pela caça, uma atividade frequente na sua área de ocorrência que vem dizimando os últimos representantes desta forma, além do corte seletivo para carvão e lenha e fragmentação do seu ambiente. Mais do $95 \%$ do habitat onde poderia ocorrer já desapareceu, sendo o desmatamento o que originou a desaparição de $P$. alagoensis em Alagoas, uma espécie que não é comum em áreas com um alto de grau de perturbação, embora $P$. alagoensis seja uma espécie bem tolerante a habitats degradados. Frequentam matas preservadas e mesmo secundárias, sendo também possível encontrar indivíduos em alguns remanescentes de Alagoas e Pernambuco, podendo ocorrem também na Paraíba e Rio Grande do Norte, então por enquanto tem limites desconhecidos.

A descrição desta subespécie é cercada de problemas, pois teve como base o estudo de exemplares de cativeiro sem procedência e que não foram depositados em museus, além da sua localidade-tipo precisa ser desconhecida (Silveira, 2008). O destino destes 
exemplares, assim como dos outros exemplares do complexo P. superciliaris que o autor da descrição usou para comparar, é desconhecido. Até o momento era impossível realizar qualquer comparação cuidadosa com as outras formas desde complexo sem a revisão de espécimes de museu, mas atualmente o MZUSP é a única instituição no mundo cuja coleção científica alberga espécimes das quatro espécies do complexo Penelope superciliaris.

Agora que determinamos a validade desta espécie, recomenda-se a proteção efetiva das localidades onde está espécie foi registrada, e busca de novas populações com coleta de exemplares nos estados do nordeste. Assim como deve ser feita a captura de alguns indivíduos para iniciar programas de reprodução em cativeiro, com vista a reintrodução nos fragmentos onde a espécie desapareceu. 


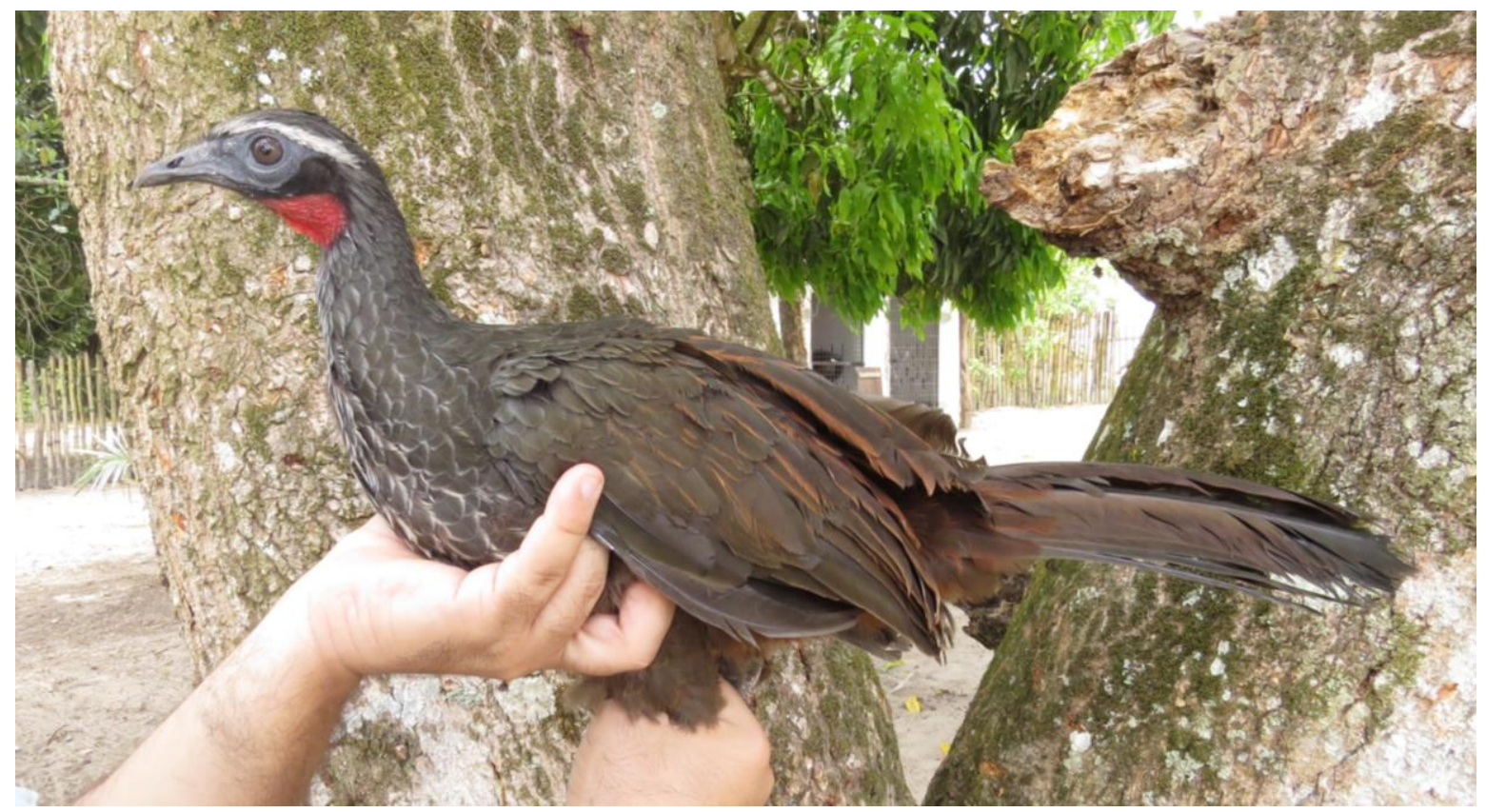

Figura 36. Indivíduo de Penelope alagoensis.

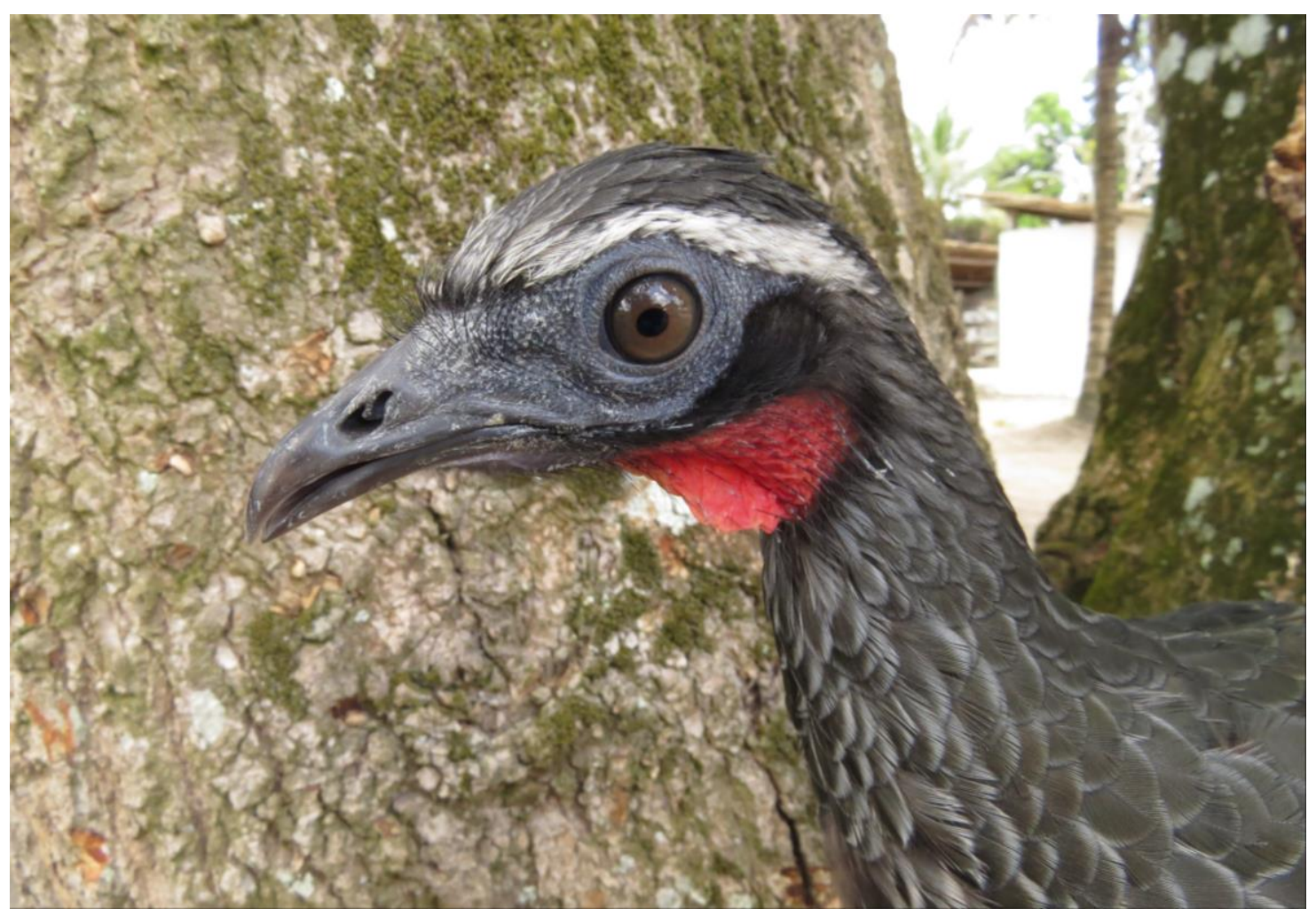

Figura 37. Superciliar branco largo e brilhante, característico de $P$. alagoensis. 


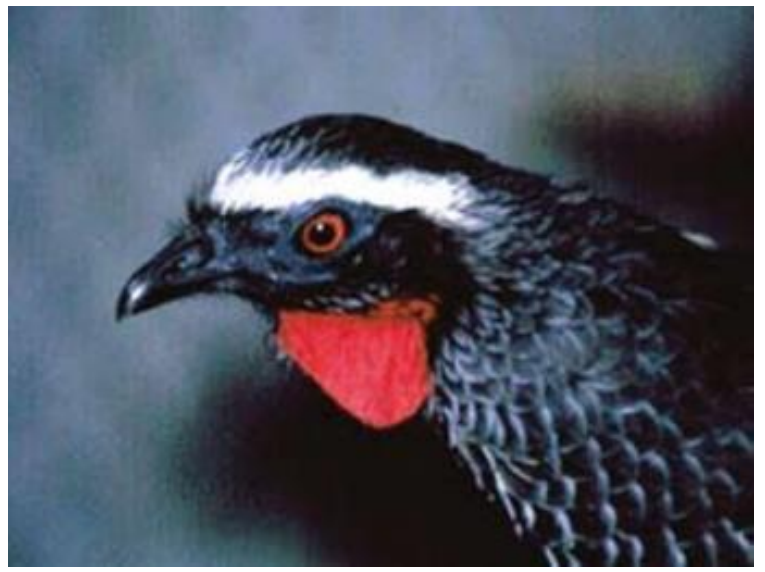

Figura 38.Penelope

algoensis no Criadouro

Científico e Cultural Poços

de Caldas. Foto: Luís Fábio

Silveira (Extraido de

Silveira et al., 2008).

Figura 39.

Mapa com registros de ocorrência de

Penelope alagoensis em usinas, reservas biológicas, reservas particulares e estações ecológicas nos estados de AL, PE, PB e RN. (Extraído de

Silveira et al., 2008).

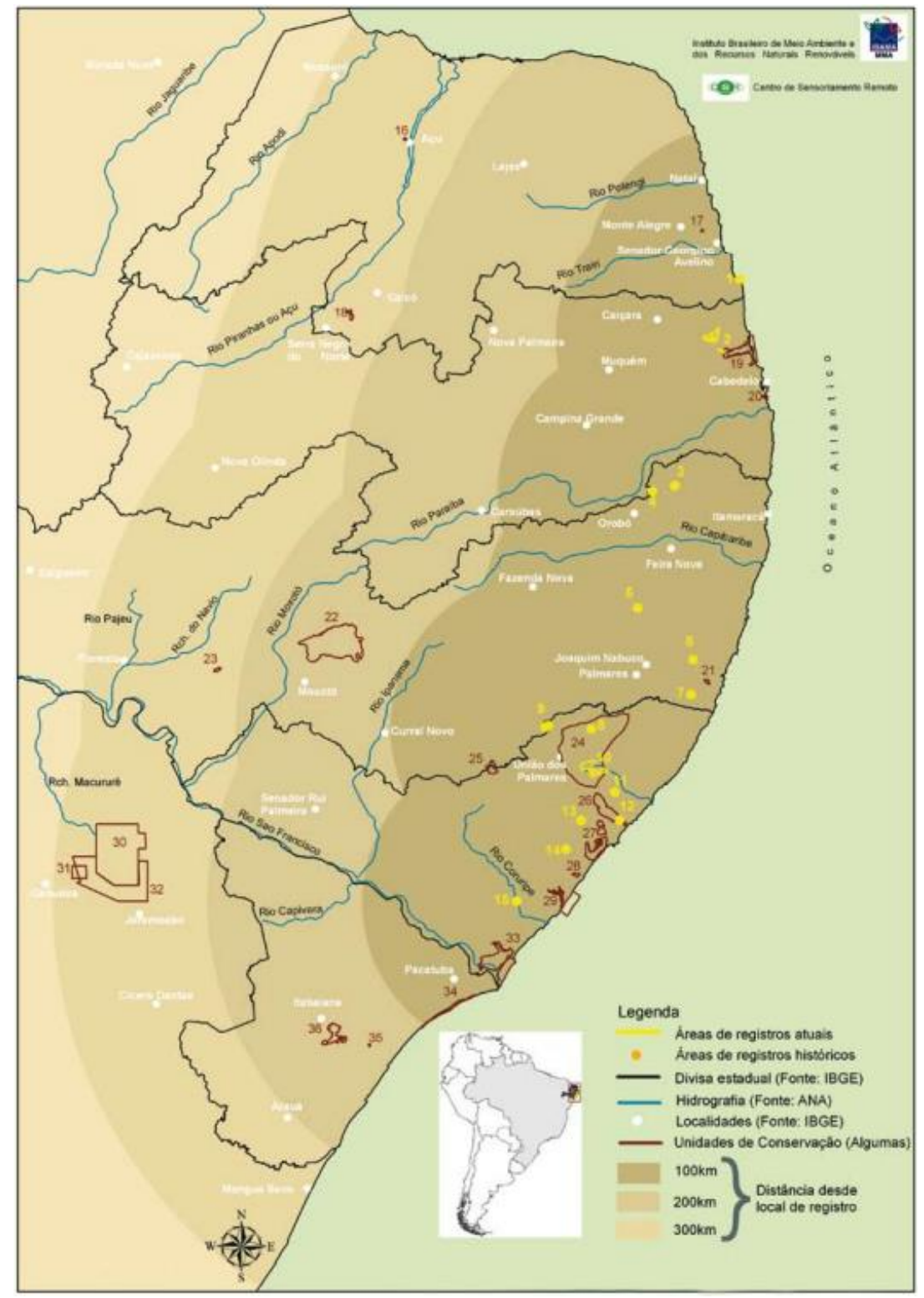



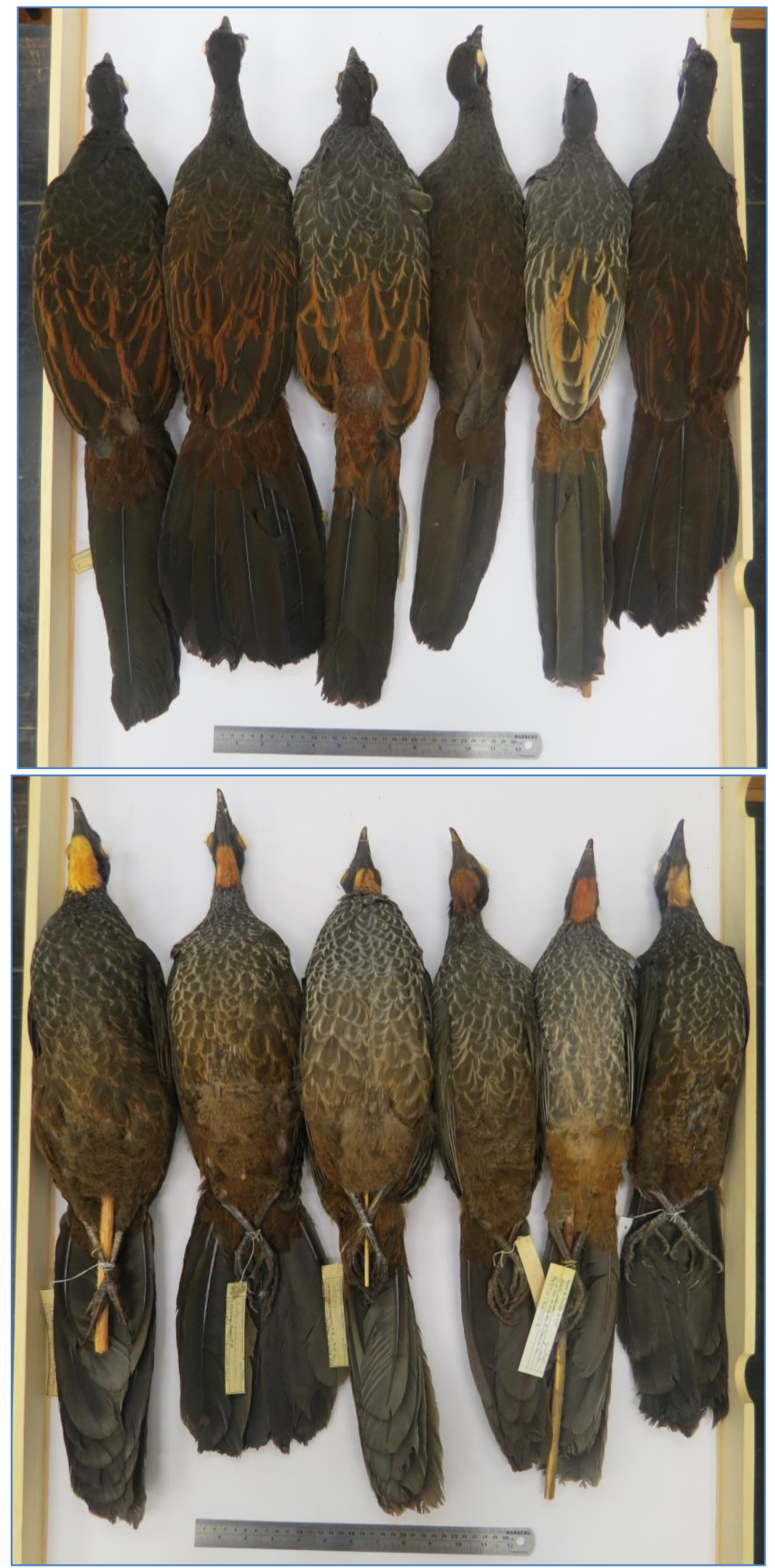

Figura 40. Vista dorsal e ventral das quatro espécies diagnosticadas (de esquerda à direita): espécimes de Penelope pseudonyma (1), Penelope superciliaris (2-4), Penelope ochromitra (5) e Penelope alagoensis (6).

\section{1: MZUSP 86400}

(Margem esquerda do Rio Parauari, AM)

\section{2: MZUSP 95546}

(margem direita do Rio

Xingu, Anapu - PA)

\section{3: MZUSP 83731}

(Santa do Araguaia,

Fazenda Fartura - PA)

\section{4: MZUSP 49342}

(Ribeirão Fundo - SP)

\section{5: MZUSP 77635}

(P.N. Serra das Confusões, Lagoa do Jacu - PI)

\section{6: MZUSP SN}

(Fazenda Santa Justina, Passo de Camaragibe - AL) 


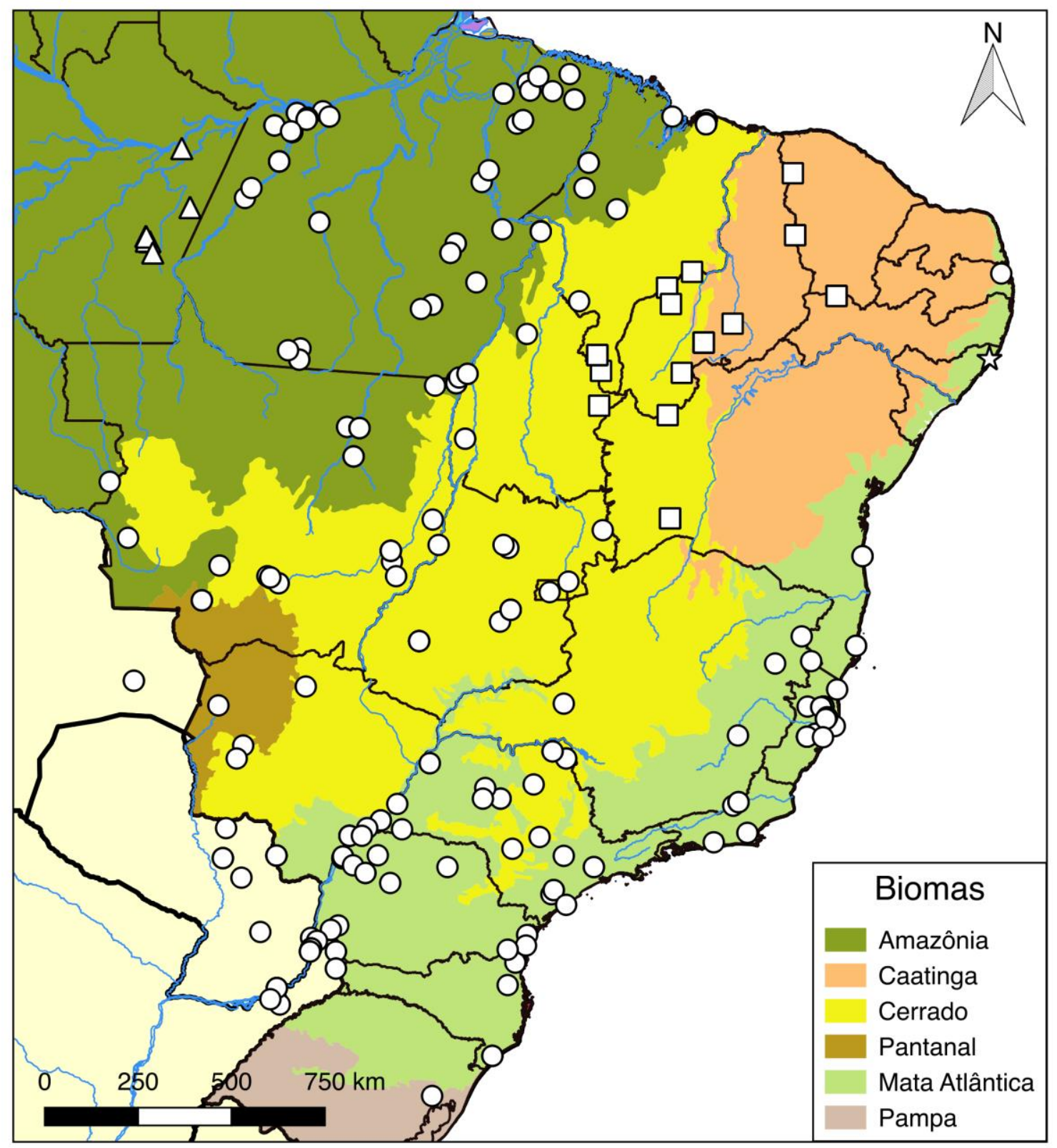

Figura 41. Espécimes de museus das quatro espécies do complexo Penelope superciliaris, separadas com base no presente estudo. Penelope superciliaris (círculos), Penelope ochromitra (quadrados), Penelope pseudonyma (triângulos) e Penelope alagoensis (estrela). 


\section{CONCLUSÕES}

- O complexo Penelope superciliaris Temminck, 1815 se divide em quatro espécies: Penelope superciliaris Temminck, 1815, Penelope pseudonyma Neumann, 1933, Penelope ochromitra Neumann, 1933 e Penelope alagoensis Nardelli, 1993;

- As quatro espécies não presentam dimorfismo sexual;

- Penelope superciliaris mostra uma alta variação na coloração da plumagem, sem estar associada a algum padrão geográfico bem delimitado;

- As espécies Penelope pseudonyma, P. ochromitra e P. alagoensis são endêmicas do Brasil. 


\section{REFERÊNCIAS BIBLIOGRÁFICAS}

Adobe ${ }^{\circledR}$ Creative Suite ${ }^{\circledR} 4$ Photoshop ${ }^{\circledR}$. 2008. JavaScript Scripting References for Windows ${ }^{\circledR}$ and Macintosh ${ }^{\circledR}$. Adobe Systems Incorporated, California, USA. Disponível em: http://www.adobe.com/br/products/photoshop.html

Arribas, M.A.; Jammes, L. \& Sagot, F. 1995. Lista de las Aves de Bolivia. Armonía/BirdLife International.

Barrowclough, G.F. 1982. Geographic Variation, Predictiveness, and Subspecies. The Auk 3: 601-603.

Baldwin, S.P.; Oberholser, H.C. \& Worley, L.G. 1931. Measurements of Birds. Scientific Publications of the Cleveland Museum of Natural History 2: $1-165$.

Baumel, J.J.; King, A.S.; Breazile, J.E.; Evans, H.E. \& Vanden Berge, J.C. 1993. Handbook of Avian Anatomy: Nomina Anatomica Avium. Second Edition. Publications of the Nuttall Ornithological Club, $\mathrm{N}^{\circ} 23$, Cambridge, Massachusetts.

Bertoni, A. de W. 1901. Aves Nuevas del Paraguay. Catálogo de las aves de Paraguay. Asunción: Anal. Cient. Parag. 216p.

BirdLife International and NatureServe. 2015. Birds species distribution maps of the world. BirdLife International, Cambridge, UK and NatureServe, Arlington, USA.

Blanchard, M.E. 1857. De la détermination de quelques Oiseaux Fossiles et des caratères Ostéologiques des Gallinacés ou Gallides. In: M. Milne Edwards, A.D. Brongniart \& J. 
Decaisne. Annales des Sciences Naturelles. Série 4, Tome VII, Paris. Pp. 91-106, Planche 10-12.

Bock, W.J. 2004. Species: the concept, category and taxon. Journal of Zoological Systematics and Evolutionary Research 42: 178-190.

Brooks, D.M.; Begazo, A.J. \& Pautrat, L. 2001. Ethics and realities of Cracid conservation: The Latin American perspective. In: Biology and Conservation of Cracids in the New Millenium, D.M. Brooks and F. Gonzalez. Eds, 2: 51-60. Houston, TX: Misc. Publ. Houston Mus. Nat. Sci.

Buffon, Georges Louis Leclerc de. 1772. Histoire naturelle des Oiseaux, Tome troisième. $417 \mathrm{p}$.

Chalukian, S. 1997. Estudio Preliminar de la Pava de Monte (Penelope obscura) en el Parque Nacional El Rey, Argentina. In: The Cracidae, Their Biology and Conservation, Strahl, S.D.; Beaujon, S.; Brooks, D.M.; Begazo, A.J.; Sedaghatkish, G. \& Olmos, F. Eds, 64-70. USA \& Canada: Hancock House.

Coimbra-Filho, A.F. \& Câmara, I.G. 1996. Os limites originais do Bioma Mata Atlântica na região Nordeste do Brasil. FBCN, Rio de Janeiro.

Cracraft, J. 1983. Species concepts and speciation analysis. Current Ornithology 1: 159187.

Cracraft, J. 1989. Speciation and its ontology: the empirical consequences of alternative species concepts for understanding patterns and processes of differentiation. In: 
Speciation and its Consequences. D. Otte \& J.A. Endler (Eds.). Massachusetts, Sinauer Associates. Pp. 28-59.

Crowe, T.M.; Bloomer, P.; Randi, E.; Lucchini, V.; Kimball, R.; Braun, E. \& Broth, J.G. 2006. Supra-generic cladistics of landfowl (Order Galliformes). Acta Zoologica Sinica, Supplement (52): 358-361.

Delacour, J. \& Amadon, D. 2004.Curassows and Related Birds: Second edition. Barcelona and New York, Lynx Edicions and The National Museum of Natural History. 476p.

del Hoyo, J.; Elliott, A. \& Sargatal, J. 1994. Handbook of the Birds of the World; Volume 2: New World Vultures to Guineafowl. Barcelona, Lynx Edicions. 638p.

del Hoyo, J. \& Kirwan, G.M. 2016. Rusky-margined Guan (Penelope superciliaris). In: del Hoyo, J.; Elliot, A.; Sargatal, J.; Christie, D.A. \& de Juana, E. (Ed). Handbook of the Birds of the World Alive. Available online at: http://www.hbw.com/node/53285 [Accessed: 15/11/2016]

del Hoyo, J. \& Motis, A. 2004. Update Chapter, p. 322-476. In: Lynx Edicions. Curassows and Related Birds: Second edition. Barcelona and New York, The National Museum of Natural History, 476p.

Donoghue, M.J. 1985. A critique of the biological species concept and recommendations for a phylogenetic alternative. Bryologist 88: 172-181. 
Ecoregistros®. 2016. [Mapa de registros da espécie Yacupoí (Penelope superciliaris) ]. Ecoregistros.org - Registros Ecológicos de la Comunidad. Disponível em: http://www.ecoregistros.org/ficha/Penelope-superciliaris

Frank-Hoeflich, K.; Silveira, L.F.; Estudillo-López, J.; García-Koch, A.M.; Ongay-Larios, L. \& Piñero D. 2007. Increased taxon and character sampling reveals novel intergeneric relationship in the Cracidae (Aves: Galliformes). J Zool Syst Evol Res, 45 (3): 242-254.

Gardner, A.I. \& Hayssen, V. A. 2004. Guide to Constructing and Understading Synonymies for Mammalian Species. Mammalian Species 739: 1-17. American Society of Mammalogists.

Google Earth. 2016. Google Inc., California, USA. Disponível em: https://www.google.com/earth/

Guix, J.C. 1997. Exclusão geográfica e ecológica de Penelope obscura, Penelope superciliaris e Pipile jacutinga (Galliformes, Cracidae) no estado de São Paulo. Ararajuba 5 (2): 195-202.

Guix, J.C. \& Ruiz, X. 1997. Weevil larvae dispersal by guan in SE Brazil. Briotrop. 29: $522-525$.

Haffer, J. 1967. Some allopatrics species pairs of birds northwestern Colombia. Auk 86: 343-365.

Hayes, F.E. 1995. Status, distribution, and biogeography of the birds of Paraguay. American Birding Association, Colorado. 230p. ISBN 1878788302. 
Hellmayr, C.E. 1929. A contribution to the Ornithology of Northeastern Brazil: Vol. XII, No. 18. Zoological Series, Field Museum of Natural History, Chicago USA. 501p.

Hellmayr, C.E. \& Conover, B. 1942. Catalogue of Birds of the Americas and the adjacent islands in Field Museum of Natural History: Part I, Number 1. Chicago, Zoological Series of Field Museum of Natural History. 636p.

Hennessey, A.B.; Herzog, S.K. \& Sagot, F. 2003. Lista Anotada de las Aves de Bolivia. Quinta edición. Santa Cruz de la Sierra, Bolivia. Armonía/BirdLife International.

Huxley, T.H. 1868. On the Classification and Distribution of the Alectoromorphae and Heteromorphae. Proceedings of the Zoological Society of London, London. Pp. 294319.

IBGE. 2012. Manual Técnico da Vegetação Brasileira. Instituto Brasileiro de Geografia e Estatística, Rio de Janeiro, Brasil. ISSN 0103-9598.

Illiger, C. 1811. Prodromus Systematis Mammalium et Avium. Berolini, Sumptidus C. Salfeld.

International Commission on Zoological Nomenclature - ICZN. 1999. International Code of Zoological nomenclature. Fourth Edition. The International Trust for Zoological Nomenclatura, London, UK. 306 pp.

International Union for Conservation of Nature - IUCN. 2012. Penelope superciliaris. The IUCN Red List of Threatened Species. http://dx.doi.org/10.2305/IUCN.UK.2012-1.RLTS.T22678370A40077351.en.

Lanyon, W.E. 1982. The subspecies concept: then, now and always. Auk 99: 603-604. 
Lichtenstein, H. \& Bratring, F.W.A. 1818. Verzeichniss von ausgestopften Säugethieren und Vögel. Tage im zoologischen Musem der Königl. Universität zu Berlim durch den Königl. Berlin.

Linnaeus, C. 1758. Systema Naturae: Editio Decima, Reformata. Holmiae, Impensis Direct. 824p.

Marcgrave, G. 1642. Iacupema. In: Historia Naturalis Brasiliae. Amsterdam. Pp. 198.

Mayr, E. 1942. Systematics and the origin of species. New York: Columbia University Press. 334p.

Mayr, E. 1963. Animal Species and Evolution. Cambridge: Belknap Press. 797p.

Mayr, E. 1982. Of what use are subspecies? Auk 99: 593-395.

McKitrick, M.C. \& Zink, R.M. 1988. Species concept in Ornithology. Condor 90: 1-14.

Merrem, B. 1786. Avium rariorum et minus cognitarum icones et descriptiones collectae e germanicus latinae factae $2: 39 \mathrm{p}$.

Monroe, B.L. 1982. A modern concept of the subspecies. The Auk 99: 608-609.

Morrone, J.J. 2009. Evolutionary Biogeography: An Integrative Approach with Case Studies. New York, Columbia University Press, 304p.

Munsell®, A.H. 1994. Soil Color Charts Revised Edition. New York, Macbeth Division of Kollmorgan Instruments Corporation, 10p. 
Nacinovic, J.B. 2012. Uma contribuição iconográfica para a identificação dos Jacu (Aves, Cracidae, Penelope) que ocorrem no Brasil. Rio de Janeiro, Agência 2A Comunicação, 80p.

Nardelli, P.M. 1993. Description of new races of Penelope superciliaris. In: The Preservation of the Alagoas Curassow, First edition. Zôo-botânica Mário Nardelli, Nilópolis, Rio de Janeiro. Pp. 9-10.

Neumann, O. 1933. Penelope superciliaris pseudonyma, P. s. argyromitra e P. s. ochromitra, subsp. nov. Bulletin of the British Ornithologists' Club 53: 93-94.

Ogilvie-Grant, W.R. 1893.Catalogue of the Birds in the British Museum: Vol. 22. London, Order of the Trustees. 585p.

Olivares, A. 1962. Aves de la región sur de la Sierra de la Macarena, Meta, Colombia. Rev. Acad. Colombiana Cienc. Exactas, Fisicas Nat. 11: 305-344.

Parker, W.K. 1866. On the Osteology of Gallinaceous Birds and Tinamous. Transactions of the Zoological Society of London, London. volume V. Pp. 149-241, Plates XXXIVXLII.

PAST. 2001. PAST: Paleontological statistics software package for education and data analysis. R. Hammer, D.A.T. Harper \& P.D. Ryan. Disponível em: http://nhm2.uio.no/norlex/past/download.html

Paynter, R.A. 1989. Ornithological Gazetteer of Paraguay. Cambridge, Museum of Comparative Zoology of Harvard University, 59p. 
Paynter, R.A. 1992. Ornithological Gazetteer of Bolivia. Cambridge, Museum of Comparative Zoology of Harvard University 185p.

Paynter, R.A. 1995. Ornithological Gazetteer of Argentina. Cambridge, Museum of Comparative Zoology of Harvard University 1043p.

Paynter, R.A. \& Traylor, M.A. 1991. Ornithological Gazetteer of Brazil. Cambridge, Museum of Comparative Zoology of Harvard University 788p.

Peters, J.L. 1934. Check-list of Birds of the World: Volume II. Cambridge, Harvard University Press. 401p.

Piacentini, V.Q.; Aleixo, A.L.P.; Agne, C.E.Q.; Maurício, G.N.; Pacheco, J.F.; Bravo, G.; Brito, G.R.R.; Naka, L.N.; Olmos, F.; Posso, S.; Silveira, L.F.; Betini, G.; Carrano, E.; Franz, I.; Lees, A.; Lima, L.; Pioli, D.; Schunck, F.; Amaral, F.R.; Bencke, G.A.; CohnHaft, M.; Figueiredo, L.F.; Straube, F. \& Césari, E. 2015. Annotated checklist of the birds of Brazil by the Brazilian Ornithological Records Committee. Revista Brasileira de Ornitologia, 23(2): 91-298.

Pinto, O. 1938.Catálogo das Aves do Brasil e Lista dos exemplares que as representam no Museu Paulista, 1era parte, Aves não Passeriformes e Passeriformes não Oscines, com exclusão da família Tyrannidae. Separata da Revista do Museu Paulista: tomo XXII. São Paulo, Brasil. 566p.

Pinto, O. 1940. Aves de Pernambuco. Arquivos de Zoologia do Est. de São Paulo, vol. I (art.5):219-282. 
Pinto, O. 1954. Resultados ornitológicos de duas viagens científicas ao Estado de Alagoas. Papéis Avulsos do Departamento de Zoologia, Secretaria da Agricultura - S. Paulo - Brasil, Vol. XII (Nº1): 1-98.

Pinto, O. 1964. Ornithologia Brasiliense, Vol. 1. São Paulo: Dept. Zool.

Pinto, O. 1978. Novo Catálogo das Aves do Brasil. Primeira Parte, Aves não Passeriformes e Passeriformes não Oscines, com exclusão da família Tyrannidae. São Paulo. 446p.

Prance, G.T. 1982. Forest refuges: evidences from woody angiosperms. In: Prance, G.T. (ed.). Biological diversification in the tropics. Columbia University Press, New York. P. 137-158.

QGIS Development Team. 2016. QGIS Geographic Information System, versão 2.14.3. Open Source Geospatial Foundation. Disponível em: http://qgis.osgeo.org

R Core Team. 2016. R: A language and environment for statistical computing. $R$ Foundation for Statistical Computing, Vienna, Austria. Disponível em: http://www.Rproject.org/

Remsen, J.V. \& Traylor, M.A. 1989. An annotated List of the Birds of Bolivia. Vermillion, South Dakota: Buteo Books.

Schifter, H.; Bauernfeind, E. \& Schifter, Th. 2007. Die Typen der Vogelsammlung des Naturhistorischen Museum Wien. Teil I. Nonpasseres. Kataloge der wissenschaftlichen Sammlungen des Naturhistorischen Museums in Wien. Band 20, Aves, Heft 1. Naturhistorisches Museum Wien. 374p. 
Sedaghatkish, G. 1996. The Importance of Seed Dispersers in the Conservation of Useful Wild Plant Species: A Case Study of the Avian Family Cracidae. M.Sc. Thesis, College Park: Univ. Maryland.

Sedaghatkish, G.; Galleti, M. \& Denny, C. 1999. The importance of Pipile as a seed disperser of economically important plants. In: Biology and Conservation of the Piping Guans (Pipile), Spec. Publ. Pp. 4-12. D.M. Brooks, A.J. Begazo and F. Olmos, Eds, CSF1, Houston.

Sharpe, R.B. 1899. A hand-list of the Genera and Species of Birds: Volume I. London, Order of the Trustees.

Sibley, C.G.; Ahlquist, J.E. \& Monroe, B.L. 1988. A classification of the living birds of the world based on DNA-DNA hybridization studies. The Auk, 105(3): 409-429.

Sibley, C.G. \& Ahlquist, J.E. 1990. Phylogeny and classification of birds: a study in molecular evolution. New Haven, Yale University Press. 976p.

Sick, H. 1993. Birds in Brazil a Natural History. New Jersey, Princeton University Press, $703 p$.

Silveira, L.F. 2008. Penelope superciliaris alagoensis Nardelli, 1993. In: Silveira, L.F. \& Straube, F.C. (Ed.). Livro Vermelho da Fauna Brasileira Ameaçada de Extinção: Aves. p. 437.

Silveira, L.F. \& Olmos, F. 2003. Cracids in coastal Alagoas State Northeastern Brazil. Annual Review of the World Pheasant Association 2002/2003: 49-52. 
Silveira, L.F. \& Olmos, F. 2007. Quantas espécies de aves existem no Brasil? Conceitos de espécie, conservação e o que falta descobrir. Revista Brasileira de Ornitologia 15(2): 289-296.

Silveira, L.F.; Olmos, F. \& Long, A.J. 2003. Birds in Atlantic Forest fragments in northeast Brazil. Cotinga 20: 32-46.

Silveira, L.F.; Soares, E.S. \& Bianchi, C.A. 2008. Plano de Ação Nacional para a Conservação de Galliformes Ameaçados de Extinção (aracuãs, jacus, jacutingas, mutuns e urus). Série Espécies Ameaçadas - No. 6. ICMBio - Brasília.

Spix, J.B. von. 1825. Penelope superciliaris jacupemba. Avium Species Novae, quas Brasiliam anus MDCCCXVII - MDCCCXX.2, p.55, pl. 72. Munique.

Strahl, S.D. \& Grajal, A. 1991. Conservation of large avian frugivores and the management of Neotropical protected areas. Oryx 25: 50-55.

Stresemann, E. 1922. Journal für Ornithologie, Jahrgang 70. Pp. 498-500. Verlag der Deutschen Ornithologischen Gesellschaft. Berlin.

Teixeira, D.M. 1997. A conservação dos Cracidae no Nordeste Extremo do Brasil. In: The Cracidae, their Biology and Conservation. USA \& Canadá, Hancock house. P. 273280.

Temminck, C.J. 1815. Histoire Naturelle Generale des Pigeons et Des Gallinaces 3. Amsterdam, Sepp \& Fils, 757p.

Vanzolini, P.E. 1992. A Supplement to the Ornithological Gazetteer of Brazil. São Paulo, Museu de Zoologia da Universidade de São Paulo, 252p. 
Vaurie, C. 1966. Systematic notes on the Bird family Cracidae. No. 6, Reviews of Nine Species of Penelope. American Museum Novitates 2251, 1-30.

Vaurie, C. 1968. Taxonomy of the Cracidae (Aves). Bulletin of the American Museum of Natural History 138 (3): 131-260.

Vuilleumier, F. 1965. Relationships and evolution within the Cracidae. Bull. Mus. Comp. Zool. Harv. 134 (1): 1-27.

WikiAves. 2016. [Mapa de registros da espécie Jacupemba (Penelope superciliaris) ]. WikiAves, a Enciclopédia das Aves do Brasil. Disponível em: http://www.wikiaves.com.br/mapaRegistros_jacupemba

Willis, E.O. \& Oniki, Y. 2003. Aves do estado de São Paulo. Rio Claro: Divisa.

Zink, R.M. 1997. Species concepts. Bull. Brit. Orn. Cl. 117: 97-109.

Zusi, R.L. 1982. Infraspecific geographic variation and the subspecies concept. Auk 99: 606-608. 